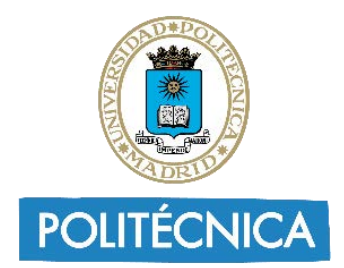

Universidad Politécnica de Madrid

E.T.S. de Ingenieros Industriales

\title{
Unwarranted Variations in Healthcare: The Role of Business Intelligence
}

\section{Doctoral Thesis}

\author{
Sina Lessanibahri
}

Supervisors:

Prof. María del Camino González Fernández

Prof. Luca Gastaldi 



\section{TRIBUNAL TESIS DOCTORAL}

\section{Unwarranted Variations in Heatlhcare: The Role of Business Intelligence}

AUTOR: Sina Lessanibahri

DIRECTOR/ES: María del Camino González Fernández y Luca Gastaldi

Tribunal nombrado por el Excmo. y Magfco. Sr. Rector de la Universidad Politécnica de Madrid el día de de 2019.

\begin{tabular}{|l|l|}
\hline Presidente & D./Dá. \\
\hline Vocal & D./Da. \\
\hline Vocal & D./Da. \\
\hline Vocal & D./Da. \\
\hline Secretario & D./Da. \\
\hline
\end{tabular}

Realizado el acto de defensa el día de de 2019 en la Escuela Técnica Superior de Ingenieros Industriales de la Universidad Politécnica de Madrid.

Calificación obtenida:

EL PRESIDENTE

VOCAL

VOCAL

VOCAL

SECRETARIO 


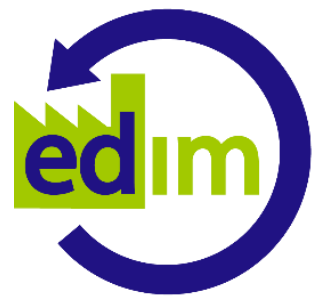

E U R O PEA N DOCTORATE IN INDUSTRIAL MANAGEMENT

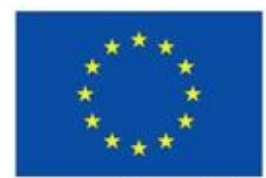

European Commission ERASMUS MUNDUS

This research was conducted within the framework of the "European Doctorate in Industrial Management"-EDIM — which is funded by The Education, Audiovisual and Culture Executive Agency (EACEA) of European Commission under Erasmus Mundus Action 1 programs.

EDIM is run by a consortium consisting of the industrial management departments of three institutions:

- Politecnico de Milano (POLIMI), Milan, Italy

- Universidad Politécnica de Madrid (UPM), Madrid, Spain

- KTH Royal Institute of Technology, Stockholm, Sweden
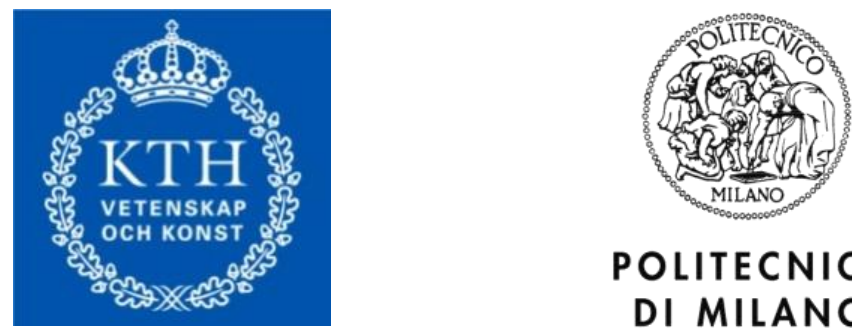

POLITECNICO

DI MILANO
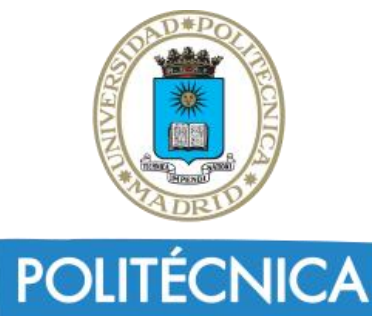
To my parents 


\section{TABLE OF CONTENTS}

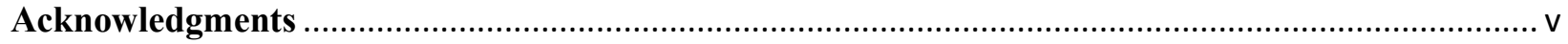

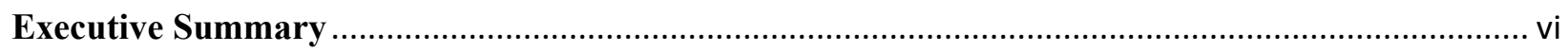

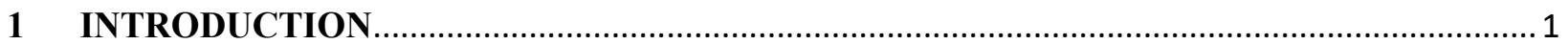

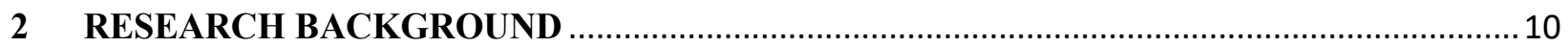

2.1 Phase 1: Unwarranted Variations in Regional Level.....................................................10

2.1.1 Performance Patterns in Secondary Care ............................................................... 13

2.1.2 Performance Patterns in Primary Care ..................................................................... 16

2.2 Phase 2: Business Intelligence and Unwarranted Variations........................................21

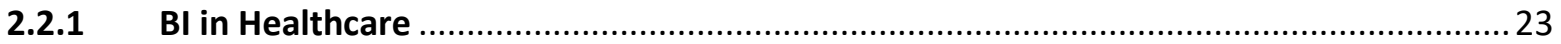

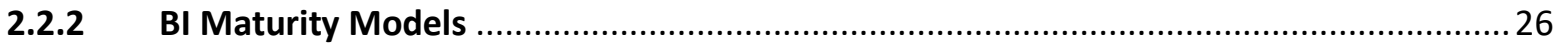

2.3 Phase 3: Advanced Analytics for Risk Adjustment ........................................................ 28

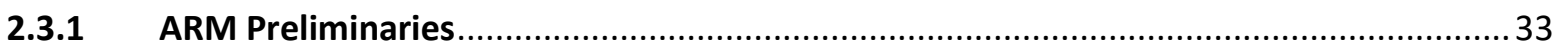

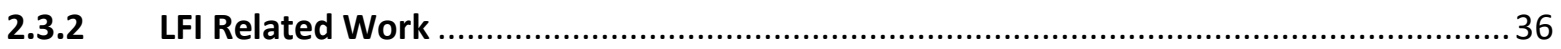

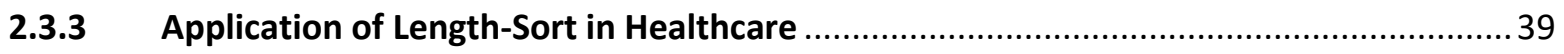

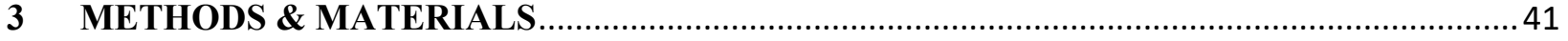

3.1 Phase 1: Unwarranted Variations in Regional Level..................................................... 41

3.1.1 Performance Patterns in Secondary Care ............................................................. 41

3.1.2 Performance Patterns in Primary Care ...................................................................... 50

3.2 Phase 2: Business Intelligence and Unwarranted Variations............................................54

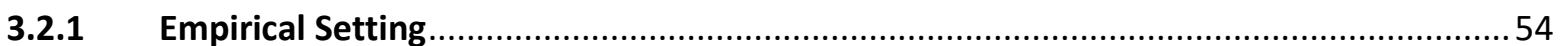

3.3 Phase 3: Advanced Analytics for Risk Adjustment ........................................................60

3.3.1 Length-Sort Algorithm for Mining LFls .................................................................. 61

3.3.2 Risk Adjustment for Unwarranted Variations Using Length-Sort................................. 81

$4 \quad$ RESULTS \& DISCUSSION

4.1 Phase 1: Unwarranted Variations in Regional Level...................................................... 88

4.1.1 Performance Patterns in Secondary Care: Results ..................................................... 88

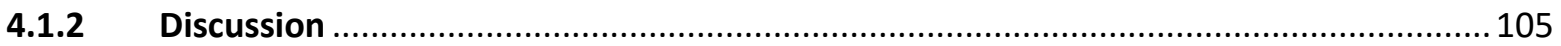

4.1.3 Performance Patterns in Primary Care : Results .......................................................... 109

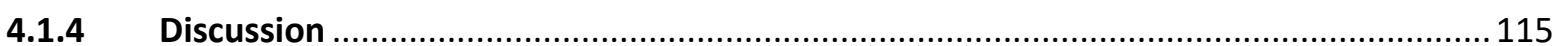

4.2 Phase 2: Business Intelligence and Unwarranted Variations.........................................119

4.2.1 Maturity Model and Assessment Questionnaire ….................................................... 120

4.2.2 A Roadmap Toward Precision Medicine for ISMETT ................................................. 127 


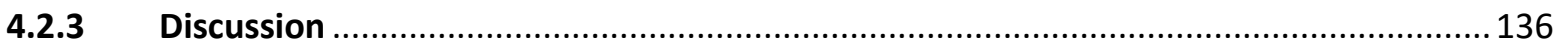

4.3 Phase 3: Advanced Analytics for Risk Adjustment ..................................................... 138

4.3.1 Experimental Result of Length-Sort Algorithm …................................................... 139

4.3.2 Discovered Rules from QOF dataset....................................................................... 154

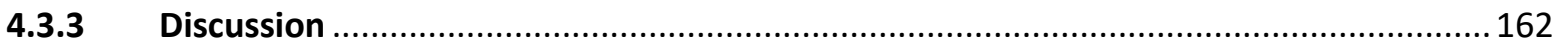

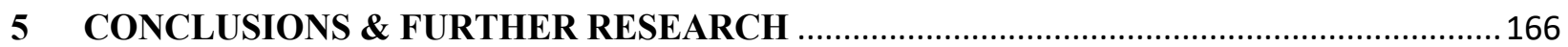

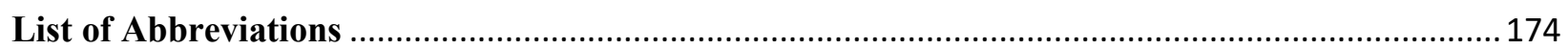

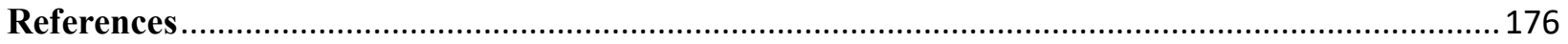

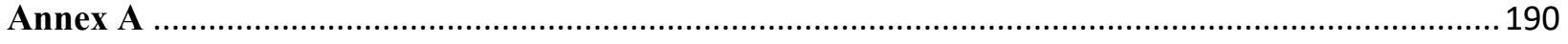

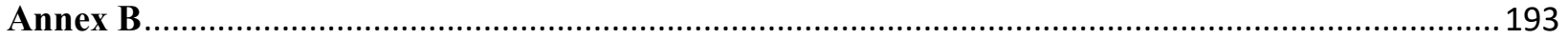




\section{LIST OF FIGURES}

Figure 1-1: The total health spending of countries measured as the percentage of their GDP during 2000 - 2017 (Source: statistics of OECD)

Figure 1-2: The conceptual model of distinction between warranted and unwarranted variation

(Source: Otsubo et al. 2016) and the area of focus of each phase of the thesis ........................................ 5

Figure 1-3: Overview of the thesis; three phases and the related five studies.........................................8

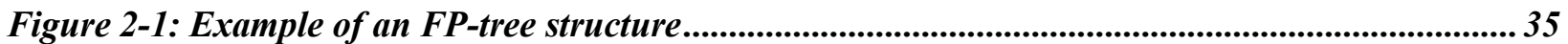

Figure 3-1 : Research stages, phases, methods and outputs.....................................................................57

Figure 3-2: The process of sorting and partitioning .......................................................................................... 63

Figure 3-3: The initial upper bound estimated through Lemma 1 for the dataset in Example 1........... 64

Figure 3-4: Pseudo code of Filter1 (First upper bound) Algorithm ........................................................... 65

Figure 3-5: Process of improving the initial upper bound by means of Lemma 2............................... 67

Figure 3-6: Pseudo code of Filter 2 (Second upper bound) Algorithm .................................................68

Figure 3-7: Pruning the candidate items based on Lemma 3 ............................................................ 70

Figure 3-8: Pseudo code for the Filter 3 algorithm.............................................................................. 71

Figure 3-9:Procedure of updating an FP-tree with transaction nodes ................................................ 74

Figure 3-10: Pseudo code of the modified FP-tree................................................................................. 75

Figure 3-11: Pseudo code of Length-Sort+LFIMiner algorithm........................................................ 76

Figure 4-1: Performance of the clusters for the four indicators........................................................... 104

Figure 4-2: Descriptive statistics and the patterns of the hospitalizations through the years .............. 110

Figure 4-3: ISMETT position on the functional dimensions of the BI maturity model ........................ 128

Figure 4-4: Perquisites and synergies among the dimensions of the BI maturity ................................. 131

Figure 4-5: Relevance and maturity for healthcare BI at ISMETT ....................................................... 133

Figure 4-6: Priority scores of the dimensions for healthcare BI at ISMETT ...................................... 136

Figure 4-7:Runtime comparison for mining all the LFIs.......................................................................... 140

Figure 4-8: Number of initial tree nodes ...................................................................................................... 143

Figure 4-9: Number Items in the H-table ............................................................................................... 145

Figure 4-10: Number of transactions involved in constructing the initial FP-tree ............................... 147

Figure 4-11: Estimated and actual maximum length of the frequent itemsets ...................................... 150

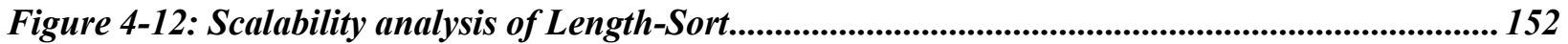

Figure 4-13: Runtime comparisons for INLA-MFP and Length-Sort ................................................ 153 


\section{LIST OF TABLES}

Table 1-1:Healthcare expenditure of several European countries in 2015 (Source: EuroStat, 2015)..... 2

Table 1-2: Overview of the methodological approach of the studies ......................................................8

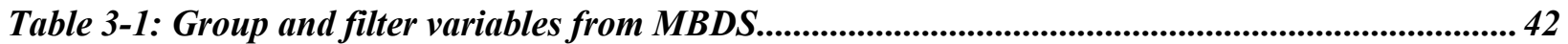

Table 3-2: Number of hospital discharges in each MDC (Type of DRG=medical; Severity =minor,

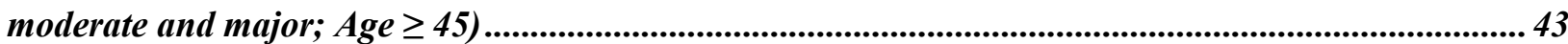

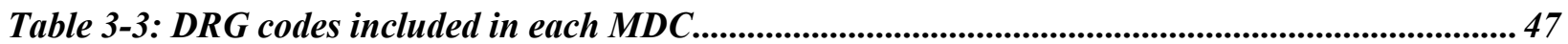

Table 3-4: Composition of the Research Task Force .......................................................................56

Table 3-5: Datasets used to evaluate the performance of the Length-Sort algorithm.............................. 80

Table 3-6: Quality Outcome Framework indicators categories ...........................................................82

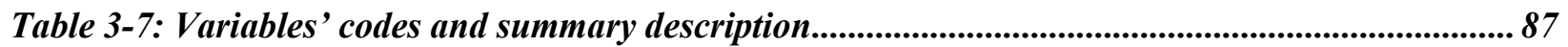

Table 4-1: Length of stay regression and indirect standardized rates ..................................................... 91

Table 4-2: Mortality regression and indirect standardized rates............................................................. 93

Table 4-3: Infection regression and indirect standardized rates................................................................95

Table 4-4: regression and indirect standardized rates of Readmissions................................................97

Table 4-5: Cronbach alpha values and correlations between the standardized rates .............................99

Table 4-6: a) EQ5 - 95 And SCV ratios b) Repeated ANOVA results............................................... 100

Table 4-7: Cluster means for the individual MDCs......................................................................................... 102

Table 4-8: Fixed effects regression for COPD admission rates.................................................................. 112

Table 4-9: Fixed effects regression for $\mathrm{CHF}$ admission rates ............................................................... 113

Table 4-10: Fixed effects regression for BP admission rates............................................................ 114

Table 4-11: Maturity levels for the 6 dimensions in the functional area.................................................. 122

Table 4-12: Maturity levels for the 7 dimensions in the technological area............................................ 123

Table 4-13: Maturity levels for the 3 dimensions in the diffusional area................................................. 124

Table 4-14: Maturity levels for the 7 dimensions in the organizational area ........................................... 125

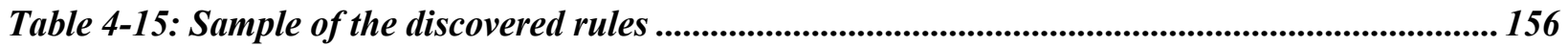

Table 4-16: Rules corresponding to geographical regions of the same level in rule 1.10 and the country level, which has not satisfied the minimum support threshold .......................................................... 161

Table 4-17: Comparing the relative importance of the variables in rule 1.9....................................... 162 


\section{Acknowledgments}

Firstly, I would like to express my sincere gratitude to my Polimi advisor Prof. Luca Gastaldi for the continuous support of my Ph.D and related research, for his patience, motivation, and knowledge. I could not have imagined having a better advisor and mentor for my Ph.D study.

My special thanks also goes to Prof. Camino González Fernández my advisor in Universidad Politécnica de Madrid. With consistent advices, ample time spent, positive attitude and guidance, she made this study possible.

I place on record, my deepest gratitude to my tutor, Prof. Mariano Corso who welcomed me to his research group and taught me how to always see the bigger picture and to have a holistic view both for the research and my future carrier.

Besides my advisors, I would like to thank my internal discussant Prof.Carlotta Orsenigo and the external opponents Prof. Giovanni Radaelli, and Prof. Prof. Davide Aloini, for their insightful comments and encouragements, which incented me to widen my research from various perspectives.

I would like to thank Prof. Felipe Ruiz, Prof.Andres Muñoz Machado, Prof. Emanuele Lettieri Cristina Mazzali and Prof. Luca Grilli for generously providing support and feedback on the research.

I am grateful to Politecnico di Milano, Universidad Politécnica de Madrid to provide me with this great opportunity. I gratefully acknowledge the funding sources of this Ph.D, the European Doctorate in Industrial Management (EDIM) programme which is part of the European Commission Erasmus Mundus Action 1. I am very grateful to the scientific committee of the EDIM for considering me to be part of the programme.

A very special gratitude goes out to Martina Sani for her kind and constant assistant through all the administrative and personal aspects during this time.

I would like to acknowledge my friends and colleagues, Danial, Isaac, Golboo, Borzoo, Keivan, Ali, Danial, Narges, Mattia, Nicole, Daniel, Rossella, Claudia, Roya, Ebru, Yulia, Enes, Milan, Shoaib and Andrea whose support helped me to overcome the challenges along this long journey.

I would like to thank my parents Amir and Fatemeh, my sister Sara, my brother Saman and my beloved in laws Vasileh, Homayoun and Sahar for their love, encouragement and spiritually helping me throughout the Ph.D and my life in general. This journey would have not been possible without their unconditional support. I am specially grateful to my father who raised me with a love of science, supported and encouraged me in any way possible to pursue my studies.

Last but certainly not least, I would like to thank the love of my life, my wife, my best friend, Sarah, who was always there for me. She was my reviewer, discussant, proofreader and I was her nightmare during the past months. She is my only constant in this chaotic world and the reason that I could survive the challenging times. Thank you for keeping me alive and sane and most importantly, thank you for being you.

May 2019 


\section{Executive Summary}

Healthcare is one of the most impactful sectors, affecting strongly all aspects of the society ranging from medical services to social, governmental, business, and economic implications. Currently, there is an emerging concern of chronic diseases, the ageing and higher mobility of care professionals, which accentuates the need for national policies to enhance the availability, approachability, eligibility and quality of the care system. These changes are driving the cost of healthcare to unsustainable levels. On the other hand, it is well known that healthcare systems suffer from service delivery variations known as unwarranted variations. These are the variations that are not explained by patients' needs or preferences. Existence of such variations indicates that the best care has not been delivered or that resources have not been appropriately deployed in healthcare organizations. These variations can occur in terms of treatment quality, expenditure, supply of health resources, etc. Detecting and reducing these variations is one of the main paths to decrease the healthcare expenditures without compromising the care quality.

The correct identification of the unwarranted variations is the corner stone to detect the underlying factors and designing effective interventions to reduce the disparities. The proper detection of the unwarranted variations has two important antecedents: first, timely access to quality data and second, reliable risk adjustments. As not all variations are unwarranted, risk adjustment methods are used to separate the "good" variations from the total observed variations.

These aspects are even more crucial when moving from larger to smaller levels of analyses. We believe that Business Intelligence (BI) is a prominent remedy for both of these vital elements. BI as a system that encompasses data collection, storage, analyses and reporting, has significant potentials in providing timely and quality data for unwarranted variations research. Moreover, BI can incorporate novel advanced analytics to better separate unwarranted variations from the total 
observed variations. However, literature reports that the success rate of BI in healthcare is significantly lower compared to other sectors. In order to cope with the above challenges, five studies categorized in three phases are developed in this $\mathrm{PhD}$ thesis.

In the first phase, the cross-regional variations in healthcare performance in Spanish provinces are assessed, examining patients' average length of hospital stay, mortality rates, readmission rates and hospital-acquired infection rates. The crude rates for the indicators have been obtained from the administrative data acquired by Spanish public hospitals, for non-surgical patients diagnosed with diseases in six Major Diagnostic Categories. These rates have been adjusted for gender, age, type of admission, severity of the condition and case-mix weights. The adjusted rates have been used as the input for a two-step clustering process, splitting the provinces into three groups based upon their performance. The results demonstrate that the clusters perform differently for mortality, average length of hospital stay and hospital-acquired infections rates, while they perform similarly for readmission rates. Moreover, the performance pattern by type of diagnostic category is similar for all the three clusters. While evidence in the literature regarding the adverse effects of length of stay reduction on readmission and mortality rates are mixed and inconclusive, our findings demonstrate that many regions in Spain can shorten the length of stay without risk of such advert effects. Similar performances across the diagnostic categories suggest that influencing factors are common and healthcare decision-makers should pay more attention to indicator-specific interventions rather than disease-specific ones. Next, we focused on the factors influencing potentially avoidable hospitalizations. The adjusted hospitalization rates were assessed for three common ambulatory care sensitive conditions -known to be responsible for potentially avoidable admissions-. The adjusted rates of the 17 Spanish autonomous communities were collected for the period between 2007 to 2015. Fixed effect model is fitted with the data that mitigate the bias caused 
by time-invariant omitted or unobserved factors. The findings show that consultation with general practitioners per capita is associated with less hospitalization rates for all three conditions. Moreover, specialists' consultations per capita and the proportion of people visiting specialists is associated with reduced hospitalizations in two of the conditions. This is an indication that primary care cannot solely be held accountable for all preventable hospitalizations.

In the second phase, we developed a comprehensive maturity model that suggest the priorities to be followed for progressively developing a BI solution. Through collaborative research in several Italian hospitals, we demonstrated that the successful implementation of BI is an evolutionary and complex path. By developing a maturity model specific for $\mathrm{BI}$ in healthcare, we provide managers with means that guide this evolutionary implementation. We identified a comprehensive set of BI dimensions and indicators that should be considered during the implementations.

Finally, in the third phase, we focused on advanced analytics that can be embedded in the BI systems and support the investigations in unwarranted variations. We first developed a novel Association Rules Mining (ARM) algorithm named Length-Sort that can discover the maximumlength association rules more efficiently. The efficiency improvement enables the analysis of larger health datasets. Next, we demonstrate the application of Length-Sort on England Quality and Outcome Framework (QOF) dataset which contains general practices' performances in terms of various evidence-based indicators. Our results show that ARM and in particular, Length-Sort can be an explorative alternative to the traditional risk adjustment method, which can be used in health policy and unwarranted variation research as a hypothesis generation tool to detect performance patterns especially, in the more granular levels of analyses. 


\section{INTRODUCTION}

Healthcare is one of the most impactful sectors, affecting strongly all aspects of the society ranging from medical services to social, governmental, business, and economic implications (Lupo, 2016). To reach effective and equitable care delivery, it is vital that healthcare systems' decision makers appropriately allocate the expenditures between diverse care activities (e.g. preventive and curative care) or care providers (e.g. hospitals or ambulatory centers) (EuroStat, 2015).

The total health expenditure of countries measured as the percentage of their Gross Domestic Product (GDP) during 2000 - 2017 is provided below in Figure 1.1 ( Organization for Economic Co-operation and Development (OECD) 2018). As it can be seen from the figure the healthcare expenditures are constantly raising through the years. The constant increase of the costs, raises major concerns about the sustainability of the healthcare systems in near future (Peiro and Maynard, 2015).

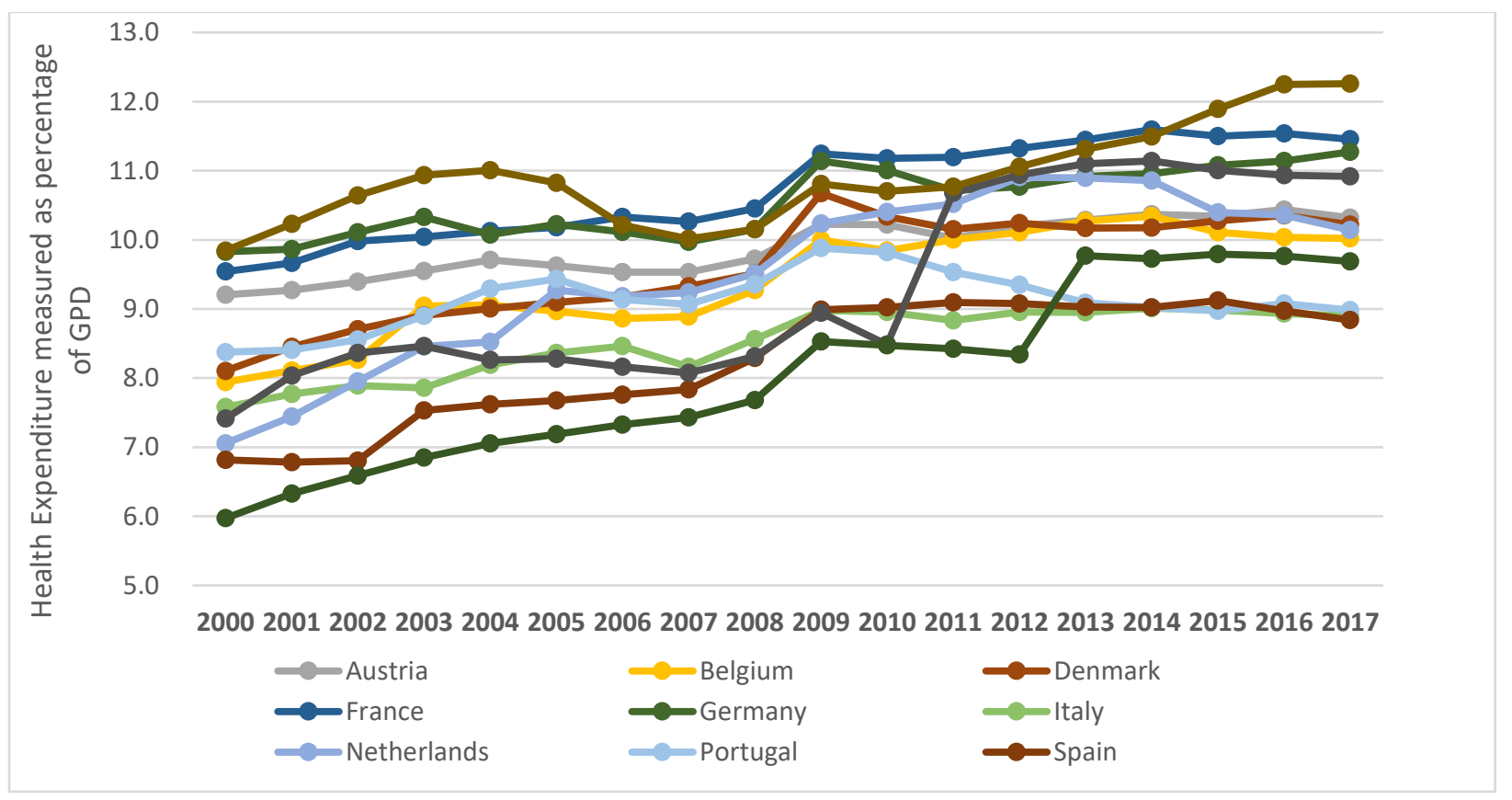


Figure 1-1: The total health spending of countries measured as the percentage of their GDP during 2000 - 2017 (Source: statistics of OECD)

Table 1-1 depicts the total and per capita health expenditures of several European countries in 2015 (EuroStat, 2015).

\begin{tabular}{|c|c|c|c|}
\hline Mustria & Million euro & Euro per inhabitant & $\begin{array}{c}\text { Percentage of gross } \\
\text { domestic product (GDP) }\end{array}$ \\
\hline Belgium & 35,631 & 4,123 & 10.34 \\
\hline Croatia & 41,462 & 3,678 & 10.11 \\
\hline Denmark & 3,246 & 771 & 7.37 \\
\hline Finland & 28,065 & 4,938 & 10.33 \\
\hline France & 19,790 & 3,612 & 9.45 \\
\hline Germany & 252,368 & 3,790 & 11.48 \\
\hline Greece & 338,207 & 4,140 & 11.15 \\
\hline Hungary & 14,448 & 1,335 & 8.19 \\
\hline Iceland & 7,936 & 806 & 7.24 \\
\hline Ireland & 1,303 & 3,938 & 8.61 \\
\hline Italy & 19,855 & 4,273 & 7.76 \\
\hline Netherlands & 148,495 & 2,445 & 8.99 \\
\hline Norway & 72,323 & 4,269 & 10.58 \\
\hline Poland & 35,220 & 6,786 & 10.11 \\
\hline Portugal & 27,280 & 718 & 6.34 \\
\hline Romania & 16,132 & 1,557 & 8.97 \\
\hline Slovakia & 7,925 & 400 & 4.95 \\
\hline Slovenia & 5,418 & 999 & 6.89 \\
\hline Spain & 3,295 & 1,597 & 8.48 \\
\hline Sweden & 98,586 & 2,123 & 9.17 \\
\hline United & 49,428 & 5,044 & 11.01 \\
\hline Kingdom & 254,821 & 3,913 & 9.76 \\
\hline & & & \\
\hline
\end{tabular}

Table 1-1:Healthcare expenditure of several European countries in 2015 (Source: EuroStat, 2015)

As seen in Table 1-1, many countries in Europe recorded healthcare expenditure of more than $3,000 €$ per inhabitant. Healthcare expenditures are increasing globally (Figure 1.1), faster than GDP (Hediger et al., 2018). Currently, it is estimated that global expenditures on healthcare would increase by 2.2 times more in 2040 (over 15.5 trillion Euro in 2040 compared to 2018 expenditure of 6.8 trillion Euro) (Dieleman et al., 2017). 
The growth of care expenditure pushes policy makers to use financial resources more efficiently and/or prioritize the delivered care services. This is becoming even more important and challenging since the initiation of the global financial crisis in 2008 (Correia et al., 2015), especially for European countries, with experiencing negative GDP growth in 2008-2012 (Thomson et al., 2014). As a result, health costs have become a source of accelerated savings in most EU countries (Correia et al., 2015). In contrast, currently there is an emerging concern of chronic diseases, the ageing and higher mobility of care professionals, which accentuates the need for national policies to enhance the availability, approachability, eligibility and quality of the care system (Correia et al., 2015). To conclude, nowadays, the proper policy response in health system, is not only critical, but even if quite challenging, should be able to include both a more efficient exploitation of financial resources as well as an improved quality healthcare supplies to fit the demand.

On the other hand, it is well known that healthcare systems suffer from practice variations. Existence of such variations indicates that the best care has not been delivered or that resources have not been appropriately deployed in healthcare organizations (Mercuri and Gafni, 2011). Consequently, a significant proportion of health expenditures is not transformed to improved health outcomes (Peiro and Maynard, 2015). These so called unwarranted variations, are the variations in care delivery that are unrelated to differences in "illness, patient's preference or medical science" (Wennberg, 2014).

Previous research on unwarranted variations revealed the existence of geographical variations in various surgical operations, medical procedures and therapies (e.g. Caldon et al., 2005; Jaffer et al., 2010; Mercuri et al., 2012; Wennberg, 1987). Over the past four decades, researchers investigating the unwarranted variations have shown that (Fisher and Skinner, 2013): 
There are systematic, consistent and pervasive variations in healthcare resource utilizations;

$\checkmark$ Characteristics of patients/populations and health conditions do not explain the variations;

$\checkmark$ Higher utilization and spending do not lead to better performance in terms of quality of care.

To address the unwarranted variations, with respect to a broad-based social science approach, studies may investigate the required change in healthcare organizations at the individual, group, organizational, and environmental levels (Ferlie and Shortell, 2001; Shortell, 2004). Scholars have tried to measure and explain the causes of unwarranted variations at regional level (Fisher et al. 2003b; Wennberg 2002), however the relative results are less effective in reducing unwarranted variation in the more granular levels, for instance, at the organizational or physician levels (Appleby et al., 2011).

Existence of unwarranted variations indicates that considerable amount of health expenditure has no effect on improving the healthcare outcomes. Thus, detecting and reducing the practice variations is one of the main paths to decrease the healthcare expenditures without compromising the care quality (Peiro and Maynard, 2015). Moreover, regions with higher spending do not usually perform better in terms of quality and health outcomes (Fisher et al., 2003b, 2003a). Thus, we urgently need investigations on regional variations and identifying opportunities for disinvestment. Accordingly, one of the objectives of this thesis is to gain deeper understanding on regional variations and the pertaining influencing factors. Thus, the first research question that the thesis opts to answer is: 
RQ1. How can healthcare policy makers better allocate resources to reduce unwarranted variations and improve care delivery?

The correct identification of the unwarranted variations is the corner stone to detect the underlying factors and designing effective interventions to reduce the disparities (Otsubo et al., 2016). Figure 1-2 depicts the conceptual model proposed by Otsubo et al. (2016) for investigating unwarranted variations.

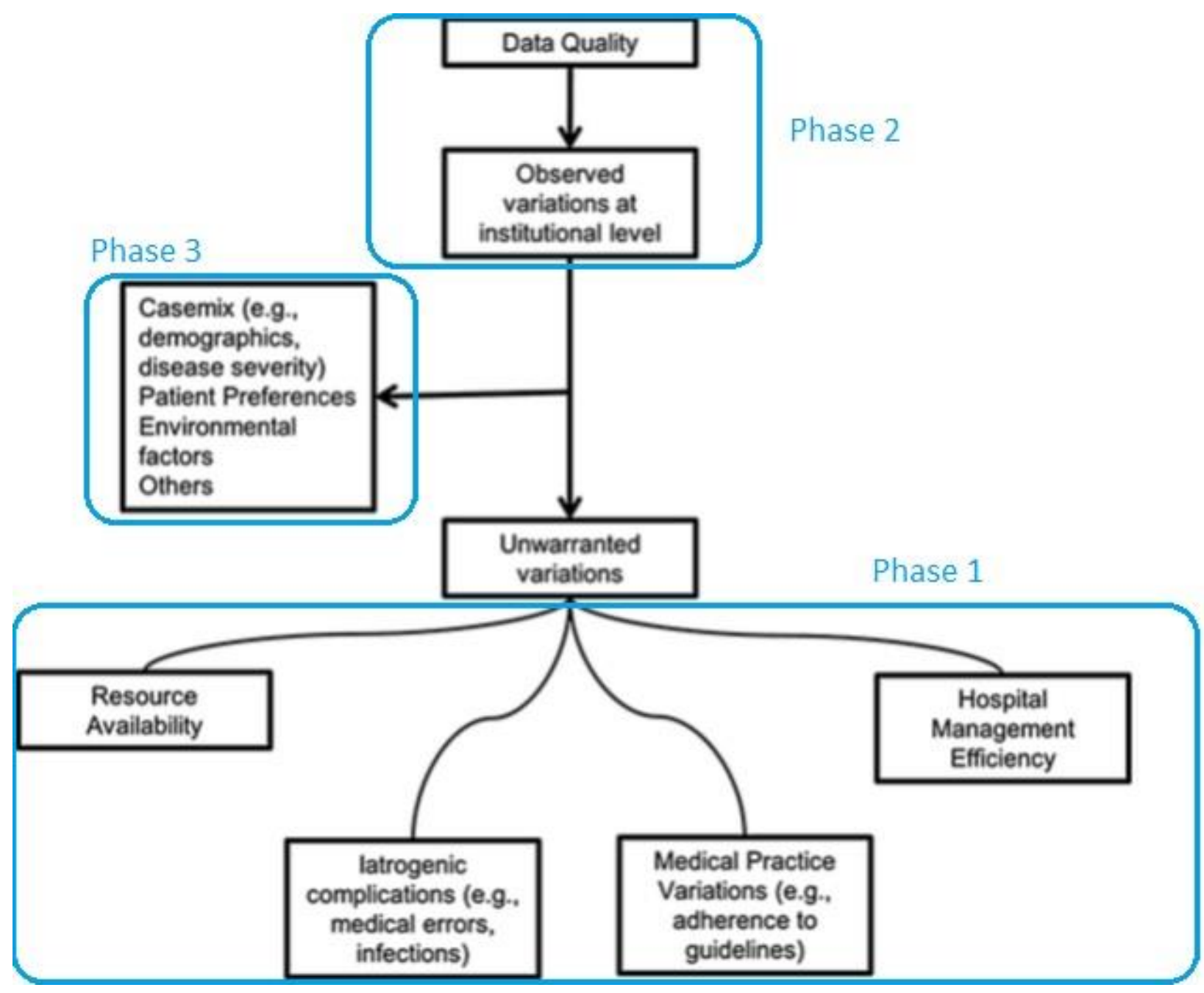

Figure 1-2: The conceptual model of distinction between warranted and unwarranted variation (Source: Otsubo et al. 2016) and the area of focus of each phase of the thesis

As we can see in Figure 1-2, data quality is one of requisites for the investigation of unwarranted variations. The Institute of Medicine defines data quality as: "timely and reliable data essential for 
public health core functions at all levels of government" (Institute of Medicine, 2003). Thus, realtime and richer administrative data are necessary to improve our understanding of practice variations (Welch et al., 2011). Proper implementation of Business Intelligence (BI), as a system that combines data collection, storage and analyses, has the potential to improve the data quality issues. Thus, the second objective of this thesis is to facilitate the implementation of the BI systems in the healthcare context. In particular, we try to answer:

RQ2. How can mangers successfully implement BI considering the idiosyncrasies of the healthcare organizations?

Quality data lead to gain the observed (crude) variations. However, not all variations are necessarily unwarranted. The warranted or good variations occur due to the differences in patients' needs or preferences (Mays, 2011). For instance, regions or hospitals that have more elderly populations/patients may have higher length of hospital stay or mortality rates. Thus, it is vital to separate the warranted variations from observed variations to gain the true level of unwarranted variations. Risk adjustment methods are the main tools used to measure the unwarranted variations. Incomplete adjustments or using the data with low quality (e.g. missing data, unavailability of confounding variables, etc.) will result in measuring variations that are due to differences between patients' needs (van Mourik et al., 2015). Interpreting such variations consequently lead to identifying spurious underlying factors and designing ineffective interventions. The shortcoming of the information systems and consequently less than optimal available data often are key challenges in risk adjustments (Iezzoni, 2003). Most of the risk adjustment methods are effective in larger levels of analyses. Moreover, implementation of Information and Communication Technologies (ICTs) such as Electronic Health Records (EHRs) has significantly increased the 
volume and velocity of health data (Porebski and Straszecka, 2018). Thus, new techniques are required to effectively analyze the larger health datasets especially in more granular levels of analyses. Thus, the third research question is:

RQ3. How to develop/improve specific BI analytic techniques that are more appropriate for the unwarranted variations framework?

As depicted in the Figures 1-2 and Figure 1-3, in this thesis, we consider three study phases and five individual studies to shed light on the abovementioned issues. Table 1-2 shows the methodological approach used in each of the five studies. 


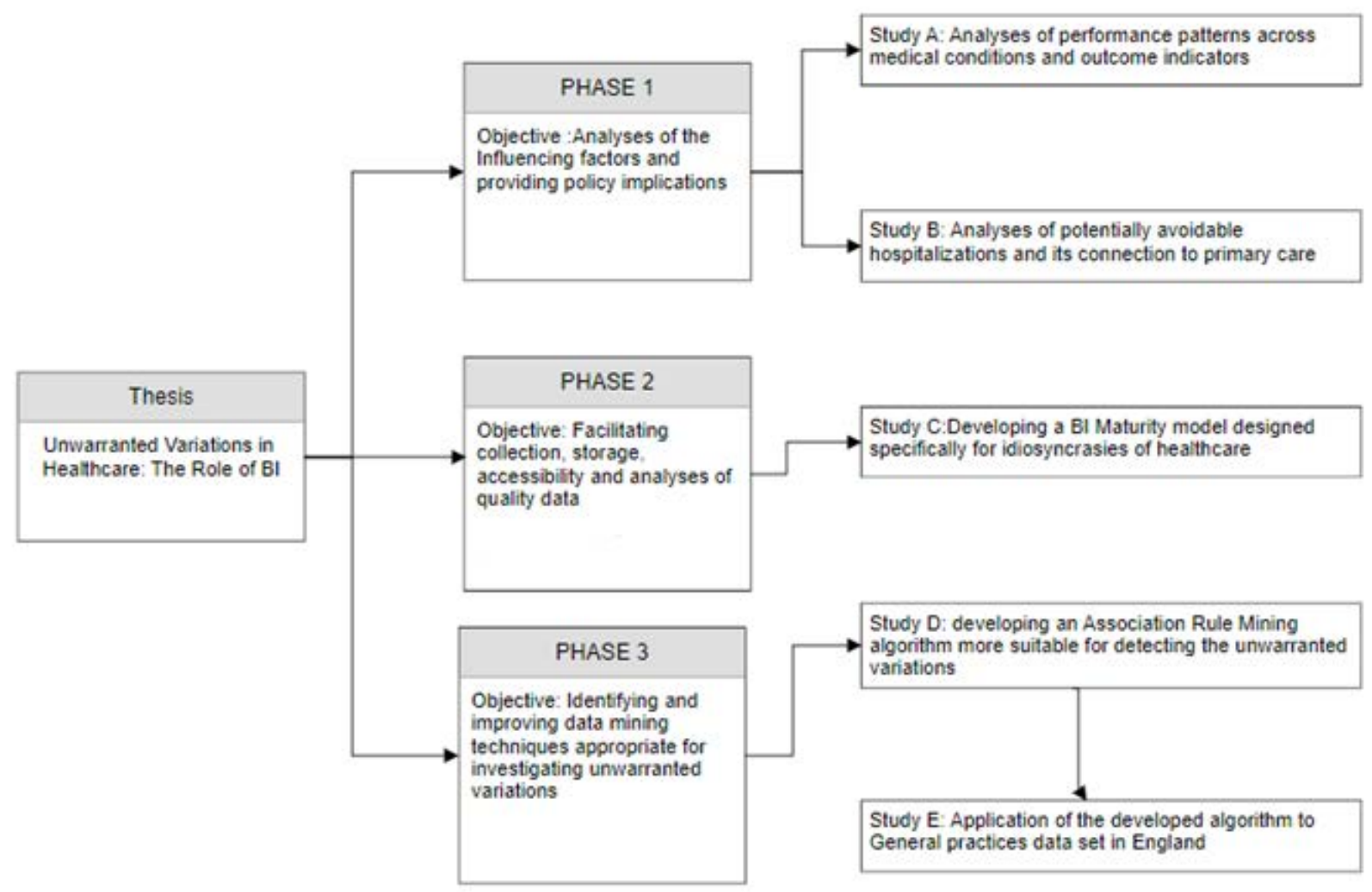

Figure 1-3: Overview of the thesis; three phases and the related five studies

\begin{tabular}{|c|c|c|c|c|c|}
\hline & & $\begin{array}{l}\text { Methodological } \\
\text { approach }\end{array}$ & Unit of Analysis & Main Data Source & $\begin{array}{c}\text { Contributing } \\
\text { to }\end{array}$ \\
\hline \multirow{2}{*}{ Phase 1} & Study 1 & $\begin{array}{c}\text { Quantitative (Regression } \\
\text { Standardization, Clustering, } \\
\text { ANOVA) }\end{array}$ & Regions (Province ) & $\begin{array}{c}\text { Spanish national } \\
\text { administrative dataset }\end{array}$ & RQ 1 \\
\hline & Study 2 & $\begin{array}{c}\text { Quantitative } \\
\text { (Panel Data Analyses) }\end{array}$ & $\begin{array}{l}\text { Regions } \\
\text { (Autonomous } \\
\text { Community) }\end{array}$ & $\begin{array}{c}\text { Spanish national } \\
\text { administrative dataset }\end{array}$ & RQ 1 \\
\hline Phase 2 & Study 3 & $\begin{array}{l}\text { Qualitative (Clinical Inquiry } \\
\text { Research) }\end{array}$ & Hospital & $\begin{array}{l}\text { Primary data from } \\
\text { ISMETT hospital }\end{array}$ & RQ 2 \\
\hline \multirow[t]{2}{*}{ Phase 3} & Study 4 & $\begin{array}{c}\text { Quantitative (Algorithm } \\
\text { Development and } \\
\text { experimental tests) }\end{array}$ & & $\begin{array}{l}\text { Real-world and } \\
\text { synthetic test datasets }\end{array}$ & RQ 3 \\
\hline & Study 5 & $\begin{array}{l}\text { Quantitative (Discretization, } \\
\text { Association Rule Mining) }\end{array}$ & General Practice & England QOF dataset & RQ 3 \\
\hline
\end{tabular}

Table 1-2: Overview of the methodological approach of the studies 
In the first phase, we focus on the regional level variations and assess their potential influencing factors in the European context. In the second phase, we focus on the data quality, especially in hospitals that are responsible for collecting significant part of healthcare data necessary for investigating the variations. And, finally, in the third phase, we demonstrate how data mining techniques - that compared to common risk adjustment methods are inherently more powerful in terms of exploratory analyses - can improve separation of warranted from unwarranted variations. 


\section{RESEARCH BACKGROUND}

This chapter presents the research background, literature and related works of the three phases of the thesis. First, we look at the theoretical background of the unwarranted variations. Next, we present an overview of the business intelligence in the healthcare context and finally we discuss the risk adjustment methods for measuring the unwarranted variations and the data mining techniques that can provide a more exploratory alternative for risk adjustment of the health data.

\subsection{Phase 1: Unwarranted Variations in Regional Level}

The field of unwarranted variations is established based on the seminal work of John E. Wennberg and Alan Gittelsohn published in Science (Wennberg and Gittelsohn, 1973). They compared the population-based rates of care delivery in 13 hospital service areas of Vermont (USA) and found extensive variations in many aspects of health service delivery, including supply of physicians, beds and personnel in nursing homes, hospital beds, common surgical procedures and hospitalization ratios. They also discovered that physicians' supply highly affects the utilizations. For instance, areas with more surgeons per population had more surgery rates. Similarly, regions with more General Practitioners (GPs) capable of performing minor surgeries had higher rates of such surgeries per population. Surprisingly, they found no correlation between higher spending and better outcomes (Wennberg and Gittelsohn, 1973). Wennberg later established one of the leading organizations for investigating the unwarranted variations (the Dartmouth Atlas of Healthcare), to document the variations in US. Even after four decades of research and providing evidence on the significant magnitude of unwarranted variations, the challenge still remains unresolved, and still more research is needed to monitor and reduce these disparities (Corallo et al., 2014; Mays, 2011; Peiro and Maynard, 2015; Wennberg, 2014). 
According to the research of Dartmouth Atlas of Healthcare, unwarranted variations occur in three categories of care services (Fisher et al., 2003b; Wennberg, 2002):

Effective care and patient treatment needs: This category includes treatments with proven effectiveness (e.g. through clinical trials). The benefits of such treatments completely justify the risks and all eligible patients should receive the treatment. Existence of eligible patients that do not receive such treatments are an indicator of underuse of care delivery. For example, prescribing statin for preventing further complications of patients with cardiovascular diseases has been considered as an effective care (Brooks et al., 2014), however, studies reported its utilization rate as low as $54 \%$ (Javed et al., 2010). Studies on variations have demonstrated both overuse (unnecessary treatments or tests) and underuse (lack of providing evidence-based treatments or necessary examinations) (Peiro and Maynard, 2015).

Preference-sensitive care: In these circumstances, several eligible treatment options are available, but there exists a trade-off between benefits and risks for each treatment, and the choice of the treatment is made by the patient. The crucial point in this category is the involvement of patients to establish a shared decision making. However, in may circumstances, the physicians' opinion overweighs the patients' preference (Wennberg, 2002).

Supply-sensitive care: In this category, care delivery is based on the available resources and medical evidence and clinical knowledge are not the core of decision-making. When it comes to the supply-sensitive care, the decisions of the GPs and medical specialists are more about how frequently common medical services (i.e. number of visits, specialist referrals, diagnostic tests, hospitalizations, etc.) should be performed rather than determining a specific treatment (Wennberg, 2010). Moreover, such decisions are not usually supported by clear medical evidence 
and/or guidelines. Therefore, physicians tend to use the relevant available resources as much as possible (Wennberg, 2010).

On the other hand, the major differences between US and European health systems (insurance coverage, regulations payment incentives, etc.) raised the question that whether the disparities observed in US would also occur in European countries. Following the experience of Dartmouth, the Atlas of Variations in Medical Practice of the Spanish National Health System (Atlas VPM) and UK national health service atlas were established and documented similar variations in Spain (Corallo et al., 2014) and UK (Mays, 2011).

Given the differences between health systems especially the fact that preference sensitive care is more regulated and professional preference is more favored in Europe, atlas VPM modified the conceptual framework of Wennberg and in addition to the effective care, they introduced two new categories for variations (Bernal-Delgado et al., 2014):

Effective care with uncertain marginal benefit: where the benefits versus risks are not optimal for patients that are not exactly in the eligible groups (e.g. knee-replacement). The benefits vs risks should be considered carefully especially for set of patients that are considered to be non-average.

Lower-value care: the treatments that their effectiveness is not supported by the medical evidences (e.g. C-section in low-risk pregnancies). These are procedures that are either replaced with more cost-effective ones, or the evidence on their effectiveness is not certain or there are relatively ineffective and their overuse should be monitored attentively (Garcia-Armesto and Angulo-Pueyo, 2015).

Assessing the variations in the abovementioned categories, Atlas VPM results confirmed that the systematic variation in care delivery in European national health systems and therefore, monitoring 
and benchmarking these variations, has important and valuable policy implications in the European context.

\subsubsection{Performance Patterns in Secondary Care}

Unwarranted variations also can be viewed from a performance measurement perspective by evaluating the variation in quality. Donabedian developed one of the main conceptual frameworks (Donabedian, 1966) to assess the quality of the healthcare (Berwick and Fox, 2016). The framework includes three facets of quality namely structure, process and outcome. Structure concerns the organizational aspect of the care delivery (e.g. administration, training the health professional), process is about the interaction between patients and professionals and finally, the outcome pertains to the desired or undesired consequences of the care delivery. Donabedian proposed that there is a set of sequential effects from structural elements to process and the observed outcomes of the care delivery. Through identifying the different elements of the structure-process-outcome trinity and their sequential order, Donabedian (1966) model provides a framework to evaluate the healthcare performance more thoroughly. However, the outcome aspect of the model garners more attention both among researchers and policy makers, as it is easier to measure and interpret (Mant, 2001). Moreover, outcomes can highlight the cumulative consequences of several service delivery facets that are more difficult to be measured directly (e.g. clinicians' behavior or their adherence to medical guidelines) (Mant, 2001).

Due to increasing pressure on healthcare to improve the quality and reduce the unnecessary costs, several outcome indicators for healthcare institutions were introduced since the mid-1990s and accordingly, monitoring the variations through such performance indicators gained popularity (Otsubo et al., 2016). Measuring the variation observed in the indicators are the focus of many studies in the literature. For instance, appropriate use of diagnostic tests (Bulger et al., 2002; 
Morgan et al., 2015), use of medications (Gellad et al., 2010; Schouten et al., 2005; Van Steenbergen et al., 2009), surgery rates (Wang et al., 2016; Wennberg, 2010) and blood transfusions (Sekimoto et al., 2010).

To answer the first research question, we investigate the performance patterns through four policy relevant outcome indicators that are frequently used in the literature (Chang et al., 2002; Chiu et al., 2007; Corallo et al., 2014).

- Average length of stay: defined as total number of days for all inpatients staying in hospital over one year divided by the total number of discharges (Martin and Smith, 1996).

- Readmission rate: defined as the total number of discharges that were followed by a subsequent unscheduled admission (same patient and same hospital) within 30 days of the first discharge, over the total number of discharges (Tsai et al., 2013).

- Mortality rate: defined as the number of in-hospital deaths over the number of discharges (Otsubo et al., 2016).

- Hospital-acquired infection rates: defined as the total number of discharges with a secondary diagnosis in the form of an infection acquired in the hospital, divided by the number of discharges (Zimlichman et al., 2013).

These four indicators are among the ones that garner the most attention both from public, payers as well as policy makers (For instance, they are frequently included in the reports developed by World Health Organization (WHO) and/or OECD). The average length of stay in a hospital is considered to be one of the most important indicators of efficiency in the delivery of care, especially when no details of the costs for individual inpatients are available (Martin and Smith, 1996). Reducing the readmission rates following both surgical procedures and medical treatment is of vital importance to clinicians and policy-makers. It is suggested that, by reducing the 
frequency of which patients are readmitted, the quality of care is improved and the related costs are reduced (Tsai et al., 2013). The mortality rate is one of the quality indicators most commonly used in the literature for both medical and surgical conditions (Otsubo et al., 2016). Hospitalacquired infections are known to be one the major threats to patients' health (Zimlichman et al., 2013). Moreover, as we discuss below, the combination of these outcome indicators provide a more holistic view of both effectiveness and efficiency of the healthcare provision.

The performance in term of a given indicator may influence other indicators as well (Alyahya et al., 2017; Lewis and Edwards, 2015; McCormack et al., 2013). For instance, shorter stay may influence the quality of the treatment and further increase the mortality and/or readmission rates. Infection rates may influence the mortality rates especially in elderly patients. The literature provides evidence both in favor and against such hypotheses. Therefore, we argue that there is a need for studies that consider these indicators simultaneously, to provide a holistic overview. Such investigations can help the managers at the organizational level and policy makers at the regional level to better grasp the extent and the causes of such variations. Only through such studies, we are able to reveal useful insights such as whether health organizations with higher variations for a given indicator have higher or lower variations in other indicators.

On the other hand, the outcome variations may be different depending on the medical conditions (Herrin et al., 2015). It is useful to know whether low or high performance of one indicator in a medical category implies also lower or higher performance in other conditions as well. Influencing factors may be different or their effect may change across conditions (Bernal-Delgado et al., 2014). Thus, in the first study of the thesis, we investigate the variations of each indicator for six Major Diagnostic categories (MDCs). We included nervous system (MDC 1), respiratory system (MDC 4), circulatory system (MDC 5), digestive system (MDC 6), diseases and disorders 
of the musculoskeletal system and connective tissue (MDC 8), and kidney and urinary tract (MDC 11). These diagnostic categories account for the majority of hospitalizations. In Spain, they were around $56 \%$ of the total admissions of non-surgical patients to public hospitals in 2011 (Public hospitals make up 75\% of total hospital activity in Spain (Alvarez Bartolomé and Gogorcena, 2014)).

The values of all indicators are adjusted for age, sex, severity of diseases, case mix weights and type of admission (urgent, scheduled). Thus, we calculated 24 adjusted rates (for each of the 4 outcome indicators in 6 diagnostic categories). The risk adjustment is performed for all the 50 provinces of Spain (See Section 3.1.1 for more details).

\subsubsection{Performance Patterns in Primary Care}

The abovementioned indicators are useful to draw policy implications for secondary care (e.g. hospitals). To answer the first research question for primary care, we also inquire into potentially avoidable hospitalizations. These are the hospitalizations that known to be preventable with timely access to high quality primary care (e.g. family doctors). Thus, in the literature, rates of the avoidable hospitalizations are considered as an outcome indicator for primary care service quality and accessibility. Potentially avoidable hospitalizations also result in significant expenditures in healthcare (Mcandrew et al., 2016).

Primary care is an essential part of every healthcare system. While primary care centres are responsible for treating ambulatory episodes of illness in a timely manner, they are also charged with controlling chronic health conditions. It is well known that poor management of chronic health conditions will result in increased morbidity (Kuh and Ben-Shlomo, 2004), while effective 
control decelerates the progression of existing conditions and lowers the risk of future morbidities (UK Prospective Diabetes Study Group, 1998). Quality and access to primary care are commonly evaluated on the basis of avoidable hospital admissions (Corallo et al., 2014; Eggli et al., 2014; Magán et al., 2011; OECD, 2017a). Ambulatory Care Sensitive Conditions (ACSCs) are conditions where effective primary care services can help to prevent the need for hospital admission (Gibson et al., 2013), also known as potentially avoidable hospitalizations. ACSCs are estimated to account for $8 \%$ to $12 \%$ of all hospital admissions (Sanderson and Dixon, 2000) and impose substantial costs on health systems both financially and in human terms. (Mcandrew et al., 2016).

A systematic literature review (Muenchberger and Kendall, 2010) led to the identification of three conceptual categories that have significant impact on avoidable hospitalizations: person-centred priorities (e.g. health status), program-centred priorities (e.g. coordination between different levels of healthcare delivery) and place-centred priorities (e.g. geographical characteristics, health insurance). In order to assess the relationship between primary care performance and potentially avoidable hospital admissions, it is essential to include proxies for the above predictors. The type of the health system also plays an important role in evaluating the effect of these priorities, because some of them are dependent on the type of the health system concerned. For instance, Gibson et al. (Gibson et al., 2013) assessed the avoidable hospitalization rates for patients with and without health insurance. Hospital admissions for ACSCs were higher among the uninsured, which confirms the impact on ACSC outcomes caused by financial barriers (Gibson et al., 2013). On the other hand, health insurance is not expected to have a high impact on ACSC hospitalizations in national health systems (Billings et al., 1996), where the overwhelming majority of people are covered by national health insurance. The secondary care sector — which 
is typically provided by a specialist or facility upon referral from a primary care doctor when more specialized knowledge, skills or equipment are necessary — can also play an important role in ACSC admissions (Freund et al., 2013), and so should be considered when investigating ACSC hospitalizations.

The empirical results about the effect that primary care and other confounding variables have on potentially avoidable hospital admissions are mixed and inconclusive (Gibson et al., 2013). For instance, Rizza et al. (Rizza et al., 2007) state that, as the number of patients per primary care doctor increases, the hospitalization rates for diabetes patients also rises while, when Griffiths et al. (Griffiths et al., 2010) examined the same variable, they found the exact opposite. These mixed findings can be caused by incomplete risk adjustments, especially for the populations' health status (Eggli et al., 2014). Poor risk adjustments are usually due to the lack of available data and unobserved variables. It follows that investigations into ACSC hospitalizations should make sufficient adjustments for the various and complex confounding variables or examine highly aggregated data relating to large geographic areas (Freund et al., 2013).

In this thesis we investigate the factors that influence preventable hospital admissions within the Spanish national healthcare system. Healthcare responsibility in Spain is delegated to regional authorities known as autonomous communities. The Spanish national health system consists of 17 regional healthcare services, and each of these regions covers several provinces (50 in total). While each regional health service answers only to its regional parliaments, the Ministry of Health plays a strong role in monitoring and co-ordinating the whole. Böhm et. al. (2013) define the Spain health system as a National Health Service (NHS) here regulations, financing and service provision are determined by the state. An NHS is one of the most common forms of health systems, 
especially in Europe, and we believe that the empirical findings and policy implications of our study can be relevant for the decision-makers in many other European countries.

Generally, when analyzing the level of variations, the type of the health system also plays an important role in the interpretation of the results. Böhm et al. (2013) recognize 6 types of health systems that empirically exist among the OECD countries. The classification is based on the three main functional processes of the healthcare systems: regulations, financing and service provisions. In this thesis, we take into account the healthcare systems of Italy (Phase 2), Spain (Phase 1) and UK (Phase 3). Italy is categorized as National Health Insurance (NHI) and Spain and UK have NHS (Böhm et al. 2013). As mentioned, in NHS, states are the main actors in all the three dimensions while in NHI, private sector also plays a role in the service provision.

We opted to use longitudinal data with panel data analysis, as this means that we can control for time-invariant unobservable and omitted variables (e.g. geographical characteristics), thus improving the reliability of the results (Further details are provided in Section 3.1.2). The factors that influence avoidable hospitalizations may differ for the different diseases (Herrin et al., 2015) and, for this reason, this paper deals with medical conditions from different specialty areas. The three illnesses considered are Chronic Obstructive Pulmonary Disease (COPD), Congestive Heart Failure (CHF) and Bacterial Pneumonia (BP), which together were the reason for more than 200,000 hospital admissions in Spain during 2015 (“National Health System’s Hospitalization Minimum Basic Data Set," n.d.). Given the frequency and cost burden of these avoidable hospitalizations, it is important to identify the influencing factors that can reduce their number. As mentioned, previous studies provide mixed evidence on the effect of the quality and accessibility of primary care on reducing the avoidable hospitalizations (Gibson et al., 2013). Thus, it is not 
clear if policy makers should allocate more budget to primary care in order to reduce avoidable hospitalizations.

The three categories of variations defined in (Wennberg, 2002) (Effective care, Preferencesensitive care and Supply-sensitive care), provide a framework for identification of the origins of the detected unwarranted variations and finding appropriate remedies to enhance the quality of the care (Corallo et al., 2014). The five outcome indicators (average length of stay, readmission rate, mortality rate, hospital-acquired infection rates and preventable hospitalization) have influencing factors both in categories of effective-care and supply-sensitive. For instance, following the evidence-based guidelines would improve the care outcome and consequently would decrease the length of stay, readmission and (avoidable) admission rates. On the other hand, availability of resources such as hospital beds can influence the professional decisions on whether a given patient should be (re-)admitted or stay longer in the hospital. Given that the clinical guidelines regarding the length of stay or admission are not usually deterministic, these outcomes are much more influenced by the supply of resources and are better fitted in supply-sensitive variations (Wennberg, 2002). These indicators consequently are more beneficial for identifying disinvestment opportunities and reallocating the expenditures for other uses (Corallo et al., 2014). Mortality and infection rates reflect (at least to some level) the quality of the care (Mant, 2001). They may imply the level of adherence to the recommended guidelines and therefore are better fitted in the evidence-based category. Thus, investigation of the five performance indicator provides a holistic overview of both quality (in terms of adherence to evidence-based guidelines) and efficiency of the healthcare system under study. 


\subsection{Phase 2: Business Intelligence and Unwarranted Variations}

The introduction of new and sophisticated medical technologies, the global trend of increased longevity, and the growth in non-transmittable chronic diseases have the potential to drive the cost of healthcare to unsustainable levels (Janssen and Moors, 2015; Qaseem et al., 2012). Public and private healthcare organizations are focusing their efforts on finding new, more affordable levels of care, and increasing efficiency (Pine et al., 2012; Romanow et al., 2012). In order to do this, information technologies have a fundamental role in transforming data into intelligence that can be used to improve patient care, healthcare facilities, and process management (Behkami and Daim, 2012; Li and Mao, 2015; Pai and Huang, 2011).

In addition to direct effect of the information technologies on efficiency, availability of high quality and real-time data plays a crucial rule in public health research and in particular in investigation of unwarranted variations. The data used in public health research come from two main categories: First, population-based data that are collected through population surveys, censuses, public registries, etc. Second, institution-based data such as EHRs, administrative datasets of hospitals and primary care registries (World Health Organization, 2008). In institutionbased category, hospitals as the main institutions in care delivery, are responsible for gathering and storing significant part of patients' data. The data repositories in hospitals are then integrated to create national and international data sources.

Currently, administrative data gathered in the hospitals are one of the most popular source of data in unwarranted variations studies. Administrative datasets, due to large sample size, are less prone to sampling error and have higher external validity. Thus, these datasets are more appropriate for investigating the practice variations (Nguyen and Barshes, 2010). However, administrative health data were traditionally gathered for financial and insurance payments purposes. They do not 
always encompass accurate and detailed clinical information (van Mourik et al., 2015). Moreover, the processing and preparation of the administrative datasets are mostly ad-hoc and time consuming.

The accuracy of the data is another important aspect. Poor documentation of health data (e.g. disease coding errors) leads to erroneous outcomes measurement and consequently flawed allocation of funds and resource (Cheng et al., 2009), and raises the healthcare expenditure to unsustainable levels.

Furthermore, bringing together the hospital databases across the countries enables learning opportunities and facilitates the mitigation of the unwarranted variations especially in the context of European national health systems (Bernal-Delgado and Estupiñán-Romero, 2018; Peiro and Maynard, 2015). Thus, the health datasets should be flexible enough to be joined in national and/or cross-country levels. The data should have enough details so that can be transformed in different standards used across the countries (e.g. different disease classifications). In summary, to improve our understanding of unwarranted variations, we need more accurate and richer datasets that can be easily joined across levels of analyses in a timely manner. To reach these goals, the improvement of the Healthcare Information Systems (HIS) is inevitable (Iezzoni, 2003). Thus, investment in health data infrastructure and information systems is essential for monitoring the performance of health systems (OECD, 2010) and consequently controlling and reducing the variations.

Developing comprehensive information systems for healthcare is also highly demanded by patients, and both public and private funders, however this requires high investments and thus, the potential benefits should be clear (Peiro and Maynard, 2015). Given the crucial role of data in 
supporting organizational enhancement, BI has become an important area of study for both researchers and practitioners (Chen et al., 2012).

\subsubsection{BI in Healthcare}

As mentioned, healthcare organizations have been under constant pressure to not only achieve more outcomes with fewer resources (Foshay and Kuziemsky, 2014), but also to progressively become information-driven systems (Gastaldi and Corso, 2012). Considering that the amount of data recorded by EHRs and medical registries is growing rapidly (Kuiler, 2014; Wang et al., 2016), healthcare organizations are trying to draw upon tools such as BI in order to improve their efficiency and effectiveness (Brooks et al., 2013; Wang et al., 2016).

If BI was initially perceived as merely a collection of tools for data analysis (Anandarajan et al., 2012), over time it has been increasingly considered a strategic weapon by several organizations (Wixom and Watson, 2012). Today, BI is usually referred to as a set of theories, methods, processes, and techniques that converts data into useful and valuable information for business purposes (Rud, 2009). BI solutions help decision-makers by providing practical information in the right form, at right time, and in right place (Negash, 2004).

Davenport and Harris (2007) define BI as a set of technologies and processes that use data, statistical and quantitative analysis, explanatory and predictive models, and fact-based management, which drive decisions and actions, enabling an accurate understanding of business performance.

The field of BI has improved significantly in the last decade (Gandomi and Haider, 2015), and has promising applications in the healthcare domain (Chen et al., 2012; El-Gayar and Timsina, 2014; Fichman et al., 2011). In fact, BI can not only improve the outcomes of healthcare organizations 
(Tremblay et al., 2012; Pine et al., 2012), but also help them to progress along the continuum from intuitive to precision medicine (Christensen et al., 2009; Gastaldi et al., 2015).

As recently highlighted (Gartner, 2015), the market of BI has grown significantly and has become the first investment priority for Chief Information Officers (CIOs). Also, the awareness of its potential benefits is increasing (Chuah and Wong, 2011; Lahrmann et al., 2011). However, the implementation of BI in healthcare proceeds relatively slowly and in an ad hoc way (Foshay and Kuziemsky, 2014).

$\mathrm{BI}$ is capable of improving data quality and adopt various data standards that provides linkage mechanism across the institution's regions and countries. For instance, BI incorporates techniques such as data visualizations that can be used to detect unexpected patterns in the health data that occur due to inaccurate or systematic missing data (e.g. Bernal-Delgado and Estupiñán-Romero, 2018). Beside the benefits of the BI on improving the data quality and integration, it has direct effects on improving the quality of the service delivery in healthcare as accurate information in a timely manner is required to realize evidence based medicine (Foshay and Kuziemsky, 2014).

BI can link and integrate data from various internal and external resources and put out a unified information repository for decision makers (Mettler and Vimarlund, 2009). This enhances the ability of health systems to record, link and monitor patients through time, treatment episodes and health status changes (Oderkirk et al., 2013) and consequently monitor the variations more effectively. Thus, we argue that successful implementation of BI in hospitals is essential to create information systems that help monitoring healthcare performance and reducing the variations.

Despite the increasing awareness of BI and its potential benefits (Chuah and Wong, 2011; Lahrmann et al., 2011), it is not very widespread in healthcare (Hanson, 2011) and the implementation proceeds relatively slow and in an ad-hoc way (Foshay and Kuziemsky, 2014). 
Moreover, when it comes to HIS, studies have reported decreased costs (e.g., Borzekowski, 2009), higher incomes (e.g.,Ayal and Seidman, 2009), and improved productivity (e.g., Lucas et al., 2010). However, other studies have reported a negative or non-existent impact of BI on the performance of healthcare organizations (Agarwal et al., 2010; Foshay and Kuziemsky, 2014).In addition, positive outcomes become less significant moving from institutional to larger scale studies (Chaudhry et al., 2006).

Successful implementation of $\mathrm{BI}$ in healthcare relies on understanding and analyzing the peculiarities and complexities of the domain (Avison and Young, 2007; Mettler and Vimarlund, 2009), though the main focus of the literature on BI was traditionally on the industrial sector (Mettler and Vimarlund, 2009). Moreover, our knowledge about interrelations between BI dimensions and how these interrelations affect BI success, is limited (Popovič et al., 2012). Thus, there is still limited research on how to successfully implement a BI solution into this domain (Foshay and Kuziemsky, 2014). More specifically, we completely lack comprehensive models to help practitioners with the priorities that should be followed to develop a proper BI solution (Chen et al., 2012).

The main challenge in implementing the BI systems has shifted from technological perspective to organizational aspects such as competences in utilization, operations and continuous development (Williams and Williams, 2007; Richardson and Bitterer, 2010). Thus, implementation and improvement of BI specially in a complex context such as healthcare, should be viewed as evolutionary process. Success of BI depends on the overall view of its design and necessary future changes (Mettler and Rohner, 2009). Given the evolutionary nature of this process, maturity models are among the most appropriate tools that can help realizing successful implementation of BI. 


\subsubsection{BI Maturity Models}

Maturity models were introduced for the first time in the 1970s (Gibson and Nolan, 1974) to guide users from an initial state of a system to a desired or naturally existing end state (Fraser et al., 2002; Marx et al., 2012). The key objective of maturity models is to detect the gap between current and desired states, and to anticipate an evolutionary path through which increasing the maturity of the system, and eventually achieve the desired state (Blondiau et al., 2015). The evolutionary path implies that the progress toward higher maturity levels is incremental, and realized through a set of intermediate states (Sen et al., 2012).

Dimensions, levels, and assessment tools are the principal elements of maturity models (Marx et al., 2012).

- Dimensions are areas of mutually-exclusive capabilities that cluster interrelated activities (Lahrmann \& Marx, 2010b). With each dimension come measures, which are used to assess the maturity of the dimension (Mettler \& Rohner, 2009).

- $\quad$ Levels are the maturity states that the dimensions assume. Each level has a distinct descriptor of the detailed corresponding maturity state (Lahrmann \& Marx, 2010a).

- $\quad$ Assessment tools are either qualitative or quantitative, and questionnaires and scoring models are among the most common (Fraser et al., 2002).

Generally, most of the maturity models in the literature are fixed-level models, i.e., models in which a fixed number of maturity levels are assumed for every dimension (Lahrmann \& Marx, 2010b). The main drawback of these models is that they are not developed with the 
interdependencies between their dimensions in mind (de Bruin et al., 2005; Maier et al., 2009). Thus, they cannot provide comprehensive guidelines for prioritizing the potential improvement paths of the BI solution that they aim to improve (Popovič et al., 2012).

Maturity models are the well-stablished tools that can assess strength and weaknesses of BI initiatives and guide the necessary transformation process (Lahrmann et al., 2011). A maturity model identifies the gap between initial state of a system (such as BI), detect the area that need more immediate focus, and guides to reach the desired level of performance (Fraser et al., 2002; Marx et al., 2012).

While there are several BI maturity models in the literature, they focus mainly on data and information, without considering the idiosyncrasies of the peculiar domain in which the models are applied (Brooks et al., 2015). Few studies deepen the idiosyncrasies of healthcare (e.g., Blondiau et al., 2015; Brooks et al., 2015), and there are no models focusing on the interdependencies among the different dimensions that characterize the BI solutions in this domain. Complex systems such as BI have various dimensions and the operability of these dimensions are inter-related. For instance, atomic data provision for each treatment procedure is necessary for automatic performance measurement of different units in different levels. Thus, the progress in maturity of one dimension without synchronized progress of the other dimension may lead to unsuccessful implementation of the BI solution as a whole. The importance of interdependencies grows with the complexity of the domain of interest. Thus, for complex systems, such as healthcare, it is crucial to explicitly measure and incorporate the interactions between different aspects, and identify the possible interdependencies among them. Thus to answer the second research question we develop a maturity model that takes into account the interactions 
between the various aspects of a BI solution in healthcare in order to effectively prioritize the interventions to be accomplished for improving its effectiveness.

In order to develop a comprehensive maturity model for BI in healthcare, We got involved in a research project initiated by observatory of digital innovation of Politecnico di Milano and the Mediterranean Institute for Transplantation and Advanced Specialized Therapies (ISMETT), a 656-employees (86-beds) private hospital in Italy with a recognized experience in using digital technologies (and especially BI). The research project was built upon Clinical Inquiry Research (CIR), a well-known and comprehensive collaborative form of research developed by Schein (2008). In CIR, the practitioners who need help have the directing role and, because of this, learning opportunities will emerge (Schein, 2008). Business process analysis and mapping (Womack and Jones, 2003), face-to-face interviews, and multi-participant interactive dialogues (Mikaelsson and Shani, 2004) were the principal collaborative mechanisms utilized. Starting from literature review, a base-line maturity model was developed, which with the help of practitioners and through iterative improvement processes progressed to a comprehensive maturity model (See Section 3.2 for more details).

\subsection{Phase 3: Advanced Analytics for Risk Adjustment}

In the theoretical framework of unwarranted variations, differentiation of warranted and unwarranted variations is significantly important (Appleby et al., 2011). As mentioned, risk adjustment techniques are the principal tools to reach this goal. Risk adjustment is in fact the process of isolating the adverse effects that are directly consequence of care delivery quality rather than the patients' characteristics (Inouye et al., 2003; Johnson, 2003). By performing risk 
adjustment, researchers are able to eliminate the effects of distorting (confounding) factors such as age, health status, etc. from the populations that are compared together. However, the effectiveness of the methods relies on the size of the populations. Thus, the adjustments are less effective for the small size of the granular levels (Roalfe et al., 2008). On the other hand, the existence of unwarranted variations implies that physicians have a strong role in introducing these variations (Peiro and Maynard, 2015; Wennberg and Gittelsohn, 1973). Thus, effective measurement of unwarranted variation is vital in smaller level of analyses such as patients registered to a physician or hospitals departments. Due to advances in information systems, and implementation of EHRs, healthcare organizations nowadays have huge amount of administrative data available in digital format (O’Malley et al., 2015; Porebski and Straszecka, 2018; Wang et al., 2018). The size and velocity of these data calls for more flexible data analyses techniques. The currently common inferential statistical tools used by health policy and health systems researchers are ad-hoc, and in many situations incapable of managing large datasets (Doddi et al., 2001). These tools are also limited in terms of data exploration (Doddi et al., 2001).Thus, developing more novel methods for risk adjustment, capable of analyzing large datasets, are necessary (Morgan et al., 2015; Schwartz et al., 2014; Welch et al., 2011).

Data mining techniques are designed to discover previously unknown relations from large datasets (Hand et al., 2001). While the discipline started in 90s, the term "Data Mining" was registered, in Medical Subject Headings (MeSH), for the first time, in 2010 (Yoo et al., 2012). We argue that recent data mining techniques are more capable in measuring the care variations for small size levels of analyses and they are also more suitable for managing large databases. Data mining techniques are becoming increasingly popular in healthcare. Insurance fraud detection and treatment effectiveness analyses are among the popular applications (Koh and Tan, 2011). 
Among the data mining techniques, Association Rules Mining (ARM) proposed by Agrawal et. al. (Agrawal et al., 1993) is one the most established and popular methods (Tan et al., 2006; Vo et al., 2017). ARM returns set of [If -Then] statements that can uncover interesting patterns within data (Agrawal et al., 1993). These patterns can help healthcare decision makers in improving the effectiveness of health delivery and in properly allocate resources (Antonelli et al., 2015). Over the past decades, ARM gained popularity in exploring clinical datasets especially as diagnosis support systems for physicians (Idri and Kadi, 2017; Karabatak and Ince, 2009; Soni et al., 2011; Stilou et al., 2001), or to discover interesting and accurate patterns to support clinical decision making (Wright et al., 2010). ARM has also been used for instance to find associations between symptoms and diagnosis (Porebski and Straszecka, 2018), co-prescription of drugs (Chen et al., 2003) , psychiatric disorders (Tai and Chiu, 2009) and co-occurrence of multiple diseases (Kost et al., 2012). ARM has been less popular in health policy and systems research. In fact, studies tend focusing on a single diagnosis or outcome (Hanauer et al., 2009), eroding the exploratory power of the ARM. ARM is capable of analyzing datasets with larger number of observations and variables, compared to the common arithmetic and statistical techniques used in risk adjustment. Including large number of variables, potentially improves the chance of discovering interesting and previously unknown patterns in the data.

The first goal of ARM is to find the most frequent values of the variables that occur together (so called itemsets). An itemset is frequent if its items (variables) are present simultaneously in the dataset more than a user-specified threshold which is known as the support. ARM then finds set of [If -Then] statements called association rules, between two subsets of the frequent itemsets. The first subset is called antecedent and the second one is referred to as the consequent. ARM calculates a confidence level for each rule. Confidence of a rule is an estimation of the conditional 
probability of consequence occurrence, given the antecedent. ARM returns rules that have confidence higher than a user specified value. As a simple example consider the following association rule:

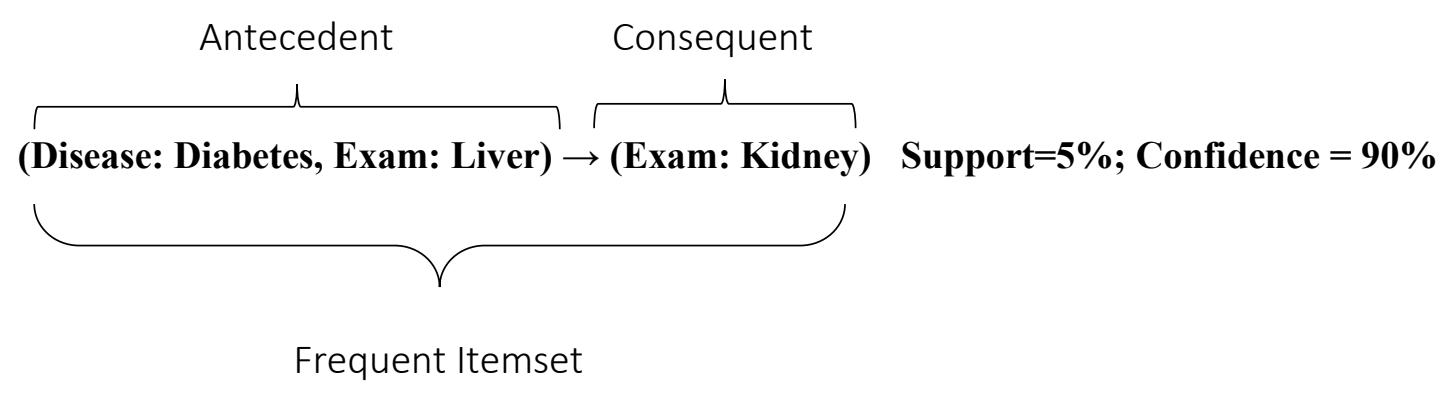

The rule states that $90 \%$ of diabetic patients that were asked to take a liver checkup test, also have taken kidney test. The support indicates that this rule applies to $5 \%$ of the total patients included in the analysis. Such associations can be compared to medical guidelines to check if they are consistent with the evidence-based care delivery.

In the unwarranted variation framework, the items for instance, would represent a given condition, morbidity or other influencing factors such as age, the treatment, the geographical region, the healthcare facility or the corresponding physician. By mining the frequent item sets, we are in fact finding the set of patients that have common and similar characteristics. Thus, the differences between treatments and care outcomes of these patients are then mostly due to the unwarranted variations as they are very similar in terms of the health status and other confounding conditions.

Since the introduction of the Apriori algorithm (Agrawal et al., 1996), association rule mining has been improving significantly, over the past two decades. Among others, Han et al. (Han et al., 2000), introduced an algorithm that discovers the association rules without candidate generation 
step required by Apriori. Deng et al. (Deng et al., 2012) introduced the concept of N-List that represents the transaction datasets more efficiently and decreases the time required for the mining process. However association rule mining are not, as yet, applicable to very large datasets (Djenouri and Comuzzi, 2017; Moens et al., 2013) or else they can be applied only to larger values of frequency thresholds. Unfortunately, in many real-world applications, the rules generated with lower frequencies have more interesting implications (Mobasher et al., 2001). For instance, rules with lower support are useful in detecting anomalies with applications in security systems and network intrusion detection (Ruiz et al., 2014) or discovery of patterns pertaining to purchases of expensive or luxury products. Thus, further improvements are needed to mine large datasets in view of finding the interesting associations more efficiently. As mentioned, ARM involves two major steps, first finding the most frequent values of a set of variables (discovery of frequent itemsets), and second, detecting the relationships between the frequent items (rule generation) (Tan et al., 2006). Of the two, the discovery of frequent itemsets is more expensive in terms of computational requirements (Tan et al., 2006).

Moreover, datasets that include a large number of items usually produce many frequent itemsets. The discovered frequent itemsets thus need to be further analyzed by experts to detect those that are interesting. Many of these itemsets, especially the ones with smaller lengths, are less interesting in practice (Tan et al., 2006) as they are redundant (Vo et al., 2017) and are included in the more representative itemsets. To overcome this problem, researchers have introduced the concepts of Maximal Frequent Itemset (MFI), which are frequent itemsets that have no frequent supersets (Agarwal et al., 2000; Lin and Kedem, 1998) and Frequent Closed Itemsets (FCI), which are frequent itemsets that have no superset with the same support level (Hashem et al., 2017; Pei et al., 2000). In a similar vein, Hu et. al. (Hu et al., 2008) worked on Maximum Length Frequent 
Itemsets (MFI) . LFI denotes the set of all frequent itemsets containing the maximum number of frequent items. This is especially important for ARM application in unwarranted variations. For a given dataset containing the patients' characteristics and health status, higher length of the frequent itemsets means the corresponding patients are more similar and consequently the difference in the care they receive is due to the unwarranted factors. Using this method, we do not need to rely on the homogeneity assumption of the sample data, thus investigating the unwarranted variation in more granular levels becomes feasible.

In this phase of the thesis, we introduce a novel algorithm, called Length-Sort that reflects over the additional hidden information in the transactions lengths to reduce the needed computational effort (See Section 3.3.1 for further details). Decreasing the computational effort consequently improve the capability of analyzing larger datasets. Our proposed algorithm is especially designed for mining maximum length as well as frequent itemsets that have number of items more than a user-specified threshold.

In the following, we have recapped the problem statement and the two main search strategies for mining frequent itemsets. Then, we review the state-of-the-art regarding algorithms for LFI mining.

\subsubsection{ARM Preliminaries}

The problem of finding the most frequent variables was first introduced in (Agrawal et al., 1993) to analyse market basket data and where the variables can only assume binary values. The variable assumes the value 1 if the item is present in the corresponding record (transaction) and is set at 0 otherwise. For instance, consider a dataset with $N_{p}$ or so variables called items, $X=\left(X_{1} \ldots X_{N_{p}}\right)$. 
In this setting, the goal is to find a subset of variables $I \subseteq\left\{1 \ldots N_{p}\right\}$ called itemset such that the probability given in Eq. 1 is greater than a given threshold (Friedman et al., 2001):

$$
\operatorname{Supp}(I)=\operatorname{Pr}\left[\bigcap_{j \in I}\left(X_{j}=1\right)\right]=\frac{1}{N_{T}} \sum_{k=1}^{N_{T}} \prod_{j \in I} X_{k j}
$$

where $N_{T}$ is the total number of data records (transactions) in the dataset and $X_{k j}$ represents the value of variable $j$ in record $k$. The probability defined in Eq.1 is known as the support of itemset $I$ and is denoted as $\operatorname{Supp}(I)$. In other words, the support of an item is its frequency divided by the total number of transactions. We refer to the frequency of an item or itemset as its support count or simply count. An itemset whose support is greater or equal to a user specified minimum threshold is called a frequent itemset. Agrawal et. al. (Agrawal et al., 1996) developed an algorithm, called the Apriori algorithm, to find frequent sets in a dataset. This algorithm exploits what is known as the Apriori Principle, which states that, any subset of a frequent itemset is also a frequent itemset (Agrawal et al., 1996).

The Apriori algorithm follows an approach known as the "level-wise search" for finding the frequent itemsets. In this approach, itemsets of size $\mathrm{K}$ are used to discover frequent item sets of size $(\mathrm{K}+1)$. Based on the Apriori principle, if a $(\mathrm{K}+1)$ itemset is frequent, then all its subsets of size $\mathrm{K}$ are also frequent. Thus, $\mathrm{a}(\mathrm{K}+1)$ itemset is a candidate itemset only if there are two frequent subsets of size K whose first (K-1) items are in common. Thus, the Apriori algorithm starts by finding all the frequent sets of size 1 , then the 1 -itemsets are used to generate candidate 2 -itemsets and so on. 
Apriori and Apriori-based algorithms are breadth-first approaches that apply a "bottom-up" search logic to mine the frequent itemsets. The drawback to these types of algorithms is the fact that they produce candidate itemsets and all these candidates are checked to detect the frequent itemsets. This requires several scans of the dataset, especially for longer frequent itemsets.

Han et al. (Han et al., 2000) introduced a Frequent Pattern-growth (FP-growth) algorithm which avoids the issue of generating candidates and only scans the dataset twice. The first scan detects the single frequent items and sorts them into descending order, according to their support level. The ordered items are stored in a header table. The FP-growth algorithm and its variants are then used to mine the Frequent-Pattern tree (FP-tree), which is a compact tree structure of the dataset that is built during the second scanning process. In addition to the support, the Header table (Htable) stores a node-link for each item. For any given item, the node-link can be used to identify all the corresponding nodes in the tree. The FP-tree and H-table store all the necessary information to mine the frequent itemsets without generating candidate itemsets. Figure 2-1 shows the example of a dataset and its corresponding FP-tree and H-table.

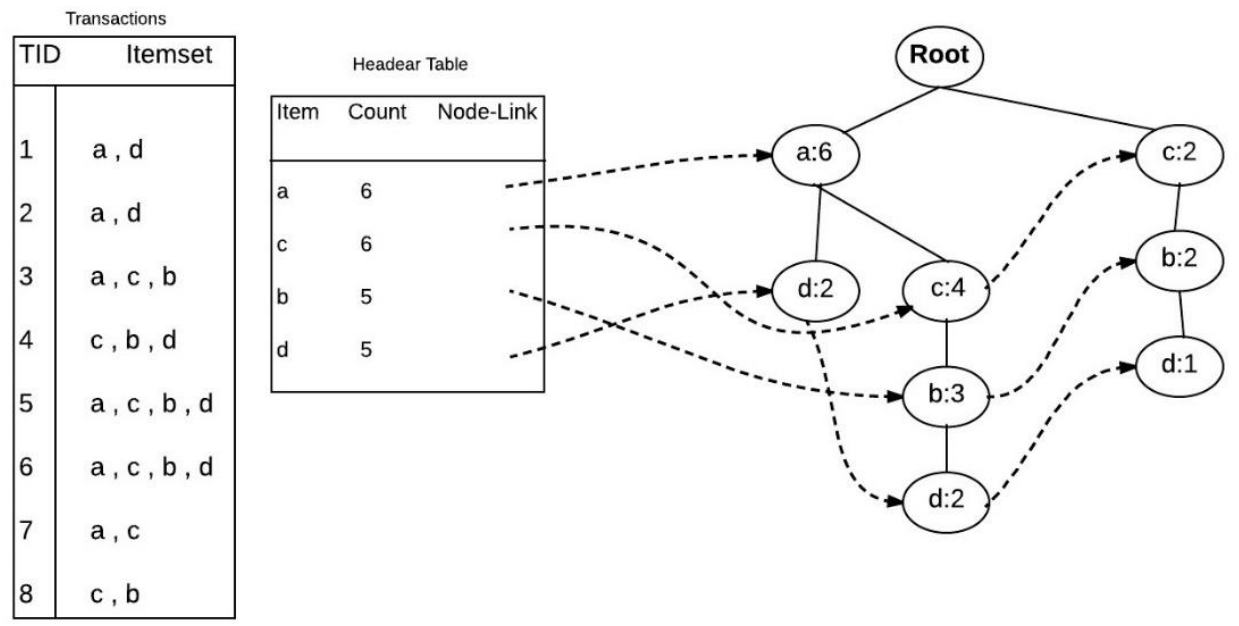

Figure 2-1: Example of an FP-tree structure 
The set of transactions that contain the itemset $I$ is called the conditional pattern base of $I$. For each item in the H-table, the FP-growth algorithm extracts the conditional pattern and constructs a conditional FP-tree. When building the conditional FP-tree, the algorithm continues recursively to mine all the frequent itemsets. As shown in previous studies, the FP-growth and its variants are computationally more efficient than in Apriori-like algorithms, especially for data sets containing longer frequent itemsets. However, as the algorithm works recursively, the FP-tree needs to be fitted into the main memory of the computer being used.

Deng et al.(Deng et al., 2012) introduced PrePost algorithm that uses PPC-tree instead of FP-tree. In PPC-tree instead of node-links, items are associated with pre-order and post-order fields that are assigned based on the tree traversals. In pre-order traversal, the ranks of the parent nodes are smaller while, the ranks of the children are smaller in post-order traversal. The pre and post order traversals start from left branches to the right. Using pre and post-orders, $\mathrm{H}$-table is not needed to mine the frequent itemsets. After construction of PPC-tree, each item is associated with a sequence of tuples, called N-List. N-List of an item consists of pre-order, post-order and count of all the tree nodes corresponding to the item. PrePost then uses the N-Lists to discover frequent itemsets in a level-wise manner. N-List structure is more compact than FP-tree and can improve the runtime of frequent itemsets mining.

\subsubsection{LFI Related Work}

To the best of our knowledge, LFIMiner (Hu et al., 2008) and MaxLFI (Tai et al., 2011) are currently the most efficient algorithms for mining the LFI. LFIMiner is an extension of the FPgrowth algorithm, and it applies three techniques to reduce the search space. After constructing 
the initial FP-tree, LFIMiner employs a procedure known as Conditional Pattern-base Pruning (CPP). In CPP procedure, while constructing the conditional pattern base of the items, any conditional transaction whose length is smaller than the length of the longest frequent itemset found so far is discarded and will not be included in the subsequent conditional FP-tree. If the surviving conditional transaction is also frequent and its length is longer than the current length, then the pruning length is updated.

In the next step, the algorithm incorporates a further process known as Frequent Item Pruning (FIP). FIP acts in a similar way to CPP, pruning the conditional transactions based on the length of the longest frequent itemset found up to that point. However, FIP removes all conditional transactions that do not contain enough frequent items. More specifically, FIP finds all the items that are frequent in the conditional pattern base, and then the conditional transactions with fewer frequent items than the current pruning length are trimmed. FIP is applied recursively, since, by eliminating the conditional transactions, other items may become infrequent, which, in turn, can result in other transactions not being long enough.

Lastly, LFIMiner applies dynamic reordering (Cheung and Osmar R. Zaiane, 2003) to the items in the header table, so that the conditional trees becomes more compact. In other words, the header tables of all the conditional trees are sorted according to the support of the items in the corresponding conditional pattern base.

As mentioned in Section 2.3.1, while constructing the FP-tree, items are sorted in supportdescending order in the header table, as well as in the set of transactions. Consequently, the same order is preserved within the conditional patterns and paths in the FP-tree. MaxLFI (Tai et al., 2011) is an extension of LFIMiner that exploits the order of the items to improve its pruning techniques. The first improvement is based on the observation that the conditional pattern base of 
an item in the $i_{\text {th }}$ position (top-down order) of the header table cannot contribute to frequent itemsets which are longer than i. The authors in (Tai et al., 2011) also introduced the Max Position of the items, defined as the maximum position of a given item in the set of sorted transactions. The Max Position of the items is recorded in an additional column in the header table during the construction of the initial FP-tree. The conditional transactions for items with Max Position $t$ cannot generate frequent itemsets longer than $t$. These two techniques are the bases of what is known as Pre-pruning CPP (PreCPP) in MaxLFI algorithm.

The effectiveness of the above mentioned pruning techniques (CPP, FIP and PreCPP) relies on the length of the longest frequent found so far. Thus, after constructing the initial FP-tree, MaxLFI scans the nodes of the tree (through the header table and node links) whose count is greater than the support threshold, in order to gain an estimate of the longest frequent itemset, prior to the pruning and the construction of the conditional FP-trees. For more detailed information on LFIMiner and MaxLFI, refer to (Hu et al., 2008) and (Tai et al., 2011).

LFI mining can be also performed by applying MFI algorithms. MFI are in fact subset of LFI. So discovering MFI and then pruning the shorter frequent itemsets afterwards, is an alternative approach to discover LFI. To the best of our knowledge, INLA-MFP (Vo et al., 2017) is the stateof-the-art algorithm for extracting MFI. INLA-MFP employs N-List structure and children-parent equivalence (Deng and Lv, 2015) pruning, to discover the MFI more efficiently.

MaxLFI, LFIMiner and INLA-MFP start the processes of pruning and estimating the maximum length, after having constructed the initial tree. However, building a tree that includes all the transactions and frequent items is computationally expensive, especially for large datasets. Moreover, in MaxLFI and LFIMiner the computational effort of constructing the subsequent conditional trees will increase as the size of the initial tree grows. Similarly, as the size of the initial 
tree increases, the number and cardinality of the N-Lists rises and consequently the cost of performing intersections needed in INLA-MFP increases.

In this thesis, we have proposed an approach for pruning both transactions and items before building the initial tree and consequently improve the efficiency of the LFI mining. Lastly, since the tree needs to be fitted into the main memory, reducing the size of the initial tree is crucial to improve the scalability of the procedure up to very large datasets.

In the rest of the thesis, we refer to the number of items present in the transaction, as the size or length of the transaction. Similarly, the length of an itemset is defined as the number of the items contained in the given itemset. Thus, the length of an itemset or transaction is the cardinality of the set or the sum of the corresponding record in the binary representation.

\subsubsection{Application of Length-Sort in Healthcare}

After development of the Length-Sort, we use the England's Quality and Outcome Framework (QOF) dataset to show the application of the ARM in detecting the performance disparities in healthcare. QOF is a national pay-for-performance scheme in UK which financially incentivizes GPs to better adhere to the evidence-based practices. As the impact of unwarranted variations has been recognized by policy makers, they try to incentivized the clinicians by schemes such as payfor-performance to reduce the variations (Otsubo et al., 2016). QOF database contains several indicators for measuring the performance of GPs in practices in evidence-based care delivery. The percentage of the eligible patients that receive the intervention specified by the indicator, is translated into a score. The score of the practices then influences the amount that the practice receives from the national health system. The adherence to the indicators is directly recorded on 
the practices' information system and is controlled in the national level database of Quality and Management Analysis System database (Kontopantelis et al., 2014). It is worth mentioning that QOF scheme is a good example of successful BI implementation in primary care practices, that facilitates monitoring the variations in an automate and timely manner.

We linked the QOF with practices' characteristics such as age, distribution of the patients registered in the practice, age categories of the GP(s) in the practice, geographical location and deprivation indexes to control for the potential confounding factors. As ARM is designed for categorical variables we demonstrated how the variables can be discretized appropriately. We discovered several rules unveiling the patterns of the practices in terms of the indicators (See Section 3.3.2 for more details). 


\section{METHODS \& MATERIALS}

This chapter highlights the methodological aspects of the thesis. In the three subsections of the chapter we present the data sources as well as the methods used for analyzing the data.

\subsection{Phase 1: Unwarranted Variations in Regional Level}

The objective of the first phase is to shed light on the policy interventions that can reduce the level of unwarranted variations across the geographical regions. To reach this objective we investigate the variations in the performance indicators of both secondary and primary care. In particular, we measure the performance differences across the regions as well as try to find the associated influencing factors. The detected factors are then base of the policy recommendations.

In the following subsections, the methodological approach of the studies in the first phase are introduced. We focus on the performance indicators of the secondary care (average length of stay, mortality rate, readmission rate and hospital acquired infection rates) in subsection 3.1 .1 and the indicator for primary care (avoidable hospitalizations) in subsection 3.1.2.

\subsubsection{Performance Patterns in Secondary Care}

In the following two subsections we focus on the various data sources incorporated in the study and the statistical techniques utilized to investigate the magnitude and patterns of the variations.

\subsubsection{Data Sources}

This study makes use of a database entitled the "Minimum Basic Hospital Data Set" (MBDS) ("ICMBD: Indicators and analysis axis model of the MBDS," n.d.) which is the largest set of administrative data on hospitalized patients in Spain (approximately 27 million records, nearly 3.5 
million per year). Because of regulations on confidentiality, patients-level records are not directly accessible. However, we were able to use the interactive functions of the MBDS platform to select the grouping and filtering variables to refine the dataset and acquire the constructs that are appropriate for our study. The 50 Spanish provinces and the MDCs were selected as the grouping variables. We then filtered by gender, age, type of admission (urgent or scheduled) and severity of the illness. Table 3-1 depicts the group and filter variables as well as the excluded cases for each indicator. For each possible combination of the filter variables' levels (48 in total), we obtained a single unique dataset. Data from 2009 to 2011 (the most recent three years with available data for all the provinces) were then aggregated.

\begin{tabular}{|c|c|c|c|}
\hline Indicator & Grouping variable & Filter variable & Exclusion \\
\hline $\begin{array}{l}\text { Average length of } \\
\text { stay }\end{array}$ & $\begin{array}{l}\text { Hospital province } \\
\text { MDC }\end{array}$ & $\begin{array}{l}\text { Age group } \\
\text { Sex } \\
\text { Type of admission } \\
\text { DRG type } \\
\text { Severity of illness }\end{array}$ & $\begin{array}{l}\text { Severity = undetermined } \\
\text { Severity = extreme } \\
\text { Age }<45 \\
\text { DRG type = surgery }\end{array}$ \\
\hline Readmission rate & $\begin{array}{l}\text { Hospital province } \\
\text { MDC }\end{array}$ & $\begin{array}{l}\text { Age group } \\
\text { Sex } \\
\text { Type of admission } \\
\text { DRG type } \\
\text { Severity of illness }\end{array}$ & $\begin{array}{l}\text { Severity = undetermined } \\
\text { Severity = extreme } \\
\text { Age }<45 \\
\text { DRG type = surgery }\end{array}$ \\
\hline Mortality rate & $\begin{array}{l}\text { Hospital province } \\
\text { MDC }\end{array}$ & $\begin{array}{l}\text { Age group } \\
\text { Sex } \\
\text { Type of admission } \\
\text { DRG type } \\
\text { Mortality risk }\end{array}$ & $\begin{array}{l}\text { Mortality risk = } \\
\text { undetermined } \\
\text { Mortality risk = extreme } \\
\text { Age }<45 \\
\text { DRG type = surgery }\end{array}$ \\
\hline $\begin{array}{l}\text { Hospital-acquired } \\
\text { infection rates }\end{array}$ & $\begin{array}{l}\text { Hospital province } \\
\text { MDC }\end{array}$ & $\begin{array}{l}\text { Age group } \\
\text { Sex } \\
\text { Type of admission } \\
\text { DRG type } \\
\text { Severity of illness }\end{array}$ & $\begin{array}{l}\text { Severity = undetermined } \\
\text { Severity = extreme } \\
\text { Age }<45 \\
\text { DRG type = surgery }\end{array}$ \\
\hline
\end{tabular}

Table 3-1: Group and filter variables from MBDS 
For each of the indicators, we considered six MDCs: nervous system (MDC 1), respiratory system (MDC 4), circulatory system (MDC 5), digestive system (MDC 6), diseases and disorders of the musculoskeletal system and connective tissue (MDC 8), and kidney and urinary tract (MDC 11). Number of hospital discharges for each of the MDCs is depicted in Table 3-2.

\begin{tabular}{|l|c|c|c|c|c|}
\hline Major Diagnostic Category & $\mathbf{2 0 0 9}$ & $\mathbf{2 0 1 0}$ & $\mathbf{2 0 1 1}$ & Total & Percentage \\
\hline MDC1. Nervous system & 131,494 & 134,992 & 133,675 & $\mathbf{4 0 0 , 1 6 1}$ & 13.28 \\
\hline MDC4. Respiratory system & 320,301 & 307,193 & 314,264 & $\mathbf{9 4 1 , 7 5 8}$ & 31.26 \\
\hline MDC5. Circulatory system & 270,560 & 272,783 & 264,730 & $\mathbf{8 0 8 , 0 7 3}$ & 26.83 \\
\hline MDC6. Digestive system & 141,837 & 143,262 & 144,528 & $\mathbf{4 2 9 , 6 2 7}$ & 14.26 \\
\hline $\begin{array}{l}\text { MDC8. Musculoskeletal } \\
\text { system and connective tissue }\end{array}$ & 52,336 & 52,803 & 51,361 & $\mathbf{1 5 6 , 5 0 0}$ & 5.20 \\
\hline $\begin{array}{l}\text { MDC11. Kidney and urinary } \\
\text { tract }\end{array}$ & 87,783 & 91,998 & 96,367 & $\mathbf{2 7 6 , 1 4 8}$ & 9.17 \\
\hline Total & $1,004,311$ & $1,003,031$ & $1,004,925$ & $\mathbf{3 , 0 1 2 , 2 6 7}$ & 100.00 \\
\hline
\end{tabular}

Table 3-2: Number of hospital discharges in each MDC (Type of DRG = medical; Severity =minor, moderate and major; Age $\geq 45$ )

Surgery admissions are excluded, and only medical inpatients are included in the study. The reason for this is that some complicated surgeries are only performed in big provincial hospitals and patients from smaller provinces are transferred to these larger hospitals.

The dataset extracted contains three age-specific groups ( 45 to 64,65 to 74 , and 75 and above), two gender categories and two admission categories. For the selected MDCs, patients aged 45 or more represent 80 percent of the total admissions. The illnesses are distinguished into four levels of severity: minor, moderate, major and extreme. The variable for level of severity was estimated by the data-owner and depends on both the primary diagnosis and the presence of comorbidities (using the Elixhauser Comorbidity Index (Elixhauser et al., 1998)) and complications reported in the secondary diagnosis. Patients with extremely severe illnesses are excluded because they tend to be referred to hospitals with more advanced facilities that can be outside patients' provinces. 
Furthermore, in several provinces, there were no hospital admissions in this category for some age groups and/or MDCs. The risk of mortality is used instead of level of severity for the mortality rate indicator.

As each MDC includes several Diagnostic Related Groups (DRG), the proportion of patients in each sub-group can vary from province to province. To control for the potential heterogeneity within the MDCs across the provinces, we applied case-mix average weights (reported as the Spanish Average Weights in the dataset), assigning them to patients according to their corresponding DRG. Case-mix weights were not applied to the readmission rate indicator due to a lack of available data. The DRG codes included in each of the MDCs are provided in Table 3-3.

\begin{tabular}{|c|c|}
\hline $\begin{array}{c}\text { Major } \\
\text { Diagnostic } \\
\text { Category } \\
\text { (MDC) } \\
\end{array}$ & DRG-APR codes and Descriptions \\
\hline 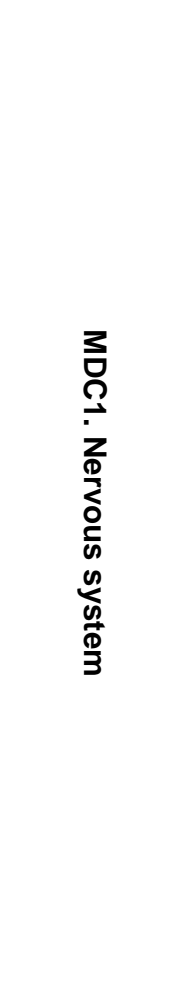 & $\begin{array}{l}20 \text { - CRANIOTOMY FOR TRAUMA } \\
21 \text { - CRANIOTOMY EXCEPT FOR TRAUMA } \\
22 \text { - VENTRICULAR SHUNT PROCEDURES } \\
23 \text { - SPINAL PROCEDURES } \\
24 \text { - EXTRACRANIAL VASCULAR PROCEDURES } \\
26 \text { - OTHER NERVOUS SYSTEM \& RELATED PROCEDURES } \\
40 \text { - SPINAL DISORDERS \& INJURIES } \\
41 \text { - NERVOUS SYSTEM MALIGNANCY } \\
42 \text { - DEGENERATIVE NERVOUS SYSTEM DISORDERS EXC MULT SCLEROSIS } \\
43 \text { - MULTIPLE SCLEROSIS \& OTHER DEMYELINATING DISEASES } \\
44 \text { - INTRACRANIAL HEMORRHAGE } \\
45 \text { - CVA \& PRECEREBRAL OCCLUSION W INFARCT } \\
46 \text { - NONSPECIFIC CVA \& PRECEREBRAL OCCLUSION WIO INFARCT } \\
47 \text { - TRANSIENT ISCHEMIA } \\
48 \text { - PERIPHERAL, CRANIAL \& AUTONOMIC NERVE DISORDERS } \\
49 \text { - BACTERIAL \& TUBERCULOUS INFECTIONS OF NERVOUS SYSTEM } \\
50 \text { - NON BACTERIAL INFECTIONS OF NERVOUS SYSTEM EXC VIRAL MENINGITIS } \\
51 \text { - VIRAL MENINGITIS } \\
52 \text { - NONTRAUMATIC STUPOR \& COMA } \\
53 \text { - SEIZURE } \\
54 \text { - MIGRAINE \& OTHER HEADACHES } \\
55 \text { - HEAD TRAUMA W COMA >1 HR OR HEMORRHAGE }\end{array}$ \\
\hline
\end{tabular}




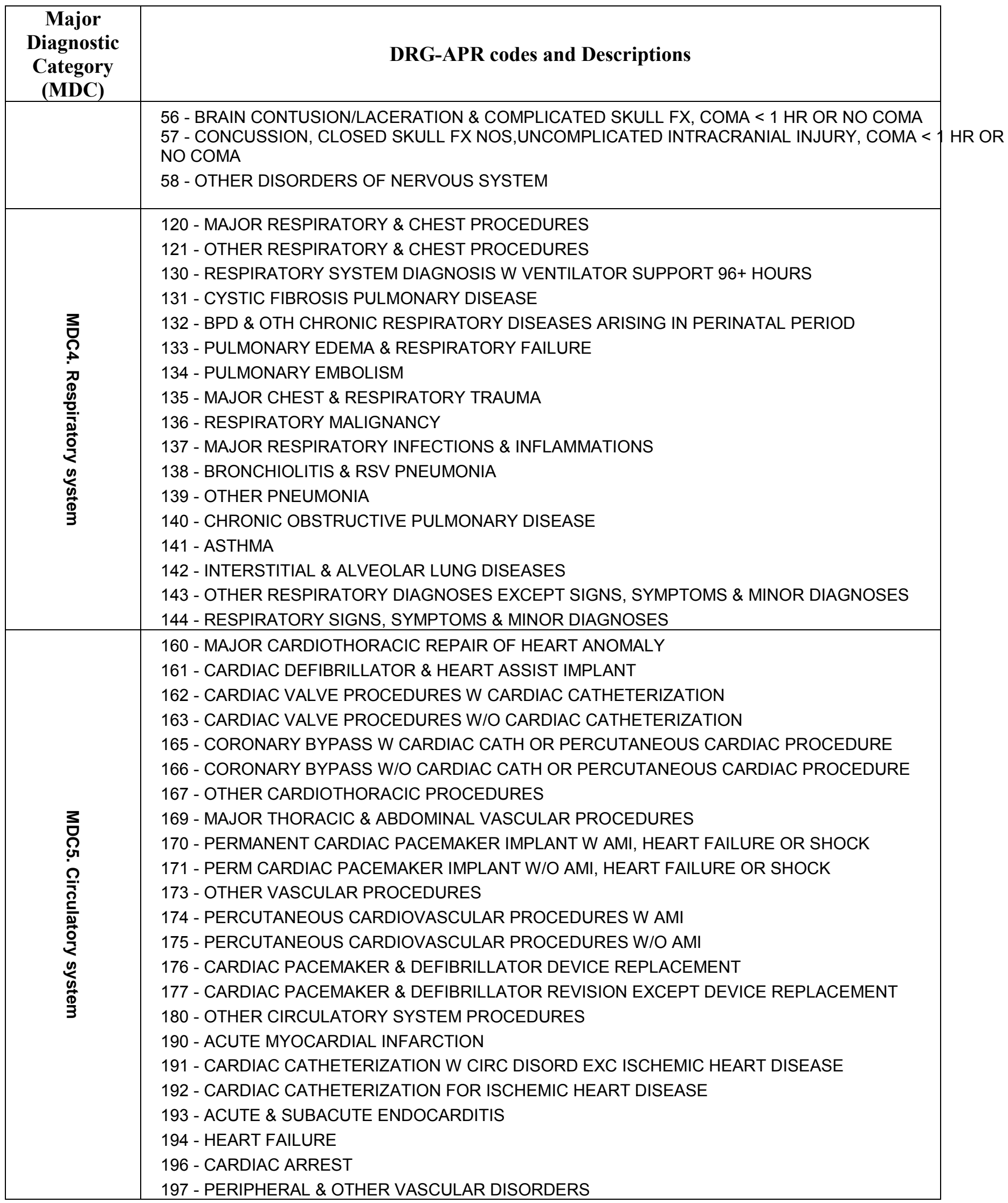




\begin{tabular}{|c|c|}
\hline $\begin{array}{c}\text { Major } \\
\text { Diagnostic } \\
\text { Category } \\
\text { (MDC) }\end{array}$ & DRG-APR codes and Descriptions \\
\hline & $\begin{array}{l}198 \text { - ANGINA PECTORIS \& CORONARY ATHEROSCLEROSIS } \\
199 \text { - HYPERTENSION } \\
200 \text { - CARDIAC STRUCTURAL \& VALVULAR DISORDERS } \\
201 \text { - CARDIAC ARRHYTHMIA \& CONDUCTION DISORDERS } \\
203 \text { - CHEST PAIN } \\
204 \text { - SYNCOPE \& COLLAPSE } \\
205 \text { - CARDIOMYOPATHY } \\
206 \text { - MALFUNCTION,REACTION,COMPLICATION OF CARDIAC/VASC DEVICE OR PROCEDURE } \\
207 \text { - OTHER CIRCULATORY SYSTEM DIAGNOSES }\end{array}$ \\
\hline 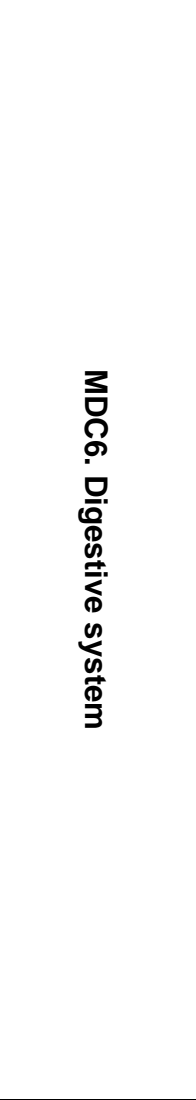 & $\begin{array}{l}220 \text { - MAJOR STOMACH, ESOPHAGEAL \& DUODENAL PROCEDURES } \\
221 \text { - MAJOR SMALL \& LARGE BOWEL PROCEDURES } \\
222 \text { - OTHER STOMACH, ESOPHAGEAL \& DUODENAL PROCEDURES } \\
223 \text { - OTHER SMALL \& LARGE BOWEL PROCEDURES } \\
224 \text { - PERITONEAL ADHESIOLYSIS } \\
225 \text { - APPENDECTOMY } \\
226 \text { - ANAL PROCEDURES } \\
227 \text { - HERNIA PROCEDURES EXCEPT INGUINAL, FEMORAL \& UMBILICAL } \\
228 \text { - INGUINAL, FEMORAL \& UMBILICAL HERNIA PROCEDURES } \\
229 \text { - OTHER DIGESTIVE SYSTEM \& ABDOMINAL PROCEDURES } \\
240 \text { - DIGESTIVE MALIGNANCY } \\
241 \text { - PEPTIC ULCER \& GASTRITIS } \\
242 \text { - MAJOR ESOPHAGEAL DISORDERS } \\
243 \text { - OTHER ESOPHAGEAL DISORDERS } \\
244 \text { - DIVERTICULITIS \& DIVERTICULOSIS } \\
245 \text { - INFLAMMATORY BOWEL DISEASE } \\
246 \text { - GASTROINTESTINAL VASCULAR INSUFFICIENCY } \\
247 \text { - INTESTINAL OBSTRUCTION } \\
248 \text { - MAJOR GASTROINTESTINAL \& PERITONEAL INFECTIONS } \\
249 \text { - NON BACTERIAL GASTROENTERITIS, NAUSEA \& VOMITING } \\
251 \text { - ABDOMINAL PAIN } \\
252 \text { - MALFUNCTION, REACTION \& COMPLICATION OF GI DEVICE OR PROCEDURE } \\
253 \text { - OTHER \& UNSPECIFIED GASTROINTESTINAL HEMORRHAGE } \\
254 \text { - OTHER DIGESTIVE SYSTEM DIAGNOSES }\end{array}$ \\
\hline 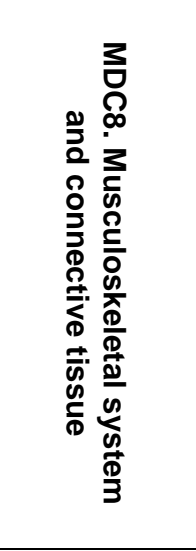 & $\begin{array}{l}301 \text { - HIP JOINT REPLACEMENT } \\
302 \text { - KNEE JOINT REPLACEMENT } \\
303 \text { - DORSAL \& LUMBAR FUSION PROC FOR CURVATURE OF BACK } \\
304 \text { - DORSAL \& LUMBAR FUSION PROC EXCEPT FOR CURVATURE OF BACK } \\
305 \text { - AMPUTATION OF LOWER LIMB EXCEPT TOES } \\
308 \text { - HIP \& FEMUR PROCEDURES FOR TRAUMA EXCEPT JOINT REPLACEMENT } \\
309 \text { - HIP \& FEMUR PROCEDURES FOR NON TRAUMA EXCEPT JOINT REPLACEMENT } \\
310 \text { - INTERVERTEBRAL DISC EXCISION \& DECOMPRESSION } \\
312 \text { - SKIN GRAFT, EXCEPT HAND, FOR MUSCULOSKELETAL \& CONNECTIVE TISSUE DIAGNOSE } \\
313 \text { - KNEE \& LOWER LEG PROCEDURES EXCEPT FOOT } \\
314 \text { - FOOT \& TOE PROCEDURES } \\
315 \text { - SHOULDER, UPPER ARM \& FOREARM PROCEDURES }\end{array}$ \\
\hline
\end{tabular}




\begin{tabular}{|c|c|}
\hline $\begin{array}{c}\text { Major } \\
\text { Diagnostic } \\
\text { Category } \\
\text { (MDC) }\end{array}$ & DRG-APR codes and Descriptions \\
\hline & $\begin{array}{l}316 \text { - HAND \& WRIST PROCEDURES } \\
317 \text { - TENDON, MUSCLE \& OTHER SOFT TISSUE PROCEDURES } \\
320 \text { - OTHER MUSCULOSKELETAL SYSTEM \& CONNECTIVE TISSUE PROCEDURES } \\
321 \text { - CERVICAL SPINAL FUSION \& OTHER BACK/NECK PROC EXC DISC EXCIS/DECOMP } \\
340 \text { - FRACTURE OF FEMUR } \\
341 \text { - FRACTURE OF PELVIS OR DISLOCATION OF HIP } \\
342 \text { - FRACTURES \& DISLOCATIONS EXCEPT FEMUR, PELVIS \& BACK } \\
343 \text { - MUSCULOSKELETAL MALIGNANCY \& PATHOL FRACTURE D/T MUSCSKEL MALIG } \\
344 \text { - OSTEOMYELITIS, SEPTIC ARTHRITIS \& OTHER MUSCULOSKELETAL INFECTIONS } \\
346 \text { - CONNECTIVE TISSUE DISORDERS } \\
347 \text { - OTHER BACK \& NECK DISORDERS, FRACTURES \& INJURIES } \\
349 \text { - MALFUNCTION, REACTION, COMPLIC OF ORTHOPEDIC DEVICE OR PROCEDURE } \\
351 \text { - OTHER MUSCULOSKELETAL SYSTEM \& CONNECTIVE TISSUE DIAGNOSES }\end{array}$ \\
\hline 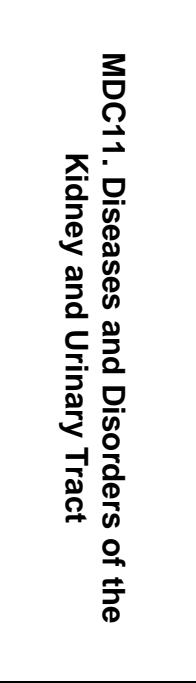 & $\begin{array}{l}440 \text { - KIDNEY TRANSPLANT } \\
441 \text { - MAJOR BLADDER PROCEDURES } \\
442 \text { - KIDNEY \& URINARY TRACT PROCEDURES FOR MALIGNANCY } \\
443 \text { - KIDNEY \& URINARY TRACT PROCEDURES FOR NONMALIGNANCY } \\
444 \text { - RENAL DIALYSIS ACCESS DEVICE PROCEDURE ONLY } \\
445 \text { - OTHER BLADDER PROCEDURES } \\
446 \text { - URETHRAL \& TRANSURETHRAL PROCEDURES } \\
447 \text { - OTHER KIDNEY, URINARY TRACT \& RELATED PROCEDURES } \\
460 \text { - RENAL FAILURE } \\
461 \text { - KIDNEY \& URINARY TRACT MALIGNANCY } \\
462 \text { - NEPHRITIS \& NEPHROSIS } \\
463 \text { - KIDNEY \& URINARY TRACT INFECTIONS } \\
465 \text { - URINARY STONES \& ACQUIRED UPPER URINARY TRACT OBSTRUCTION } \\
466 \text { - MALFUNCTION, REACTION, COMPLIC OF GENITOURINARY DEVICE OR PROC } \\
468 \text { - OTHER KIDNEY \& URINARY TRACT DIAGNOSES, SIGNS \& SYMPTOMS }\end{array}$ \\
\hline
\end{tabular}

Table 3-3: DRG codes included in each MDC

\subsubsection{Methods}

We performed standardisations by regression models (Israëls, 2013) ( in particular, logistic and linear regression) instead of indirect standardisations because the former allows continuous variables to be included. In total 24 sets of standardised rates were calculated for the combinations of 4 indicators and 6 MDCs. The confidence intervals were calculated for the standardised rates 
based on Poisson's approximation (Israels, 2013) for the mortality, readmission and hospitalacquired infection rates. If the standardised value for a province was close to 1 , it meant that the performance in the region to which the province belongs followed, by and large, the average pattern (the reference population in this study is the combined admissions for every MDC in all 50 provinces). All standardised rates having p-values greater than 0.05 were replaced by 1 (the average pattern).

To grasp the size in variation across the country, we calculated 5-95 percentile External Quotient (EQ5-95) and Systematic Component of Variations (SCV) (McPherson et al., 1982).

$$
\text { Regression Rates } \cong I S R_{i}=\frac{o_{i}}{E_{i}}
$$

Where $O_{i}$ observed cases of a given indicator in region $i$ and $E_{i}$ is the expected cases. The SCV is calculated as following (McPherson et al., 1982):

$$
S C V=\frac{1}{K}\left(\sum_{i}^{K} \frac{\left(O_{i}-E_{i}\right)^{2}}{E_{i}{ }^{2}}-\sum_{i}^{K} \frac{1}{E_{i}}\right)
$$

Where $K$ total number of provinces. Regression rates are acquired from regression analyses (See Tables 4-1 to 4-4 in Section 4.1.1) and $E_{i}$ are calculated from Eq. 3-1. Substituting the values in Eq. 3-2 we get the SCVs.

As the distribution of the length of stay is not Poisson, SCV is not calculated for this indicator. Finally, the standardised rates were divided into nine groups, based on how they differed from the average pattern, with the following categories then being defined: $<-50 \%,-50 \%$ to $-35 \%,-35 \%$ to $-20 \%,-20 \%$ to $-5 \%,-5 \%$ to $5 \%, 5 \%$ to $20 \%, 20 \%$ to $35 \%, 35 \%$ to $50 \%$ and $>50 \%$. The categories are given values from 1 to 9 . This provide a set of reasonable categories for the performance levels and mitigate the effect of outliers (regions with very high or low performance levels). 


\section{Factor analysis and Clustering}

In next step we use factor analysis and clustering method. These allow to identify the group of regions that have similar patterns. Comparing the similarities (within clusters) and differences between the clusters shed lights on the levels of the unwarranted variations as well as their influencing factors.

Using factor analysis, the four underlying factors were detected, one for each of the performance indicators. Using a single factor for each indicator, instead of the six different rates for the MDCs, helps the findings to be more easily generalized (Herrin et al., 2015) and interpreted.

The underlying factors derived from the factor analysis were used to perform a two-step clustering analysis. In the first step, hierarchical clustering was used to determine the appropriate number of clusters. Then, K-means clustering was applied to classify the provinces into three groups.

\section{Analyse of variance}

ANOVA is used to compare the performance indicators across the clusters and MDCs to detect the statistically significant differences. Analysing the significant differences sheds lights on the underlying factors of the unwarranted variations.

Two sets of ANOVA tests were performed. First, we compared each performance indicator across the $6 \mathrm{MDCs}$ to check whether the performance indicators were similar across the MDCs. As the observations of a given region across the MDCs are not independent, we used repeated measures ANOVA (within-subjects ANOVA). Second, we ran one-way ANOVA (Scheffé) to identify the differences between each pair of the 3 clusters for each of the four factors predicted by factor analyses. 


\subsubsection{Performance patterns in Primary Care}

This section focuses on the preventive hospitalizations which is commonly considered as a performance indicator of primary care. The data sources and statistical techniques to draw conclusion on this aspect of healthcare performance are explained in the two following subsections. By analyzing the unwarranted variations in the preventable hospitalizations and including various relevant confounding variables we try to identify policy recommendations that can reduce the level of variations and promote better care delivery in primary care.

\subsubsection{Data Sources}

This study has acquired data from several sources. Similar to the previous study, the first data source is MBDS ("National Health System's Hospitalization Minimum Basic Data Set," n.d.). The second source of data were the statistical portal for the Spanish NHS primary ("The Primary Health Care Information System (SIAP)," n.d.) and a specialized care information system(“The Specialized Care Information System (SIAE)," n.d.), which contains information about the number of consultations taking place in primary and specialized care. Third, we used data available from the "Health Barometer", an annual survey conducted by the Spanish Ministry of Health ("Health Barometer, Ministry of Health, Consumption and Social Welfare," n.d.). Respondents to the survey are randomly selected and interviewed at their home on the basis of a structured questionnaire, and include Spanish NHS users and non-users. Fourth and finally, the relevant covariates were collected from the Spanish national institute of statistics ("Spain Institute of Statistics," n.d.). All the variables described below were collected for 2007 to 2015 in 17 regions 
(Two autonomous cities, Ceuta and Melilla, have not been included in the analyses because of missing data. Population-wise, they are considerably smaller than the other 17 regions). Two observations were discarded because data were missing for some variables. In total, the sample contained 151 region-year elements.

\section{Dependent variables}

The dependant variables are the avoidable hospitalization rates for $\mathrm{COPD}, \mathrm{CHF}$ and $\mathrm{BP}$, acquired from MBDS (“National Health System's Hospitalization Minimum Basic Data Set," n.d.). The ACSCs included in the analysis are the three most common conditions flagged up as avoidable hospital admissions in the dataset. These indicators were adapted from the OECD's healthcare quality indicators (Kelley and Hurst, 2006) and are calculated as the number of patients admitted with the corresponding health conditions per 10,000 population in the autonomous communities. The admission rates have been standardized (by the data owner) to the age and gender of the total European population. Details of inclusion and exclusion criteria are provided in Appendix A.

\section{Explanatory variables}

As proxy of primary care resources and utilization, we used three variables for the number of consultations with GPs, nurses and specialists (outpatients only) per capita. We have also included primary care expenditure measured as a percentage of the total expenditure on public health relating to primary care. To measure the proportion of the population that used primary care services, we included the quota relating to those who consulted family doctors and specialists in each year. The two variables were acquired from the health barometer survey ("Health Barometer, Ministry of Health, Consumption and Social Welfare," n.d.) and measure the percentage of 
respondents who visited a GP or specialist (excluding diagnostic test visits and similar) in the 12 months prior to the period in which the survey took place.

We included several other variables from the health barometer survey relating to the patients' perceived quality of treatment received from their GP and their satisfaction about the time between asking for an appointment and seeing their GP and/or and a specialist. The patients' satisfaction with their GP care has been included in order to measure the relative quality of these consultations and the patients' satisfaction concerning the waiting time to see a GP or specialist is used as a proxy for ease of access to these services. As lifestyle influences the severity of chronic diseases, we also included the patients' perception of their GPs' lifestyle advice (smoking, alcohol consumption, exercise, etc.). For the last four variables, respondents were asked to rate their satisfaction from 1 to 10 , and the scores were averaged out for each region.

\section{Covariates}

Since this study is limited to admissions to public hospitals (which make up $75 \%$ of all hospitals in Spain (Alvarez Bartolomé and Gogorcena, 2014)), we have included the ratio between private and public hospitals' functioning beds to control for the quota of patients who use private health services, across all regions in the study. Similarly, total hospitalization ratios are also added to the model, because health professionals may have the tendency to hospitalize patients more often in some regions than in others.

To control for social-economic factors, we have considered three variables, these being education level, measured by the percentage of 25 to 64 year-olds with no upper secondary education qualifications (International Standard Classification of Education 2 (ISCED 2)), the average annual household net income (in 10,000 euros) and unemployment rates, taken from the national 
institute of statistics ("Spain Institute of Statistics," n.d.). For average income, we used data from 2008 to 2016, as they had been measured for the year prior to the survey. In other words, as the respondents were asked about the income of the previous year, survey data from 2008 to 2016 represent the average income from 2007 to 2015 .

\subsubsection{Methods}

As we are using longitudinal data, we have opted to apply panel data analysis. Using panel data and longitudinal analysis allows to mitigate the bias of unavailable confounding variables and consequently increases the reliability of analysis.

In both the fixed and the random effects models, the dependant variables were each of the three ACSC ratios. As we found evidence of the presence of heteroscedasticity (Modified Wald test pvalue $<0.001$ for all three ACSCs), we used robust (Huber/White) estimators. As the Hausman test is not defined for Huber/White estimators, we performed the robust version of the Hausman test (Wooldridge, 2010) in order to choose between fixed and random effects. The test confirmed the existence of regional fixed effects for all three models ( $\mathrm{p}$-value $<0.001$ ). By using the fixed effects model, we were able to control for the omitted confounding variables that do not vary over time. For instance, among the factors mentioned in the first section, there was no need to include variables for a place's livability (geographical characteristics, air pollution, etc.) or for several determinants of health status (e.g. a disease prevalent in particular ethnic groups). 


\subsection{Phase 2: Business Intelligence and Unwarranted Variations}

As discussed in Chapter 2, in order to increase the chances of successful BI implementation, healthcare-specific maturity models are needed. The following subsections present the empirical setting used to develop an instance of such maturity models as well as a practical road map to realize the advantages of $\mathrm{BI}$ in hospitals. As mentioned the hospitals are often the main source of administrative data which are used for analyzing the unwarranted variations. Thus, the maturity of the BI in hospitals improves the availability and quality of the health data needed for reliable unwarranted variation investigation.

This phase of the study has been conducted in collaboration with a research team in Polytechnic University of Milan (led by one of the thesis supervisors) as well as the practitioners working in the few Italian hospitals. The main contributions of the thesis author were in performing literature review and preparation of research background, data analysis (e.g. analyses regarding the roadmap, refining the characteristics of each maturity level etc.), writing and critical review of the publication resulting from this investigation.

\subsubsection{Empirical Setting}

In order to develop and apply our maturity model, we built upon a CIR project with:

- ISMETT, a 656-employees (86-beds) private hospital in Italy with a recognized experience in using digital technologies (and especially BI) for improving healthcare treatment ${ }^{1}$;

\footnotetext{
${ }^{1}$ ISMETT is public-private partnership between the Region of Sicily (through the Civico Hospital in Palermo) and $U P M C$, an integrated global health enterprise headquartered in Pittsburgh, and one of the leading not-for-profit health systems in the United States. ISMETT is the first hospital in Southern Italy to receive Joint Commission International (JCI) accreditation, and has been recently authorized by the Italian Ministry of Health as an IRCCS. IRCCSs are research-oriented hospitals operating in Italy with competences in research and treatment of important diseases, which represent a national network where basic and translational biomedical research is undertaken in synergy with the delivery of high qualitative healthcare. For more information, see Ferré et al. (2014).
} 
- Five hospitals representative of the variety of the Italian healthcare industry and with experience in the development of BI solutions.

All six hospitals were selected because of their experience in BI-measured in terms of the percentage of budget delivered to BI.

CIR is a well-known collaborative form of research developed by Schein (2008). Unlike most other collaborative research approaches, with CIR the learning opportunity arises in a situation led by practitioners who needs help (Coghlan and Brannick, 2005) and, because of this, is more likely to reveal important data. In these settings, researcher have a role of process facilitator and helps practitioners in discovering insights through self-diagnosis/self-intervention (Stebbins and Shani, 2009).

The request for a joint collaborative research came directly from the executives of ISMETT, interested in developing a model to assess and improve the maturity of its BI solution. A Research Task Force (RTF) was formed. Modeled on the leading literature on collaborative research (Mohrman and Mohrman, 2004), the RTF included both researchers and practitioners. All members are depicted in Table 3-4 together with their expertise and their role into the project. 


\begin{tabular}{|l|l|c|l|}
\hline Member & Expertise & $\begin{array}{l}\text { Years of } \\
\text { expertise }\end{array}$ & Main role into the project \\
\hline Researcher 1 & $\begin{array}{l}\text { Management of complex } \\
\text { projects into the } \\
\text { healthcare domain }\end{array}$ & 15 & Coordination of the overall project \\
\hline Researcher 2 & Maturity models & 4 & $\begin{array}{l}\text { Development/improvement of the maturity } \\
\text { model }\end{array}$ \\
\hline Researcher 3 & Bl in healthcare & 4 & Application of the maturity model to ISMETT \\
\hline Practitioner 1 & $\begin{array}{l}\text { Management control and } \\
\text { decision support systems } \\
\text { in healthcare }\end{array}$ & 10 & Engagement of ISMETT practitioners \\
\hline Practitioner 2 & Bl in healthcare & 6 & Developing/improvement of the maturity model \\
\hline Practitioner 3 & Bl in healthcare & 2 & Reporting of project results \\
\hline
\end{tabular}

Table 3-4: Composition of the Research Task Force

The RTF subdivided its work into two stages that are respectively related to the development of the BI maturity model and its application to ISMETT. Figure 3-1 summarizes the stages as well as the four phases characterizing them, which are derived by Mohrman and Mohrman (2004). The figure reports also the various roles played by the RTF, the methods that have been used and the output produced. 

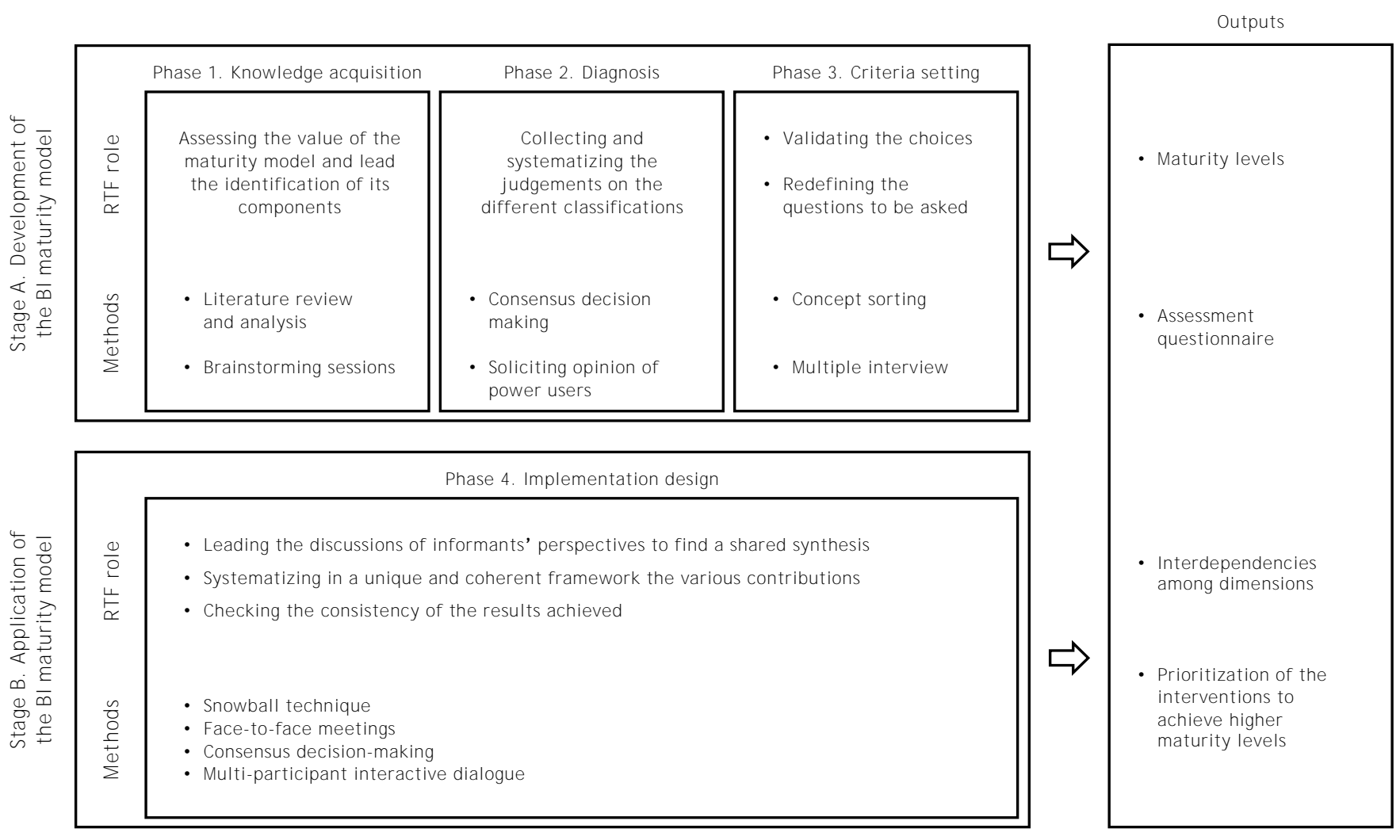

Figure 3-1 : Research stages, phases, methods and outputs

\subsubsection{Development of the BI Maturity Model}

As shown in Figure 3-1, this stage of the CIR project consists of three phases: knowledge acquisition, diagnosis, criteria setting. Each of them is deepened in the following sections. It is important to note that, while the phases are presented in a linear logic, in reality they were highly intertwined, and the final maturity model was the result of a continuous iteration among them. This iteration has been stopped when a new instance of a phase failed to add further insights. A last section proposes the overall outputs that has been achieved: the BI maturity model and the questionnaire through which assessing the maturity of the BI solution in a healthcare organization. 


\section{Knowledge Acquisition}

Given the complexity of creating the model, its development required the design of intermediate constructs (Sen et al., 2012). First, we extensively analyzed the literature, also taking into account all the sectors in which BI maturity is evaluated (not only healthcare). We wanted to understand the criteria used to define and select the metrics by which to assess the maturity of the BI solution, and identify potential logics to group these metrics. This exercise allowed producing a preliminary version of the BI maturity model, which we progressively refined through phase 2 and 3 . The preliminary model was significantly different from the one that will be presented in section 4.4: literature analysis would have missed key aspects such as data provisioning or supplier coordination. Despite several limits, the initial model provided a useful base to discuss with practitioners and focus their contributions.

Information acquisition and knowledge systematization were accomplished in multiple modes depending on the specific intent, on the specific stage of model elaboration and on the experience developed. Three brainstorming sessions (McGraw and Harbison-Briggs, 1989) were used within the RTF to elicit ideas for model conceptualization. The objectives of this phase were to assess the potential value of the maturity model, and to identify the different areas and dimensions characterizing a BI solution in healthcare.

\section{Diagnosis}

Eight sessions of consensus decision-making have been used to progressively converge on the various dimensions of the model. Consensus decision-making is very useful to find the best solution to a problem by letting a group weigh in on the advantages and disadvantages of each alternative (Sen et al., 2012). Each session lasted at least two hours. In the first one, leveraging on 
the results of phase 1, we generated ideas by working alone and in pairs (as suggested by Verganti, 2017). Next, we collected all the ideas in a unique list, and we discussed them with the aims of: (i) building on other intuitions and strengthen other ideas; (ii) converge on the most promising dimensions.

When the RTF was unable to achieve a consensus, it converged on a set of (no more than three) alternatives and asked the experts of the other hospitals engaged into the CIR project to discuss and evaluate these alternatives. Virtual sessions of multi-participant interactive dialogues created consensus, and allowed tackling the most controversial topics. In two cases, a blind evaluation by both the members of the RTF and the engaged experts were necessary.

\section{Criteria Setting}

In this phase, the RTF used four sessions of concept-sorting (McGraw and Harbison-Briggs, 1989) to define the maturity levels of the various dimensions. Concept sorting is a knowledge generation mode that is useful once a maturity model is outlined and its key areas are identified (Sen et al., 2012). Each session was based on an area of dimensions of the maturity model (e.g. the technological ones, see paragraph 4.4 for further details). The members of the RTF worked in pairs (different from the ones of the previous phase) and produced preliminary alternatives for the maturity levels. Next, these alternatives have been sorted into meaningful groups, exploring and explicating through peer discussions the reasons for fitting various levels into the same categories. If preliminary sessions lasted up to four hours, the latest ones allowed converging on the final maturity levels in shorter timeframes.

The RTF also sent e-mails to a panel of three power-users of the BI solution in ISMETT to solicit their opinions on some technical issues associated to the maturity levels. The power-users have 
been chosen together with ISMETT CIO from a list of five employees who participated in the development of the BI solutions and/or attended technical courses on how using it. Overall, 12 streams of topics have been discussed with these three power-users. Examples span from the definition of the maturity levels imagined for the interface of the BI solution (see Table 4-11) to the definition of the capabilities to be assessed in normal users (see Table 4-14).

All maturity levels have been validated with the help of both the power-users as well as the experts from the five healthcare organizations engaged into the CIR project.

\subsection{Phase 3: Advanced Analytics for Risk Adjustment}

In section 2.3 we discussed the potential of ARM in the domain of unwarranted variations and how the length of the extracted rules has important implication for risk adjustment. We also argued that given the computational complexity and overwhelming number of discovered rules mitigates the application of the ARM for risk-adjustments. In the following sections we introduce the novel algorithm (Length-Sort) that we developed to mine the rules with maximum length. We present the methods that we use to estimate the maximum length of the frequent itemsets and prune the dataset items and transactions prior to constructing the FP-tree accordingly. We have also presented a modified FP-tree structure that can be updated with new transactions and items in the event that the estimated maximum length is not equal to the actual length. The datasets used to demonstrate the superior efficiency of the Length-Sort presented. Finally, in section 3.3.2 we present the QOF and other relevant datasets that are used to show the application of the LengthSort in a real-world scenario. As we will see in the following finding maximum length association rules using Length sort allows for better identification of confounding variables. Identification and 
inclusion of the confounding variables are crucial for reliable risk adjustment and consequently valid separation of unwarranted variations from total observed variations.

\subsubsection{Length-Sort Algorithm for Mining LFIs}

The Length-Sort algorithm exploits information embedded in the variations within the transactions' lengths, which exists for the very fact that there are these variations. The process starts by sorting the transactions according to their lengths in descending order. Then, based on these lengths, the dataset is partitioned, so that each partition consists of transactions of the same length. The cumulative support of each variable is calculated from the partitions, going from the longest length to the shortest. The cumulative support of a given item in the partition of length $\mathrm{K}$ is the support of the item in that partition plus the support of the item in the partitions with longer lengths. Example 1 illustrates the partitioning process.

Example 1. As shown in Figure 3-2a, the original dataset contains 11 items and 14 transactions. The last column shows the transaction lengths. The transactions are sorted according to their lengths, and same-length rows are used to construct the partitions, as illustrated in Figure 3-2b. Finally, the cumulative counts of the items are calculated for each partition. Note that the cumulative count (support) of an item in the last partition (partition 7 in Figure 3-2. c) is the total count (support) of the item in the dataset. 


\begin{tabular}{|c|c|c|c|c|c|c|c|c|c|c|c|c|}
\hline $\begin{array}{c}\text { Trans. } \\
\text { ID }\end{array}$ & Item1 & Item2 & Item3 & Item4 & Item5 & Item6 & Item7 & Item8 & Item9 & Item10 & Item11 & $\begin{array}{c}\text { Trans. } \\
\text { Length }\end{array}$ \\
\hline $\mathbf{1}$ & 1 & 1 & 0 & 0 & 1 & 1 & 1 & 0 & 1 & 1 & 0 & $\mathbf{7}$ \\
\hline $\mathbf{2}$ & 1 & 1 & 1 & 1 & 0 & 1 & 1 & 0 & 0 & 0 & 1 & $\mathbf{7}$ \\
\hline $\mathbf{3}$ & 1 & 1 & 1 & 1 & 0 & 0 & 1 & 0 & 0 & 0 & 1 & $\mathbf{6}$ \\
\hline $\mathbf{4}$ & 1 & 1 & 1 & 1 & 0 & 0 & 0 & 0 & 1 & 0 & 0 & $\mathbf{5}$ \\
\hline $\mathbf{5}$ & 0 & 1 & 1 & 1 & 1 & 0 & 1 & 0 & 0 & 0 & 1 & $\mathbf{6}$ \\
\hline $\mathbf{6}$ & 1 & 1 & 1 & 1 & 1 & 0 & 1 & 1 & 0 & 0 & 1 & $\mathbf{8}$ \\
\hline $\mathbf{7}$ & 1 & 1 & 1 & 1 & 1 & 0 & 0 & 1 & 0 & 0 & 0 & $\mathbf{6}$ \\
\hline $\mathbf{8}$ & 1 & 1 & 0 & 1 & 0 & 0 & 0 & 0 & 0 & 0 & 0 & $\mathbf{3}$ \\
\hline $\mathbf{9}$ & 0 & 0 & 1 & 1 & 0 & 0 & 0 & 0 & 0 & 0 & 0 & $\mathbf{2}$ \\
\hline $\mathbf{1 0}$ & 0 & 1 & 0 & 0 & 0 & 1 & 0 & 0 & 0 & 0 & 0 & $\mathbf{2}$ \\
\hline $\mathbf{1 1}$ & 1 & 0 & 0 & 0 & 0 & 0 & 1 & 0 & 0 & 0 & 0 & $\mathbf{2}$ \\
\hline $\mathbf{1 2}$ & 0 & 0 & 1 & 1 & 0 & 0 & 0 & 0 & 0 & 0 & 0 & $\mathbf{2}$ \\
\hline $\mathbf{1 3}$ & 1 & 0 & 0 & 0 & 0 & 0 & 0 & 0 & 0 & 0 & 0 & $\mathbf{1}$ \\
\hline $\mathbf{1 4}$ & 0 & 1 & 0 & 0 & 0 & 0 & 0 & 0 & 0 & 0 & 0 & $\mathbf{1}$ \\
\hline
\end{tabular}

a) Dataset of Example 1

\begin{tabular}{|c|c|c|c|c|c|c|c|c|c|c|c|c|c|}
\hline $\begin{array}{c}\text { Trans. } \\
\text { ID }\end{array}$ & Item1 & Item2 & Item3 & Item4 & Item5 & Item6 & Item7 & Item8 & Item9 & Item10 & Item11 & $\begin{array}{l}\text { Trans. } \\
\text { Length }\end{array}$ & Partition \\
\hline 6 & 1 & 1 & 1 & 1 & 1 & 0 & 1 & 1 & 0 & 0 & 1 & 8 & 1 \\
\hline 1 & 1 & 1 & 0 & 0 & 1 & 1 & 1 & 0 & 1 & 1 & 0 & 7 & \multirow{2}{*}{2} \\
\hline 2 & 1 & 1 & 1 & 1 & 0 & 1 & 1 & 0 & 0 & 0 & 1 & 7 & \\
\hline 3 & 1 & 1 & 1 & 1 & 0 & 0 & 1 & 0 & 0 & 0 & 1 & 6 & \multirow{3}{*}{3} \\
\hline 5 & 0 & 1 & 1 & 1 & 1 & 0 & 1 & 0 & 0 & 0 & 1 & 6 & \\
\hline 7 & 1 & 1 & 1 & 1 & 1 & 0 & 0 & 1 & 0 & 0 & 0 & 6 & \\
\hline 4 & 1 & 1 & 1 & 1 & 0 & 0 & 0 & 0 & 1 & 0 & 0 & 5 & 4 \\
\hline 8 & 1 & 1 & 0 & 1 & 0 & 0 & 0 & 0 & 0 & 0 & 0 & 3 & 5 \\
\hline 9 & 0 & 0 & 1 & 1 & 0 & 0 & 0 & 0 & 0 & 0 & 0 & 2 & \multirow{4}{*}{6} \\
\hline 10 & 0 & 1 & 0 & 0 & 0 & 1 & 0 & 0 & 0 & 0 & 0 & 2 & \\
\hline 11 & 1 & 0 & 0 & 0 & 0 & 0 & 1 & 0 & 0 & 0 & 0 & 2 & \\
\hline 12 & 0 & 0 & 1 & 1 & 0 & 0 & 0 & 0 & 0 & 0 & 0 & 2 & \\
\hline 13 & 1 & 0 & 0 & 0 & 0 & 0 & 0 & 0 & 0 & 0 & 0 & 1 & \multirow{2}{*}{7} \\
\hline 14 & 0 & 1 & 0 & 0 & 0 & 0 & 0 & 0 & 0 & 0 & 0 & 1 & \\
\hline
\end{tabular}

b) Sorting transactions based on length and the partitioning of the dataset 


\begin{tabular}{|c|c|c|c|c|c|c|c|c|c|c|c|c|}
\hline & Item1 & Item2 & Item3 & Item4 & Item5 & Item6 & Item7 & Item8 & Item9 & Item10 & Item11 & $\begin{array}{c}\text { Partition } \\
\text { Length }\end{array}$ \\
\hline $\begin{array}{c}\text { Partition } \\
1\end{array}$ & 1 & 1 & 1 & 1 & 1 & 0 & 1 & 1 & 0 & 0 & 1 & 8 \\
\hline $\begin{array}{c}\text { Partition } \\
2 \\
\end{array}$ & 3 & 3 & 2 & 2 & 2 & 2 & 3 & 1 & 1 & 1 & 2 & 7 \\
\hline $\begin{array}{c}\text { Partition } \\
\mathbf{3} \\
\end{array}$ & 5 & 6 & 5 & 5 & 4 & 2 & 5 & 2 & 1 & 1 & 4 & 6 \\
\hline $\begin{array}{c}\text { Partition } \\
4\end{array}$ & 6 & 7 & 6 & 6 & 4 & 2 & 5 & 2 & 2 & 1 & 4 & 5 \\
\hline $\begin{array}{c}\text { Partition } \\
5 \\
\end{array}$ & 7 & 8 & 6 & 7 & 4 & 2 & 5 & 2 & 2 & 1 & 4 & 3 \\
\hline $\begin{array}{c}\text { Partition } \\
6 \\
\end{array}$ & 8 & 9 & 8 & 9 & 4 & 3 & 6 & 2 & 2 & 1 & 4 & 2 \\
\hline $\begin{array}{c}\text { Partition } \\
7 \\
\end{array}$ & 9 & 10 & 8 & 9 & 4 & 3 & 6 & 2 & 2 & 1 & 4 & 1 \\
\hline
\end{tabular}

c) Cumulative counts for each item in the partitions

Figure 3-2: The process of sorting and partitioning

In order to prune the dataset and discover the LFI more efficiently, we estimated an initial upper bound for the maximum length of the frequent itemsets. The initial upper bound estimation is obtained through the following Lemma:

Lemma 1 (first upper bound): Assume a dataset partitioned as previously explained, with a maximum partition size $\mathrm{P}$. The possible $\mathrm{P}$ partition lengths are denoted by $K_{i} ; i \in\{1 \ldots P\}$. The number of items in partition $K_{i}$ with a cumulative support that is greater than the minimum support is denoted by $F_{i} . K^{*}$ is defined as $\operatorname{Max}\left\{K_{i} \mid K_{i} \leq F_{i}\right\}$ and the maximum length is then less than or equal to $K^{*}$.

Proof: By contradiction, we assume that L (the maximum length) is greater than $K^{*}$ Thus, the support of the set of $\mathrm{L}$ items is greater than or equal to the minimum support. It is trivial that the itemset is also frequent in a set of transactions whose length is equal to or greater than L. Furthermore, according to the Apriori principle, the individual supports of these L items are also 
greater than the minimum support. Thus, we have a partition size $L(1 \leq L \leq \mathrm{P})$ which has $\mathrm{L}$ frequent items. But $L>K^{*}$, thus $K^{*}$ cannot be the $\operatorname{Max}\left\{K_{i} \mid K_{i} \leq F_{i}\right\}$, which contradicts the assumption.

Example 2. Consider the dataset in Example 1 and a minimum support count of 4 . The number of frequent items in each partition is shown in Figure 3-3.

\begin{tabular}{|l|rcc|}
\hline & Length & $\begin{array}{c}\text { No. } \\
\text { Frequent } \\
\text { Items }\end{array}$ \\
\hline Partition 1 & 8 & $\leq$ & 0 \\
\hline Partition 2 & 7 & $\leq$ & 3 \\
\hline Partition 3 & $6 \leq$ & 7 \\
\hline Partition 4 & $5 \leq$ & 7 \\
\hline Partition 5 & $3 \leq$ & 7 \\
\hline Partition 6 & $2 \leq$ & 7 \\
\hline Partition 7 & $1 \leq$ & 7 \\
\hline
\end{tabular}

Figure 3-3: The initial upper bound estimated through Lemma 1 for the dataset in Example 1

The length is 6 for partition 3, and it is the largest length for which the number of frequent items is greater than the length. Thus, in this example, the initial upper bound for the maximum length is 6. It important to note that the inequality of Lemma 1 needs to be checked for every potential partition size, not just for the partitions that were actually found in the dataset. For instance, in Figure 3-3, there is a jump from partition length 5 to 3 . Thus, we need to check whether $K_{4}=4$ is equal to or smaller than $F_{4}=F_{5}=7$. To note, it obviously does not matter in this example, as the upper bound was already found to be 6 and there is no need to check for any potential (or actual) partitions whose lengths are less than 6. 
Thus, using Lemma 1, it is possible to calculate the initial upper bound for the maximum lengths.

Figure 3-4 illustrates the algorithm for estimating the first upper bound.

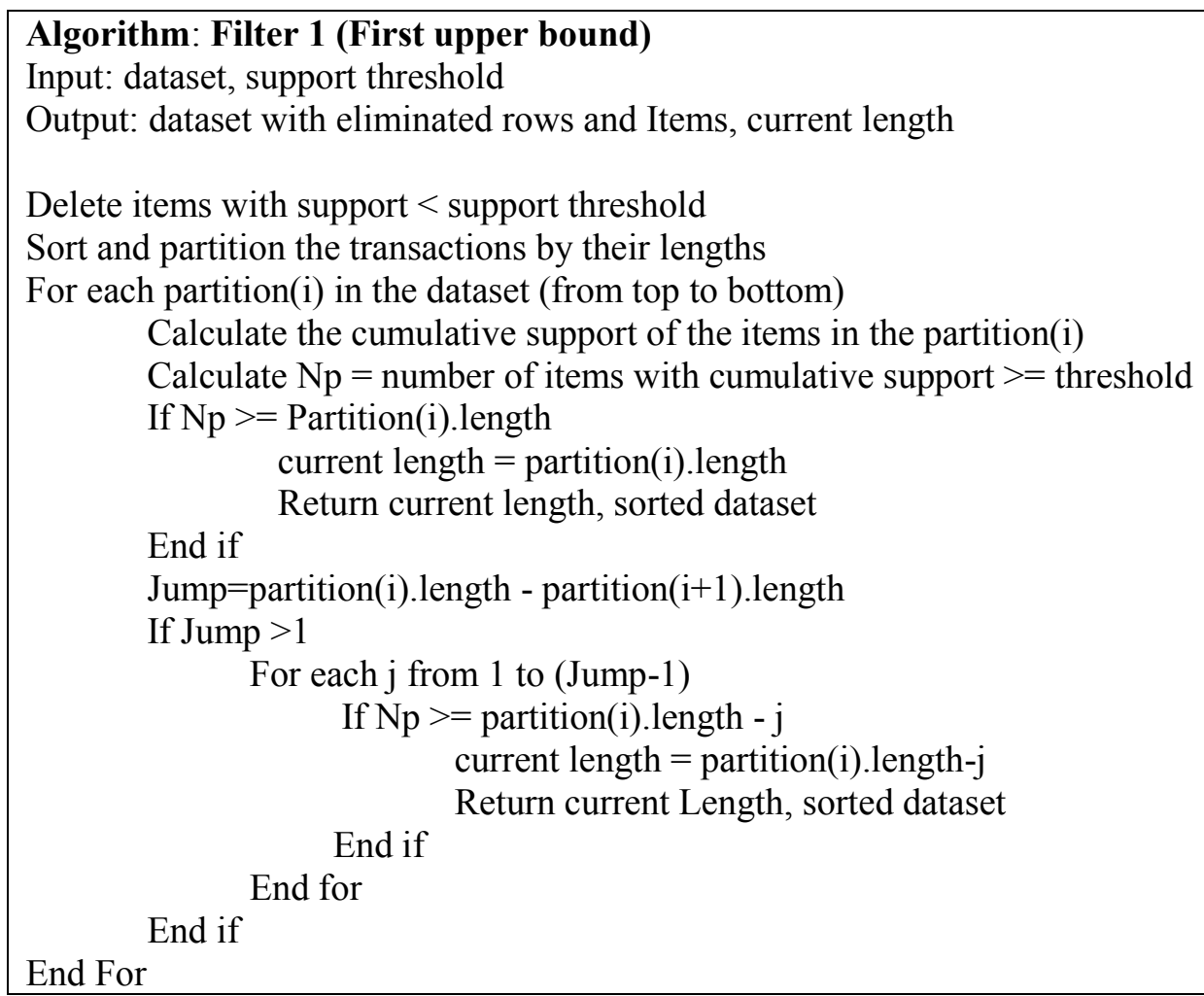

Figure 3-4: Pseudo code of Filter1 (First upper bound) Algorithm

The initial upper bound obtained through Lemma 1 may not be close enough to the actual maximum length for the larger real-world datasets. The initial upper bound can be improved further by using Lemma 2.

Lemma 2 (Second upper bound): If there is a frequent itemset of length $K_{i}$, then $F_{i}$ remains greater than or equal to $K_{i}$ after eliminating all the non-frequent (according to the cumulative support) items in the partition of size $K_{i}$ 
Proof: If there is a frequent itemset of size $K_{i}$, through the Apriori principle, we know that all the items in that frequent itemset are also frequent and since, only the non-frequent items have been eliminated, we have $F_{i} \geq K_{i}$.

So, by eliminating the non-frequent items in the partition corresponding to the size of initial upper bound, we can check whether the initial upper bound holds. This is especially effective since it is performed iteratively. First, all the non-frequent items in the partition that are the same size or greater of the first upper bound are eliminated from the dataset. If some of the transactions fall into smaller partitions and more items become infrequent, then the process is repeated. If the initial upper bound decreases after the iterations $\left(F_{i} \geq K_{i}\right)$, this means there are no frequent itemsets of that size and we can move to the next smaller length $\left(K_{i}-1\right)$ and repeat the process using the updated length. As the length is reduced, some of the previously pruned items and/or transactions will be restored.

Example 3 illustrates the application of Lemma 2.

Example 3. Consider the dataset in Example 1. By using Lemma 2, all the non-frequent items in partitions of length 6 can be eliminated. The process of sorting by length and partitioning is performed once again. The results are illustrated in Figure 3-5. 


\begin{tabular}{|c|c|c|c|c|c|c|c|c|c|c|c|c|}
\hline & Item1 & Item2 & Item3 & Item4 & Item5 & Item6 & Item7 & Item8 & Item9 & Item10 & Item11 & Length \\
\hline $\begin{array}{c}\text { Partition } \\
\mathbf{1}\end{array}$ & $\mathbf{1}$ & $\mathbf{1}$ & $\mathbf{1}$ & $\mathbf{1}$ & $\mathbf{1}$ & $\mathbf{0}$ & $\mathbf{1}$ & $\mathbf{1}$ & $\mathbf{0}$ & $\mathbf{0}$ & $\mathbf{1}$ & $\mathbf{8}$ \\
\hline $\begin{array}{c}\text { Partition } \\
\mathbf{2}\end{array}$ & $\mathbf{3}$ & $\mathbf{3}$ & $\mathbf{2}$ & $\mathbf{2}$ & $\mathbf{2}$ & $\mathbf{2}$ & $\mathbf{3}$ & $\mathbf{1}$ & $\mathbf{1}$ & $\mathbf{1}$ & $\mathbf{2}$ & $\mathbf{7}$ \\
\hline $\begin{array}{c}\text { Partition } \\
\mathbf{3}\end{array}$ & $\mathbf{5}$ & $\mathbf{6}$ & $\mathbf{5}$ & $\mathbf{5}$ & $\mathbf{4}$ & $\mathbf{2}$ & $\mathbf{5}$ & $\mathbf{2}$ & $\mathbf{1}$ & $\mathbf{1}$ & $\mathbf{4}$ & $\mathbf{6}$ \\
\hline $\begin{array}{c}\text { Partition } \\
\mathbf{4}\end{array}$ & $\mathbf{6}$ & $\mathbf{7}$ & $\mathbf{6}$ & $\mathbf{6}$ & $\mathbf{4}$ & $\mathbf{2}$ & $\mathbf{5}$ & $\mathbf{2}$ & $\mathbf{2}$ & $\mathbf{1}$ & $\mathbf{4}$ & $\mathbf{5}$ \\
\hline $\begin{array}{c}\text { Partition } \\
\mathbf{5}\end{array}$ & $\mathbf{7}$ & $\mathbf{8}$ & $\mathbf{6}$ & $\mathbf{7}$ & $\mathbf{4}$ & $\mathbf{2}$ & $\mathbf{5}$ & $\mathbf{2}$ & $\mathbf{2}$ & $\mathbf{1}$ & $\mathbf{4}$ & $\mathbf{3}$ \\
\hline $\begin{array}{c}\text { Partition } \\
\mathbf{6}\end{array}$ & $\mathbf{8}$ & $\mathbf{9}$ & $\mathbf{8}$ & $\mathbf{9}$ & $\mathbf{4}$ & $\mathbf{3}$ & $\mathbf{6}$ & $\mathbf{2}$ & $\mathbf{2}$ & $\mathbf{1}$ & $\mathbf{4}$ & $\mathbf{2}$ \\
\hline $\begin{array}{c}\text { Partition } \\
\mathbf{7}\end{array}$ & $\mathbf{9}$ & $\mathbf{1 0}$ & $\mathbf{8}$ & $\mathbf{9}$ & $\mathbf{4}$ & $\mathbf{3}$ & $\mathbf{6}$ & $\mathbf{2}$ & $\mathbf{2}$ & $\mathbf{1}$ & $\mathbf{4}$ & $\mathbf{1}$ \\
\hline
\end{tabular}

a) Partitions and the cumulative supports of the items. Items 6, 8, 9 and 10 have a cumulative count of less than 4 in partition 3 and can be omitted by means of Lemma 2 .

\begin{tabular}{|l|rcc|}
\hline & Length & $\begin{array}{c}\text { No. Frequent } \\
\text { Items }\end{array}$ \\
\hline Partition 1 & 7 & $\leq$ & 0 \\
\hline Partition 2 & 6 & $\leq$ & 5 \\
\hline Partition 3 & 5 & $\leq$ & 6 \\
\hline Partition 4 & 4 & $\leq$ & 7 \\
\hline Partition 5 & $3 \leq$ & 7 \\
\hline Partition 6 & $2 \leq$ & 7 \\
\hline Partition 7 & $1 \leq$ & 7 \\
\hline
\end{tabular}

b) After discarding the infrequent items, the dataset is sorted and partitioned and the new upperbound is estimated

Figure 3-5: Process of improving the initial upper bound by means of Lemma 2

After removing the infrequent items, the upper bound has decreased to 5. Based on Lemma 2, there is no frequent itemset of size 6 and the new upper bound is 5 .

Figure 3-6 depicts the algorithm for estimating the second upper bound. 


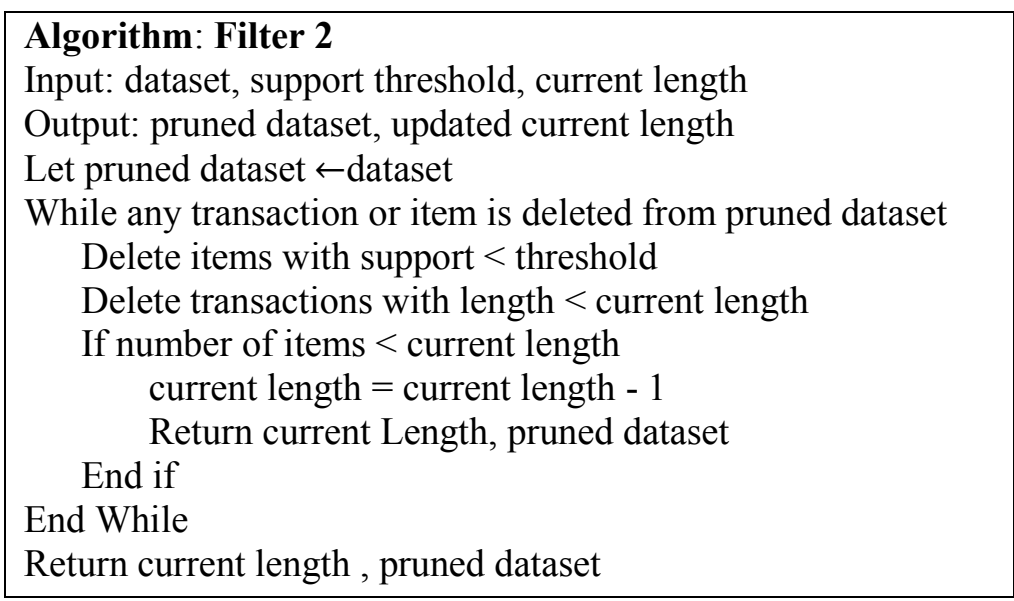

Figure 3-6: Pseudo code of Filter 2 (Second upper bound) Algorithm

As illustrated in the Figure 3-6, we have pruned both the items and the transactions from the dataset. It should be noted that, with the help of the estimated maximum length, it is also possible to prune the dataset vertically. As also highlighted in (Singh and Ram, 2013), the transactions whose length is less than the estimated maximum length are not able to contribute to LFI, so they can be omitted from the dataset.

Use of the first two Lemmas was sufficient to derive an exact estimate of the upper bound in the example but, for the larger datasets with numerous items, a further improvement to the upper bound is needed. Furthermore, the number of candidate items that potentially can form an element in LFI should be further pruned to mine the maximum frequent itemsets efficiently. Lemma 3 further improves the upper bound.

Lemma 3: If there is a frequent itemset of size $K_{i}$ and $v$ is an item in that frequent set, after removing $v$ from the dataset, for at least $\left(K_{i}-1\right)$ items, the sum of the cumulative supports of the partitions with lengths equal or greater than $K_{i}$ is reduced by an amount equal or greater than the minimum support threshold. In other words, the following inequality 


$$
\sum_{l \in\left\{m \mid P_{m} \geq K_{i}\right\}}\left(\operatorname{CSupp}_{j l}^{B}-\operatorname{CSupp}_{j l}^{A}\right) \geq \operatorname{Min} \operatorname{Supp} \quad j \in\{\text { items }\}
$$

holds for at least $K_{i}-1$ items where:

- $\operatorname{CSupp}_{j l}^{B}$ is the cumulative support of item $j$ in partition l before eliminationg item $v$,

- $\quad \operatorname{CSupp}_{j l}^{A}$ is the cumulative support of item $j$ in partition lafter eliminationg item $v$,

- $\left\{m \mid P_{m} \geq K_{i}\right\}$ is the set of indices of partitions with length equal or greater than

$K_{i}$ before eliminating item $v$.

- Min Supp is the minimum support treshold

- Min Count is the minimum count treshold

Proof: Since item $v$ is in a frequent itemset with length equal to $K_{i}$, there are at least Min Count transactions that simultaneously contain $v$ and $\left(K_{i}-1\right)$ other items. By removing item $v$, the length of each of these transactions is reduced by one and, consequently, the transactions are moved to the next partition with a shorter length. It is trivial that these are transactions with lengths equal to or greater than $K_{i}$. Thus, for each of the $\left(K_{i}-1\right)$ items, at least Min Count transactions are transferred to the lower partitions. Hence, after removing $v$, for each item in the frequent itemset, the sum of cumulative supports in the partitions that are greater than or equal to $K_{i}$ plus Min Count is smaller or equal to the sum of the cumulative supports of the same item before the elimination process:

$$
\begin{gathered}
\sum_{l \in\left\{m \mid P_{m} \geq K_{i}\right\}}\left(\text { CCount }_{j l}^{A}\right)+\text { Min Supp } \leq \sum_{l \in\left\{m \mid P_{m} \geq K_{i}\right\}}\left(\text { CCount }_{j l}^{B}\right) \quad \text { for } K_{i}-1 \text { items } \\
\Rightarrow \sum_{l \in\left\{m \mid P_{m} \geq K_{i}\right\}}\left(\text { CCount }_{j l}^{B}-\text { CCount }_{j l}^{A}\right) \geq \operatorname{Min} \text { Count } \quad \text { for } K_{i}-1 \text { items }
\end{gathered}
$$

Dividing the inequality by $N_{T}$, the total number of transactions, we obtain Eq. 3-3. 
By using Lemma 3, we can eliminate more of the items that are not in a frequent itemset of a given length. This is achieved by eliminating the items one by one and calculating the sum of the cumulating support of the other items in partitions with lengths greater or equal to the given length. This process is performed on smaller subset of the dataset. Example 4 shows the application of Lemma 3 to the dataset shown in the example.

Example 4. Following the previous example, the upper bound is 5 and there are six frequent items in the partition with length 5 . So, if there is any frequent set of size 5 , it is also a subset of the set of these six items. Instead of checking all the subsets, we can use Lemma 3 and further prune the candidate items. The six individually frequent items are eliminated one by one from the data and the differences between the cumulative supports of other items are then calculated.

\begin{tabular}{|c|c|c|c|c|c|c|c|c|}
\hline & & \multicolumn{6}{|c|}{ Difference between the sums of cumulative counts } & \multirow{2}{*}{$\begin{array}{l}\text { Number of items whose } \\
\text { count is reduced by more } \\
\text { than the minimum support }\end{array}$} \\
\hline & & Item 1 & Item 2 & Item 3 & Item 4 & Item 7 & Item 11 & \\
\hline \multirow{6}{*}{ 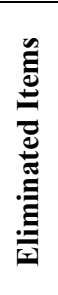 } & Item 1 & & 4 & 4 & 4 & 3 & 3 & 3 \\
\hline & Item 2 & 4 & & 5 & 5 & 4 & 4 & 5 \\
\hline & Item 3 & 4 & 5 & & 5 & 4 & 4 & 5 \\
\hline & Item 4 & 4 & 5 & 5 & & 4 & 4 & 5 \\
\hline & Item 7 & 3 & 4 & 4 & 4 & & 4 & 4 \\
\hline & Item 11 & 3 & 4 & 4 & 4 & 4 & & 4 \\
\hline
\end{tabular}

Figure 3-7: Pruning the candidate items based on Lemma 3

The counts in each row of Figure 3-7 are calculated from Eq. 3-3. The last column shows the number of items for which the sum of cumulative counts has been reduced by more than the minimum count (4). As can be seen in the first row, after eliminating Item 1, the sum of the cumulative counts for three items was reduced by an amount that is greater than the minimum threshold. Thus, according to Lemma 3, Item 1 cannot be in a frequent itemset of size 5 . This 
means that the set $\{$ Item 2 , Item 3 , Item 4, Item 7, Item 11$\}$ is the only remaining candidate set of length 5. By scanning the dataset, this set is confirmed as the only frequent itemset of size 5 and, hence, the only element in the LFI.

Lemma 3 is especially useful in combination with Lemma 2. After items have been eliminated through Lemma 3, we can use the Lemma 2 algorithm to further prune both the items and the transactions. Figure 3-8 shows the algorithm for pruning the items using Lemma 3 . It is straightforward to show that, for a given item $j$, after removing the item $v$, the value of the lefthand side of Eq. 3-3 is in fact the $v$-conditional support in transactions with length greater than or equal to the partition size $l$. Thus, as illustrated in Figure 3-8, instead of calculating the left-hand side of Eq. 3-3 directly, we can calculate the conditional supports in the dataset where all the transactions that were not long enough have already been pruned using the Filter 2 algorithm.

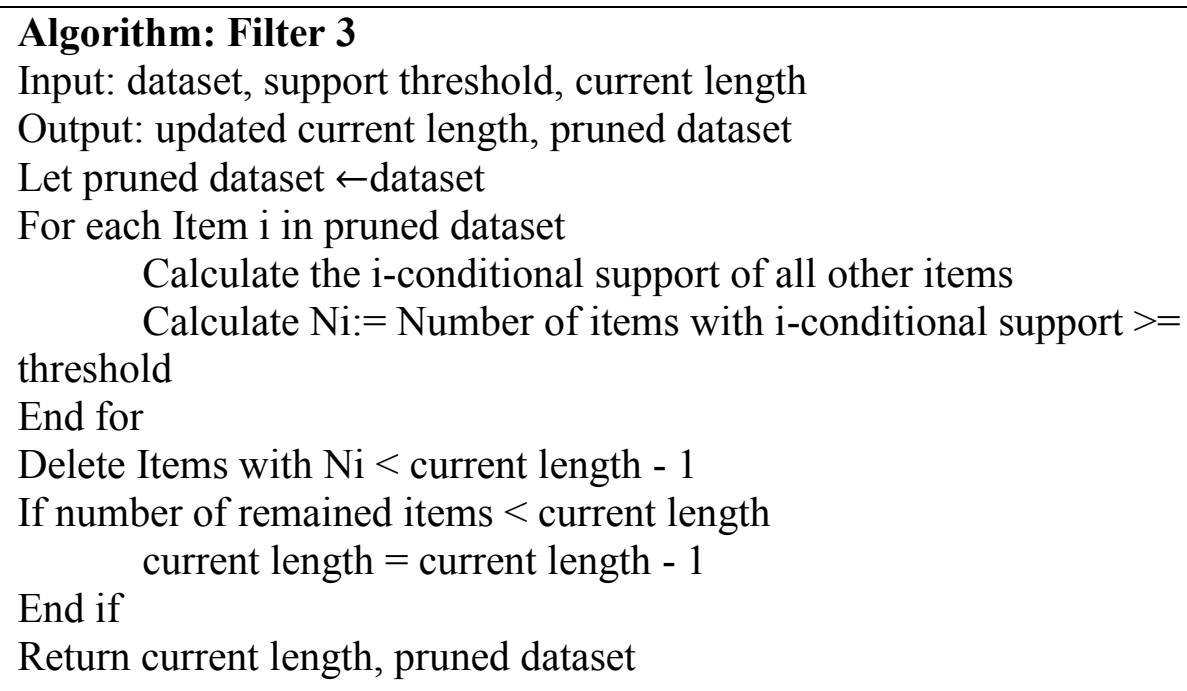

Figure 3-8: Pseudo code for the Filter 3 algorithm 
As seen in the previous example, the estimated upper bound was equal to the maximum length. However, this is not a given for larger real-world datasets. In other words, some items that are not present in LFI, can still survive the pruning techniques of Lemmas 2 and 3. This results in estimating the maximum length that is greater than the actual length. For example, assume an item that is present in 5 transactions corresponding to a maximum length itemset and 6 transactions corresponding to another maximum length itemset. If the minimum count threshold is 11 , the given item is not in any frequent itemset, but it will pass the pruning techniques of Lemmas 2 and 3. In this case, some of the removed items and/or transactions need to be restored and, therefore, we have suggested a modified FP-tree structure that allows this to be achieved more efficiently.

\subsubsection{Constructing and updating the FP-tree}

After obtaining the final estimate of the upper bound (when no further improvements to the estimate or reduction of the dataset are possible), we built the FP-tree and mined the reduced data set using the LFIMiner or MaxLFI algorithms. If the maximum length found is equal to the upper bound, then the upper bound found is accurate and no further mining is required. If the maximum length found is less than the upper bound, then we need to repeat the data pruning process with the updated length (the length of the longest frequent itemset found in the first run). The length found in the first run is, in fact, the lower bound, so, in the worst case scenario, we need to perform two runs of the algorithm to ensure that the results are complete. In order to improve efficiency in the second run, we have proposed a modified FP-tree structure, which can be updated with new transactions and items. So, instead of rebuilding the whole tree, we will simply add the pruned transactions and items that would not be eliminated using the new length. 
After repeating the pruning steps (Lemma 2 and 3 ) with the updated length and comparing the new reduced data set with previous one, the algorithm detects the transactions and items that need to be added to the initial FP-tree. Adding the new transactions is straightforward; we simply add them starting from the root node in the tree. In order to add new items, we considered a FP-tree structure with the transaction node-links. Therefore, in addition to the item node-links in the traditional FPtree, we added a column to the dataset in which to store the transaction node-links. These nodelinks store the node in the tree that corresponds to the last item in the transaction. We can add the new variables belonging to the transaction, starting from the node associated to the transaction's node-link.

In other words, in the event that the actual maximum length is less than the upper bound, the transactions eliminated in the first run whose lengths are greater than or equal to the new maximum length are added to the data. The new items (those that are not in the first tree header table) are then sorted according to their support and added to the end of the header table. The new transactions are inserted in the FP-tree, starting from the null node (Node-Link=1), while, for the transactions with Node-Link $\neq 1$, only new items are inserted in the tree, starting from each transaction's node-link. Figure 3-9 gives an example of updating an FP-tree with new transactions and items. 


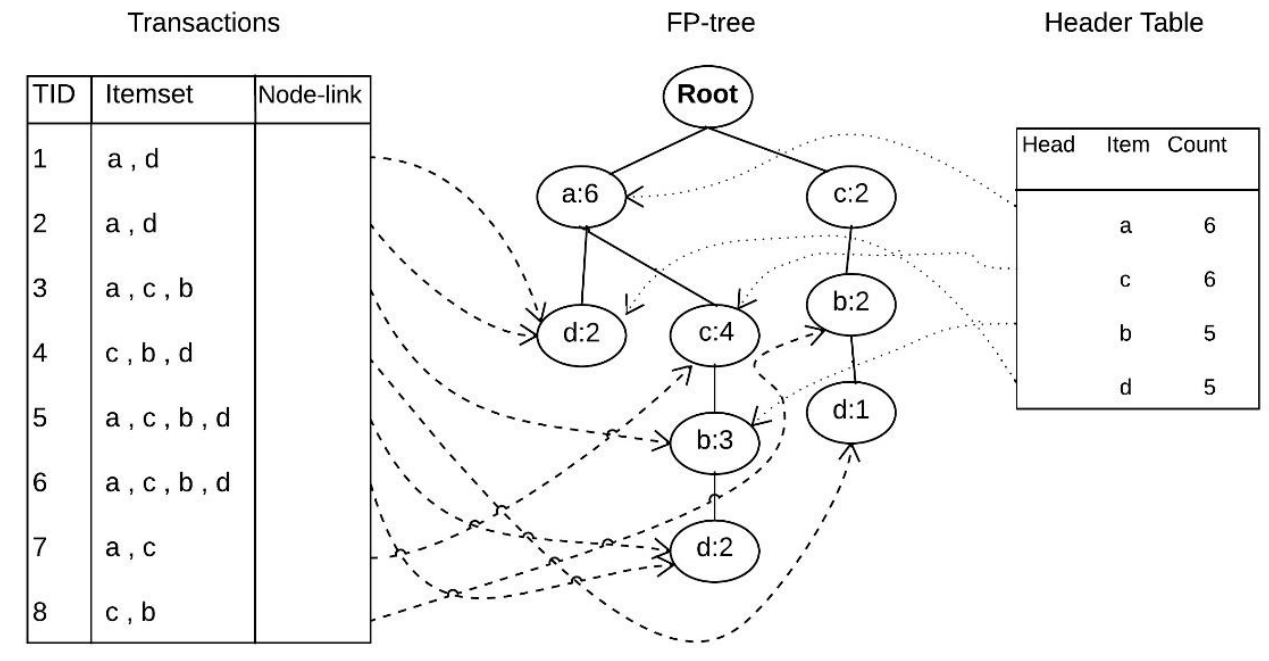

a) An FP-tree with transaction Node-link

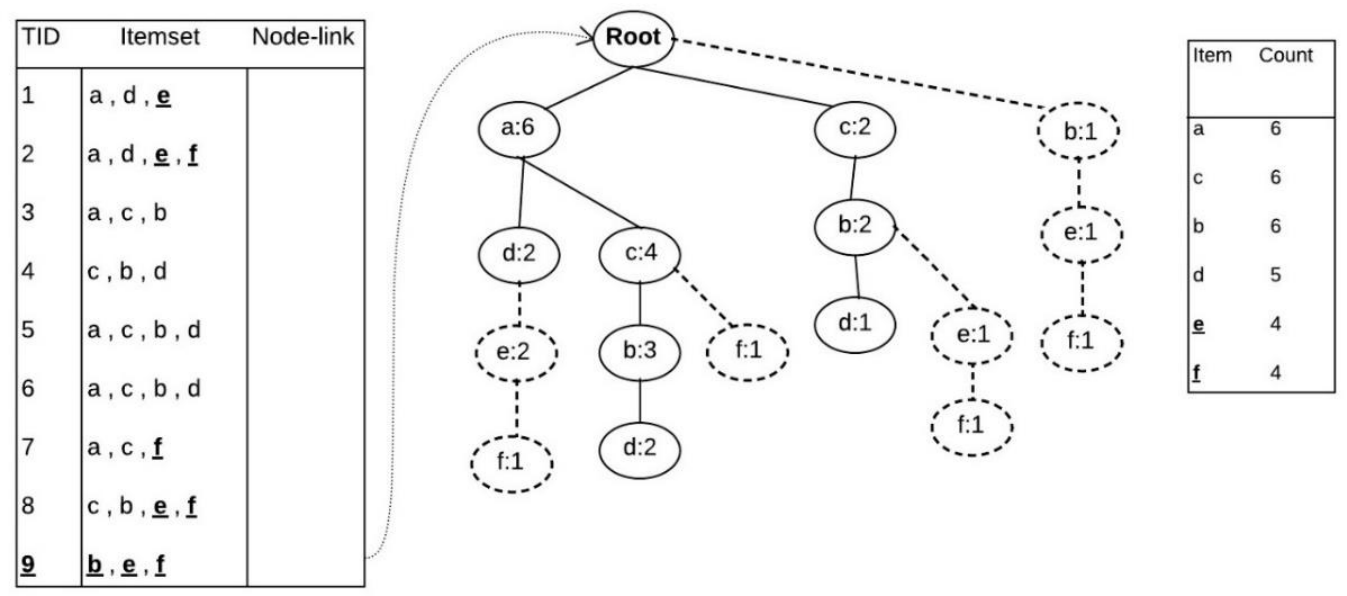

b) The updated FP-tree. Transaction $\underline{\mathbf{9}}$ and Items $\underline{\mathbf{e}}$ and $\underline{\mathbf{f}}$ are added to the dataset. The transaction is added starting from the root node and new items are added according to the transactions' node-links

Figure 3-9:Procedure of updating an FP-tree with transaction nodes

Figure 3-10 illustrates the algorithm of the modified FP-tree. 




Figure 3-10: Pseudo code of the modified FP-tree

Mining the constructed FP-tree can be performed using any selected algorithm. This means that our proposed algorithm can be added to the many tree-based frequent itemset mining procedures. In our experimental evaluation, we considered MaxLFI and LFIMiner. Figure 3-11 shows the Length-Sort+LFIMiner algorithm; this is our proposed pruning algorithm to complement and improve the efficiency of LFIMiner used for mining frequent itemsets with a maximum length. 


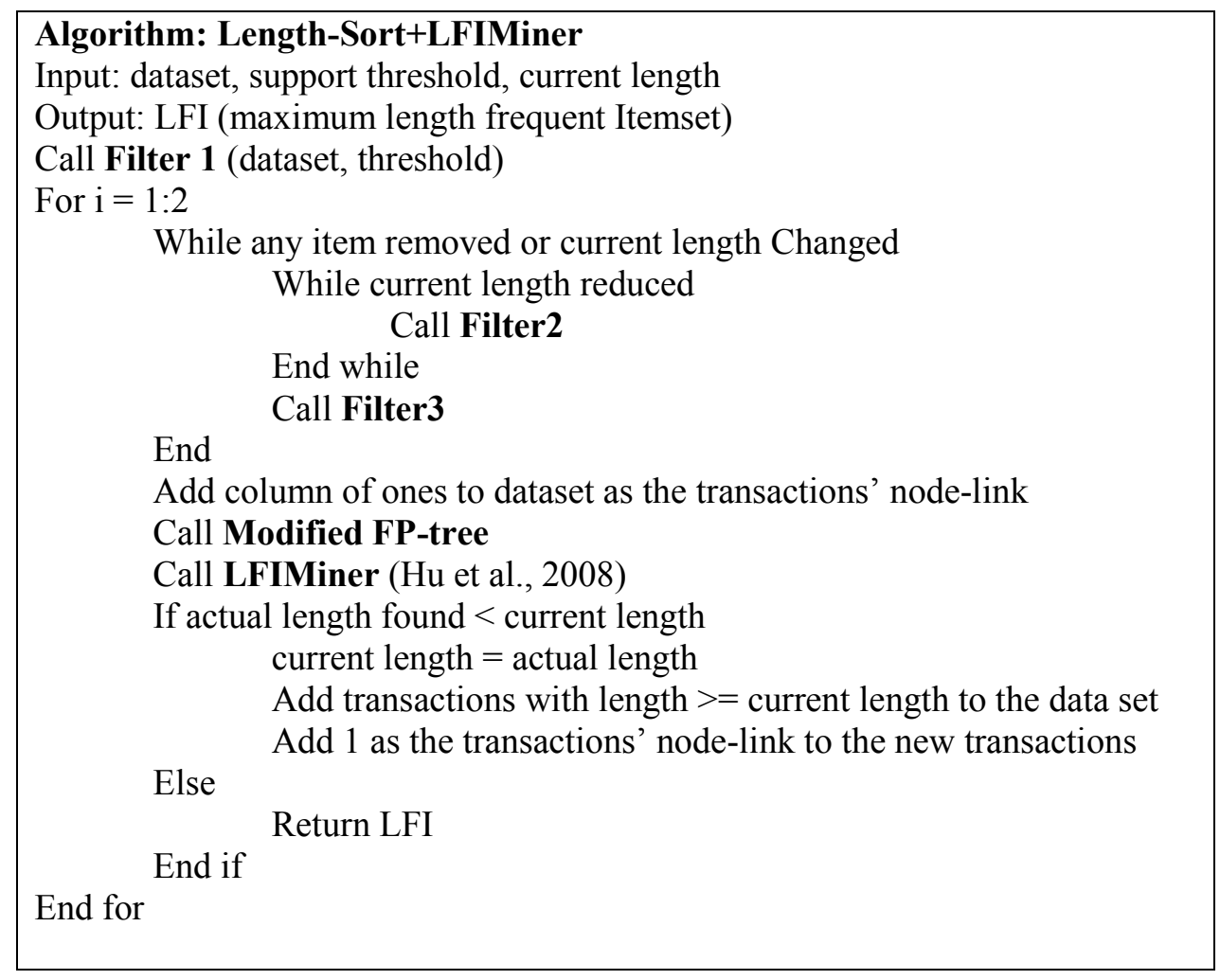

Figure 3-11: Pseudo code of Length-Sort+LFIMiner algorithm

Length-Sort+MaxLFI is similar to the algorithm presented in Figure 3-11, and only LFIMiner is replaced by MaxLFI. Similarly for Length-Sort+INLA-MFP, LFIMiner is replaced with INLAMFP (Vo et al., 2017) and instead of FP tree, we construct PPC-tree (Deng et al., 2012) in algorithm presented in Figure 3-11. The modified tree approach and transactions node-link can be applied to PPC-trees as well. And finally, for mining frequent itemsets longer than a user-specified threshold, the call of Filter 1 is replaced with the user input for the minimum length of the frequent itemsets.

It is worth pointing out that improvement in efficiency is achieved, as Length-Sort pre-prunes the dataset such that LFIMiner or MaxLFI will be used on a much smaller subset of the dataset. 
In addition to FP-tree construction and LFIMiner, Length-Sort+LFIMiner calls three other procedures, namely Filter 1, 2 and 3. The main operations of Filter 1 are: support counting, calculations of transactions' lengths and sorting the vector of the lengths. Assuming that $N$ is the number of transactions and $\omega$ is the average transaction length, these operations require $O(N \omega)$, $O(N \omega)$ and $O(N \log N)$ respectively. Filter 2 performs support counting and calculating the transactions' lengths sp needs $O(N \omega)$ time. Operations of Filter 2 are performed on smaller proportion of datasets, which have smaller number of transactions and items. So $O(N \omega)$ is the worst-case scenario complexity. Algorithm of Filter 2 is repeated each time that items or transactions are removed or the current length estimate is updated. As the length is updated only if variables or transactions are pruned, the number of iterations is bounded by $L+V$, where $L$ is the number of removed transactions and $V$ is the number of pruned items. Thus, the complexity of all calls for Filter 2 is $O((L+V) N \omega)$. It is worth mentioning that in Length-Sort, items and transactions are not necessarily pruned one at the time and we expect that several items and/or transactions are removed in each iteration. This specially happens more often in transactions' removal as they are pruned based on the length and usually there are several transactions with the same length in the datasets.

Filter 3 calculates $M-1 i$-conditional supports (where $M$ is the number of items). The support counting is needed for transactions that contain item $i$, and is limited by the maximum support of the items, denoted as $\Phi$. So, in worst-case scenario, each call of Filter 3 requires $O(M \Phi \omega)$. So Filter 3 is more sensitive to the number of survived items. Filter 3 is repeated much less than Filter 2 and it is called only if no further items or transactions can be pruned by Filter 2 .

It can be noted that as $L+V$ increases, more time is spent by Length-Sort. However, the more pruned transactions and items, the less computational effort is needed for constructing the tree and 
the rest of the mining process. So Length-Sort can improve the computational effort of the itemsets mining, if the time complexity requirement of the mining algorithm for the pruned transactions and items is more than the requirements mentioned above. In the case that Length-Sort does not prune any items or transactions, it will add $\mathrm{O}(N \log N+N \omega+M \Phi \omega)$ time to the mining algorithm.

Modified FP-tree algorithms adds one column to the dataset to store the transactions Node-Link. As the column is added to reduced dataset, this does not increase the space requirement unless, space required by $L \times V$ is less than $N$. In our implementation of filter 3, a matrix of size $M^{2}$ is created to hold the information of the i-conditional supports. Again this can increase the memory requirement only if the space requirement of the matrix is more than the initial tree.

\subsubsection{Experimental environment}

In this section, we have presented the experimental environment and the datasets used to evaluate the performance of Length-Sort compared to the state-of-the-art algorithms. The tests were performed using an Intel core i7, $2.4 \mathrm{GHz}$ laptop with $12 \mathrm{~GB}$ main memory running Linux Ubuntu 16.4. The Length-Sort, LFIMiner, MaxLFI, PPC-tree and INLA-MFP algorithms were implemented in MATLAB 2016b. To construct the FP-tree, we modified the MATLAB implementation of the FP-growth algorithm available at ("FP-Growth Association Rule Mining in MATLAB," n.d.).

To evaluate the performance of the proposed algorithm, we carried out experiments on one synthetic and nine real-world datasets used in many previous studies (e.g., (Agrawal et al., 1993; Deng, 2016; Djenouri and Comuzzi, 2017; Hashem et al., 2017; Salam and Khayal, 2012; Tanbeer 
et al., 2009; Wu et al., 2017)). These are among the most widely used datasets to compare the performance of the frequent itemsets mining algorithms. The included datasets have different distributions in terms of number of transactions and items. The tests are performed on various support thresholds to assure the objectivity of the experiments.

BMS-Web-View 1 and 2 include sequences of the click streams that were collected from a typical e-commerce webpage. The Groceries dataset presented in (Hahsler et al., 2006) contains one month's worth of real point-of-sale transactions. The dataset was gathered from a typical grocery store and contains 9,835 transactions. The purchased items are aggregated into 169 categories. Similarly, the Retail (Brijs et al., 1999) dataset contains anonymized transactions from a Belgian retail store. The Kosarak dataset contains sequences of click-streams from a news website. This dataset is large and consists of almost 1 million transactions. Chain Store is another large data set containing customer transactions in a given retail store (Fournier-Viger et al., 2016). T10I4D100K is a synthetic transaction dataset generated by the IBM Almaden Quest research group Mushrooms, Chess and Susy are the datasets with more density. Susy is also the largest dataset considered and includes five million transactions and 191 items representing the characteristics measured by particle detectors in the accelerator. All the datasets used in the experiments, are publicly accessible from ("Frequent Itemset Mining Dataset Repository," n.d.) and/or (“SPMF:An Open-Source Data Mining Library," n.d.). More details of the data sets are provided in Table 3-5. 


\begin{tabular}{|c|c|c|c|c|}
\hline Data set & $\begin{array}{c}\text { No. } \\
\text { Transactions }\end{array}$ & No. Items & $\begin{array}{l}\text { Average } \\
\text { Length }\end{array}$ & $\begin{array}{l}\text { Standard } \\
\text { Deviation of } \\
\text { Length }\end{array}$ \\
\hline Groceries & 9,835 & 169 & 4.40 & 3.58 \\
\hline$\frac{\text { BMS-Web- }}{\text { View1 }}$ & 59,601 & 497 & 2.42 & 3.22 \\
\hline$\frac{\text { BMS-Web- }}{\underline{\text { View2 }}}$ & 77,512 & 3,340 & 4.62 & 6.07 \\
\hline Retail & 88,162 & 16,470 & 10.30 & 8.16 \\
\hline Kosarak & 990,002 & 41,270 & 8.10 & 23.62 \\
\hline Chain Store & $1,112,949$ & 46,086 & 7.22 & 8.90 \\
\hline T10I4D100K & 100,000 & 1,000 & 10.09 & 3.66 \\
\hline Mushrooms & 8124 & 128 & 23 & 0 \\
\hline Chess & 3196 & 76 & 37 & 0 \\
\hline Susy & 5000000 & 191 & 18.58 & 0.49 \\
\hline
\end{tabular}

Table 3-5: Datasets used to evaluate the performance of the Length-Sort algorithm

The datasets were encoded into sparse matrices for the Length-Sort+LFIMiner and LengthSort+MaxLFI algorithms. The time needed for the encoding was added to the final runtime of these two algorithms. The output of the Length-Sort was again transformed into transactional lists, which are the appropriate input for constructing the FP-tree. Even though this may not be a very efficient approach, we believe that it reveals how far Length-Sort improves the performance, in spite of the time needed for dataset manipulation (i.e. if Length-Sort is coupled with other algorithms that can only accept input data in the form of transaction lists). Improving the efficiency of LFI mining is not the sole purpose of this study, as, in addition, we have tried to demonstrate that Length-Sort can be coupled with many other existing algorithms to mine large datasets, for instance to obtain the maximum length or frequent/closed/maximum itemsets that are longer than a given threshold. 


\subsubsection{Risk Adjustment for Unwarranted Variations Using Length-Sort}

The following paragraph describe the datasets that were used to demonstrate the application of Length-Sort as and risk-adjustment approach in healthcare. We also explain how the raw data were prepared to become the appropriate input for the Length-Sort algorithm.

\subsubsection{Data Source and Data Preperation}

The first dataset used in this study is the QOF 2016-2017 (NHS England, n.d.). It includes several clinical and public health indicators measuring the performance of more than 7,000 GP practices in England. GPs participation in the QOF is not obligatory. However, given the incentives provided by NHS, the participation rate is very high (95.4). The QOF measures the performance in 7 categories. Each category includes several indicators that are further divided in sub-indicators. Table 3-6, depicts the categories and the indicators. Each indicator has a specific disease register that records the number of patients who have the condition in a given practice. 


\begin{tabular}{|c|c|}
\hline$Q O F$ group & Indicator \\
\hline \multirow{8}{*}{ Cardiovascular } & Atrial fibrillation \\
\hline & Blood pressure \\
\hline & Secondary prevention of coronary heart disease \\
\hline & Cardiovascular disease - primary prevention (30-74) \\
\hline & Heart failure \\
\hline & Hypertension \\
\hline & Peripheral arterial disease \\
\hline & Stroke and transient ischaemic attack \\
\hline \multirow[t]{2}{*}{ Respiratory } & Asthma \\
\hline & Chronic obstructive pulmonary disease \\
\hline \multirow[t]{2}{*}{ Lifestyle } & Obesity $(16+)$ \\
\hline & Smoking \\
\hline \multirow{4}{*}{ High dependency and other long-term conditions } & Cancer \\
\hline & Chronic kidney disease $(18+)$ \\
\hline & Diabetes mellitus $(+17)$ \\
\hline & Palliative care \\
\hline \multirow{5}{*}{ Mental health and neurology } & Dementia \\
\hline & Depression $(18+)$ \\
\hline & Epilepsy $(18+)$ \\
\hline & Learning disabilities \\
\hline & Mental health \\
\hline \multirow{2}{*}{ Musculoskeletal } & Osteoporosis $(50+)$ \\
\hline & Rheumatoid $(16+)$ \\
\hline \multirow[t]{2}{*}{ Fertility, bstetrics and gynaecology } & Cervical screening (25-64) \\
\hline & Contraception $(<55)$ \\
\hline
\end{tabular}

Table 3-6: Quality Outcome Framework indicators categories

For each sub-indicator, QOF contains exceptions and achievements. Exceptions are the patients in the register that are not included in the calculation of the achievement scores. GPs can decide to exclude patients for reasons such as patient's refusal of receiving a treatment or canceling the appointments. Achievement of each indicator is calculated as the percentage of patients (excluding the exceptions) who have received the care, as specified by the indicator.

The second source of data is the dataset of NHS payments to practices (NHS England, n.d.). We included the number of weighted patients, total payments, total payment due QOF achievements and enhanced services' payments for activities such as childhood vaccination, rotavirus and shingles immunisation. As practices size affects the total payment, we divided each subcategory 
of NHS payments by the number of weighed patients. The number of weighted patients is calculated (by the data owner) using Carr-Hill formula (British Medical Association (BMA), 2015; Carr-Hill et al., 1994), which takes into account age and gender, morbidity and mortality, number of newly registered patients, rurality, cost of leaving and patients in nursing or residual homes. The number of weighted patients is used to adjust the total payments for patient demographic and practice workloads.

We acquired the third source of the data from the practices workforce dataset (NHS England, n.d.), which contains variables such as the GPs' gender, age category, contract type, rurality, whether or not the practice dispense drugs, total patients and percentages of male, female, young and elderly patients, locum and salaried GPs and percentage of GPs who obtained their degree in UK. As the list size of practices' patient varies, we also included the ratios of patients-to-GPs and patients-tonurses as proxies of the available human resources.

We also acquired the 2015 deprivation indexes for Lower Layer Super Output Areas (LSOA) (Ministry of Housing Communities \& Local Government, n.d.). LSOAs are areas (around 32,000 areas) in England that are used to report small area statistics. The deprivation dataset includes the deciles of several deprivation indexes for each LSOA (e.g. health, elders, education etc.). Each practice usually delivers services to several LSOAs, thus, we joined the deprivation data with practices Patients Registered dataset (NHS England, n.d.). The dataset contains number of patients from each LSOA registered at a given practice. Then, based on the number of the patients in each LSOA, we calculated the weighted average of the deprivation indices for each practice. Around 44,130 patients $(0.08 \%$ of total patients) had missing LSOA codes. For these patients the deprivation indices were replaced with the median. 
To assess also the regional variations (similar to the assessment performed on Spain MBDS dataset in the first phase of the thesis), three sets of geographic areas are included in the analyses. Health Education England (HEE) regions (13 areas with average of 573 practices per area), four large geographical areas with average of 1,860 practices per area and, finally, NHS England local office areas (14 areas with average of 532 practices per area).

All datasets were joined using the practice codes (the unique identification code of the GP practices assigned by England NHS). Only practices that were available in all 4 datasets (7,066 practices) were included in the final analyses. Total number of included variables is 99 (202 binary variables after discretization).

As ARM is designed for binary or categorical variables, we discretized the continuous variables based on their percentiles. For majority of variables we defined three categories, lowest 20 percentiles, between 20 to 80 percentiles and top 20 percentiles. We only included variables corresponding to the top and bottom 20 percentiles. This will result in discovering patterns pertaining to high and low performing practices, which are potentially more useful for decision makers. We set the minimum thresholds of 0.02 for support, 0.7 for confidence and 2 for lift and conviction. We also set the algorithm to find rules that contain at least 4 variables.

Table 3-7 summarizes the variables, their explanations and the corresponding discretization thresholds. 


\begin{tabular}{|c|c|c|c|}
\hline Category & Variable name & Description & Levels \\
\hline \multirow{3}{*}{ 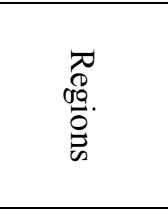 } & Q70 to Q84 & Region codes of NHS England local offices & Binary \\
\hline & Y54 to Y57 & $\begin{array}{l}\text { Geographical region codes for North, } \\
\text { Midland/east, London and South of England }\end{array}$ & Binary \\
\hline & $\begin{array}{l}\text { YDF21 to } \\
\text { YDF33 }\end{array}$ & Health Education England (HEE) regions & Binary \\
\hline \multirow{13}{*}{ 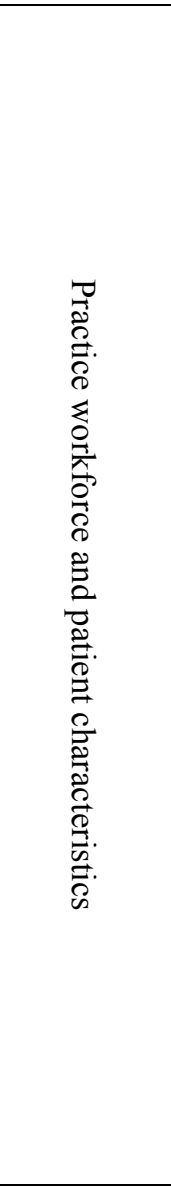 } & $\%$ Male14 & $\begin{array}{c}\text { Percentage of male patients with age of } 14 \text { or } \\
\text { less }\end{array}$ & $\begin{array}{c}\text { Lowest and highest } 20 \\
\text { percentiles }\end{array}$ \\
\hline & $\%$ Female14 & $\begin{array}{c}\text { Percentage of female patients with age of } 14 \text { or } \\
\text { less }\end{array}$ & $\begin{array}{c}\text { Lowest and highest } 20 \\
\text { percentiles }\end{array}$ \\
\hline & $\%$ Tot14 & Percentage of patients with age of 14 or less & $\begin{array}{c}\text { Lowest and highest } 20 \\
\text { percentiles }\end{array}$ \\
\hline & $\%$ Male65 & $\begin{array}{l}\begin{array}{l}\text { Percentage of male patients with age of } 65 \text { or } \\
\text { more }\end{array} \\
\text {. }\end{array}$ & $\begin{array}{c}\text { Lowest and highest } 20 \\
\text { percentiles }\end{array}$ \\
\hline & $\%$ Female65 & $\begin{array}{l}\text { Percentage of female patients with age of } 65 \text { or } \\
\text { more }\end{array}$ & $\begin{array}{c}\text { Lowest and highest } 20 \\
\text { percentiles }\end{array}$ \\
\hline & $\%$ Tot65 & Percentage of patients with age of 65 or more & $\begin{array}{c}\text { Lowest and highest } 20 \\
\text { percentiles }\end{array}$ \\
\hline & Depriv & $\begin{array}{l}\text { Health deprivation and disability score } \\
\text { corresponding to the practices' registered } \\
\text { patients }\end{array}$ & $\begin{array}{c}\text { Lowest (more deprived) and } \\
\text { highest (less deprived) } 30 \\
\text { percentiles }\end{array}$ \\
\hline & GP_Young & $\begin{array}{c}\text { Percentage of the GPs in a center that are } 34 \\
\text { years old or younger }\end{array}$ & $\begin{array}{c}\text { Low if the ration is less than } \\
50 \% \text {; high if it is greater than } \\
50 \%\end{array}$ \\
\hline & GP_Elder & $\begin{array}{c}\text { Percentage of the GPs in a center that are } 60 \\
\text { years old or older }\end{array}$ & $\begin{array}{c}\text { Low if the ration is less than } \\
50 \% \text {; high if it is greater than } \\
50 \%\end{array}$ \\
\hline & GP_degree_UK & $\begin{array}{l}\text { The percentage of the GPs in a center that } \\
\text { achieved their degree in the UK }\end{array}$ & $\begin{array}{c}\text { Low if the ration is less than } \\
50 \% \text {; High if it is greater than } \\
50 \%\end{array}$ \\
\hline & Contract & $\begin{array}{l}\text { Type of the contract held between the practice } \\
\text { and NHS }\end{array}$ & GMS, PMS, APMS \\
\hline & Rurality & $\begin{array}{c}\text { Whether the practice is located in urban or } \\
\text { rural area }\end{array}$ & Urban; Rural \\
\hline & Dispensing & Whether or not the practice dispense drugs & Binary \\
\hline \multirow{4}{*}{ 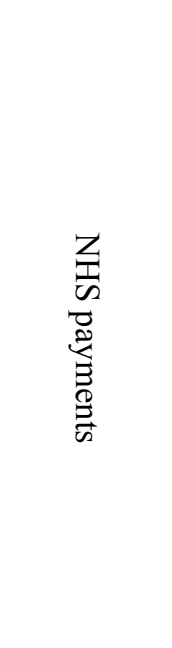 } & QOF_Payments & $\begin{array}{l}\text { Total amount paid to practice due to } \\
\text { achievements in QOF, divide by the number of } \\
\text { weighted patients }\end{array}$ & $\begin{array}{l}\text { Lowest and highest } 20 \\
\text { percentiles }\end{array}$ \\
\hline & NHS_Payments & $\begin{array}{l}\text { The total NHS payment to practice divided by } \\
\text { the number of weighted patients }\end{array}$ & $\begin{array}{l}\text { Lowest and highest } 20 \\
\text { percentiles }\end{array}$ \\
\hline & NES_Payment & $\begin{array}{l}\text { Payments to practice regarding the national } \\
\text { enhanced services, divided by the number of } \\
\text { weighted patients }\end{array}$ & $\begin{array}{l}\text { Lowest and highest } 20 \\
\text { percentiles }\end{array}$ \\
\hline & Rot_Payment & $\begin{array}{l}\text { Payments regarding the enhanced service of } \\
\text { Rotavirus and Shingles Immunization, divided } \\
\text { by the number of weighted patients }\end{array}$ & $\begin{array}{l}\text { Lowest and highest } 20 \\
\text { percentiles }\end{array}$ \\
\hline
\end{tabular}




\begin{tabular}{|c|c|c|c|}
\hline Category & Variable name & Description & Levels \\
\hline & Vaccin_Payment & $\begin{array}{l}\text { Payments regarding the enhanced service of } \\
\text { Childhood Vaccination and Immunization } \\
\text { Scheme, divided by the number of weighted } \\
\text { patients }\end{array}$ & $\begin{array}{l}\text { Lowest and highest } 20 \\
\text { percentiles }\end{array}$ \\
\hline & Mening_Payment & $\begin{array}{l}\text { Payments regarding the enhanced service of } \\
\text { Meningitis, divided by the number of weighted } \\
\text { patients }\end{array}$ & $\begin{array}{l}\text { Lowest and highest } 20 \\
\text { percentiles }\end{array}$ \\
\hline \multirow{14}{*}{ 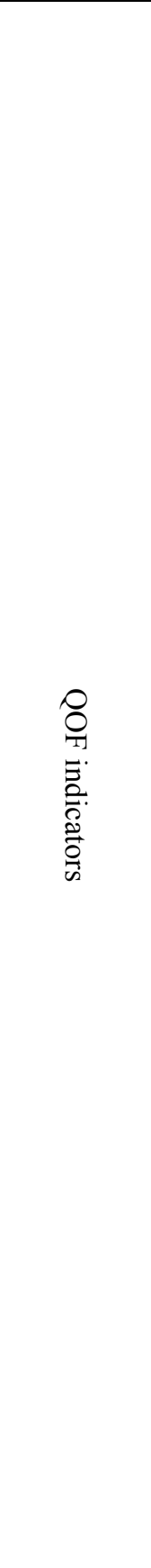 } & STIA003 & $\begin{array}{l}\text { Ratio of patients with TIA or stroke that have } \\
\text { measured blood pressure of } 150 / 90 \mathrm{mmHg} \text { or } \\
\text { less in the past } 12 \text { months }\end{array}$ & $\begin{array}{c}\text { Lowest and highest } 20 \\
\text { percentiles }\end{array}$ \\
\hline & STIA007 & $\begin{array}{l}\text { Ratio of patients with TIA or non-hemorrhagic } \\
\text { stroke that take an antiplatelet agent or an anti- } \\
\text { coagulant in the last } 12 \text { months }\end{array}$ & $\begin{array}{l}\text { Lowest and highest } 20 \\
\text { percentiles }\end{array}$ \\
\hline & STIA009 & $\begin{array}{l}\text { Ratio of patients with Transient Ischemic } \\
\text { Attack (TIA) or stroke who received influenza } \\
\text { immunization during August 1st and March } \\
31^{\text {st }}\end{array}$ & $\begin{array}{l}\text { Lowest and highest } 20 \\
\text { percentiles }\end{array}$ \\
\hline & COPD003 & $\begin{array}{l}\text { Ratio of patients with Chronic obstructive } \\
\text { pulmonary disease (COPD) who had review in } \\
\text { the last } 12 \text { months, including breathlessness } \\
\text { assessment }\end{array}$ & $\begin{array}{l}\text { Lowest and highest } 20 \\
\text { percentiles }\end{array}$ \\
\hline & COPD007 & $\begin{array}{c}\text { Ratio of patients with COPD who received } \\
\text { influenza immunization during August } 1 \text { st and } \\
\text { March } 31^{\text {st }}\end{array}$ & $\begin{array}{l}\text { Lowest and highest } 20 \\
\text { percentiles }\end{array}$ \\
\hline & CHD005 & $\begin{array}{l}\text { Ratio of patients with coronary heart disease } \\
\text { who take aspirin or alternative anti-platelet or } \\
\text { an anti-coagulant in the last } 12 \text { months }\end{array}$ & $\begin{array}{l}\text { Lowest and highest } 20 \\
\text { percentiles }\end{array}$ \\
\hline & CHD007 & $\begin{array}{c}\text { Ratio of patients with Coronary Heart Disease } \\
\text { who received influenza immunization during } \\
\text { August } 1 \text { st and March } 31^{\text {st }}\end{array}$ & $\begin{array}{l}\text { Lowest and highest } 20 \\
\text { percentiles }\end{array}$ \\
\hline & DM002 & $\begin{array}{l}\text { Ratio of patients with diabetes that have } \\
\text { measured blood pressure of } 150 / 90 \mathrm{mmHg} \text { or } \\
\text { less in the past } 12 \text { months }\end{array}$ & $\begin{array}{l}\text { Lowest and highest } 20 \\
\text { percentiles }\end{array}$ \\
\hline & DM008 & $\begin{array}{l}\text { Ratio of patients with diabetes mellitus whose } \\
\text { last value of IFCC-HbAlc is equal or less than } \\
64 \mathrm{mmol} / \mathrm{mol} \text { in the last } 12 \text { months }\end{array}$ & $\begin{array}{c}\text { Lowest and highest } 20 \\
\text { percentiles }\end{array}$ \\
\hline & DM009 & $\begin{array}{l}\text { Ratio of patients with diabetes mellitus whose } \\
\text { last value of IFCC-HbAlc is equal or less than } \\
75 \mathrm{mmol} / \mathrm{mol} \text { in the last } 12 \text { months }\end{array}$ & $\begin{array}{c}\text { Lowest and highest } 20 \\
\text { percentiles }\end{array}$ \\
\hline & DM012 & $\begin{array}{l}\text { Ratio of patients with diabetes that had a foot } \\
\text { examination and risk classification in the last } \\
12 \text { month }\end{array}$ & $\begin{array}{l}\text { Lowest and highest } 20 \\
\text { percentiles }\end{array}$ \\
\hline & DM018 & $\begin{array}{c}\text { Ratio of patients with diabetes mellitus who } \\
\text { received influenza immunization during } \\
\text { August 1st and March } 31^{\text {st }}\end{array}$ & $\begin{array}{l}\text { Lowest and highest } 20 \\
\text { percentiles }\end{array}$ \\
\hline & DEP003 & $\begin{array}{l}\text { Ratio of patients } 18 \text { or over with recent } \\
\text { depression diagnoses who have been reviewed } \\
\text { between } 10 \text { and } 56 \text { days after the diagnosis }\end{array}$ & $\begin{array}{l}\text { Lowest and highest } 20 \\
\text { percentiles }\end{array}$ \\
\hline & DEM004 & $\begin{array}{l}\text { Ratio of patients with dementia who had a } \\
\text { face-to-face review in the last } 12 \text { months }\end{array}$ & $\begin{array}{c}\text { Lowest and highest } 20 \\
\text { percentiles }\end{array}$ \\
\hline
\end{tabular}




\begin{tabular}{|c|c|c|c|}
\hline Category & Variable name & Description & Levels \\
\hline MH007 & $\begin{array}{c}\text { Ratio of patients with bipolar affective } \\
\text { disorder, schizophrenia or other psychoses } \\
\text { whose alcohol consumption is recorded } \\
\text { RA002 }\end{array}$ & $\begin{array}{c}\text { Ratio of patients with rheumatoid arthritis who } \\
\text { had a face-to-face review in the last 12 months }\end{array}$ & $\begin{array}{c}\text { Lowest and highest 20 } \\
\text { percentiles }\end{array}$ \\
\cline { 2 - 4 } & PAD004 & $\begin{array}{c}\text { Ratio of patients with peripheral arterial } \\
\text { disease that take aspirin or alternative anti- } \\
\text { platelet in the last 12 months }\end{array}$ & $\begin{array}{c}\text { Lowest and highest 20 } \\
\text { percentiles }\end{array}$ \\
\cline { 2 - 4 } & HYP006 & $\begin{array}{c}\text { Ratio of patients with hypertension that have } \\
\text { measured blood pressure of 150/90 mmHg or } \\
\text { less in the past 12 months }\end{array}$ & $\begin{array}{c}\text { Lowest and highest 20 } \\
\text { percentiles }\end{array}$ \\
\hline
\end{tabular}

Table 3-7: Variables' codes and summary description 


\section{RESULTS \& DISCUSSION}

In this chapter the results of the thesis are presented and discussed. Similar to previous chapters the results are presented in three macro paragraphs, each dedicated to each phase of the thesis and to each research question presented in the first chapter. Section 4.1 highlights the findings regarding the performance patterns in regional level. Section 4.2 introduce the maturity model that was developed following the process described in section 3.2. Finally, section 4.3 presents the experimental results of the Length-Sort performance comparison, as well as the discovered rules from QOF dataset.

\subsection{Phase 1: Unwarranted Variations in Regional Level}

This section is divided in two paragraphs; the first one is dedicated to describe the variations in the indicators of secondary care and the second to highlight the performance variation in the primary care.

\subsubsection{Performance Patterns in Secondary Care: Results}

As mentioned in Chapter 3, logistic regression was used for the mortality rate, readmission rate and hospital-acquired infection rate. Linear regression was used for the average length of hospital stay, to overcome the effect of the confounding variables as far as possible (50 dummy variables were introduced for the provinces, 10 dummy variables for age, gender, severity of illness and type of admission, and a continuous variable was included for the case-mix average weight). 
Tables 4-1 to 4-4 depict the calculated standardised rates for each indicator and MDC. As mentioned we used the regression rates for factor and cluster analyses, however the Indirect Standardised Rates (ISRs) are also calculated for comparison. In logistic regressions (Mortality infection and readmission rates) the odds ratios are an approximate of the indirect standardized rates. In linear regression the standardized rates for each province is calculated with the weighted average from each parameter and variable (Israëls, 2013). As mentioned the case-mix weights were not available for readmission rates. So as can be seen in the tables Regression and ISRs are very similar. In a similar vein, the two rates are very close when the coefficient corresponding to case-mix weight is small (e.g. Length of Stay MDC11). In each regression, the provinces that have closest mean to overall mean (based on the contrasts) are selected as the reference category. For infection rates, few provinces were excluded as they have zero infection cases due to small number of admissions. The rates for this provinces are replaced with value one (the average value). The number of admissions in each sub category of confounding variables are included as the frequency weights, thus the sample size reported in the tables are the sum of the frequency weights. 
Province 1

Province 2

Province 3

Province 4

Province 5

Province 6

Province 7

Province 8

Province 9

Province 10

Province 11

Province 12

Province 13

Province 14

Province 15

Province 16

Province 17

Province 18

Province 19

Province 20

Province 21

Province 22

Province 23

Province 24

Province 25

Province 26

Province 27

Province 28

Province 29

Province 30

Province 31

Province 32

Province 33

Province 34

Province 35

Province 36

Province 37

Province 38

Province 39

Province 40

Province 41

Province 42

Province 43

\begin{tabular}{|c|c|c|c|c|c|c|c|c|c|c|c|c|c|c|c|c|c|c|c|c|c|c|c|}
\hline \multicolumn{4}{|c|}{ Length of Stay MDC1 } & \multicolumn{4}{|c|}{ Length of Stay MDC4 } & \multicolumn{4}{|c|}{ Length of Stay MDC5 } & \multicolumn{4}{|c|}{ Length of Stay MDC6 } & \multicolumn{4}{|c|}{ Length of Stay MDC8 } & \multicolumn{4}{|c|}{ Length of Stay MDC11 } \\
\hline B & $\mathbf{P}$ & RGS rate & ISR & B & P I & RGS rate & ISR & B & P 1 & RGS rate & ISR & B & $\mathbf{P} \mathbf{I}$ & RGS rate & ISR & B & P I & RGS rate & ISR & B & P I & RGS rate & ISR \\
\hline-0.99 & 0.00 & 0.91 & 0.81 & -1.25 & 0.00 & 0.90 & 0.92 & -0.21 & 0.00 & 0.96 & 0.97 & 0 (Ref) & & 1.02 & 1.01 & -0.39 & 0.00 & 0.97 & 0.98 & -0.51 & 0.00 & 0.94 & 0.93 \\
\hline-2.06 & 0.00 & 0.79 & 0.86 & -0.60 & 0.00 & 0.98 & 0.98 & 0.82 & 0.00 & 1.11 & 1.10 & -0.67 & 0.00 & 0.93 & 0.93 & -2.95 & 0.00 & 0.65 & 0.68 & -0.72 & 0.00 & 0.91 & 0.92 \\
\hline-1.39 & 0.00 & 0.87 & 0.81 & -1.82 & 0.00 & 0.84 & 0.84 & -1.15 & 0.00 & 0.83 & 0.82 & -0.67 & 0.00 & 0.93 & 0.94 & -1.56 & 0.00 & 0.82 & 0.82 & -1.06 & 0.00 & 0.86 & 0.85 \\
\hline 0.52 & 0.00 & 1.08 & 1.10 & 1.52 & 0.00 & 1.23 & 1.22 & 0.02 & 0.12 & 0.99 & 0.98 & 0.43 & 0.00 & 1.08 & 1.09 & 0.70 & 0.00 & 1.11 & 1.10 & 0.84 & 0.00 & 1.13 & 1.13 \\
\hline 2.40 & 0.00 & 1.28 & 1.25 & 2.00 & 0.00 & 1.29 & 1.29 & 0.47 & $\mathbf{0 . 0 0}$ & 1.06 & 1.06 & 0.38 & 0.00 & 1.07 & 1.07 & 0.80 & 0.00 & 1.12 & 1.12 & 1.97 & 0.00 & 1.29 & 1.29 \\
\hline-0.37 & 0.00 & 0.98 & 0.92 & -0.04 & 0.00 & 1.05 & 1.05 & 0.08 & 0.00 & 1.00 & 1.01 & 0.41 & 0.00 & 1.08 & 1.06 & -0.59 & 0.00 & 0.95 & 0.94 & 0.41 & 0.00 & 1.07 & 1.08 \\
\hline-0.31 & 0.00 & 0.98 & 0.99 & -0.34 & 0.00 & 1.01 & 1.01 & -0.19 & 0.00 & 0.96 & 0.96 & -1.12 & 0.00 & 0.88 & 0.88 & -1.14 & 0.00 & 0.88 & 0.88 & 0.14 & 0.00 & 1.03 & 1.03 \\
\hline-1.93 & 0.00 & 0.81 & 0.82 & -2.10 & 0.00 & 0.80 & 0.81 & -1.14 & 0.00 & 0.83 & 0.83 & -1.53 & 0.00 & 0.82 & 0.81 & -1.28 & 0.00 & 0.86 & 0.86 & -1.32 & 0.00 & 0.82 & 0.82 \\
\hline-2.39 & 0.00 & 0.76 & 0.78 & -0.08 & 0.00 & 1.04 & 1.04 & -0.03 & 0.04 & 0.99 & 1.00 & -0.91 & 0.00 & 0.90 & 0.89 & -1.44 & 0.00 & 0.84 & 0.83 & -0.71 & 0.00 & 0.91 & 0.91 \\
\hline-1.79 & 0.00 & 0.82 & 0.82 & $\mathbf{- 0 . 0 7}$ & 0.00 & 1.04 & 1.05 & O(Ref) & & 0.99 & 0.99 & -0.43 & 0.00 & 0.97 & 0.97 & -0.92 & 0.00 & 0.90 & 0.89 & 0.80 & 0.00 & 1.12 & 1.13 \\
\hline-0.51 & 0.00 & 0.96 & 1.01 & 1.36 & 0.00 & 1.21 & 1.21 & 1.01 & 0.00 & 1.13 & 1.14 & 1.02 & 0.00 & 1.16 & 1.19 & 0.92 & 0.00 & 1.13 & 1.13 & 0.77 & 0.00 & 1.12 & 1.12 \\
\hline 0.39 & 0.00 & 1.06 & 1.09 & 0.27 & 0.00 & 1.08 & 1.09 & 0.40 & 0.00 & 1.05 & 1.05 & 0.69 & 0.00 & 1.11 & 1.13 & -0.93 & 0.00 & 0.90 & 0.90 & 0.73 & 0.00 & 1.11 & 1.12 \\
\hline-1.30 & 0.00 & 0.88 & 0.90 & 0.11 & 0.00 & 1.06 & 1.06 & 0.21 & 0.00 & 1.02 & 1.02 & -0.21 & 0.00 & 1.00 & 1.01 & -0.91 & 0.00 & 0.91 & 0.92 & 0.41 & 0.00 & 1.07 & 1.08 \\
\hline 0.49 & 0.00 & 1.07 & 1.08 & -0.26 & 0.00 & 1.02 & 1.02 & -0.38 & 0.00 & 0.94 & 0.94 & -0.29 & 0.00 & 0.98 & 0.98 & $\mathbf{- 0 . 8 5}$ & 0.00 & 0.91 & 0.91 & -0.36 & 0.00 & 0.96 & 0.95 \\
\hline 4.33 & 0.00 & 1.49 & 1.54 & 1.19 & 0.00 & 1.19 & 1.19 & 1.10 & 0.00 & 1.15 & 1.14 & 1.45 & 0.00 & 1.21 & 1.24 & 1.55 & 0.00 & 1.21 & 1.22 & 1.88 & 0.00 & 1.28 & 1.28 \\
\hline-1.29 & 0.00 & 0.88 & 0.80 & -1.67 & 0.00 & 0.85 & 0.85 & -1.60 & 0.00 & 0.76 & 0.77 & -0.87 & 0.00 & 0.91 & 0.84 & -1.96 & 0.00 & 0.78 & 0.75 & -0.81 & 0.00 & 0.89 & 0.89 \\
\hline-2.81 & 0.00 & 0.71 & 0.74 & -2.17 & 0.00 & 0.80 & 0.80 & -0.92 & 0.00 & 0.86 & 0.86 & -1.91 & 0.00 & 0.77 & 0.76 & -1.43 & 0.00 & 0.84 & 0.82 & -1.21 & 0.00 & 0.84 & 0.83 \\
\hline 0.72 & 0.00 & 1.10 & 1.10 & 0.14 & 0.00 & 1.07 & 1.06 & 0.94 & 0.00 & 1.12 & 1.11 & -0.35 & 0.00 & 0.98 & 0.99 & -0.89 & 0.00 & 0.91 & 0.90 & -0.38 & 0.00 & 0.96 & 0.96 \\
\hline-1.03 & 0.00 & 0.90 & 0.95 & -2.53 & 0.00 & 0.75 & 0.76 & -2.02 & $\mathbf{0 . 0 0}$ & 0.70 & 0.73 & -1.39 & 0.00 & 0.84 & 0.84 & -1.42 & 0.00 & 0.84 & 0.87 & -1.35 & 0.00 & 0.82 & 0.83 \\
\hline-0.62 & $\mathbf{0 . 0 0}$ & 0.95 & 0.85 & -1.51 & 0.00 & 0.87 & 0.89 & -0.34 & $\mathbf{0 . 0 0}$ & 0.94 & 0.96 & -0.02 & 0.29 & 1.02 & 0.98 & 0.19 & 0.00 & 1.04 & 1.04 & -0.70 & 0.00 & 0.91 & 0.91 \\
\hline 0(Ref) & & 1.02 & 0.99 & 0.49 & 0.00 & 1.11 & 1.11 & 1.66 & 0.00 & 1.22 & 1.23 & 0.71 & 0.00 & 1.12 & 1.10 & 0.60 & 0.00 & 1.09 & 1.08 & 0.80 & 0.00 & 1.13 & 1.11 \\
\hline-0.84 & 0.00 & 0.93 & 0.86 & -0.35 & 0.00 & 1.01 & 1.01 & -0.03 & 0.05 & 0.99 & 1.00 & -0.70 & 0.00 & 0.93 & 0.90 & 1.22 & 0.00 & 1.17 & 1.06 & 0.84 & 0.00 & 1.13 & 1.12 \\
\hline 0.38 & 0.00 & 1.06 & 1.07 & 0.56 & 0.00 & 1.12 & 1.12 & -0.45 & 0.00 & 0.93 & 0.93 & 0.25 & 0.00 & 1.05 & 1.08 & 1.08 & 0.00 & 1.15 & 1.15 & 0.38 & 0.00 & 1.07 & 1.07 \\
\hline-1.03 & 0.00 & 0.90 & 0.92 & 1.17 & 0.00 & 1.19 & 1.19 & 2.06 & 0.00 & 1.28 & 1.28 & 0.86 & 0.00 & 1.13 & 1.14 & 0.87 & 0.00 & 1.13 & 1.13 & 1.26 & 0.00 & 1.19 & 1.19 \\
\hline-1.43 & 0.00 & 0.86 & 0.87 & -1.17 & 0.00 & 0.91 & 0.92 & -0.60 & 0.00 & 0.91 & 0.90 & -1.55 & 0.00 & 0.82 & 0.80 & -0.78 & 0.00 & 0.92 & 0.92 & -0.78 & 0.00 & 0.90 & 0.89 \\
\hline-2.26 & 0.00 & 0.77 & 0.75 & -0.90 & 0.00 & 0.94 & 0.95 & -0.55 & 0.00 & 0.91 & 0.91 & -0.94 & 0.00 & 0.90 & 0.87 & -2.15 & 0.00 & 0.75 & 0.77 & -0.32 & 0.00 & 0.96 & 0.97 \\
\hline 1.91 & 0.00 & 1.23 & 1.25 & 0.57 & 0.00 & 1.12 & 1.12 & 1.32 & 0.00 & 1.18 & 1.17 & 0.82 & 0.00 & 1.13 & 1.14 & O(Ref) & & 1.02 & 1.03 & 1.36 & 0.00 & 1.21 & 1.20 \\
\hline 0.71 & 0.00 & 1.10 & 1.10 & -0.19 & 0.00 & 1.03 & 1.02 & 0.66 & 0.00 & 1.08 & 1.07 & 0.25 & 0.00 & 1.05 & 1.06 & 1.73 & 0.00 & 1.23 & 1.20 & 0.37 & 0.00 & 1.06 & 1.05 \\
\hline 0.58 & 0.00 & 1.08 & 1.11 & 1.62 & 0.00 & 1.24 & 1.23 & 0.36 & 0.00 & 1.04 & 1.03 & 0.73 & 0.00 & 1.12 & 1.15 & -0.52 & 0.00 & 0.95 & 0.96 & 0.39 & 0.00 & 1.07 & 1.07 \\
\hline-0.26 & 0.00 & 0.99 & 0.95 & -0.14 & 0.00 & 1.03 & 1.04 & -0.01 & 0.47 & 0.99 & 1.00 & 0.03 & 0.02 & 1.03 & 1.01 & 0.09 & 0.17 & 1.03 & 1.03 & 0(Ref) & & 1.01 & 1.01 \\
\hline 0.68 & 0.00 & 1.09 & 1.09 & -0.10 & 0.00 & 1.04 & 1.04 & 0.67 & 0.00 & 1.09 & 1.08 & -0.36 & 0.00 & 0.98 & 0.96 & -1.23 & 0.00 & 0.87 & 0.88 & 0.15 & 0.00 & 1.03 & 1.03 \\
\hline 1.80 & 0.00 & 1.22 & 1.24 & 1.17 & 0.00 & 1.19 & 1.19 & 2.39 & 0.00 & 1.33 & 1.31 & 1.03 & 0.00 & 1.16 & 1.18 & 2.09 & 0.00 & 1.28 & 1.28 & 2.18 & 0.00 & 1.32 & 1.33 \\
\hline 1.36 & 0.00 & 1.17 & 1.15 & -0.59 & 0.00 & 0.98 & 0.98 & 0.34 & 0.00 & 1.04 & 1.04 & 0.75 & 0.00 & 1.12 & 1.12 & 0.92 & 0.00 & 1.13 & 1.14 & 0.45 & 0.00 & 1.07 & 1.08 \\
\hline-0.61 & $\mathbf{0 . 0 0}$ & 0.95 & 0.91 & 0.08 & 0.00 & 1.06 & 1.05 & -0.84 & $\mathbf{0 . 0 0}$ & 0.87 & 0.88 & -1.21 & 0.00 & 0.86 & 0.87 & 0.64 & 0.00 & 1.10 & 1.09 & 1.30 & 0.00 & 1.20 & 1.20 \\
\hline 2.19 & 0.00 & 1.26 & 1.28 & 1.38 & 0.00 & 1.21 & 1.23 & 2.98 & 0.00 & 1.41 & 1.42 & 1.47 & 0.00 & 1.21 & 1.25 & 0.46 & 0.00 & 1.07 & 1.09 & 1.15 & 0.00 & 1.17 & 1.19 \\
\hline 0.72 & 0.00 & 1.10 & 1.12 & 0.79 & 0.00 & 1.14 & 1.14 & 1.49 & 0.00 & 1.20 & 1.19 & 0.94 & 0.00 & 1.15 & 1.17 & 2.00 & 0.00 & 1.27 & 1.27 & 0.53 & 0.00 & 1.09 & 1.09 \\
\hline-0.86 & 0.00 & 0.92 & 0.92 & -0.32 & 0.00 & 1.01 & 1.02 & -0.97 & 0.00 & 0.85 & 0.86 & -0.38 & 0.00 & 0.97 & 1.02 & -1.53 & 0.00 & 0.83 & 0.82 & -0.65 & 0.00 & 0.92 & 0.93 \\
\hline 3.09 & 0.00 & 1.36 & 1.38 & 1.59 & 0.00 & 1.24 & 1.24 & 2.64 & 0.00 & 1.36 & 1.38 & 0.76 & 0.00 & 1.12 & 1.15 & 3.16 & 0.00 & 1.41 & 1.41 & 2.96 & 0.00 & 1.43 & 1.45 \\
\hline-1.46 & 0.00 & 0.86 & 0.90 & 0(Ref) & & 1.05 & 1.06 & -0.81 & 0.00 & 0.88 & 0.88 & -0.33 & 0.00 & 0.98 & 0.99 & 0.50 & 0.00 & 1.08 & 1.08 & 0.37 & 0.00 & 1.06 & 1.06 \\
\hline-1.27 & 0.00 & 0.88 & 0.84 & -0.48 & 0.00 & 0.99 & 0.99 & -0.31 & 0.00 & 0.95 & 0.94 & -0.28 & 0.00 & 0.99 & 0.97 & -1.38 & 0.00 & 0.85 & 0.87 & -0.72 & 0.00 & 0.91 & 0.89 \\
\hline-0.68 & 0.00 & 0.94 & 1.00 & 0.07 & 0.00 & 1.06 & 1.05 & 0.65 & 0.00 & 1.08 & 1.07 & 0.60 & 0.00 & 1.10 & 1.10 & -0.26 & 0.00 & 0.99 & 0.98 & 0.08 & 0.00 & 1.02 & 1.01 \\
\hline 2.72 & 0.00 & 1.32 & 1.31 & 2.11 & 0.00 & 1.30 & 1.28 & 0.99 & 0.00 & 1.13 & 1.13 & 0.61 & 0.00 & 1.10 & 1.10 & 1.02 & 0.00 & 1.14 & 1.14 & 1.68 & 0.00 & 1.25 & 1.24 \\
\hline-2.31 & 0.00 & 0.76 & 0.80 & -1.35 & 0.00 & 0.89 & 0.89 & -0.90 & 0.00 & 0.86 & 0.86 & -1.38 & 0.00 & 0.84 & 0.82 & -0.48 & 0.00 & 0.96 & 0.95 & -1.03 & 0.00 & 0.86 & 0.86 \\
\hline
\end{tabular}




\begin{tabular}{|c|c|c|c|c|c|c|c|c|c|c|c|c|c|c|c|c|c|c|c|c|c|c|c|c|}
\hline \multirow[b]{3}{*}{ Province 44} & \multicolumn{4}{|c|}{ Length of Stay MDC1 } & \multicolumn{4}{|c|}{ Length of Stay MDC4 } & \multicolumn{4}{|c|}{ Length of Stay MDC5 } & \multicolumn{4}{|c|}{ Length of Stay MDC6 } & \multicolumn{4}{|c|}{ Length of Stay MDC8 } & \multicolumn{4}{|c|}{ Length of Stay MDC11 } \\
\hline & B & $\mathbf{P} \mathbf{F}$ & GS rate & ISR & B & P I & GS rate & ISR & B & $\mathbf{P} \mathbf{R}$ & GS rate & ISR & B & $\mathbf{P} \mathbf{P}$ & RGS rate & ISR & B & $\mathbf{P} \mathbf{R}$ & QGS rate & ISR & B & $\mathbf{P R}$ & QGS rate & ISR \\
\hline & 0.84 & 0.00 & 1.11 & 1.03 & 1.50 & 0.00 & 1.23 & 1.22 & 1.17 & 0.00 & 1.16 & 1.15 & 0.11 & 0.00 & 1.04 & 1.02 & 3.38 & 0.00 & 1.44 & 1.25 & 1.21 & 0.00 & 1.18 & 1.17 \\
\hline Province 45 & 4.13 & 0.00 & 1.47 & 1.51 & 0.41 & 0.00 & 1.10 & 1.11 & 0.53 & 0.00 & 1.06 & 1.05 & 0.85 & 0.00 & 1.13 & 1.12 & -0.25 & 0.00 & 0.99 & 0.99 & 1.48 & 0.00 & 1.22 & 1.22 \\
\hline Province 46 & -1.51 & 0.00 & 0.85 & 0.86 & -1.84 & 0.00 & 0.83 & 0.83 & -0.88 & 0.00 & 0.87 & 0.86 & -1.36 & 0.00 & 0.84 & 0.85 & -1.82 & 0.00 & 0.79 & 0.79 & -1.42 & 0.00 & 0.81 & 0.81 \\
\hline Province 47 & -0.07 & 0.11 & 1.01 & 0.99 & 0.88 & 0.00 & 1.15 & 1.16 & 0.75 & 0.00 & 1.10 & 1.10 & 0.21 & 0.00 & 1.05 & 1.06 & -1.28 & 0.00 & 0.86 & 0.87 & 1.33 & 0.00 & 1.20 & 1.22 \\
\hline Province 48 & -0.65 & 0.00 & 0.95 & 0.88 & -1.31 & 0.00 & 0.90 & 0.91 & -0.90 & 0.00 & 0.86 & 0.87 & 0.29 & 0.00 & 1.06 & 1.05 & -0.43 & 0.00 & 0.96 & 0.97 & -0.17 & 0.00 & 0.99 & 0.98 \\
\hline Province 49 & -0.03 & 0.50 & 1.01 & 1.01 & 0.43 & 0.00 & 1.10 & 1.10 & -0.24 & 0.00 & 0.96 & 0.95 & 0.09 & 0.00 & 1.03 & 1.05 & 0.55 & 0.00 & 1.09 & 1.09 & 1.98 & 0.00 & 1.29 & 1.28 \\
\hline Province 50 & 2.15 & 0.00 & 1.25 & 1.25 & 1.62 & 0.00 & 1.24 & 1.25 & 1.65 & 0.00 & 1.22 & 1.24 & 0.90 & 0.00 & 1.14 & 1.14 & 1.26 & 0.00 & 1.17 & 1.18 & 1.25 & 0.00 & 1.19 & 1.19 \\
\hline case-mix weight & 11.32 & 0.00 & & & & 0.00 & & & -1.94 & 0.00 & & & 7.93 & 0.00 & & & & 0.00 & & & 1.32 & 0.00 & & \\
\hline 65-74 & 0.13 & 0.00 & & & 0.11 & 0.00 & & & 0.55 & 0.00 & & & 0.32 & 0.00 & & & 0.67 & 0.00 & & & 0.71 & 0.00 & & \\
\hline $\begin{array}{l}>74 \\
\text { Sex }\end{array}$ & -0.46 & 0.00 & & & -0.06 & 0.00 & & & 0.60 & 0.00 & & & 0.17 & 0.00 & & & 0.40 & 0.00 & & & 0.92 & 0.00 & & \\
\hline $\begin{array}{l}\text { Female } \\
\text { Mortality Risk }\end{array}$ & 0.25 & 0.00 & & & -0.02 & 0.00 & & & 0.11 & 0.00 & & & 0.58 & 0.00 & & & -0.14 & 0.00 & & & 0.09 & 0.00 & & \\
\hline $\begin{array}{l}\text { Moderate } \\
\text { Mortaty KI }\end{array}$ & 1.54 & 0.00 & & & 2.08 & 0.00 & & & 2.13 & 0.00 & & & 0.53 & 0.00 & & & 3.00 & 0.00 & & & 1.63 & 0.00 & & \\
\hline $\begin{array}{c}\text { Major } \\
\text { Admission }\end{array}$ & -0.05 & 0.15 & & & 4.34 & 0.00 & & & 5.08 & 0.00 & & & 0.78 & 0.00 & & & 7.56 & 0.00 & & & 4.00 & 0.00 & & \\
\hline Emergency & -1.07 & 0.00 & & & -0.53 & 0.00 & & & 1.82 & 0.00 & & & 1.80 & 0.00 & & & 1.14 & 0.00 & & & 1.40 & 0.00 & & \\
\hline Constant & -1.66 & 0.00 & & & 8.26 & 0.00 & & & 4.20 & 0.00 & & & -0.71 & 0.00 & & & \begin{tabular}{|l|l|}
3.41 \\
\end{tabular} & 0.00 & & & \begin{tabular}{|l|}
2.27 \\
\end{tabular} & 0.00 & & \\
\hline $\mathbf{N}$ & 398,840 & & & & 939,432 & & & & 804,53 & & & & 428,421 & & & & 156,098 & & & & 275,261 & & & \\
\hline R2 & 0.6538 & & & & 0.8338 & & & & 0.86 & & & & 0.85 & & & & \begin{tabular}{|l|l|}
0.71 \\
\end{tabular} & & & & 0.83 & & & \\
\hline
\end{tabular}

Table 4-1: Length of stay regression and indirect standardized rates 


\begin{tabular}{|c|c|c|c|c|c|c|c|c|c|c|c|c|c|c|c|c|c|c|}
\hline \multirow[b]{2}{*}{ Variable } & \multicolumn{3}{|c|}{ Mortality MDC1 } & \multicolumn{3}{|c|}{ Mortality MDC4 } & \multicolumn{3}{|c|}{ Mortality MDC5 } & \multicolumn{3}{|c|}{ Mortality MDC6 } & \multicolumn{3}{|c|}{ Mortality MDC8 } & \multicolumn{3}{|c|}{ Mortality MDC11 } \\
\hline & OR & $\mathbf{P}$ & ISR & OR & $\mathbf{P}$ & ISR & OR & $\mathbf{P}$ & ISR & OR & $\mathbf{P}$ & ISR & OR & $\mathbf{P}$ & ISR & OR & $\mathbf{P}$ & ISR \\
\hline Province 1 & 0.92 & 0.31 & 90 & 0.87 & & 0.83 & 0.77 & 0.00 & & & 0.42 & 0.92 & 0.66 & 0.02 & & & 0.29 & 1.01 \\
\hline Province 2 & 0.99 & 0.84 & 05 & 0.85 & 0.00 & 0.90 & 1.09 & 0.17 & 1.10 & 0.74 & 0.00 & 0.90 & .99 & 0.95 & & 63 & 0.00 & 0.78 \\
\hline Province 3 & 01 & 0.89 & 00 & 0.94 & 0.06 & 0.96 & 1(Ref) & & 1.04 & 0.82 & 0.00 & 87 & 0.91 & 0.47 & 91 & 0.79 & 00 & 86 \\
\hline rovi & 81 & 0.01 & 39 & 0.98 & 0.60 & 1.06 & 1.05 & 0.42 & & 1.14 & 0.07 & 1.28 & 1.24 & 0.21 & 1.21 & 1.30 & 0.01 & .35 \\
\hline & 1.38 & 0.00 & 32 & 1.33 & 0.00 & 1.35 & 1.13 & 0.08 & & 1.45 & 0.00 & 1.39 & 1.42 & 0.10 & 36 & 1.34 & 0.02 & 1.35 \\
\hline & 95 & 0.44 & & 1.09 & 0.02 & 1. & 1.00 & 0.96 & & 1.14 & 0.04 & 1.13 & 1.14 & 0.40 & & 1.28 & 0.01 & 1.35 \\
\hline e 7 & 0.82 & 0.00 & & 0.68 & 0.00 & 0.76 & 0.85 & 0.00 & & 0.69 & 0.00 & & & 0.63 & & & 0.04 & \\
\hline & 0.72 & 0.00 & & 0.67 & 0.00 & & 0.72 & 0.00 & & 0.62 & 0.00 & & 0.64 & 0.00 & & 0.56 & 0.00 & \\
\hline & 78 & 0.00 & & 0.6 & 0.0 & & 78 & 0 & & 6 & & & & 0.0 & & & 00 & \\
\hline & 04 & 0.63 & & & 0.00 & & 1.54 & 00 & & & & & & & & & 00 & \\
\hline & 12 & 0.08 & & 1.30 & 0.00 & & 32 & 00 & & 7 & 0.69 & & 96 & 0.80 & & & 00 & \\
\hline & 1.36 & 0.00 & & 1.43 & 0.00 & & .54 & 0.00 & & 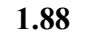 & 0.00 & & 51 & 0.02 & & 1.32 & & 41 \\
\hline & 1(Ref) & & & 1.04 & 0.33 & & .08 & 0.11 & & 4 & 0.32 & & 07 & 0.68 & 15 & 1(Ref) & & 09 \\
\hline & & 0.75 & & 1.07 & 0.11 & & 1.07 & 0.13 & & 07 & 0.34 & & & 0.00 & 72 & 1.02 & 0.84 & .21 \\
\hline & & 0.32 & & 0.96 & 0.25 & 1.05 & 0.92 & 0.07 & & 1.06 & 0.30 & 20 & 18 & 0.23 & 20 & & 0.86 & .20 \\
\hline & & 0.00 & & 0.56 & 0.00 & 0.59 & 0.66 & 0.00 & & 0.62 & 0.00 & & 72 & 0.21 & & & 0.00 & .46 \\
\hline & & 0.64 & & 0.70 & 0.00 & 0. & 0.95 & 0.28 & & 0.70 & 0.00 & 76 & & 0.00 & & & 03 & \\
\hline & & 0.55 & & 0.83 & 0.00 & 0. & 27 & 0.00 & & 1.23 & 0.00 & & & 0.31 & & & 00 & 18 \\
\hline & 94 & 0.48 & 02 & 0.60 & 0.00 & 0. & 0.84 & 0.04 & & 0.5 & & & & 0.27 & & & 09 & \\
\hline & .09 & 0.21 & 14 & 0.96 & 0.33 & 0.88 & 0.76 & 0.00 & & 1(Ref) & & & 0.73 & 0.04 & & 0.91 & 0.29 & .94 \\
\hline & 40 & 0.00 & & 1.78 & 0.00 & 1.67 & 1.48 & 0.00 & & 133 & 0.00 & & 1.62 & 0.00 & & & 0.00 & .44 \\
\hline & 0 & 0.00 & & 0.91 & 0.11 & & 0.95 & 0.47 & & 0 & 0.00 & & 0.8 & 0.29 & & & 0.74 & 06 \\
\hline & & 0.00 & & & 0.0 & & & 0.00 & & & 0.00 & & 1.6 & 0.00 & & & .01 & 65 \\
\hline & 00 & 0.15 & & 0.77 & & & 81 & 0.00 & & 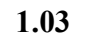 & 0.62 & 06 & 1(Ref) & & & & .81 & 01 \\
\hline & & 0.00 & & 0.74 & 0.00 & & .99 & 0.81 & & 0.71 & 0.00 & 72 & 0.78 & 0.16 & & & 01 & .76 \\
\hline & & 0.43 & & & & & & & & & & & & 54 & & & 01 & \\
\hline & & 0.10 & & & & & & & & & & & & 0.41 & & & 01 & 1.35 \\
\hline & & 0.00 & & 70 & 0.00 & & & 0.00 & & & 0.00 & & & 0.16 & & & 0.00 & 0.74 \\
\hline & & 0.63 & & & 0.00 & & & 0.00 & & & & & & 0.30 & & & 0.95 & .10 \\
\hline & & 0.00 & & & 0.00 & & & 0.00 & & & 0.03 & & & 0.38 & 0 & & 0.07 & 0.91 \\
\hline & & 0.00 & & & 0.00 & & .98 & 0.68 & & & 0.00 & & & 0.12 & 1.2 & & 0.00 & 1.47 \\
\hline & & 0.21 & & & 0.09 & & & 0.00 & & & 0.00 & & & 0.04 & 1.2 & & 0.01 & 1.45 \\
\hline & & 0.00 & & & 0.00 & & & 0.00 & & & 0.00 & 1. & & 0.05 & 1 & & 0.01 & 1.26 \\
\hline & & 0.12 & & 0.8 & 0.0 & & 0.86 & 0.02 & & & 0.00 & & & 0.05 & & & 0.00 & 1.69 \\
\hline & & 0.1 & & & 0.0 & & & 0.0 & & & 0.00 & & & 0.12 & & & 00 & 1.69 \\
\hline & & 0.0 & & & & & & & & & 0.0 & & & 0.01 & & & 00 & 1.46 \\
\hline & & 0.06 & & & 0.08 & & & 0.00 & & & 0.01 & & & 0.18 & & & 09 & 0.97 \\
\hline & & 0.00 & & & 0.00 & & & 0.02 & & & 0.15 & & & 0.00 & 52 & & 01 & 1.37 \\
\hline & & 0.19 & 96 & 1.20 & 0.00 & 1.23 & & 0.01 & & 6 & 0.54 & & 0.93 & 0.67 & 08 & & 00 & 1.43 \\
\hline & & 0.09 & & 1.03 & 0.65 & & 0.88 & 0.14 & & 1.06 & 0.60 & & 0.72 & 0.20 & 82 & .86 & 0.32 & 0.88 \\
\hline & & 0.51 & & & 0.00 & & 1.13 & 0.00 & & 1.02 & 0.69 & & & 0.18 & 16 & & 0.21 & 1.23 \\
\hline & & 0.78 & & 0.70 & 0.00 & & 0.62 & 0.00 & & 1.06 & 0.64 & & 0.55 & 0.03 & 0.69 & & 0.69 & 1.08 \\
\hline Province 43 & 0.87 & 0.05 & 0.93 & 0.75 & 0.00 & 0.83 & 0.90 & 0.05 & 0.93 & 0.96 & 0.54 & 0.99 & 0.67 & 0.02 & 0.71 & 0.85 & 0.08 & 0.93 \\
\hline
\end{tabular}




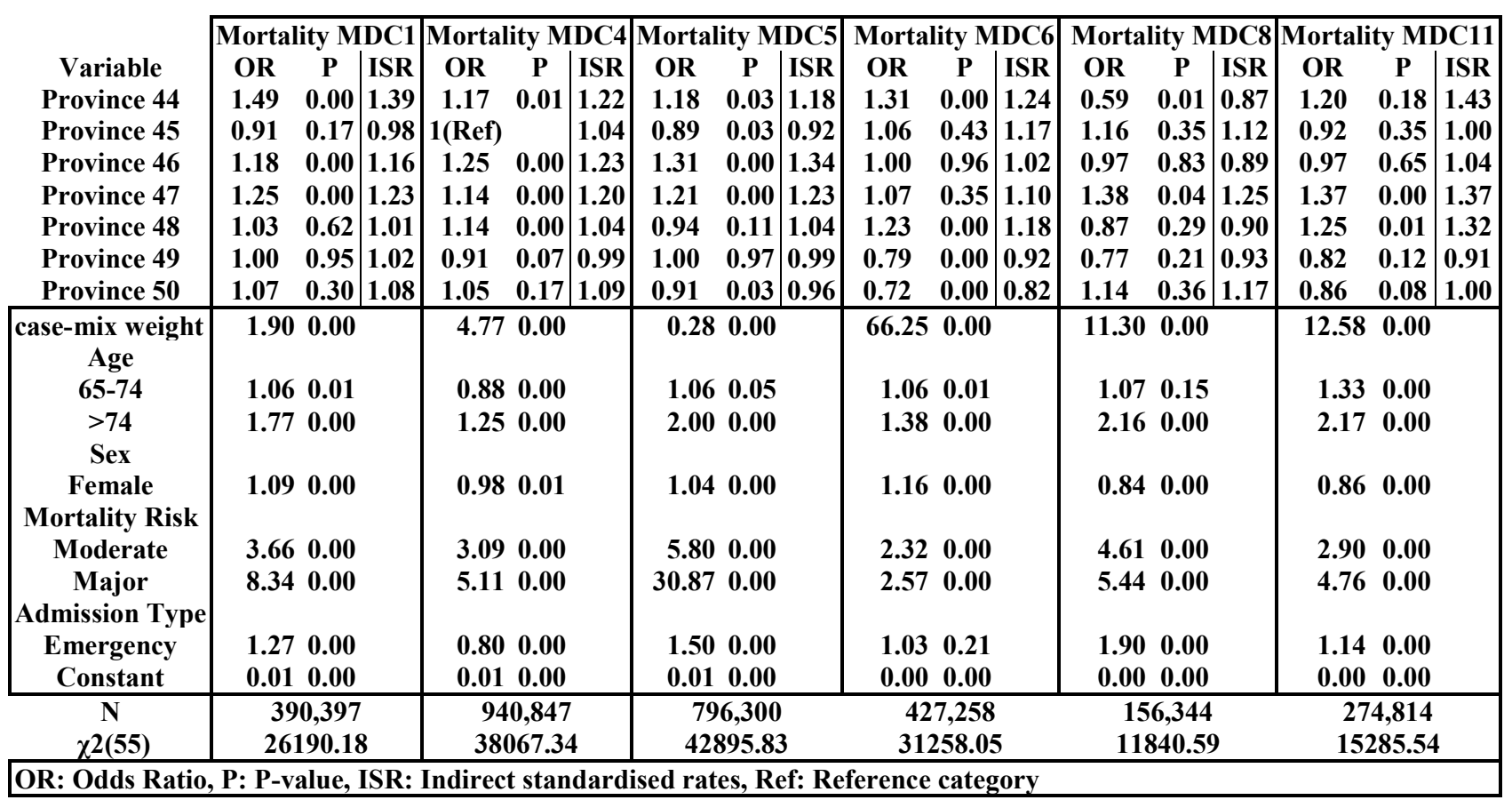

Table 4-2: Mortality regression and indirect standardized rates 


\begin{tabular}{|c|c|c|c|c|c|c|c|c|c|c|c|c|c|c|c|c|c|c|}
\hline \multirow[b]{2}{*}{ Variable } & \multicolumn{3}{|c|}{ Infection rate MDC1 } & \multicolumn{3}{|c|}{ Infection rate MDC4 } & \multicolumn{3}{|c|}{ Infection rate MDC5 } & \multicolumn{3}{|c|}{ Infection rate MDC6 } & \multicolumn{3}{|c|}{ Infection rate MDC8 } & \multicolumn{3}{|c|}{ Infection rate MDC11 } \\
\hline & OR & $\mathbf{P}$ & ISR & OR & $\mathbf{P}$ & | ISR & OR & $\mathbf{P}$ & ISR & OR & $\mathbf{P}$ & ISR & OR & $\mathbf{P}$ & $\mid$ ISR & OR & $\mathbf{P}$ & ISR \\
\hline Province 1 & 0.72 & 0.46 & 0.72 & 0.60 & 0.11 & 0.63 & 0.46 & 0.03 & 0.47 & 0.98 & 0.94 & 0.98 & 0.75 & 0.61 & 0.83 & 0.49 & 0.07 & 0.51 \\
\hline Province 2 & 0.49 & 0.10 & 0.52 & 0.63 & 0.10 & 0.64 & 0.78 & 0.39 & 0.79 & 0.59 & 0.04 & 0.58 & 0.75 & 0.66 & 0.83 & 0.85 & 0.60 & 0.87 \\
\hline Province 3 & 0.83 & 0.43 & 0.81 & 0.47 & 0.00 & 0.48 & 0.60 & 0.01 & 0.60 & 0.71 & 0.01 & 0.73 & 0.96 & 0.92 & 0.95 & 0.98 & 0.92 & 0.99 \\
\hline Province 4 & 1.51 & 0.13 & 1.61 & 0.51 & $\mathbf{0 . 0 3}$ & 0.51 & 0.71 & 0.21 & 0.71 & 0.33 & 0.00 & 0.34 & 0.87 & 0.81 & 0.91 & 0.40 & 0.03 & 0.39 \\
\hline Province 5 & 0.69 & 0.49 & 0.69 & Excluded & & & 0.41 & 0.04 & 0.41 & 0.27 & 0.03 & 0.27 & 0.48 & 0.49 & 0.48 & 0.37 & 0.10 & 0.35 \\
\hline Province 6 & 0.82 & 0.50 & 0.80 & 0.50 & 0.01 & 0.52 & 0.70 & 0.12 & 0.70 & 0.56 & 0.01 & 0.54 & 0.46 & 0.19 & 0.44 & 0.67 & 0.17 & 0.68 \\
\hline Province 7 & 1.24 & 0.42 & 1.29 & 1.63 & 0.02 & 1.63 & 1.51 & 0.04 & 1.50 & 1.26 & 0.11 & 1.29 & 1.07 & 0.89 & 1.13 & 0.81 & 0.41 & 0.83 \\
\hline Province 8 & 1.03 & 0.87 & 1.09 & 1.23 & 0.24 & 1.23 & 1.27 & 0.17 & 1.26 & 1.29 & 0.00 & 1.32 & 1.16 & 0.68 & 1.17 & 1.64 & 0.01 & 1.59 \\
\hline Province 9 & 0.70 & 0.33 & 0.73 & 1.25 & 0.34 & 1.25 & 0.76 & 0.30 & 0.76 & 0.81 & 0.29 & 0.78 & 0.79 & 0.64 & 0.79 & 0.52 & 0.06 & 0.50 \\
\hline Province 10 & 0.34 & 0.04 & 0.35 & 0.72 & 0.27 & 0.73 & 0.46 & 0.02 & 0.46 & 0.74 & 0.24 & 0.75 & 0.92 & 0.90 & 0.95 & 1.30 & 0.39 & 1.29 \\
\hline Province 11 & 0.60 & 0.09 & 0.64 & 0.50 & 0.02 & 0.50 & 0.67 & 0.09 & 0.67 & 0.48 & 0.00 & 0.52 & 0.86 & 0.75 & 0.93 & 0.83 & 0.48 & 0.84 \\
\hline Province 12 & 1.21 & 0.54 & 1.25 & 0.70 & 0.24 & 0.72 & 0.57 & 0.07 & 0.57 & 0.81 & 0.35 & 0.85 & 0.63 & 0.48 & 0.62 & 0.74 & 0.37 & 0.75 \\
\hline Province 13 & 0.43 & 0.04 & 0.46 & 0.89 & 0.61 & 0.89 & 0.95 & 0.80 & 0.95 & 0.69 & 0.06 & 0.73 & 0.60 & 0.40 & 0.63 & 0.77 & 0.35 & 0.77 \\
\hline Province 14 & 0.46 & 0.03 & 0.48 & 0.74 & 0.23 & 0.74 & 0.59 & 0.03 & 0.59 & 0.56 & 0.01 & 0.56 & 0.60 & 0.40 & 0.60 & 0.83 & 0.50 & 0.83 \\
\hline Province 15 & 0.89 & 0.67 & 0.94 & 0.56 & 0.01 & 0.56 & 0.66 & 0.06 & 0.66 & 0.66 & 0.01 & 0.72 & 1.11 & 0.81 & 1.14 & 0.90 & 0.65 & 0.94 \\
\hline Province 16 & Excluded & & 0.00 & 0.25 & 0.02 & 0.26 & 0.48 & 0.10 & 0.49 & 0.72 & 0.33 & 0.66 & Excluded & & 0.00 & 0.16 & 0.07 & 0.15 \\
\hline Province 17 & 0.78 & 0.47 & 0.84 & 0.49 & 0.01 & 0.49 & 0.54 & 0.02 & 0.54 & 0.74 & 0.17 & 0.76 & 0.79 & 0.61 & 0.72 & 1.08 & 0.76 & 1.07 \\
\hline Province 18 & 0.91 & 0.74 & 0.94 & 0.65 & 0.12 & 0.65 & 1.06 & 0.80 & 1.05 & 0.55 & 0.02 & 0.59 & 1(Ref) & & 0.97 & 0.53 & 0.06 & 0.56 \\
\hline Province 19 & 0.46 & 0.20 & 0.50 & 0.89 & 0.72 & 0.88 & 1.30 & 0.37 & 1.29 & 1.21 & 0.42 & 1.18 & 1.28 & 0.69 & 1.54 & 0.98 & 0.95 & 0.95 \\
\hline Province 20 & 0.69 & 0.26 & 0.65 & 0.56 & $\mathbf{0 . 0 3}$ & 0.61 & 0.64 & 0.08 & 0.65 & 0.94 & 0.68 & 0.87 & 0.95 & 0.90 & 0.95 & 0.79 & 0.39 & 0.77 \\
\hline Province 21 & 0.66 & 0.27 & 0.67 & 0.32 & 0.02 & 0.33 & 0.73 & 0.22 & 0.73 & 0.67 & 0.12 & 0.65 & 0.82 & 0.72 & 0.81 & 0.72 & 0.35 & 0.71 \\
\hline Province 22 & 0.73 & 0.49 & 0.74 & 0.72 & 0.35 & 0.74 & 0.81 & 0.49 & 0.82 & 0.74 & 0.29 & 0.70 & 2.38 & $\mathbf{0 . 0 3}$ & 1.86 & 0.96 & 0.92 & 0.95 \\
\hline Province 23 & 0.43 & 0.04 & 0.44 & 0.50 & $\mathbf{0 . 0 3}$ & 0.51 & 0.38 & 0.00 & 0.38 & 0.51 & 0.01 & 0.55 & 0.71 & 0.54 & 0.69 & 0.48 & 0.05 & 0.53 \\
\hline Province 24 & 0.82 & 0.58 & 0.84 & 0.85 & 0.50 & 0.85 & 0.90 & 0.64 & 0.89 & 0.80 & 0.24 & 0.81 & 1.17 & 0.73 & 1.17 & 1.52 & 0.12 & 1.38 \\
\hline Province 25 & 0.82 & 0.60 & 0.88 & 0.51 & 0.04 & 0.52 & 1.17 & 0.55 & 1.17 & 0.85 & 0.51 & 0.82 & 1.23 & 0.67 & 1.18 & 0.86 & 0.65 & 0.82 \\
\hline Province 26 & 0.49 & 0.15 & 0.51 & 0.49 & 0.06 & 0.49 & 1.10 & 0.72 & 1.09 & 0.47 & 0.02 & 0.47 & 0.22 & 0.16 & 0.24 & 0.50 & 0.10 & 0.52 \\
\hline Province 27 & 2.87 & 0.00 & 2.96 & 1.81 & 0.01 & 1.80 & 1.40 & 0.16 & 1.39 & 1.90 & 0.00 & 1.93 & 1.48 & 0.40 & 1.54 & 1.37 & 0.27 & 1.35 \\
\hline Province 28 & 0.77 & 0.20 & 0.80 & 1.01 & 0.97 & 1.00 & 0.90 & 0.56 & 0.91 & 1(Ref) & & 1.04 & 1.18 & 0.65 & 1.18 & 0.84 & 0.38 & 0.83 \\
\hline Province 29 & 1.44 & 0.13 & 1.50 & 1.80 & 0.00 & 1.80 & 1.42 & 0.08 & 1.41 & 1.37 & 0.01 & 1.52 & 1.26 & 0.60 & 1.31 & 1.30 & 0.26 & 1.28 \\
\hline Province 30 & 1.02 & 0.93 & 1.01 & 1.04 & 0.84 & 1.08 & 0.99 & 0.96 & 1.00 & 0.75 & 0.06 & 0.73 & 1.29 & 0.53 & 1.20 & 0.94 & 0.78 & 0.88 \\
\hline Province 31 & 0.54 & 0.10 & 0.56 & 0.48 & 0.02 & 0.50 & 0.64 & 0.10 & 0.64 & 0.51 & 0.00 & 0.51 & 1.14 & 0.76 & 1.07 & 0.51 & 0.08 & 0.50 \\
\hline ince 32 & 3.15 & 0.00 & 3.29 & 1.27 & 0.30 & 1.26 & 2.84 & 0.00 & 2.80 & 3.19 & 0.00 & 3.39 & 0.56 & 0.30 & 0.57 & 1.05 & 0.87 & 1.14 \\
\hline ce 33 & 1.03 & 0.92 & 1.02 & 1.17 & 0.44 & 1.19 & 1.8 & 0.00 & 1.85 & 1.42 & 0.00 & 1.43 & 0. & 0.80 & 0.85 & 1.05 & 0 . & 1.02 \\
\hline Prov & 2.21 & 0.01 & 2.19 & 0.60 & 0.19 & 0.59 & 0.80 & 0.44 & 0.81 & 0.27 & 0.01 & 0.27 & 0.51 & 0.39 & 0.53 & 1.00 & 0.99 & 1.01 \\
\hline Province 35 & 2.85 & 0.00 & 2.90 & 2.28 & 0.00 & 2.35 & 2.94 & 0.00 & 2.87 & 2.28 & 0.00 & 2.38 & 1.83 & 0.17 & 1.86 & 1.72 & 0.02 & 1.72 \\
\hline Province 36 & 0.93 & 0.80 & 0.98 & 1.13 & 0.55 & 1.12 & 0.76 & 0.22 & 0.75 & 0.76 & 0.11 & 0.82 & 0.47 & 0.15 & 0.47 & 0.60 & 0.07 & 0.63 \\
\hline Province 37 & 1.44 & 0.25 & 1.47 & 1.63 & 0.04 & 1.64 & 1.03 & 0.92 & 1.02 & 1.33 & 0.11 & 1.52 & 0.45 & 0.23 & 0.44 & 1.08 & 0.80 & 1.15 \\
\hline Province 38 & 1.24 & 0.47 & 1.27 & 1.91 & 0.00 & 1.91 & 1.38 & 0.17 & 1.36 & 1.55 & 0.00 & 1.67 & 0.97 & 0.95 & 0.93 & 2.23 & 0.00 & 2.15 \\
\hline Province 39 & 0.72 & 0.34 & 0.76 & 1.28 & 0.27 & 1.30 & 1.14 & 0.58 & 1.13 & 1.24 & 0.22 & 1.28 & 1.67 & 0.23 & 1.74 & 0.98 & 0.94 & 0.95 \\
\hline Province 40 & 0.89 & 0.82 & 0.87 & 0.88 & 0.76 & 0.88 & 0.86 & 0.68 & 0.87 & 0.77 & 0.50 & 0.73 & 0.41 & 0.41 & 0.48 & 0.76 & 0.56 & 0.70 \\
\hline Province 41 & 1.61 & 0.03 & 1.71 & 1.60 & 0.02 & 1.59 & 1.19 & 0.36 & 1.19 & 1.25 & 0.06 & 1.30 & 0.93 & 0.85 & 0.91 & 1.50 & 0.06 & 1.48 \\
\hline Province 42 & 0.23 & 0.14 & 0.25 & 0.97 & 0.95 & 0.96 & 0.44 & 0.08 & 0.44 & 0.48 & 0.14 & 0.50 & Excluded & & 0.00 & 0.20 & 0.12 & 0.20 \\
\hline Province 43 & 1.33 & 0.31 & 1.43 & 1(Ref) & & 1.00 & 1(Ref) & & 1.00 & 0.65 & 0.04 & 0.67 & 0.92 & 0.87 & 0.90 & 1(Ref) & & 1.00 \\
\hline
\end{tabular}




\begin{tabular}{|c|c|c|c|c|c|c|c|c|c|c|c|c|c|c|c|c|c|c|}
\hline \multirow[b]{2}{*}{ Variable } & \multicolumn{3}{|c|}{ Infection rate MDC1 } & \multicolumn{3}{|c|}{ Infection rate MDC4 } & \multicolumn{3}{|c|}{ Infection rate MDC5 } & \multicolumn{3}{|c|}{ Infection rate MDC6 } & \multicolumn{3}{|c|}{ Infection rate MDC8 } & \multicolumn{3}{|c|}{ Infection rate MDC11 } \\
\hline & OR & $\mathbf{P}$ & ISR & OR & $\mathbf{P}$ & $\mid$ ISR $\mid$ & OR & $\mathbf{P}$ & ISR & OR & $\mathbf{P}$ & ISR & OR & $\mathbf{P}$ & $\mid$ ISR $\mid$ & OR & $\mathbf{P}$ & ISR \\
\hline Province 44 & Excluded & & 0.00 & 0.62 & 0.25 & 0.63 & 0.72 & 0.38 & 0.73 & 1.05 & 0.88 & 1.02 & 1.17 & 0.74 & 1.31 & 1.00 & 1.00 & 1.00 \\
\hline Province 45 & 0.86 & 0.62 & 0.99 & 1.63 & 0.02 & 1.68 & 1.29 & 0.24 & 1.29 & 1.15 & 0.45 & 1.11 & 1.37 & 0.51 & 1.30 & 0.77 & 0.36 & 0.76 \\
\hline Province 46 & 0.33 & 0.00 & 0.34 & 0.40 & 0.00 & 0.41 & $\mathbf{0 . 5 0}$ & 0.00 & 0.50 & 0.36 & 0.00 & 0.37 & 0.53 & 0.15 & 0.51 & 0.48 & 0.00 & 0.49 \\
\hline Province 47 & 0.48 & 0.08 & 0.48 & 0.64 & 0.11 & 0.65 & 0.65 & 0.10 & 0.66 & 0.49 & 0.00 & 0.50 & 0.53 & 0.29 & 0.54 & 0.89 & 0.69 & 0.85 \\
\hline Province 48 & 1(Ref) & & 0.99 & 1.39 & 0.12 & 1.48 & 1.21 & 0.34 & 1.23 & 1.23 & 0.07 & 1.23 & 0.95 & 0.90 & 0.98 & 0.65 & 0.10 & 0.65 \\
\hline Province 49 & 3.94 & 0.00 & 3.99 & 4.71 & 0.00 & 4.64 & 2.28 & 0.00 & 2.26 & 3.55 & 0.00 & 3.61 & 3.13 & 0.01 & 3.52 & 4.06 & 0.00 & 3.76 \\
\hline Province 50 & 0.65 & 0.15 & 0.67 & 0.92 & 0.71 & 0.95 & 0.58 & 0.02 & 0.58 & 0.60 & 0.00 & 0.61 & 0.90 & 0.80 & 0.86 & 0.82 & 0.45 & 0.81 \\
\hline $\begin{array}{c}\text { case-mix weight } \\
\text { Age }\end{array}$ & 2.24 & 0.06 & & 0.53 & 0.41 & & 0.84 & 0.77 & & 8.39 & 0.00 & & 7.02 & 0.00 & & 10.44 & 0.00 & \\
\hline 65-74 & 0.90 & 0.23 & & 0.85 & 0.02 & & 1.04 & 0.53 & & 0.91 & 0.09 & & 1.17 & 0.18 & & 0.94 & 0.39 & \\
\hline $\begin{array}{l}>74 \\
\text { Sex }\end{array}$ & 0.75 & 0.00 & & 0.84 & 0.01 & & 0.84 & 0.00 & & 0.71 & 0.00 & & 1.02 & 0.83 & & 0.65 & 0.00 & \\
\hline $\begin{array}{c}\text { Female } \\
\text { Mortality Risk }\end{array}$ & 0.91 & 0.14 & & 0.83 & 0.00 & & 0.91 & 0.02 & & 1.01 & 0.82 & & 0.95 & 0.58 & & 0.83 & 0.00 & \\
\hline Moderate & 4.07 & 0.00 & & 2.22 & 0.00 & & 3.41 & 0.00 & & 1.92 & 0.00 & & 2.39 & 0.00 & & 1.64 & 0.01 & \\
\hline $\begin{array}{c}\text { Major } \\
\text { Admission Type }\end{array}$ & 9.40 & 0.00 & & 4.57 & 0.00 & & 7.37 & 0.00 & & 2.41 & 0.01 & & 2.36 & 0.01 & & 1.91 & 0.11 & \\
\hline Emergency & 0.83 & 0.08 & & 0.86 & 0.10 & & 0.60 & 0.00 & & 0.78 & 0.00 & & 0.65 & 0.00 & & 0.76 & 0.00 & \\
\hline Constant & 0.00 & 0.00 & & $\mathbf{0 . 0 0}$ & 0.00 & & 0.00 & 0.00 & & $\mathbf{0 . 0 0}$ & 0.00 & & 0.00 & 0.00 & & 0.00 & 0.00 & \\
\hline $\begin{array}{l}\mathrm{N} \\
\chi 2 \\
\end{array}$ & $\begin{array}{r}323,55 \\
1091.45 \\
\end{array}$ & $\begin{array}{l}54) \\
5\end{array}$ & & $\begin{array}{r}\mathbf{8 1 4 , 0} \\
\mathbf{8 7 7 . 0 7} \\
\end{array}$ & & & $\begin{array}{r}622 \\
1487 .\end{array}$ & $\begin{array}{l}54 \\
56) \\
\end{array}$ & & $\begin{array}{r}345 \\
1700 .\end{array}$ & $\begin{array}{l}29 \\
8(56) \\
\end{array}$ & & $\begin{array}{r}109,4 \\
438.18 \\
\end{array}$ & & & $\begin{array}{r}208,( \\
975.05 \\
\end{array}$ & $\begin{array}{l}28 \\
(56)\end{array}$ & \\
\hline
\end{tabular}

Table 4-3: Infection regression and indirect standardized rates 


\begin{tabular}{|c|c|c|c|c|c|c|c|c|c|c|c|c|c|c|c|c|c|c|}
\hline Variable & \multicolumn{3}{|c|}{ Readmission MDC1 } & \multicolumn{5}{|c|}{\begin{tabular}{|l|} 
Readmission MDC4 \\
Readmission
\end{tabular}} & \multicolumn{4}{|c|}{$\begin{array}{l}\text { MDC5 } \\
\text { Readmission MDC6 }\end{array}$} & \multicolumn{3}{|c|}{ Readmission MDC8 } & \multicolumn{3}{|c|}{ Readmission MDC11 } \\
\hline Province 2 & 1.37 & 0.00 & 1.33 & 1.04 & 0.39 & 1.01 & 0.94 & 0.29 & 0.92 & 1.16 & 0.02 & 1.13 & 1.88 & 0.00 & 1.75 & 1.24 & 0.00 & 1.21 \\
\hline Province 4 & 0.82 & 0.04 & 0.83 & 1.00 & 0.95 & 0.98 & 1.08 & 0.12 & 1.04 & 0.95 & 0.45 & 0.95 & 0.85 & 0.30 & 0.85 & 1.04 & 0.67 & 1.02 \\
\hline Province 5 & 1.12 & 0.31 & 1.11 & 0.93 & 0.26 & 0.92 & 0.90 & 0.09 & 0.89 & 1.02 & 0.83 & 1.00 & 0.77 & 0.23 & 0.79 & 0.99 & 0.95 & 0.98 \\
\hline Province 6 & 1.36 & 0.00 & 1.33 & 1.40 & 0.00 & 1.29 & 1.26 & 0.00 & 1.18 & 1.19 & 0.00 & 1.16 & 1.16 & 0.26 & 1.15 & 1.20 & 0.01 & 1.16 \\
\hline Province 7 & 0.95 & 0.55 & 0.96 & 1.00 & 0.92 & 0.97 & 0.98 & 0.61 & 0.95 & 0.98 & 0.69 & 0.98 & 1.12 & 0.39 & 1.10 & 1.03 & 0.69 & 1.02 \\
\hline Province 10 & 1.04 & 0.64 & 1.04 & 0.99 & 0.85 & 0.97 & 1.02 & 0.66 & 0.99 & 1.06 & 0.42 & 1.04 & 1(Ref) & & 1.00 & 1.00 & 0.98 & 0.99 \\
\hline Province 11 & 0.84 & 0.04 & 0.85 & 1.02 & 0.63 & 1.00 & 1.02 & 0.61 & 0.99 & 0.99 & 0.87 & 0.98 & 0.95 & 0.69 & 0.94 & 0.89 & 0.14 & 0.88 \\
\hline Province 12 & 0.78 & 0.01 & 0.80 & 0.85 & 0.00 & 0.85 & 1(Ref) & & 0.97 & 0.89 & 0.08 & 0.89 & 0.70 & 0.03 & 0.72 & 0.82 & 0.02 & 0.83 \\
\hline Province 13 & 1.26 & 0.01 & 1.24 & 1.08 & 0.11 & 1.04 & 0.91 & 0.04 & 0.90 & 1(Ref) & & 1.00 & 1.28 & 0.09 & 1.24 & 1(Ref) & & 1.00 \\
\hline Province 14 & 0.95 & 0.56 & 0.96 & 0.94 & 0.23 & 0.93 & 0.92 & 0.10 & 0.91 & 0.85 & 0.01 & 0.86 & 0.80 & 0.17 & 0.81 & 0.99 & 0.92 & 0.97 \\
\hline Province 15 & 0.91 & 0.24 & 0.92 & 0.98 & 0.69 & 0.96 & 0.94 & 0.17 & 0.92 & 0.96 & 0.38 & 0.95 & 0.93 & 0.55 & 0.93 & 0.81 & 0.00 & 0.82 \\
\hline Province 20 & 0.93 & 0.36 & 0.93 & 1.06 & 0.18 & 1.03 & 1.02 & 0.61 & 0.99 & 1.00 & 0.96 & 0.98 & 1.07 & 0.59 & 1.06 & 0.95 & 0.44 & 0.95 \\
\hline nce 21 & 1.02 & 0.86 & 1.02 & 1(Ref) & & 0.98 & 1.06 & 0.27 & 1.02 & 0.80 & 0.00 & 0.81 & 0.93 & 0.65 & 0.94 & 0.95 & 0.56 & 0.94 \\
\hline ce 22 & 0.67 & 0.00 & 0.69 & 0.87 & 0.03 & 0.88 & 0.79 & 0.00 & 0.79 & 0.71 & 0.00 & 0.73 & 0.77 & 0.08 & 0.78 & 0.99 & 0.92 & 0.98 \\
\hline ce 23 & 1.17 & 0.07 & 1.15 & 0.92 & 0.11 & 0.91 & 1.24 & 0.00 & 1.17 & 0.95 & 0.39 & 0.95 & 1.15 & 0.30 & 1.13 & 1.05 & 0.52 & 1.04 \\
\hline Province 24 & 0.89 & 0.23 & 0.90 & 1.12 & 0.02 & 1.07 & 0.94 & 0.21 & 0.92 & 1.00 & 1.00 & 0.99 & 1.13 & 0.38 & 1.12 & 0.99 & 0.90 & 0.99 \\
\hline nce 25 & 0.72 & 0.00 & 0.74 & 0.80 & 0.00 & 0.81 & 0.94 & 0.23 & 0.92 & 0.68 & 0.00 & 0.71 & 1.19 & 0.21 & 1.17 & 0.77 & 0.00 & 0.79 \\
\hline ice 26 & 1.04 & 0.66 & 1.04 & 0.93 & 0.16 & 0.92 & 1.05 & 0.37 & 1.01 & 1.03 & 0.62 & 1.02 & 1.03 & 0.86 & 1.03 & 0.94 & 0.50 & 0.94 \\
\hline Province 27 & 1(Ref) & & 1.00 & 1.03 & 0.55 & 1.00 & 0.91 & 0.07 & 0.89 & 1.06 & 0.35 & 1.04 & 1.12 & 0.41 & 1.10 & 1.09 & 0.28 & 1.06 \\
\hline Province 28 & 0.98 & 0.82 & 0.99 & 0.96 & 0.30 & 0.95 & 0.96 & 0.24 & 0.94 & 0.97 & 0.43 & 0.96 & 0.98 & 0.86 & 0.98 & 1.00 & 1.00 & 0.99 \\
\hline ice 29 & 0.58 & 0.00 & 0.60 & 0.76 & 0.00 & 0.77 & 0.87 & 0.00 & 0.86 & 0.87 & 0.02 & 0.88 & 1.04 & 0.76 & 1.04 & 0.88 & 0.08 & 0.88 \\
\hline Province 30 & 1.05 & 0.55 & 1.04 & 1.03 & 0.50 & 1.00 & 1.02 & 0.59 & 0.99 & 1.03 & 0.51 & 1.02 & 1.02 & 0.87 & 1.02 & 1.07 & 0.25 & 1.05 \\
\hline nce 31 & 0.76 & 0.00 & 0.78 & 0.92 & 0.09 & 0.91 & 0.85 & 0.00 & 0.84 & 0.82 & 0.00 & 0.83 & 0.57 & 0.00 & 0.65 & 0.91 & 0.26 & 0.91 \\
\hline Province 41 & 0.97 & 0.69 & 0.97 & 0.92 & 0.07 & 0.91 & 0.91 & 0.03 & 0.90 & 0.84 & 0.00 & 0.85 & 0.93 & 0.55 & 0.92 & 0.96 & 0.51 & 0.94 \\
\hline Province 42 & 1.20 & 0.17 & 1.18 & 0.95 & 0.53 & 0.94 & 1.10 & 0.15 & 1.07 & 0.97 & 0.73 & 0.96 & 0.99 & 0.94 & 1.00 & 1.13 & 0.34 & 1.12 \\
\hline Province 43 & 0.75 & 0.00 & 0.76 & 0.97 & 0.54 & 0.95 & 1.02 & 0.68 & 0.99 & 0.97 & 0.54 & 0.96 & 0.69 & 0.01 & 0.70 & 0.89 & 0.11 & 0.90 \\
\hline
\end{tabular}




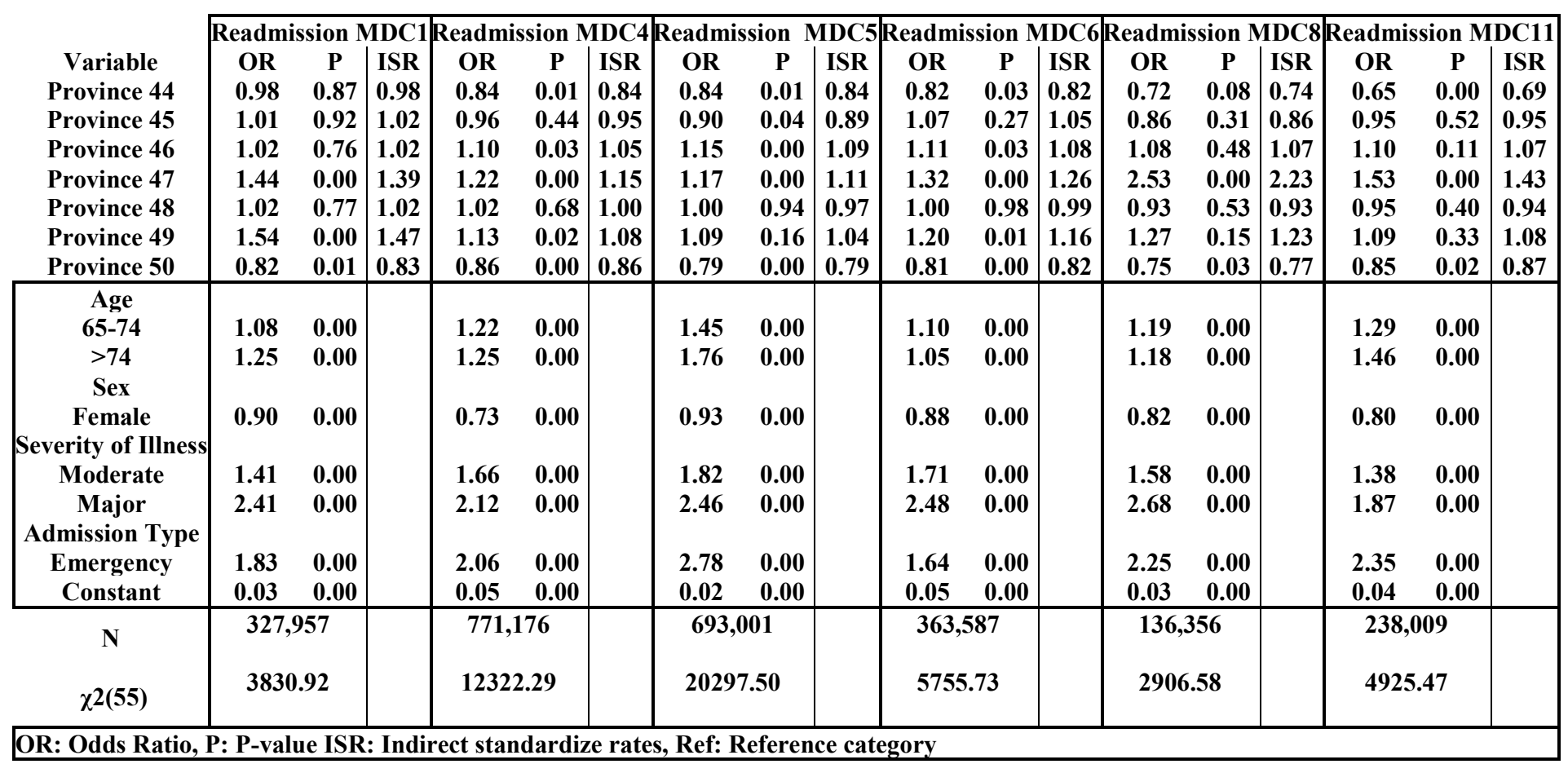

Table 4-4: regression and indirect standardized rates of Readmissions 
Table 4-5 shows the correlations between the standardised rates (the regression rates presented in Tables 4-1 to 4-4). As depicted in the table, most of the significant correlations are those between the variables associated to the MDCs for a given indicator. This suggests that the standardised rates of the six MDCs can construct a factor for each indicator. This is confirmed by high values of Cronbach's alpha indicating significant homogeneity. It is worth mentioning that there are significant positive correlations between mortality rate and readmission rates for some MDCs. As these correlations are between adjusted rates, the correlations may imply that provinces that are not performing well in terms of mortality rate are also less successful in optimizing patients' stay (for instance lack of end-of-life planning). The correlations between readmissions and length of stay are not statistically significant but the signs are negative for almost all the MDCs. This may

favour the speculation that shortening the length of stay may introduce advert impact on readmission rates. Table 4-6.a gives the $E Q_{5-95}$ and SCVs for the indicators in the six selected diagnostic groups. 


\begin{tabular}{|c|c|c|c|c|c|c|c|c|c|c|c|c|c|c|c|c|c|c|c|c|c|c|c|c|}
\hline & 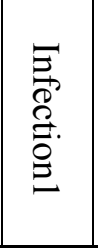 & 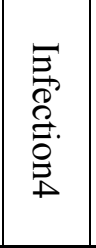 & 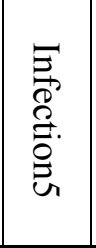 & 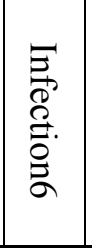 & 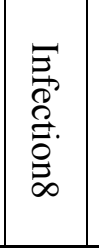 & 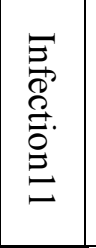 & $\begin{array}{l}3 \\
\stackrel{3}{2} \\
\stackrel{2}{2} \\
\stackrel{\Xi}{\Xi}\end{array}$ & 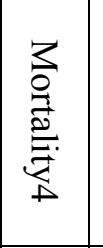 & 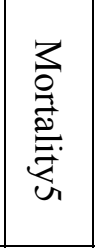 & 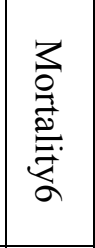 & 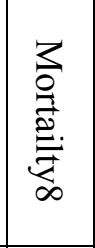 & 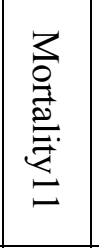 & 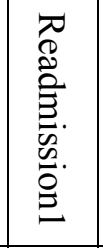 & 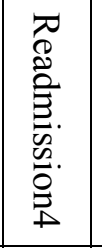 & 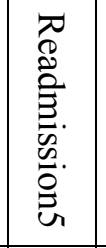 & 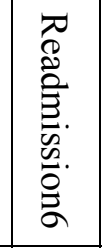 & 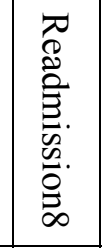 & 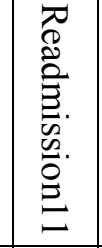 & 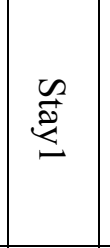 & 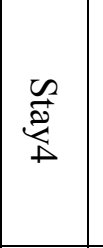 & 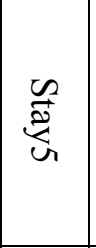 & 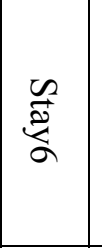 & $\underset{\infty}{\stackrel{\infty}{\Perp ્ \infty}}$ & 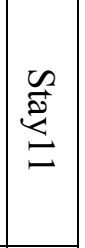 \\
\hline Infection1 & 1.00 & & & & & & & & & & & & & & & & & & & & & & & \\
\hline Infection4 & 0.37 & 1.00 & & & & & & & & & & & & & & & & & & & & & & \\
\hline Infection5 & $0.52 *$ & $0.60 *$ & 1.00 & & & & & & & & & & & & & & & & & & & & & \\
\hline Infection6 & 0.47 & $0.66 *$ & $0.66 *$ & 1.00 & & & & & & & & & & & & & & & & & & & & \\
\hline Infection8 & 0.36 & 0.30 & 0.35 & 0.35 & 1.00 & & & & & & & & & & & & & & & & & & & \\
\hline Infection11 & 0.29 & 0.38 & 0.38 & 0.42 & 0.38 & 1.00 & & & & & & & & & & & & & & & & & & \\
\hline Mortality1 & -0.07 & -0.09 & -0.31 & -0.12 & -0.11 & -0.10 & 1.00 & & & & & & & & & & & & & & & & & \\
\hline Mortality4 & -0.03 & 0.09 & $\mid-0.17$ & 0.07 & 0.07 & 0.02 & $0.69 *$ & 1.00 & & & & & & & & & & & & & & & & \\
\hline Mortality5 & -0.09 & -0.02 & -0.13 & 0.01 & 0.02 & -0.10 & $0.61 * 0$ & $0.76 *$ & 1.00 & & & & & & & & & & & & & & & \\
\hline Mortality6 & 0.11 & 0.08 & -0.10 & 0.02 & -0.03 & -0.13 & $0.67 * 0$ & $0.72 *$ & $0.58 *$ & 1.00 & & & & & & & & & & & & & & \\
\hline Mortality8 & -0.05 & 0.01 & -0.05 & -0.07 & 0.03 & 0.08 & 0.43 & $0.63 *$ & $0.65 *$ & 0.48 & 1.00 & & & & & & & & & & & & & \\
\hline Mortality11 & 0.15 & 0.09 & -0.11 & 0.05 & $0.16-$ & -0.04 & $0.65 * 0$ & $0.81 *$ & $0.63 *$ & $0.84 *$ & $0.55 *$ & 1.00 & & & & & & & & & & & & \\
\hline Readmission1 & -0.02 & -0.07 & -0.12 & -0.14 & $4-0.12$ & -0.09 & 0.04 & -0.14 & -0.21 & -0.06 & -0.09 & -0.09 & 1.00 & & & & & & & & & & & \\
\hline Readmission4 & -0.02 & -0.20 & -0.05 & -0.05 & -0.13 & -0.06 & -0.03 & -0.06 & -0.18 & 0.03 & -0.07 & 0.10 & $0.70 *$ & 1.00 & & & & & & & & & & \\
\hline Readmission5 & -0.03 & -0.27 & -0.01 & -0.02 & $2-0.13$ & -0.34 & -0.03 & -0.07 & -0.02 & 0.06 & -0.07 & 0.02 & $0.57 *$ & $0.62 *$ & * 1.00 & & & & & & & & & \\
\hline Readmission6 & \begin{tabular}{|l|}
0.09 \\
\end{tabular} & 0.11 & 0.07 & -0.06 & $6-0.18$ & \begin{tabular}{|l|}
-0.13 \\
\end{tabular} & -0.01 & -0.06 & -0.15 & 0.11 & -0.04 & 0.01 & $0.74 *$ & $0.60 * 1$ & $* 0.55 *$ & * 1.00 & & & & & & & & \\
\hline Readmission 8 & -0.07 & -0.03 & 0.04 & -0.07 & $7-0.11$ & \begin{tabular}{|l|}
-0.09 \\
\end{tabular} & -0.07 & -0.12 & -0.04 & -0.21 & 0.05 & -0.13 & $0.55 *$ & 0.45 & 0.38 & 0.46 & 1.00 & & & & & & & \\
\hline Readmission11 & 0.01 & -0.09 & -0.06 & -0.12 & $2-0.11$ & -0.12 & -0.08 & -0.03 & -0.14 & -0.12 & 0.13 & 0.01 & $0.66^{*}$ & $0.63 *$ & * 0.49 & $0.64 *$ & * $0.61 *$ & * 1.00 & & & & & & \\
\hline Stay1 & 0.18 & 0.26 & 0.12 & 0.12 & 0.04 & 0.02 & 0.37 & 0.44 & 0.24 & 0.43 & 0.39 & 0.42 & -0.29 & -0.15 & -0.27 & -0.09 & -0.11 & -0.23 & 1.00 & & & & & \\
\hline Stay4 & 0.23 & 0.25 & 0.14 & 0.03 & 0.16 & 0.13 & 0.45 & $0.54 *$ & 0.40 & 0.47 & 0.39 & $0.55 *$ & -0.16 & -0.21 & -0.30 & -0.03 & -0.04 & $4-0.19$ & $0.72 *$ & 1.00 & & & & \\
\hline Stay5 & 0.21 & 0.21 & 0.17 & 0.18 & 0.13 & 0.17 & 0.37 & 0.48 & 0.32 & 0.40 & 0.29 & 0.43 & -0.20 & -0.17 & -0.30 & -0.10 & -0.08 & -0.07 & $0.60 * 0$ & $0.75^{*}$ & 1.00 & & & \\
\hline Stay6 & 0.16 & 0.24 & 0.02 & 0.18 & 0.10 & 0.04 & 0.46 & $0.64 *$ & 0.34 & $0.60 *$ & 0.40 & $0.61 *$ & -0.15 & -0.01 & -0.16 & 0.06 & -0.05 & -0.12 & $0.75 * \mathrm{C}$ & $0.72 * 0$ & $0.65 *$ & 1.00 & & \\
\hline Stay8 & 0.22 & 0.25 & 0.23 & 0.32 & 0.28 & 0.14 & 0.29 & 0.35 & 0.14 & 0.37 & 0.12 & 0.46 & -0.24 & -0.04 & - -0.09 & -0.21 & -0.20 & -0.35 & $0.58 * 0$ & $0.58 * 0$ & $0.53 * 0$ & $0.58 *$ & 1.00 & \\
\hline Stay11 & 0.21 & 0.24 & 0.15 & 0.17 & 0.30 & 0.21 & $\mid 0.43$ & $\mid 0.48$ & 0.36 & 0.49 & 0.46 & $0.59 *$ & $\mid-0.10$ & 0.01 & -0.21 & -0.08 & 0.01 & -0.08 & $0.72 * 0$ & $0.80 * 0$ & $0.69 * 0$ & $0.71 * 0$ & $0.67 *$ & 1.00 \\
\hline \multicolumn{25}{|c|}{ * Bonferroni p-value $<0.05$} \\
\hline Cronbach alpha & \multicolumn{6}{|c|}{0.82} & \multicolumn{6}{|c|}{0.91} & \multicolumn{6}{|c|}{0.87} & \multicolumn{6}{|c|}{0.92} \\
\hline
\end{tabular}

Table 4-5: Cronbach alpha values and correlations between the standardized rates 


\begin{tabular}{|c|c|c|c|c|c|c|c|}
\hline & \multirow{2}{*}{$\begin{array}{l}\text { Average length of } \\
\text { stay }\end{array}$} & \multicolumn{2}{|c|}{ Mortality Rate } & \multicolumn{2}{|c|}{ Readmission Rate } & \multicolumn{2}{|c|}{$\begin{array}{c}\text { Hospital- } \\
\text { Acquired Infection } \\
\text { Rate }\end{array}$} \\
\hline & & $E Q_{5-95}$ & $\begin{array}{l}\text { SCV } \\
(\times 10)\end{array}$ & $E Q_{5-95}$ & $\begin{array}{l}\text { SCV } \\
(\times 10)\end{array}$ & $E Q_{5-95}$ & $\begin{array}{c}\text { SCV } \\
(\times 10)\end{array}$ \\
\hline MDC 1 & 1.77 & 1.94 & 0.38 & 2.30 & 0.62 & 6.69 & 5.11 \\
\hline MDC 4 & 1.54 & 2.73 & 0.84 & 1.52 & 0.17 & 4.75 & 4.67 \\
\hline MDC 5 & 1.60 & 2.06 & 0.49 & 1.50 & 0.15 & 4.94 & 2.64 \\
\hline MDC 6 & 1.40 & 2.39 & 0.89 & 1.69 & 0.29 & 6.97 & 3.72 \\
\hline MDC 8 & 1.64 & 2.72 & 0.96 & 2.56 & 0.97 & 1.83 & 1.14 \\
\hline MDC 11 & 1.57 & 2.35 & 0.76 & 1.67 & 0.20 & 3.54 & 2.93 \\
\hline
\end{tabular}

a)

\begin{tabular}{|c|c|c|c|c|}
\hline & $\begin{array}{c}\text { Average length } \\
\text { of stay }\end{array}$ & $\begin{array}{c}\text { Mortality } \\
\text { Rate }\end{array}$ & $\begin{array}{c}\text { Readmission } \\
\text { Rate }\end{array}$ & $\begin{array}{c}\text { Hospital- } \\
\text { Acquired } \\
\text { Infection Rate }\end{array}$ \\
\hline $\begin{array}{c}\text { Box's } \\
\text { epsilon P- } \\
\text { value }\end{array}$ & 0.058 & 0.351 & 0.805 & 0.099 \\
\cline { 2 - 5 } & 0.131 (MDC 1,4,5,6 and 8) & & 0.1713 (MDC 1,4,5,6, and 11) \\
\hline
\end{tabular}

b)

Table 4-6: a) $E Q_{5-95}$ And SCV ratios b) Repeated ANOVA results

As shown in Table 4-6, the $E Q_{5-95}$ has the highest value for the indicator of hospital-acquired infections corresponding to diseases of the digestive system (MCD6). This shows an almost seven-fold difference across all the provinces of Spain, while the difference for diseases of the nervous system (MCD1) has the highest SCV value. Results also show that the size in variation is as high as two-fold for mortality rates in 
most diagnostic categories, while the average length of hospital stay and readmission rate vary less across the country.

Table 4-6 also depicts the result of the repeated measures ANOVA. Considering the 0.05 confidence level, the ANOVA test indicate that the mean values of the indicator are not different across the six MDCs. The p-values for infections rate and average length of stay are rather close to the cut off threshold. However, if we leave out the MDC11 in average length of stay and MDC8 in Infections rates the p-value increases significantly. This means that we can safely assume the similarity of means of average length of stay and infections rates for at least 5 out of 6 MDCs.

Table 4-7 shows the mean values of the indicators for the three clusters presented for the six MDCs.

By comparing the mean values of the indicators, the performance of the provinces aggregated by cluster (Table 4-7) does not vary significantly across the six MDCs. For instance, the mean values for average length of stay for Cluster 1 are 3.66, 4.22, 4.05, 4.11, 3.88 and 4.11 for MDCs 1, 4, 5, 6 and 11, respectively. All the values are slightly below that of the average pattern (which is 5). This pattern is the same for most of the other clusters and indicators. It follows that, if any region has higher (or lower) value than the average for an indicator associated to a given MDC, then the values of all the other MDCs relating to the same indicator in that region are also higher (or lower) than the average value which is also in accordance with the ANOVA results. 


\begin{tabular}{|c|c|c|c|c|}
\hline & $\begin{array}{c}\text { Average } \\
\text { Length of Stay }\end{array}$ & Mortality Rate & $\begin{array}{l}\text { Readmission } \\
\text { Rate }\end{array}$ & $\begin{array}{c}\text { Hospital- } \\
\text { Acquired } \\
\text { Infection Rate }\end{array}$ \\
\hline & \multicolumn{4}{|c|}{ MDC 1 (Diseases of the Nervous System) } \\
\hline Cluster 1 & 3.66 & 3.77 & 5.27 & 4.77 \\
\hline Cluster 2 & 6 & 5.47 & 4.82 & 4.17 \\
\hline \multirow[t]{2}{*}{ Cluster 3} & 5.46 & 5.8 & 4.73 & 6.53 \\
\hline & \multicolumn{4}{|c|}{ MDC 4 (Diseases of the Respiratory System) } \\
\hline Cluster 1 & 4.22 & 2.88 & 5.11 & 3.77 \\
\hline Cluster 2 & 6.11 & 5.05 & 5 & 3.58 \\
\hline \multirow[t]{2}{*}{ Cluster 3} & 5.86 & 6.8 & 5.06 & 6.53 \\
\hline & \multicolumn{4}{|c|}{ MDC 5 (Diseases of the Circulatory System) } \\
\hline Cluster 1 & 4.05 & 3.88 & 5.27 & 4.22 \\
\hline Cluster 2 & 5.70 & 5.11 & 4.70 & 2.88 \\
\hline \multirow[t]{2}{*}{ Cluster 3} & 5.73 & 6.53 & 5.2 & 5.93 \\
\hline & \multicolumn{4}{|c|}{ MDC 6 (Diseases of the Digestive System) } \\
\hline Cluster 1 & 4.11 & 2.66 & 5.11 & 3.88 \\
\hline Cluster 2 & 5.70 & 5.29 & 4.76 & 2.17 \\
\hline \multirow[t]{2}{*}{ Cluster 3} & 5.73 & 6.66 & 5 & 6.73 \\
\hline & \multicolumn{4}{|c|}{$\begin{array}{c}\text { MDC } 8 \text { (Diseases and Disorders of the Musculoskeletal System and } \\
\text { Connective Tissue) }\end{array}$} \\
\hline Cluster 1 & 3.88 & 3.66 & 4.94 & 5 \\
\hline Cluster 2 & 5.47 & 5.47 & 4.76 & 5 \\
\hline \multirow[t]{2}{*}{ Cluster 3} & 5.73 & 6.93 & 4.6 & 5.8 \\
\hline & \multicolumn{4}{|c|}{ MDC 11 (Diseases of the Kidney and Urinary Tract) } \\
\hline Cluster 1 & 4.11 & 3 & 5.33 & 4.55 \\
\hline Cluster 2 & 6.11 & 5.70 & 4.76 & 4.23 \\
\hline Cluster 3 & 6.2 & 7.06 & 4.93 & 5.53 \\
\hline
\end{tabular}

Table 4-7: Cluster means for the individual MDCs

Figure 4-1 shows the comparison between performances in the clusters for the four indicators. The Scheffé test was performed on each of the indicators to assess whether the mean values of the indicators vary significantly from cluster to cluster. The results show that there are no significant differences among the readmissions rates between the three clusters. 


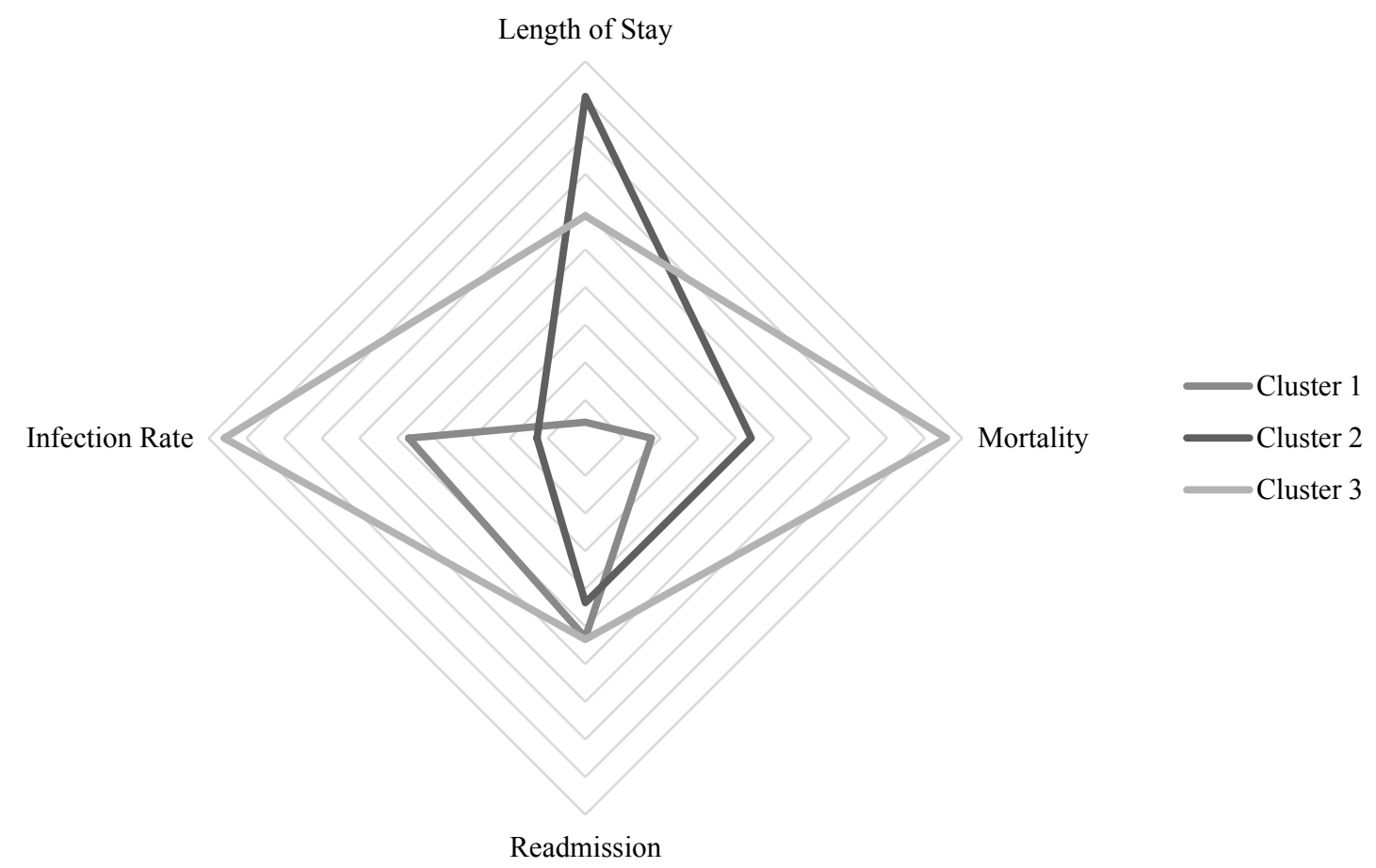

a) radar chart for the mean values of the indicators

\begin{tabular}{|c|c|c|c|c|}
\hline & Mortality & Readmission & Length of Stay & $\begin{array}{c}\text { Hospital } \\
\text { Acquired } \\
\text { Infection }\end{array}$ \\
\hline Cluster 1 & Lower Rate & Average Rate & Lower Rate & Lower Rate \\
\hline Cluster 2 & Lower Rate & Average Rate & Higher Rate & Lowest Rate \\
\hline Cluster 3 & Higher Rate & Average Rate & Average Rate & Higher Rate \\
\hline
\end{tabular}

b) comparison of performance for the three clusters; same levels (lower, average, etc.) in the table indicate that the means of the clusters for the corresponding indicator are not significantly different according to the Scheffé test ( $\mathrm{P}$-value $>0.05)$. 


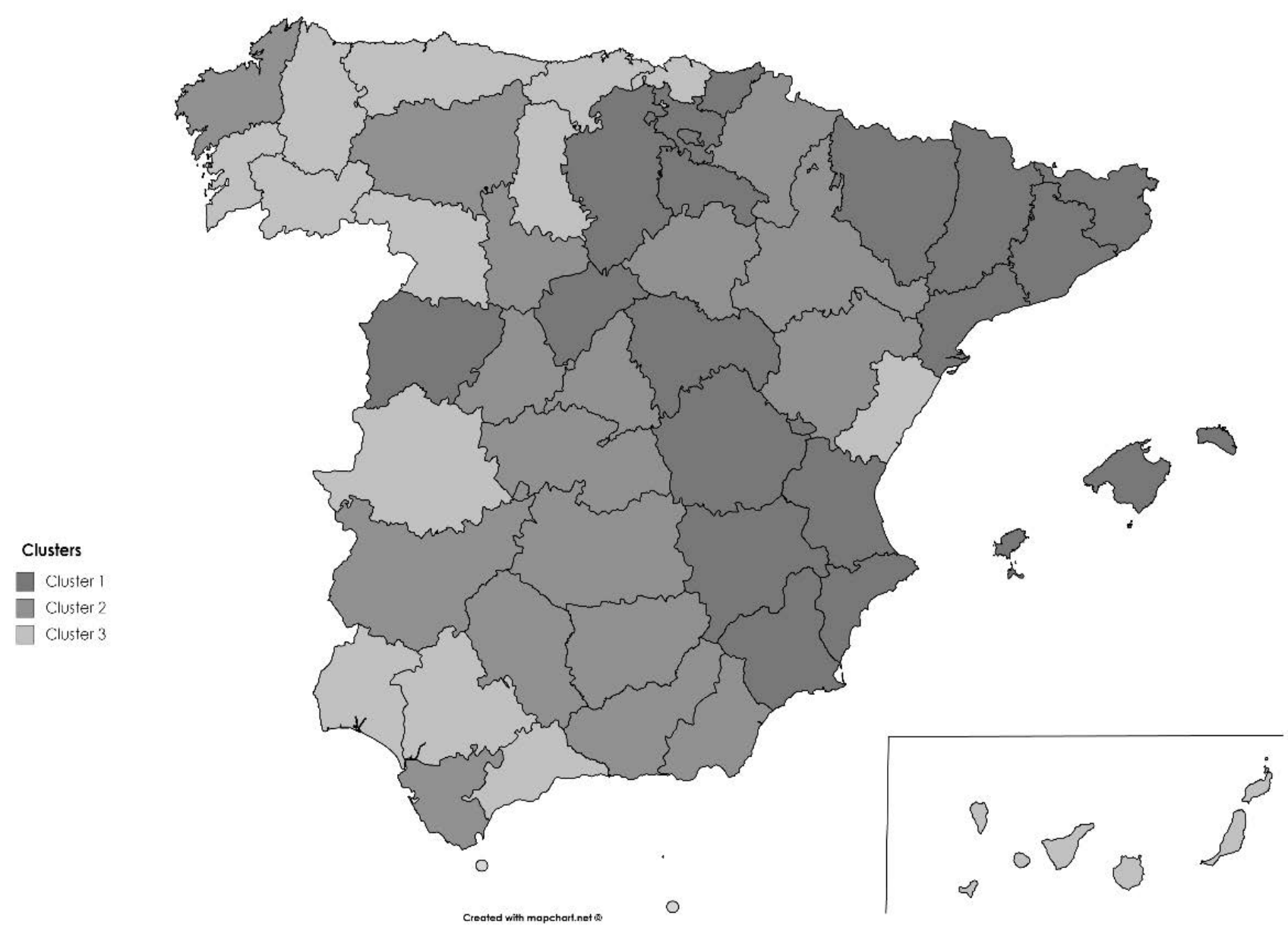

c) Map of the Spanish provinces distinguished by cluster

\section{Figure 4-1: Performance of the clusters for the four indicators}

Comparing the mean values of the four indicators across the clusters (Figure 4-1) reveals the specific patterns associated to each cluster. Cluster 1 includes provinces with high performing healthcare systems, as their values are close or lower than the average for all the performance indicators. The provinces in Cluster 2 perform worse for average length of stay, while they perform best for hospital-acquired infection rates and readmission rates. Cluster 3 includes provinces that perform below average for both mortality rates and hospital-acquired infection rates. 


\subsubsection{Discussion}

Healthcare is going through difficult time. Aging populations and rising prevalence of chronic disease mandates higher quality and accessible care (Correia et al., 2015). On the other hand, the substantially increasing of health expenditure is forcing the healthcare policy makers and managers to do more with less resources (Thomson et al., 2014).

Detection and reduction of the unnecessary and unwarranted variations in care provision is one of the promising paths towards more equitable and accessible healthcare. Policy interventions, resource allocation and planning are the tools used by the decision makers in order to drive the level of the "bad" variations to a minimum. Designing effective policy interventions is conditional on uncovering the variations and their influencing factors. In this thesis, we help decision makers to reach this goal by identifying both the magnitude of variations as well as their associated factors.

In secondary care setting, our results suggest that the adjusted rates of each indicator in the 6 MDCs are highly correlated and construct a single factor. Moreover, ANOVA test shows that the relative performances of the indicators are similar across the MDCs. This outcome is aligned with the findings of Tsai et. al. showing similar patterns for surgical readmission rates in high and low performing hospitals for six examined surgical procedures (Tsai et al., 2013). This demonstrates that the regions (provinces) are performing similar in different diagnostic categories. Consequently, we assert that the influencing factors are similar across the diagnostic categories. In other words, the associated factors related to the unwarranted variations in regional level are not dependent on the diagnostic categories. This has important policy implications for reducing the unwarranted variations. For the considered outcome indicators, policy makers at the regional level should prioritize indicator-specific interventions rather than the disease specific ones. Lewis and Edwards (2015) identified several indicator-specific interventions that can reduce

the patients' length of stay, including: the patient progress tracking systems in real-time; effective 
discharge planning; active support for discharged patients seven days a week; end-of-life planning (Lewis and Edwards, 2015). For interventions such as patient progress tracking in real-time, health information systems also play an important role as the real-time tracking of patients are dependent on information systems that can keep and update the patients' status automatically and instantly. This indicates that information systems such as BI can have direct effect on unwarranted variations reduction.

Among the included outcome indicators, our study asserts that hospital acquired infection rates have the highest variation across the regions (as high as 7 fold in digestive system diseases). This suggests that inpatients' infections should be one of the top priorities for healthcare decision makers in Spain. This is especially important because healthcare associated infections are considered as a significant public health problem and a threat to the safety of patients (Zimlichman et al., 2013). On the other hand, hospitalacquired infection rates can affect both mortality and average length of stay (Ott et al., 2013) and, given that Cluster 3 (lower performance) rates are highest for this indicator, it raises the question of whether the high mortality rates found in the provinces of this cluster is caused by their low performance or high infection rates. In Europe, the national rates of healthcare associated infections vary from $2.3 \%$ to $10.8 \%$ (including surgical infections) moreover, underreporting, unavailability of diagnostic tests and different coding systems contribute to variations in the observed rates (European Centre for Disease Prevention and Control, 2013). Although we aggregated patient admission data for a three-year period to achieve more robust estimations, there were still few provinces with small numbers or no reported infections for a given MDC. Thus, this finding is a "tin opener" that uncovers the potential problems and calls for further indepth investigations and actions (Carter et al., 2002)

Using clustering analyses, we identified three distinct groups of regions. The performances of the three clusters are different in length of stay, mortality and infection rates while they have similar readmission rates. It is interesting to note that the best performing cluster (Cluster 1) has low or average rates in all 
the performance indicators. These performance variations imply the potentials for improvements (Lewis and Edwards, 2015). In particular, it is possible to lower the length of stay in the other two clusters without adverse impacts in readmission, mortality or infection rates. As mentioned before, variations in length of stay are in supply-sensitive category and consequently, they provide opportunities for disinvestments. On the other hand, there is a growing concern in the literature that cost-driven incentives to reduce the average time patients spend in hospital may impair their medical outcome, leading to, for example, higher rates of readmission(Li et al., 2013). Thus, designing the guidelines and/or interventions targeting the length of stay should be performed attentively. Very short lengths of stay may affect health outcome negatively and even increase the overall cost of treatment (OECD, 2011; Saczynski et al., 2010). For instance, according to Lazar et al.(2001), the reduced average length of stay is associated with significant increase in the risk of readmission for patients who underwent a coronary artery bypass graft. In contrast, some studies found that shorter average lengths of stay are not correlated with a higher risk of readmission (Bohmer et al., 2002; Engelman et al., 1994; Saczynski et al., 2010) or mortality (Saczynski et al., 2010).

Considering the mixed findings reported, it is reasonable to argue that reducing the average length of stay to a given threshold may benefit overall efficiency in hospitals, but any further decrease below this threshold increases the risk of negative patient outcome. For instance, Freeman et al.(2013) observed that the relationship between length of stay and readmission rate for lung cancer patients constructs a U-shaped curve. Comparing the indicators corresponding to Cluster 1 and Cluster 2, we see that, for the provinces in Cluster 1, the average lengths of stay are significantly shorter, with no increases in readmission or mortality rates. This suggests that Clusters 2 and 3 still have the potential to reduce their average length of stay without any adverse outcomes, in the form of higher risk of readmission or mortality. In other words, the current level of length of stay in cluster 1 provides an estimate for such threshold that can be applied to clusters 2 and 3. 
The longer length of stay can be interpreted as the overuse of the resources (hospital beds, workforce, etc.)(Nuti et al., 2010). An important factor - both in private and public healthcare systems (Keyhani et al., 2013) - contributing to the overuse is the mismatch between allocated resources and the populations needs (Basu et al., 2012; Saini et al., 2017). Thus, the higher than average length of stay, especially in provinces of Cluster 2, may be controlled by disinvestments in the relevant resources. As suggested by Nuti et al. (2010) for the length of stay of medical DRGs, the amount of these disinvestments can be practically calculated as the total direct cost of avoidable inpatients bed-days. Specifically, the gap between the length of stay of Cluster 2 and Cluster 1 is estimated in terms of avoidable in-patients bed days. These saving then can be reallocated to improve other indicators (e.g., hospital acquired infections) or can be redirected to other provinces.

Our results also show that the Clusters have no substantial difference on the difference in readmission rates. This is consistent with the findings of some of the previous studies (Krumholz et al., 2009; Singh et al., 2014), asserting that the patients' characteristics are mainly responsible for variations in the readmission rates and only a small proportion of these variations depend on the care providers' performance. Similarly, Herrin et al.(2015) assert that only a small part of the variation is due to differences in hospital performance, and community factors such as socio-economic status, physician mix and nursing home quality are the principle variables explaining the variations in risk of readmission. However, similar performance in terms of readmission could be because all provinces are performing equally badly and improvements are still necessary (Krumholz et al., 2009). 


\subsubsection{Performance Patterns in Primary Care: Results}

The results of the secondary care performance indicators were presented in the previous subsection. The following paragraph depict the results of the analyses (See Section 3.1.2) performed to evaluate the performance of the Spanish primary care in terms of the potentially avoidable hospitalizations.

The descriptive statistics of the variables (See Section 3.1.2.1) are given in Figure 4-2. On comparing the national averages for ACSC admission rates in 2007 and 2015, we can see that, while COPD admission rates in 2015 were similar to those in 2007, CHF and BP hospitalizations increased by $20 \%$ and $19 \%$, respectively. Figure 4-2 also shows the trends for admissions relating to the three conditions over the years. As the figure shows, CHF hospitalizations started to increase in 2007, while the trend for COPD and BP admissions grew from 2013 to 2015.

\begin{tabular}{l|cccccc} 
& \multicolumn{3}{c}{ All years } & \multicolumn{2}{c}{2007} & \multicolumn{2}{c}{2015} \\
\hline & Mean & S.D. & Mean & S.D. & Mean & S.D. \\
COPD & 18.19 & 5.41 & 19.11 & 5.83 & 19.22 & 5.31 \\
CHF & 14.67 & 2.95 & 13.68 & 3.10 & 16.48 & 3.24 \\
BP & 12.47 & 2.73 & 12.00 & 2.58 & 14.24 & 3.25 \\
GP consultations per capita & 5.60 & 1.23 & 5.79 & 1.39 & 5.38 & 1.05 \\
Nurse consultations per capita & 2.85 & 0.75 & 2.75 & 1.07 & 2.87 & 0.67 \\
Specialist consultations per capita & 1.88 & 0.25 & 1.70 & 0.22 & 2.04 & 0.28 \\
primary care expenditure & 14.48 & 1.81 & 14.51 & 2.07 & 13.94 & 1.69 \\
GP visits as a proportion of total population & 71.90 & 5.18 & 72.27 & 4.79 & 71.07 & 5.49 \\
Specialist visits as a proportion of t. population & 45.14 & 4.60 & 43.76 & 5.03 & 43.98 & 5.12 \\
GP treatment perceived quality & 7.66 & 0.36 & 7.45 & 0.39 & 7.69 & 0.30 \\
GP visit waiting time & 6.66 & 0.53 & 6.51 & 0.71 & 6.83 & 0.39 \\
Specialist visit waiting time & 4.86 & 0.53 & 4.80 & 0.69 & 4.90 & 0.41 \\
Lifestyle advice & 7.43 & 0.40 & 7.20 & 0.42 & 7.47 & 0.26 \\
Private to public hospital beds ratio & 0.40 & 0.26 & 0.36 & 0.18 & 0.41 & 0.27 \\
Hospitalization rate & 116.6 & 16.14 & 116.94 & 14.89 & 117.96 & 17.64 \\
Education & 46.16 & 8.11 & 50.06 & 7.79 & 42.32 & 7.81 \\
Average household income & 27.46 & 4.34 & 28.27 & 4.01 & 26.71 & 4.18 \\
Unemployment rate & 18.54 & 7.41 & 2.44 & 4.75 & 20.75 & 5.54
\end{tabular}

a) Descriptive statistics of the variables included in the model 


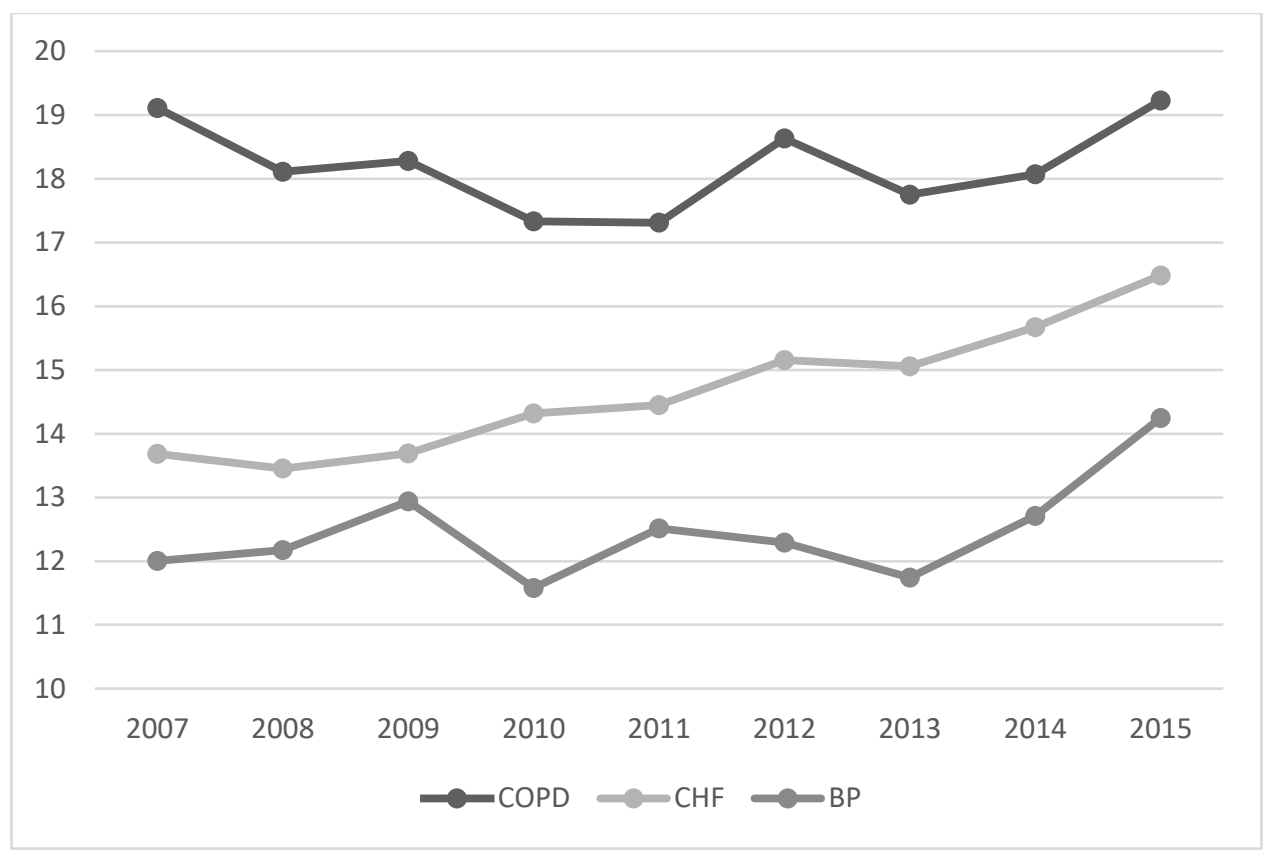

b) The average standardised ACSC admissions from 2007 to 2015. source: Spanish Ministry of Health (averages calculated by the authors)

Figure 4-2: Descriptive statistics and the patterns of the hospitalizations through the years

Tables 4-8 to 4-10 present the coefficients and the 95 percent confidence intervals in the fixed effects models for $\mathrm{COPD}, \mathrm{CHF}$ and $\mathrm{BP}$ admission rates. Higher GP and specialist consultations per capita are significantly associated to a decrease in COPD hospitalizations, while higher nurse consultations per capita are associated to an increase in admissions rates. Patient satisfaction with GP advice on lifestyle is another factor that is associated with lower COPD admission rates.

Higher GPs consultations per capita are related to lower CHF admissions. Considering a 90\% confidence level, the patients' satisfaction in their treatment $(\mathrm{P}$-value $=0.096)$ is another explanatory variable that contributes to fewer hospitalizations. At the same time, there were higher admission rates in regions where patients are more satisfied with the waiting time to see their GP. 
Reflecting the other two conditions, more GP consultations per capita $(\mathrm{P}$-value $=0.058)$ are associated to a decrease in BP admission rates. Satisfaction with GP treatment and the proportion of population that consults specialists are also linked to a reduced number of BP hospitalizations. Similar to COPD, the BP hospitalization rates are lower in regions that patients are more satisfied with the GPs' advice on lifestyle. 


\begin{tabular}{|c|c|c|c|}
\hline \multirow{2}{*}{$\begin{array}{l}\text { COPD } \\
\text { GP consultations per capita }\end{array}$} & \multirow{2}{*}{$\begin{array}{l}\text { Coefficient } \\
-1.06^{* *}\end{array}$} & \multicolumn{2}{|c|}{ 95\% Confidence Intervals } \\
\hline & & -2.00 & -0.11 \\
\hline Nurse consultations per capita & $1.18^{* *}$ & 0.12 & 2.25 \\
\hline Specialist consultations per capita & $-2.65^{* * *}$ & -4.19 & -1.10 \\
\hline PRIMARY CARE expenditure & -0.12 & -0.54 & 0.29 \\
\hline GP visits as a proportion of total population & -0.04 & -0.14 & 0.07 \\
\hline $\begin{array}{l}\text { Specialist visits as a proportion of tot. } \\
\text { population }\end{array}$ & 0.04 & -0.07 & 0.16 \\
\hline GP treatment perceived quality & 1.57 & -1.08 & 4.21 \\
\hline GP visit waiting time & 1.14 & -0.51 & 2.78 \\
\hline Specialist visit waiting time & -0.01 & -2.14 & 2.12 \\
\hline Lifestyle advice & $-2.05^{* *}$ & -4.01 & -0.08 \\
\hline Private to public hospital beds ratio & -1.98 & -9.91 & 5.95 \\
\hline Hospitalization rate & 0.03 & -0.06 & 0.11 \\
\hline Education & $-0.18^{*}$ & -0.39 & 0.03 \\
\hline Average household income & 0.10 & -0.21 & 0.41 \\
\hline Unemployment rate & $-0.12^{* *}$ & -0.24 & -0.01 \\
\hline Constant & 29.27 & 3.19 & 55.35 \\
\hline $\begin{array}{l}\mathrm{N}=151 ; \mathrm{R}^{2}=0.94 ; \mathrm{F} \text {-test }(\text { model }) \mathrm{P} \text {-value }<0.001 \\
{ }^{*} \mathrm{P} \text {-value }<0.1 ;{ }^{*} \mathrm{P} \text {-value }<0.05 ; * * \mathrm{P} \text {-value }<\end{array}$ & & & \\
\hline
\end{tabular}

Table 4-8: Fixed effects regression for COPD admission rates 


\begin{tabular}{|c|c|c|c|}
\hline \multirow{2}{*}{$\begin{array}{l}\text { CHF } \\
\text { GP consultations per capita }\end{array}$} & \multirow{2}{*}{$\begin{array}{l}\text { Coefficient } \\
-0.48^{* *}\end{array}$} & \multicolumn{2}{|c|}{ 95\% Confidence Intervals } \\
\hline & & -0.96 & -0.01 \\
\hline Nurse consultations per capita & 0.54 & -0.27 & 1.36 \\
\hline Specialist consultations per capita & 0.35 & -1.14 & 1.84 \\
\hline Primary Care expenditure & 0.01 & -0.19 & 0.21 \\
\hline GP visits as a proportion of total population & 0.00 & -0.04 & 0.03 \\
\hline $\begin{array}{l}\text { Specialist visits as a proportion of tot. } \\
\text { population }\end{array}$ & -0.05 & -0.11 & 0.01 \\
\hline GP treatment perceived quality & $-1.55^{*}$ & -3.40 & 0.31 \\
\hline GP visit waiting time & $1.20^{* *}$ & 0.33 & 2.07 \\
\hline Specialist visit waiting time & -0.15 & -0.71 & 0.40 \\
\hline Lifestyle advice & 0.11 & -1.79 & 2.02 \\
\hline Private to public hospital beds ratio & $-3.76^{* * *}$ & -6.30 & -1.22 \\
\hline Hospitalization rate & $0.03^{*}$ & 0.00 & 0.06 \\
\hline Education & $-0.20^{* *}$ & -0.36 & -0.03 \\
\hline Average household income & -0.04 & -0.25 & 0.17 \\
\hline Unemployment rate & 0.02 & -0.05 & 0.09 \\
\hline Constant & $29.23^{* * *}$ & 16.50 & 41.95 \\
\hline $\begin{array}{l}\mathrm{N}=151 ; \mathbf{R}^{2}=0.93 ; \mathrm{F} \text {-test(model) } \mathrm{P} \text {-value }<0.001 \\
* \mathrm{P} \text {-value }<0.1 ; * * \mathrm{P} \text {-value }<0.05 ; * * \mathrm{P} \text {-value }\end{array}$ & & & \\
\hline
\end{tabular}

Table 4-9: Fixed effects regression for $\mathrm{CHF}$ admission rates 


\begin{tabular}{|c|c|c|c|}
\hline \multirow{2}{*}{$\begin{array}{l}\text { BP } \\
\text { GP consultations per capita }\end{array}$} & \multirow{2}{*}{$\begin{array}{l}\text { Coefficient } \\
-0.57^{*}\end{array}$} & \multicolumn{2}{|c|}{ 95\% Confidence Intervals } \\
\hline & & -1.16 & 0.02 \\
\hline Nurse consultations per capita & 0.75 & -0.32 & 1.83 \\
\hline Specialist consultations per capita & 0.83 & -1.34 & 3.00 \\
\hline PRIMARY CARE expenditure & 0.03 & -0.24 & 0.30 \\
\hline GP visits as a proportion of total population & -0.01 & -0.09 & 0.07 \\
\hline $\begin{array}{l}\text { Specialist visits as a proportion of tot. } \\
\text { population }\end{array}$ & $-0.07^{* *}$ & -0.14 & 0.00 \\
\hline GP treatment perceived quality & 1.35 & -0.37 & 3.08 \\
\hline GP visit waiting time & -0.09 & -1.01 & 0.82 \\
\hline Specialist visit waiting time & -0.01 & -0.89 & 0.87 \\
\hline Lifestyle advice & $-1.79^{* * *}$ & -2.93 & -0.64 \\
\hline Private to public hospital beds ratio & 0.17 & -3.07 & 3.41 \\
\hline Hospitalization rate & 0.01 & -0.05 & 0.06 \\
\hline Education & $-0.21^{* * *}$ & -0.35 & -0.08 \\
\hline Average household income & $0.25^{*}$ & -0.04 & 0.54 \\
\hline Unemployment rate & -0.02 & -0.10 & 0.07 \\
\hline Constant & $21.45^{* *}$ & 2.29 & 40.61 \\
\hline $\begin{array}{l}\mathrm{N}=151 ; \mathrm{R}^{2}=0.89 ; \mathrm{F} \text {-test(model) } \mathrm{P} \text {-value }<0.001 \\
* \mathrm{P} \text {-value }<0.1 ; * \text { P-value }<0.05 ; * * \mathrm{P} \text {-value }\end{array}$ & & & \\
\hline
\end{tabular}

Table 4-10: Fixed effects regression for $\mathrm{BP}$ admission rates 
The hospitalization rates and the ratio of private to public hospital beds are among the significant covariates for CHF. The positive coefficient of hospitalization rates confirms the effect of physicians' propensity toward hospitalizations on the rate of CHF admissions. The significant and negative coefficient of the private to public hospitalizations implies that the CHF hospitalization rates are lower in regions that have more private hospital beds per capita.

Other significant covariates are unemployment rate for COPD condition, average household income (positive coefficient) for BP and education rates for all three conditions. It is worth noting that the coefficients of education (measured as the percentage of people who have not completed their secondary education) and unemployment rates are both negative. This means that admissions are higher in regions with a more educated population and lower unemployment. More elaborate discussion on this aspect is provided in the following section.

\subsubsection{Discussion}

The unwarranted variations in health expenditures per capita is not only due to the differences in costs per admission, but also the rate of admissions is a substantial driver (Gottlieb et al., 2010). Thus, in order to reduce the costs, the unwarranted variations in admissions are also crucially important. A considerable proportion of the admission are due to the preventable admissions caused by ambulatory sensitive conditions (Sanderson and Dixon, 2000). Timely and effective monitoring of patients with such condition -performed by primary care physicians- is reported as the main remedy to reduce such preventable admissions (Gibson et al., 2013). Thus, in this thesis, we also considered several popular proxies that are used in the literature for assessing the supply and use of primary care and specialist services and investigated the potential effects of these proxies on preventable hospitalizations linked to COPD, CHF 
and BP. Our results demonstrate that more GP consultations per capita are associated to lower levels of admission in all three cases. This is similar to the findings of several other studies in the literature (e.g. Rizza et al., 2007; Griffiths et al., 2010; Rosano et al., 2013), confirming the influencing role that primary care plays on preventable admissions. Our findings, however, are in contrast with the work by AnguloPueyo et al. (2017), who found no association between primary care supply and ACSCs in Spain. As their dependent variable, the authors considered a mixed factor obtained from several ACSCs (including COPD and CHF) and a variable factor to measure primary care supply composed of the number of primary care centres plus the number of GP and nurse consultations. As our results suggest, not all the proxies of primary care supply are associated with admission rates. Moreover, the significant variables are not exactly the same for all three conditions. Thus, using a single factor instead of individual variables may contribute towards generating the insignificant association between primary care resources and ACSC admissions found in (Angulo-Pueyo et al., 2017).

In OECD countries, GPs see their patients 6.9 times on average per year (OECD, 2017b) while the average is lower in Spain, with a maximum of 5.9 times in 2008 and a minimum of 5.38 times in 2015. Thus, given the association between more GP consultations and lower ACSC admissions, we suggest that encouraging people to see their GPs should be a main priority for Spanish public health decision-makers, in view of reducing avoidable hospitalizations.

As the results suggest, specialist consultations per capita are an important factor in reducing COPD hospitalizations. This is consistent with the results found by Kim et al. (2016), who state that having access to a specialist contributes significantly to fewer hospital admissions for patients with COPD. The higher proportion of population that visits a specialist is also associated with drops in BP admissions. In Spain, GPs act as gatekeepers (Chaupain-Guillot and Guillot, 2015; Dimitrovová and Perelman, 2018), which means that patients can only access a specialist through a GP's referral, and this gatekeeping function 
could influence the number of ACSC hospitalizations (Rosano et al., 2013). Our findings, therefore, suggest that there is clear need for GPs to refer patients with COPD and BP more often. It should however be noted that other confounding variables (e.g. travel time (Kim et al., 2016)) could also be the reason behind fewer specialist visits.

As previously mentioned, we included the patients' satisfaction with the time between asking for an appointment to actually visiting their GP or specialist as a proxy for ease of access to primary care and specialist services. Satisfaction in the time patients wait before they can get an appointment to see their GP correlates positively with CHF admissions. This implies that regions with higher satisfaction rates have higher CHF admissions. A plausible explanation is that GPs in regions where they see their patient less often have more free time and can arrange appointments sooner, meaning that patients are more satisfied with the waiting time.

Similarly, nurse-led consultations have a positive correlation with COPD. This is in contrast with the results found by Griffiths et al. (2010), who found a negative association between nurse staffing levels and COPD and Asthma admissions in UK. The authors, however, found a positive association between nurse staffing levels and diabetes admissions (Griffiths et al., 2010). Given that our results show the important role played by specialists in lowering COPD admissions, this may imply that nurse-led consultations are not as effective, and more highly specialised consultations could prevent unnecessary COPD hospitalizations in Spain. Another speculation is that, through a lack of available GPs, more patients are directed towards nurse consultations.

GP advice on lifestyle is another factor that contributes to lower admission rates for both COPD and BP. This is to be expected, and during consultations, GPs can encourage their patients to adopt a more healthy lifestyle (Lerman, 2005; Worcester et al., 2003) and this, as a consequence, can reduce the probability of hospital admissions. 
The positive coefficient of CHF hospitalization rates is consistent with the findings in (Angulo-Pueyo et al., 2017; Thygesen et al., 2015), showing that a susceptibility towards hospitalization is correlated with potentially avoidable hospitalizations.

Among the socio-economic factors in play, educational level is the only variable correlated with all three ACSCs. However, as its coefficient is negative, this means that admission rates are higher in regions with more educated people. This is probably due to the fact that more educated people often have busier lives and are more likely to miss or not make medical appointments through lack of time. The more stressful lifestyle in the big cities and regions, with their better economic conditions, can provide another plausible explanation. Given the data at our disposal, we were unable to control separately for these confounding variables. Our line of thought on this last point was the same as that taken previously, when we observed the positive coefficient of the average household income in BP admissions and the negative association of unemployment rates in COPD admissions. Consistent with the findings of (Angulo-Pueyo et al., 2017), unemployment rates are not significantly correlated to ACSC hospitalization for CHF and BP.

To summarize; our result show that specialists' consultations per capita is linked with less COPD admissions and proportion of people visiting specialists is associated with reduced BP hospitalizations. The association of GPs consultation with less avoidable hospitalizations confirms the role of primary care. However, the significant role of specialists in reducing the preventable COPD and BP hospitalizations is an indication that primary care cannot solely be held accountable for all preventable hospitalizations and specialized care and its coordination with primary care have also significant influence. Thus, in order to reduce the unwarranted variations in terms of avoidable hospitalizations, policy makers need to stimulate the Spanish population to visit both GPs and specialist more often, in order to reduce the avoidable hospitalizations. 
It is worth mentioning that have been restricted in our work by the laws on confidentiality and privacy and were unable to access data at patient level. This meant that we could not include potential influencing factors, such as continuity of care, effective coordination between GPs and specialists and distance to the care centre. We do not think, however, that this last factor would influence the results. According to the EU survey, Statistics on Income and Living Conditions (EU-SILC), the share of Spanish respondents who gave distance as the reason for unmet medical needs was less than $0.1 \%$ between 2008 and 2015 .

As demonstrated in the studies of the first phase, the national-level administrative datasets can be used to investigate the patterns and factors associated with unwarranted variations in regional levels. Similarly, these datasets have been commonly used to shed light on factors in institution-level studies. However, underlying factors such as clinicians' behaviours are observable when variations are quantified in granular levels of analysis such as departments or groups of patients treated by the same clinician. The effect of such factors is more likely to be glossed over in geographical- or even hospital-level analyses.

\subsection{Phase 2: Business Intelligence and Unwarranted Variations}

As mentioned before, the objective of the second phase of the thesis is to develop a healthcare specific maturity model, and support the hospital decision makers to unleash the disruptive potential of the BI and consequently improve the data availability and quality to better measure and mitigate the unwarranted variations. In section 4.2.1 we introduce the maturity model and the related assessment questionnaire. In section 4.2.2 we present the developed roadmap that shows the immediate and future areas that managers need to focus. This helps to reach the full potentials of the BI, providing quality data and enables the 
application of more advanced analytical techniques to seamless and reliable discovery of unwarranted variations.

\subsubsection{Maturity Model and Assessment Questionnaire}

In Section 3.2.1 we explained the process to define the dimensions needed for the assessment of the BI solution maturity in the secondary care settings. These 23 dimensions have been clustered in four different areas:

- Functional area (6 dimensions), which represent the different functionalities of the BI solution (e.g., the possibility of actively supporting decision-making in the clinical, quality, production, or economic domain);

- Technological area (7 dimensions), which represent the technological features of the BI solution (e.g., the number of interoperability standards supported by the solution);

- Diffusional area (3 dimensions), which measure the pervasiveness of the BI solution (e.g., its use by clinicians and nurses);

- Organizational area (7 dimensions), which describe how the healthcare organization manages the BI solution (e.g., strategic coherence between BI development and company needs).

Four maturity levels have been defined for each dimension:

- Initial: the dimension is not covered or the implementation is in the early stages;

- Managed: the dimension is implemented in a limited manner;

- Systematic: the dimension is fully implemented;

- Disrupted: the dimension is fully implemented and exploited for all its potential. 
According the members of the RTF, the experts and the power-users engaged into the research endeavor, these four levels, combined to the aforementioned 23 dimensions, form a model that is enough detailed and simple to suggest effective improvement paths to be pursued by healthcare organizations.

Tables 4-11 to 4-14 show the dimensions and maturity levels defined for each of the four areas. 


\begin{tabular}{|c|c|c|c|c|}
\hline Dimension & $\begin{array}{c}\text { Level 1: } \\
\text { Initial }\end{array}$ & $\begin{array}{l}\text { Level 2: } \\
\text { Managed }\end{array}$ & $\begin{array}{c}\text { Level 3: } \\
\text { Systematic }\end{array}$ & $\begin{array}{c}\text { Level 4: } \\
\text { Disrupted }\end{array}$ \\
\hline 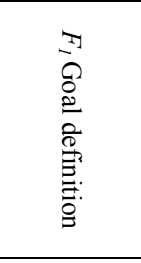 & $\begin{array}{l}\text { The support of the BI solution } \\
\text { to goal definition is limited to: } \\
\text { - Data at organizational level } \\
\text { - Annual reports }\end{array}$ & $\begin{array}{l}\text { BI solution supports goal } \\
\text { definition in more than } 50 \% \text { of } \\
\text { the cases with: } \\
\text { - Data at unit and/or ward } \\
\text { level } \\
\text { - Inputs of consolidated targets } \\
\text { - Quarterly reports }\end{array}$ & $\begin{array}{l}\text { BI solution supports goal } \\
\text { definition in more than } 50 \% \text { of } \\
\text { the cases with: } \\
\text { - Data on single event and/or } \\
\text { cure episode } \\
\text { - Budget development } \\
\text { - Monthly reports }\end{array}$ & $\begin{array}{l}\text { BI solution supports goal } \\
\text { definition in more than } 50 \% \text { of } \\
\text { the cases with: } \\
\text { - Atomic data at the level of } \\
\text { single treatment procedure } \\
\text { - Dynamic budget } \\
\text { management } \\
\text { - Weekly or daily reports }\end{array}$ \\
\hline 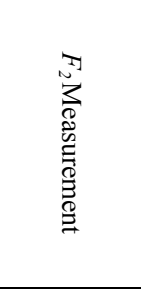 & $\begin{array}{l}\text { The support of the BI solution } \\
\text { to performance measurement } \\
\text { is limited to: } \\
\text { - Data at organizational level } \\
\text { - Annual reports and data }\end{array}$ & $\begin{array}{l}\text { BI solution supports } \\
\text { performance measurement } \\
\text { with: } \\
\text { - Data at unit and/or ward } \\
\text { level } \\
\text { - Manual measures only for } \\
\text { some operative units } \\
\text { - Quarterly reports and data }\end{array}$ & $\begin{array}{l}\text { BI solution supports } \\
\text { performance measurement } \\
\text { with: } \\
\text { - Data on single event and/or } \\
\text { cure episode } \\
\text { - Manual measures for all the } \\
\text { operative units } \\
\text { - Monthly reports and data }\end{array}$ & $\begin{array}{l}\text { BI solution supports } \\
\text { performance measurement } \\
\text { with: } \\
\text { - Atomic data at the level of } \\
\text { single treatment procedure } \\
\text { - Automatic measures for all } \\
\text { the operative units } \\
\text { - Weekly or daily reports and } \\
\text { data }\end{array}$ \\
\hline 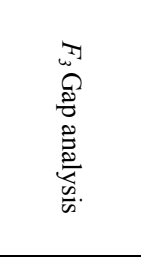 & $\begin{array}{l}\text { The support of the BI solution } \\
\text { to gap analysis is limited to: } \\
\text { - Data at organizational level } \\
\text { - Annually gap analyses and } \\
\text { reports }\end{array}$ & $\begin{array}{l}\text { BI solution supports gap } \\
\text { analysis with: } \\
\text { - Data at unit and/or ward } \\
\text { level } \\
\text { - Only data collection } \\
\text { - Quarterly gap analyses and } \\
\text { reports }\end{array}$ & $\begin{array}{l}\text { BI solution supports gap } \\
\text { analysis with: } \\
\text { - Data on single event and/or } \\
\text { cure episode } \\
\text { - Data collection and gap } \\
\text { visualization } \\
\text { - Monthly gap analyses and } \\
\text { reports }\end{array}$ & $\begin{array}{l}\text { BI solution supports gap } \\
\text { analysis with: } \\
\text { - Atomic data at the level of } \\
\text { single treatment procedure } \\
\text { - Data collection and } \\
\text { automatic gap analyses } \\
\text {-Real time gap analyses and } \\
\text { reports }\end{array}$ \\
\hline 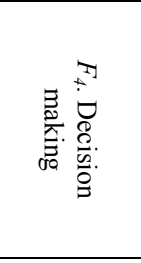 & $\begin{array}{l}\text { The support of the BI solution } \\
\text { to decision making is limited } \\
\text { to: } \\
\text { - Data at organizational level } \\
\text { - Annually updated data and } \\
\text { reports }\end{array}$ & $\begin{array}{l}\text { BI solution supports decision } \\
\text { making with: } \\
\text { - Data at unit and/or ward } \\
\text { level } \\
\text { - Ex-post analyses } \\
\text { - Quarterly updated data and } \\
\text { reports }\end{array}$ & $\begin{array}{l}\text { BI solution supports decision } \\
\text { making with: } \\
\text { - Data on single event and/or } \\
\text { cure episode } \\
\text { - Online Analytical Processing } \\
\text { (OLAP) } \\
\text { - Monthly updated data and } \\
\text { reports }\end{array}$ & $\begin{array}{l}\text { BI solution supports decision } \\
\text { making with: } \\
\text { - Atomic data at the level of } \\
\text { single treatment procedure } \\
\text { - Active support to decision } \\
\text { making } \\
\text { - Real time updated data and } \\
\text { reports }\end{array}$ \\
\hline 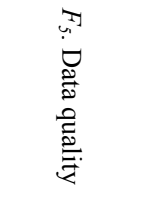 & $\begin{array}{l}\text { No automatic quality control } \\
\text { over inbound and outbound } \\
\text { data }\end{array}$ & $\begin{array}{l}\text { The BI solution automatically } \\
\text { performs quality control for } \\
\text { less than } 40 \% \text { of the inbound } \\
\text { and outbound data }\end{array}$ & $\begin{array}{l}\text { The BI solution automatically } \\
\text { performs quality control less } \\
\text { than } 80 \% \text { of the inbound and } \\
\text { outbound data }\end{array}$ & $\begin{array}{l}\text { The BI solution automatically } \\
\text { and systematically } \\
\text { controls all the inbound and } \\
\text { outbound data }\end{array}$ \\
\hline 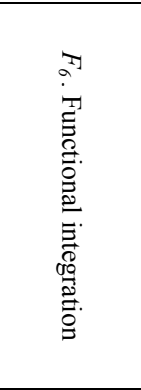 & $\begin{array}{l}\text { The BI solution does not allow } \\
\text { working in an integrated } \\
\text { manner (integration within and } \\
\text { across different domains/ } \\
\text { areas) }\end{array}$ & $\begin{array}{l}\text { The BI solution allows } \\
\text { working in an integrated } \\
\text { manner: } \\
\text { - Within each of the economic, } \\
\text { production and qualitative } \\
\text { domains in less than } 30 \% \text { of } \\
\text { the cases } \\
\text { - Between two domains } \\
\text { - Between two functional } \\
\text { areas (goal definition, } \\
\text { measurement, gap analysis, } \\
\text { decision making) }\end{array}$ & $\begin{array}{l}\text { The BI solution allows } \\
\text { working in an integrated } \\
\text { manner: } \\
\text { - Within each of the economic, } \\
\text { production and qualitative } \\
\text { domains in less than } 70 \% \text { of } \\
\text { the cases } \\
\text { - Between all three domains in } \\
\text { less than } 50 \% \text { of the cases } \\
\text { - Between three functional } \\
\text { areas }\end{array}$ & $\begin{array}{l}\text { The BI solution allows } \\
\text { working in an integrated } \\
\text { manner: } \\
\text { - Within each of the economic, } \\
\text { production and qualitative } \\
\text { domains in more than } 70 \% \text { of } \\
\text { the cases } \\
\text { - Between all three domains in } \\
\text { more the } 50 \% \text { of the cases } \\
\text { - Between all functional areas }\end{array}$ \\
\hline
\end{tabular}

Table 4-11: Maturity levels for the 6 dimensions in the functional area 


\begin{tabular}{|c|c|c|c|c|}
\hline Dimension & $\begin{array}{c}\text { Level 1: } \\
\text { Initial } \\
\end{array}$ & $\begin{array}{l}\text { Level 2: } \\
\text { Managed }\end{array}$ & $\begin{array}{c}\text { Level 3: } \\
\text { Systematic }\end{array}$ & $\begin{array}{c}\text { Level 4: } \\
\text { Disrupted }\end{array}$ \\
\hline 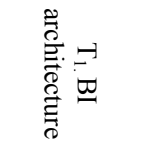 & $\begin{array}{l}\text { There is no real BI } \\
\text { architecture as the data } \\
\text { collection and analytics are } \\
\text { mainly paper based }\end{array}$ & $\begin{array}{l}\text { The BI solution does not } \\
\text { support decoupling between } \\
\text { transactions and analytics }\end{array}$ & $\begin{array}{l}\text { The BI solution supports } \\
\text { transactional and analytics } \\
\text { decoupling }\end{array}$ & $\begin{array}{l}\text { The BI solution has multi- } \\
\text { level architecture for analytics }\end{array}$ \\
\hline 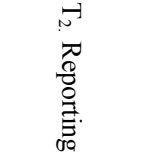 & $\begin{array}{l}\text { The BI solution produces only } \\
\text { static reports (text, tables, etc.) } \\
\text { and the reports are distributed } \\
\text { in paper format }\end{array}$ & $\begin{array}{l}\text { The BI solution produces } \\
\text { static reports with graphical } \\
\text { data; reports are distributed } \\
\text { digitally but manually }\end{array}$ & $\begin{array}{l}\text { The BI solution supports } \\
\text { dynamic data navigation and } \\
\text { reports are distributed } \\
\text { automatically and digitally }\end{array}$ & $\begin{array}{l}\text { The BI solution supports } \\
\text { dynamic statistical analysis } \\
\text { and the reports are directly and } \\
\text { constantly available }\end{array}$ \\
\hline $\begin{array}{l}\omega \\
\vec{\Xi} \\
\stackrel{\overrightarrow{0}}{0} \\
\overrightarrow{0} \\
0 \\
0\end{array}$ & $\begin{array}{l}\text { No real BI solutions in the } \\
\text { organization }\end{array}$ & $\begin{array}{l}\text { The BI solution has a client- } \\
\text { server interface only } \\
\text { accessible through specific } \\
\text { devices }\end{array}$ & $\begin{array}{l}\text { The BI solution is web-based } \\
\text { and is accessible through all } \\
\text { the desktop devices }\end{array}$ & $\begin{array}{l}\text { The BI solution has advanced } \\
\text { RIA interface, accessible } \\
\text { through all the mobile devices }\end{array}$ \\
\hline 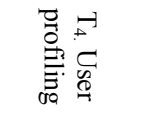 & $\begin{array}{l}\text { The BI solution does not } \\
\text { support user profiling }\end{array}$ & $\begin{array}{l}\text { The BI solution only supports } \\
\text { macro-area profiling }\end{array}$ & $\begin{array}{l}\text { The BI solution supports } \\
\text { single user profiling }\end{array}$ & $\begin{array}{l}\text { The BI solution supports } \\
\text { context-based profiling }\end{array}$ \\
\hline 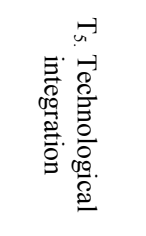 & $\begin{array}{l}\text { - The BI solution is not } \\
\text { automatically alimented by } \\
\text { other internal systems } \\
\text { - Alimentation with external } \\
\text { system is completely manual. }\end{array}$ & $\begin{array}{l}\text { - The BI solution is } \\
\text { automatically alimented by } \\
\text { less than } 50 \% \text { of the other } \\
\text { internal systems } \\
\text { - Alimentation with external } \\
\text { systems is mono-directional } \\
\text { but manual to some extent. }\end{array}$ & $\begin{array}{l}\text { - The BI solution is } \\
\text { automatically alimented by } \\
\text { less than } 85 \% \text { of the other } \\
\text { internal systems } \\
\text { - Alimentation with external } \\
\text { systems is bi-directional but } \\
\text { manual to some extent. }\end{array}$ & $\begin{array}{l}\text { - The BI solution is } \\
\text { automatically alimented by } \\
\text { more than } 85 \% \text { of the other } \\
\text { internal systems } \\
\text { - Alimentation with external } \\
\text { systems is bi-directional and } \\
\text { automatic }\end{array}$ \\
\hline 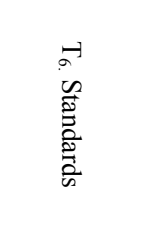 & $\begin{array}{l}\text { The BI solution does not } \\
\text { support any interoperability } \\
\text { standards }\end{array}$ & $\begin{array}{l}\text { - The BI solution has } \\
\text { interoperability standards for } \\
\text { less than } 50 \% \text { of the } \\
\text { applications } \\
\text { - There is only one } \\
\text { interoperability standard } \\
\text { supported by the BI solution }\end{array}$ & $\begin{array}{l}\text { - The BI solution has } \\
\text { interoperability standards for } \\
\text { less than } 85 \% \text { of the } \\
\text { applications } \\
\text { - There are few } \\
\text { interoperability standards } \\
\text { supported by the BI solution }\end{array}$ & $\begin{array}{l}\text { - The BI solution has } \\
\text { interoperability standards for } \\
\text { more than } 85 \% \text { of the } \\
\text { applications } \\
\text { - Majority of the } \\
\text { interoperability standards are } \\
\text { supported by the BI solution }\end{array}$ \\
\hline 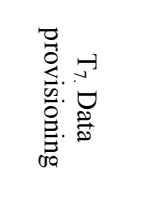 & $\begin{array}{l}\text { - In more than } 50 \% \text { of the } \\
\text { cases the alimented data are } \\
\text { aggregated to organizational } \\
\text { level } \\
\text { - Data are alimented every } \\
\text { quarter }\end{array}$ & $\begin{array}{l}\text { - In more than } 50 \% \text { of the } \\
\text { cases the alimented data are at } \\
\text { unit and/or ward level } \\
\text { - Data are alimented monthly }\end{array}$ & $\begin{array}{l}\text { - In more than } 50 \% \text { of the } \\
\text { cases the alimented data are in } \\
\text { event or cure episode level } \\
\text { - Data are alimented are } \\
\text { alimented weekly or daily }\end{array}$ & $\begin{array}{l}\text { - In more than } 50 \% \text { of the } \\
\text { cases the alimented data are } \\
\text { available for each treatment } \\
\text { procedure } \\
\text { - Data are alimented in real } \\
\text { time }\end{array}$ \\
\hline
\end{tabular}

Table 4-12: Maturity levels for the 7 dimensions in the technological area 


\begin{tabular}{|c|c|c|c|c|}
\hline Dimension & $\begin{array}{c}\text { Level 1: } \\
\text { Initial } \\
\end{array}$ & $\begin{array}{l}\text { Level 2: } \\
\text { Managed }\end{array}$ & $\begin{array}{c}\text { Level 3: } \\
\text { Systematic }\end{array}$ & $\begin{array}{l}\text { Level 4: } \\
\text { Disrupted }\end{array}$ \\
\hline 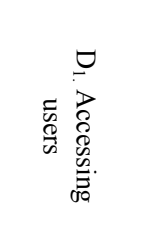 & $\begin{array}{l}\text { - Less than } 50 \% \text { of the } \\
\text { administrative and clinical } \\
\text { directors have access to the BI } \\
\text { solution } \\
\text { - Less than } 25 \% \text { of the other } \\
\text { users have access to the BI } \\
\text { solution }\end{array}$ & $\begin{array}{l}\text { - Between } 50 \% \text { and } 70 \% \text { of } \\
\text { the directors have access to } \\
\text { the BI solution } \\
\text { - Between } 25 \% \text { to } 50 \% \text { of the } \\
\text { other users have access to the } \\
\text { BI solution }\end{array}$ & $\begin{array}{l}\text { - Between } 70 \% \text { and } 90 \% \text { of the } \\
\text { directors have access to the BI } \\
\text { solution } \\
\text { - Between } 50 \% \text { to } 75 \% \text { of the } \\
\text { other users have access to the } \\
\text { BI solution }\end{array}$ & $\begin{array}{l}\text { - More than } 90 \% \text { of the } \\
\text { directors have access to the } \\
\text { BI solution } \\
\text { - More than } 75 \% \text { of the other } \\
\text { users have access to the BI } \\
\text { solution }\end{array}$ \\
\hline 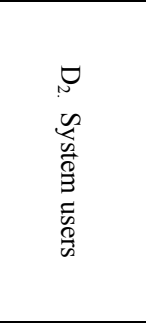 & $\begin{array}{l}\text { The BI solution does not trace } \\
\text { user access }\end{array}$ & $\begin{array}{l}\text { - Less than } 50 \% \text { of the } \\
\text { administrative and clinical } \\
\text { directors that have access to } \\
\text { the BI solution consistently } \\
\text { use it } \\
\text { - Less than } 25 \% \text { of the other } \\
\text { administrative and clinical } \\
\text { staff that have access to the } \\
\text { BI solution consistently use it }\end{array}$ & $\begin{array}{l}\text { - Between } 50 \% \text { and } 75 \% \text { of the } \\
\text { administrative and clinical } \\
\text { directors that have access to } \\
\text { the BI solution consistently } \\
\text { use it } \\
\text { - Between } 25 \% \text { and } 50 \% \text { of the } \\
\text { other administrative and } \\
\text { clinical staff that have access } \\
\text { to the BI solution consistently } \\
\text { use it }\end{array}$ & $\begin{array}{l}\text { - More than } 75 \% \text { of the } \\
\text { administrative and clinical } \\
\text { directors that have access to } \\
\text { the BI solution consistently } \\
\text { use it } \\
\text { - Less than } 50 \% \text { of the other } \\
\text { administrative and clinical } \\
\text { staff that have access to the } \\
\text { BI solution consistently use } \\
\text { it }\end{array}$ \\
\hline $\begin{array}{l}\forall \\
0 \\
0 \\
0 \\
0 \\
0 \\
0 \\
0 \\
0 \\
0 \\
0 \\
0 \\
0 \\
0 \\
00 \\
0 \\
0\end{array}$ & $\begin{array}{l}\text { - The BI solution does not } \\
\text { support any of the four } \\
\text { functional activities (goal } \\
\text { definition, measurement, gap } \\
\text { analysis, active decision support) } \\
\text { in the administrative processes } \\
\text { (general accounting, logistics, } \\
\text { human resources, etc.) } \\
\text { - The BI solution does not } \\
\text { support any of the four } \\
\text { functional activities in the } \\
\text { clinical realm (emergency room, } \\
\text { outpatient, inpatient, imaging, } \\
\text { laboratory, operating room, etc.) }\end{array}$ & $\begin{array}{l}\text { - The BI solution supports } \\
\text { only one or two of the four } \\
\text { functional activities in the } \\
\text { administrative processes } \\
\text { - The BI solution supports } \\
\text { only one or two of the four } \\
\text { functional activities in the } \\
\text { clinical realm }\end{array}$ & $\begin{array}{l}\text { - The BI solution supports } \\
\text { three of the four functional } \\
\text { activities in the administrative } \\
\text { processes } \\
\text { - The BI solution supports } \\
\text { three of the four functional } \\
\text { activities in the clinical realm }\end{array}$ & $\begin{array}{l}\text { - The BI solution supports all } \\
\text { the four functional activities } \\
\text { in the administrative } \\
\text { processes } \\
\text { - The BI solution supports all } \\
\text { the four functional activities } \\
\text { in the clinical realm }\end{array}$ \\
\hline
\end{tabular}

Table 4-13: Maturity levels for the 3 dimensions in the diffusional area 


\begin{tabular}{|c|c|c|c|c|}
\hline Dimension & $\begin{array}{l}\text { Level 1: } \\
\text { Initial }\end{array}$ & $\begin{array}{c}\text { Level 2: } \\
\text { Managed }\end{array}$ & $\begin{array}{c}\text { Level 3: } \\
\text { Systematic }\end{array}$ & $\begin{array}{c}\text { Level 4: } \\
\text { Disrupted }\end{array}$ \\
\hline 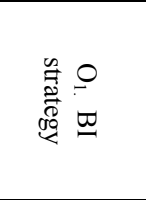 & $\begin{array}{l}\text { There is no BI strategy defined } \\
\text { in the organization for } \\
\text { economic, production or } \\
\text { qualitative aspects }\end{array}$ & $\begin{array}{l}\text { - The BI strategy is defined in } \\
\text { term of local strategies (in } \\
\text { units or department level } \\
\text { - The local strategies are only } \\
\text { partially aligned with the } \\
\text { corporate strategy }\end{array}$ & $\begin{array}{l}\text { The BI strategy is defined in } \\
\text { the corporate level and is } \\
\text { aligned with the business } \\
\text { strategy }\end{array}$ & $\begin{array}{l}\text { The BI solution lead the } \\
\text { change management within } \\
\text { the organization }\end{array}$ \\
\hline 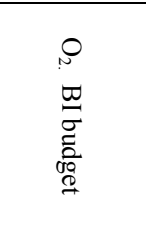 & $\begin{array}{l}\text { - Average annual spending on BI } \\
\text { is less than } 1 \% \text { of the ICT } \\
\text { operational expenditure } \\
\text { - Average annual spending on BI } \\
\text { is less than } 1 \% \text { of the ICT } \\
\text { capital expenditure }\end{array}$ & $\begin{array}{l}\text { - Average annual spending on } \\
\text { BI is between } 1 \% \text { and } 3 \% \text { of } \\
\text { the ICT operational } \\
\text { expenditure } \\
\text { - Average annual spending on } \\
\text { BI is between } 1 \% \text { and } 3 \% \text { of } \\
\text { the ICT capital expenditure }\end{array}$ & $\begin{array}{l}\text { - Average annual spending on } \\
\text { BI is between } 3 \% \text { and } 7 \% \text { of } \\
\text { the ICT operational } \\
\text { expenditure } \\
\text { - Average annual spending on } \\
\text { BI is between } 3 \% \text { and } 7 \% \text { of } \\
\text { the ICT capital expenditure. - }\end{array}$ & $\begin{array}{l}\text { - Average annual spending } \\
\text { on BI is more than } 7 \% \text { of the } \\
\text { ICT operational expenditure } \\
\text { - Average annual spending } \\
\text { on BI more than } 7 \% \text { of the } \\
\text { ICT capital expenditure }\end{array}$ \\
\hline 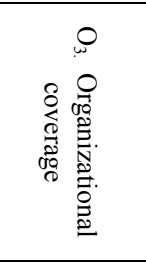 & $\begin{array}{l}\text { - There are no internal resources } \\
\text { in administrative, ICT and } \\
\text { clinical realms dealing with BI } \\
\text { - There are no internal } \\
\text { procedures specified for the BI } \\
\text { solution }\end{array}$ & $\begin{array}{l}\text { - There are internal resources } \\
\text { in administrative, ICT and } \\
\text { clinical realms dedicated to } \\
\text { BI, but the resources are not } \\
\text { exclusive } \\
\text { - Only for few aspects the } \\
\text { internal procedures are } \\
\text { specified for the BI solution }\end{array}$ & $\begin{array}{l}\text { - There are internal resources } \\
\text { in administrative, ICT and } \\
\text { clinical realms exclusively } \\
\text { dedicated to BI } \\
\text { - For most of the technical and } \\
\text { operational aspects, the } \\
\text { internal procedures are } \\
\text { specified for the BI solution }\end{array}$ & $\begin{array}{l}\text { - There is an ad hoc unit } \\
\text { exclusively dedicated to } \\
\text { control and manage the BI } \\
\text { - The ad hoc unit defines and } \\
\text { controls the procedures for } \\
\text { the BI solution }\end{array}$ \\
\hline 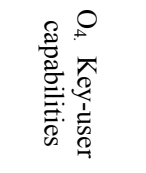 & $\begin{array}{l}\text { There are no key-users of the BI } \\
\text { solution }\end{array}$ & $\begin{array}{l}\text { - Key-users have only } \\
\text { technical capabilities } \\
\text { - The key-users training } \\
\text { programs are sporadic and } \\
\text { focused on technical issues }\end{array}$ & $\begin{array}{l}\text { - The key-users possess } \\
\text { process capabilities } \\
\text { - The key-users training } \\
\text { programs are sporadic and } \\
\text { focused on all BI issues }\end{array}$ & $\begin{array}{l}\text { - Key-users can anticipate } \\
\text { users' needs/problems } \\
\text { - The key-users training } \\
\text { programs are continuative } \\
\text { and focused on all BI issues }\end{array}$ \\
\hline 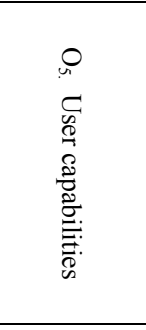 & $\begin{array}{l}\text { - The administrative and clinical } \\
\text { directors do not possess BI } \\
\text { expertise (e.g. analysis and } \\
\text { interpretation of the reports) } \\
\text { - Other administrative and } \\
\text { clinical users do not possess BI } \\
\text { expertise. }\end{array}$ & $\begin{array}{l}\text { - The administrative and } \\
\text { clinical directors are only } \\
\text { able to interpret static reports } \\
\text { - Other administrative and } \\
\text { clinical users are only able to } \\
\text { interpret static reports }\end{array}$ & $\begin{array}{l}\text { - The administrative and } \\
\text { clinical directors have the } \\
\text { competencies to manage } \\
\text { dynamic reports } \\
\text { - Other administrative and } \\
\text { clinical users only have the } \\
\text { competency to interpret static } \\
\text { reports }\end{array}$ & $\begin{array}{l}\text { - The administrative and } \\
\text { clinical directors have the } \\
\text { competencies to manage } \\
\text { sophisticated reports and } \\
\text { perform "pull" analysis } \\
\text { - Other administrative and } \\
\text { clinical users have the } \\
\text { competencies to manage } \\
\text { sophisticated reports and } \\
\text { perform "pull" analysis }\end{array}$ \\
\hline 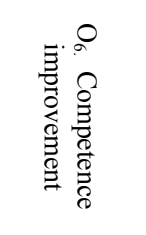 & $\begin{array}{l}\text { There are no training programs } \\
\text { to improve the BI competencies } \\
\text { of the clinical and administrative } \\
\text { users }\end{array}$ & $\begin{array}{l}\text { The BI training programs are } \\
\text { mainly focused on } \\
\text { highlighting BI importance }\end{array}$ & $\begin{array}{l}\text { There are ad hoc BI training } \\
\text { programs focusing on specific } \\
\text { issues }\end{array}$ & $\begin{array}{l}\text { - Continuous BI training } \\
\text { programs } \\
\text { - The BI training programs } \\
\text { are designed to create power } \\
\text { users that further contribute } \\
\text { to improve competencies of } \\
\text { the other users }\end{array}$ \\
\hline 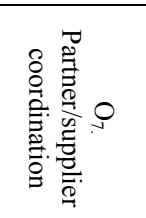 & $\begin{array}{l}\text { - There are no coordination and } \\
\text { regulatory mechanisms with BI } \\
\text { suppliers } \\
\text { - The BI suppliers have no role } \\
\text { in BI management }\end{array}$ & $\begin{array}{l}\text { - Service level agreements } \\
\text { limited to ICT topics } \\
\text { - Reactive involvement of the } \\
\text { BI suppliers limited to } \\
\text { technical issues }\end{array}$ & $\begin{array}{l}\text { - Service level agreements for } \\
\text { continuous update and } \\
\text { improvement of the BI } \\
\text { - Reactive involvement of the } \\
\text { BI suppliers for operating } \\
\text { issues }\end{array}$ & $\begin{array}{l}\text { - The BI suppliers provide } \\
\text { performance management } \\
\text { and KPIs for the BI solution } \\
\text { - The BI suppliers' } \\
\text { involvement is proactive and } \\
\text { innovation oriented }\end{array}$ \\
\hline
\end{tabular}

Table 4-14: Maturity levels for the 7 dimensions in the organizational area 
Each dimension has been further subdivided into more granular sub-dimensions (metrics and sub-metrics) to assure a comprehensive and accurate measurement of the maturity of the BI solutions. Some metrics (e.g., the frequency of goal definition) have sub-metrics that reflect the different domains in which the metric can be measured (e.g., definition of the goal in the economic domain, in the production domain, and in the qualitative domain). In these cases, the maturity levels reported in the table are valid for each sub-metric ${ }^{2}$. At most granular level 119 metrics/sub-metrics are defined. See Tables B.1to B.4, in Appendix B, for a detailed representation of the granular dimensions as well as the different maturity levels.

For each metric and/or sub-metric, the RTF produced a question (except for few sub-metrics that are assessed with more than one question) with four possible answers that reflect the increasing levels of maturity. All questions have been tested and refined with the experts from the five Italian healthcare organizations involved with the CIR project. Specifically, we shared the questionnaire with the engaged informants, asking them to fill it in advance and to take notes on the aspects that were not completely clear. Next, we scheduled multiple face-to-face interviews in order to analyze whether the model and the questionnaire should be modified. Each meeting has been led by at least two members of the RTF, and lasted approximately two hours. In the first one we checked the coherence of the answers provided by the experts with their BI solutions. Next, we focused on the comprehensiveness, the understandability and the accuracy of both the model and the questionnaires.

We revised the metrics and the maturity levels in order to make them mutually exclusive and collectively exhaustive. Moreover, we slightly changed the wording of the questions used to assess the maturity levels.

\footnotetext{
2 The economic, production, and qualitative domains are used in several dimensions of the BI maturity model. Economic domain refers to costs and revenues of the healthcare organization, e.g., the cost of a hospitalisation. Production domain refers to volumes and hospital length of stay in the healthcare organization, e.g., the number of admissions per department. Qualitative domain refers to the quality of the output of the healthcare organization, e.g., the number of admissions related to a Major Diagnostic Category (MDC).
} 
Table B.5, in Appendix B, shows a sample of the developed questionnaire. Following the suggestion of an expert engaged into the CIR project, for each metric we ask not only to evaluate the current maturity levels achieved by a hospital, but also the levels expected to be achieved in the next three years-according to the strategic plans already programmed and/or what seemed feasible targets in the considered timeframe. This choice further increased the level of actionability of the model, which is able not only to easily spot inharmonious developments related to the BI solution, but also to consider the gaps that are reasonable to fill in the near future.

\subsubsection{A Roadmap Toward Precision Medicine for ISMETT}

ISMETT's assessment of the BI maturity model allowed it to support, with sound evidence, management's impression that most of the efforts made by ISMETT regarding its BI solutions had been in the technological area, in which the hospital had achieved an extremely high overall level of maturity. The other areas were expected to be improved over the three years following the assessment. This is consonant with what is suggested by both the literature (e.g., Sen et al., 2012) and the practitioners involved in the research project: inhomogeneous developments tend to be resource-consuming, risky, and ineffective.

As an example of the considerations that the assessment enabled, consider the dimensions in the functional area (Table 4-11). Figure 4-3 highlights high maturity levels for the dimensions, which were expected to grow in the three years after the assessment. Among the four canonical phases characterizing a management control system $\left(F_{1}, F_{2}, F_{3}\right.$ and $\left.F_{4}\right)$, the one relative to "measurement" was the most supported by the BI solution. Looking at the expected maturities, respondents envisioned a development profile once again driven by "measurement," but in which the other phases surpassed or approached level 3 of maturity. 


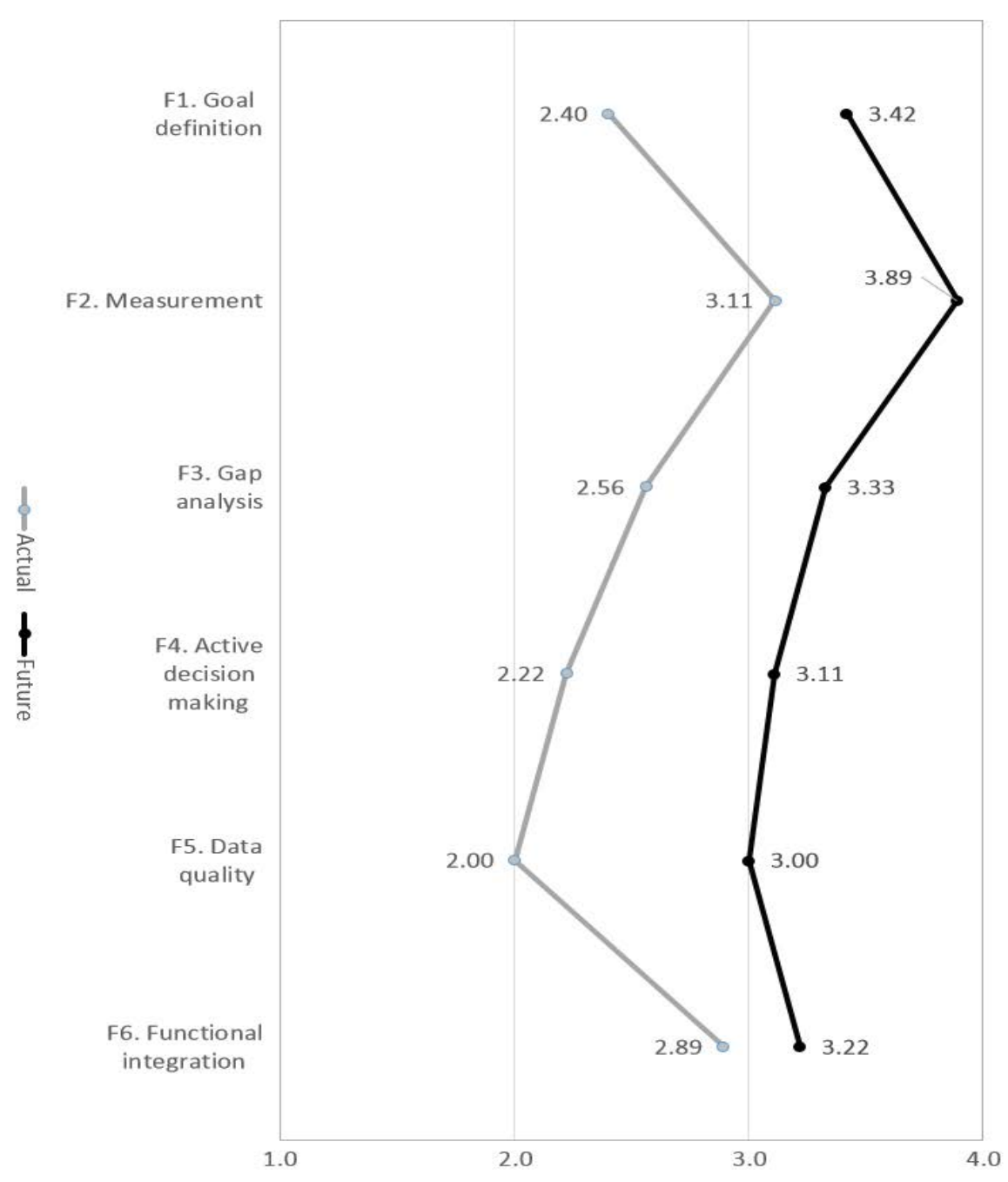

Figure 4-3: ISMETT position on the functional dimensions of the BI maturity model

As mentioned, one of the main outputs of this stage is the framework of interdependencies (in terms of synergies and prerequisites) between the dimensions. Figure 4-4 depicts the final framework produced by RTF. Considering two dimensions of the model (X and Y), allowed to identify four different relationships between them: 
- Strong prerequisite $(\boldsymbol{\nabla})$ : this relationship indicates that in order to increase the maturity of $\mathrm{X}$, it is necessary to have previously reached mid-high ( 3 or 4) levels of maturity in $\mathrm{Y}^{3}$;

- Prerequisite $(\rightarrow)$ : this relationship indicates that in order to increase the maturity of $\mathrm{X}$, it is suggested to have previously reached mid-high (3 or 4) levels of maturity in Y;

- Strong synergy $(\bullet)$ : this relationship indicates that it is necessary to simultaneously evolve the maturity of $\mathrm{X}$ and $\mathrm{Y}$;

- Synergy $(\bullet)$ : this relationship indicates that it is suggested to simultaneously evolve the maturity of $\mathrm{X}$ and $\mathrm{Y}$.

The figure provides a healthcare organization aiming to increase the maturity of its BI solution, with important information to lead each intervention/investment. A vertical analysis of the table emphasizes the prerequisites and the synergies necessary and/or suggested to increase the maturity of a dimension. For example, consider the dimension "active support to decision-making" (the fourth column in the functional area). As indicated in Figure 4-3, ISMETT had a maturity level of 2.22, consonant with current needs, but expected to achieve a level of 3.11 over the next three years. To realize this maturity growth, it is not sufficient to improve the level of data granularity, the functional support, and the frequency through which the BI solution supports this function in economic, production, and qualitative domains. Figure 44 suggests that many other dimensions, both within the same development area as well as outside it, are critical in achieving this improvement.

\footnotetext{
${ }^{3}$ For example, it is necessary to reach at least level 3 of maturity for the metric relative to BI strategy (presence of a corporate strategy at a corporate level, see $O_{1}$ in Table B.4) in order to increase the maturity of the percentage of users who can access the system $\left(D_{1}\right.$ in Table B.3).
} 
Figure 4-4 is extremely useful, even if read horizontally. In this case, it is possible to verify the impacts produced by a dimension on the others, emphasizing the dimensions that have the highest priority due to the fact that they are a strong prerequisite of many other dimensions.

We linked the framework of the interdependencies presented in Figure 4-4 with the maturity levels of the various dimensions of the BI model in order to determine different clusters of dimensions to be prioritized. To accomplish this task, we: (i) averaged the maturity levels of the different metrics characterizing each dimension; (ii) translated the various prerequisites and synergies of each dimension into a comprehensive value, calculated according to a predefined set of scores: 4 points for each strong prerequisite of the dimension; 3 points for each prerequisite; 2 points for each strong synergy; 1 point for each synergy. The relevance (priority) comprehensive value for a given dimension is calculated by summing the scores on the row corresponding to the dimension in Figure 4-4; (iii) checked the consistency of the results in the RTF; (iv) presented them to the BI experts in ISMETT to collect their feedback; and (v) validated the different clusters of dimension prioritization. 


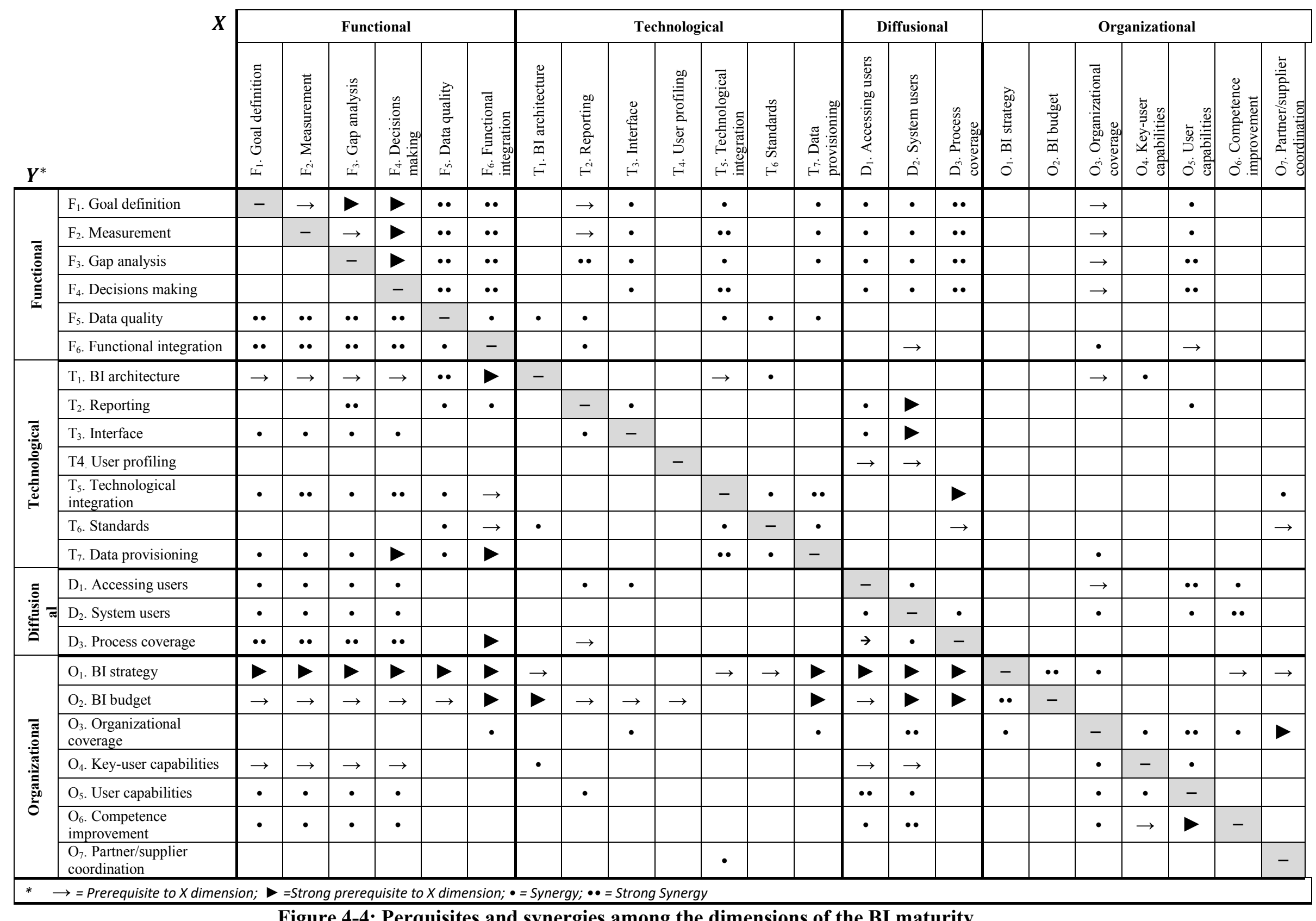

Figure 4-4: Perquisites and synergies among the dimensions of the BI maturity 
Crossing the relevance scores with the maturity levels assessed through the questionnaire (e.g., the values in Figure 4-3 for the functional area), it has been possible to determine the four clusters depicted in Figure 4-5

The four clusters are the following:

- Strategic dimensions: dimensions in which ISMETT should consolidate its investments because they are already mature, but are also highly relevant (and often strong prerequisites) for the evolution of other dimensions;

- Critical dimensions: dimensions on which ISMETT has to focus as soon as possible because they are not mature, and are highly relevant (and often strong prerequisites) for the evolution of other dimensions;

- Consolidated dimensions: dimensions in which ISMETT should invest marginal resources because they have received a number of investments in the past (reflected in high levels of maturity), and their development has less influence on the development of other dimensions;

- Postponable dimensions: dimensions that should be considered after having tackled the critical dimensions, since their development has less influence on the development of other dimensions, even if, in a logic of homogeneous development of the BI solution, their maturity levels have to be aligned with others eventually.

The four clusters of dimensions have to be approached with different modalities, resources, and timings.

\footnotetext{
${ }^{4}$ Two dimensions from the figure - BI strategy and BI budget - are considered as outliers. According to practitioners these dimensions are so relevant that they represent two pre-requisites of any BI solution aiming to be effective within a healthcare organization.
} 


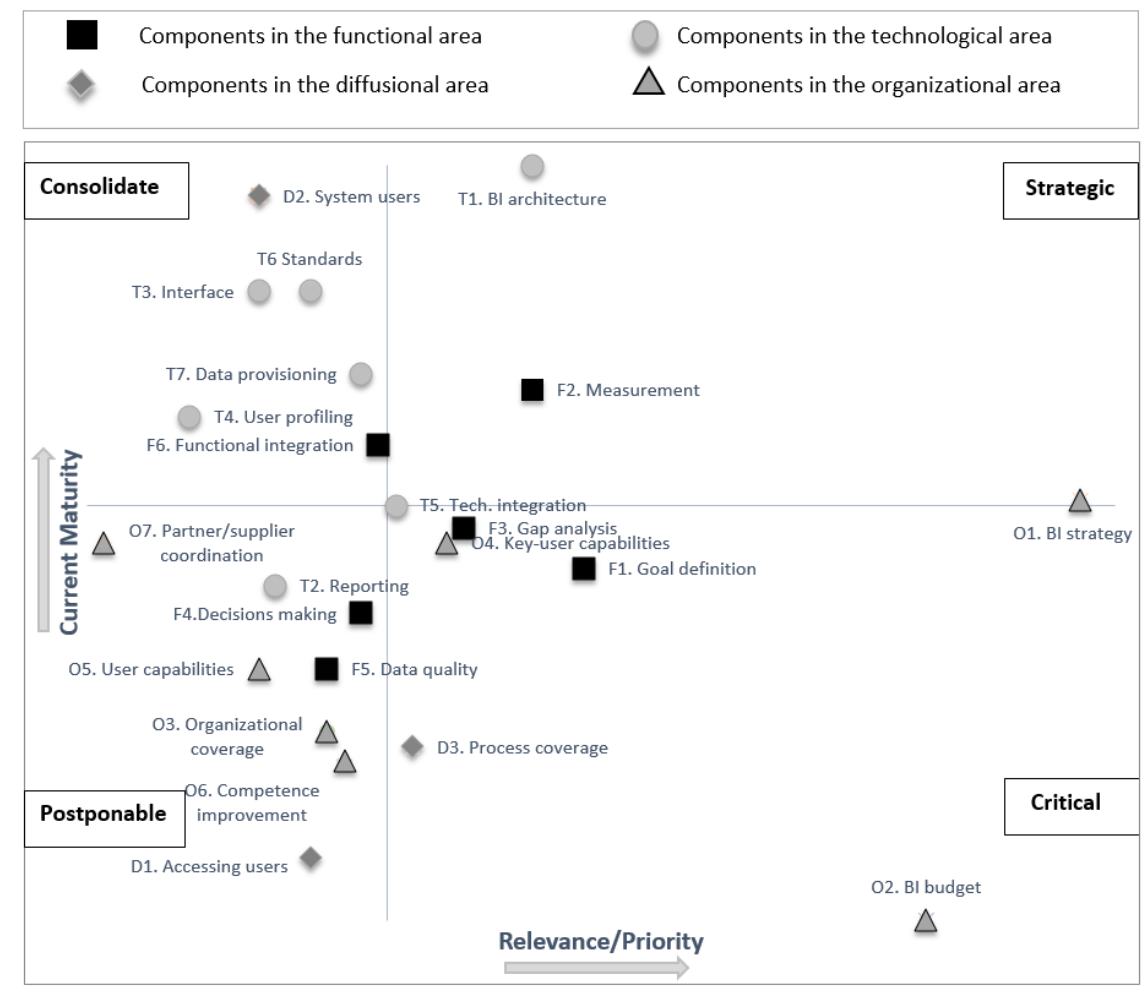

Figure 4-5: Relevance and maturity for healthcare BI at ISMETT

In order to develop an even more specific, systematic and effective action plan, and to harmonize the improvement of the maturity of the various dimensions, the RTF calculated a score for each dimension. Starting with Figure 4-4, it translated the various prerequisites and synergies of each dimension and their current and expected maturity into a comprehensive value (see Figure 4-6). Consider two dimensions $Y_{j}$ and $X_{j}$, where $Y_{j}$ is a prerequisite of (or has synergy with) $X_{j}$. To prioritize the development of dimensions, a score is assigned to each dimension $Y_{j}$ based on Eq.4-1:

$$
\text { Score } Y_{j}=\sum_{i=1}^{n}\left[\left(E M_{X_{i}}-A M_{X_{i}}\right) \frac{1}{A M_{X_{i}}} \frac{\left(P S_{Y_{j} X_{i}}-A_{Y_{j}}\right)+\left|P S_{Y_{j} X_{i}}-A M_{Y_{j}}\right|}{2}\right] \quad \forall j=1 \ldots n
$$


Where:

- $\boldsymbol{n}$ : number of components

- Score $Y_{j}$ : overall score given to component $Y_{j}$,

- $\boldsymbol{E M}_{\boldsymbol{X}_{\boldsymbol{i}}}$ : expected maturity of component $X_{i}$ infuture

- $\quad \boldsymbol{A M}_{\boldsymbol{X}_{\boldsymbol{i}}}$ : current maturity of component $X_{i}$

- $\quad P S_{Y_{j} X_{i}}$ : number of points given based on the relationship between $Y_{j}$ and $X_{i}$ (predefined scores of $4,3,2$ or 1 respectively for strong prequisite,prequisite , strong interdependency and interdependecy)

The higher values of the assigned score indicate the need for immediate investment or focus on the dimension.

The first part of Eq.4-1 takes into account the difference between the expected and current maturity of the dependent dimension $X_{i}$, and the second coefficient $\left(\frac{1}{A M_{X_{i}}}\right)$ considers the inverse of the current maturity level of $\mathrm{X}_{\mathrm{i}}$, thus, the higher the difference between expected and actual maturity and the lower the current maturity of the dependent dimension $X_{i}$; the higher the score given to $Y_{j}$. Finally, the third coefficient calculates the positive part of the difference of the relation score and the current maturity of $Y_{j}$. If the current maturity of $Y_{j}$ is less than the maturity needed to develop $X_{i}$, this coefficient is positive; otherwise, it is zero. For example, if the dimension $Y_{j}$ is a prerequisite of $X_{i}$, but the current maturity of $Y_{j}$ is high enough (3 or 4), the third coefficient is zero and eliminates the effect of the relation on the score of $Y_{j}$. For better illustrations, the detailed calculations of the F4. Standards score are provided in the following.

According to Figure 4-4, $\mathrm{F}_{4}$ is prerequisite of or has synergy with $\mathrm{F}_{5}, \mathrm{~F}_{6}, \mathrm{~T}_{3}, \mathrm{~T}_{5}, \mathrm{D}_{1}, \mathrm{D}_{2}, \mathrm{D}_{3}, \mathrm{O}_{3}$ and $\mathrm{O}_{5}$ and the influence on the other dimensions is 0 : 


$$
\begin{aligned}
& \text { Score of F4 }=\overbrace{(3-2) * \frac{1}{2} * \frac{(2-2.22)+|2-2.22|}{2}}^{F 5}+\overbrace{(3.22-2.89) * \frac{1}{2.89} * \frac{(2-2.22)+|2-2.22|}{2}}^{F 6} \\
& +\overbrace{(3.5-3.5) * \frac{1}{3.5} * \frac{(1-2.22)+|1-2.22|}{2}}^{T 3}+\overbrace{(3.3-2.65) * \frac{1}{2.65} * \frac{(2-2.22)+|2-2.22|}{2}}^{T 5} \\
& +\overbrace{(2-1.25) * \frac{1}{1.25} * \frac{1-2.22+|1-2.22|}{2}}^{D 1}+\overbrace{(4-3.88) * \frac{1}{3.88} * \frac{(1-2.22)+|1-2.22|}{2}}^{D 2} \\
& +\overbrace{(2.45-1.69) * \frac{1}{1.69} * \frac{(2-2.22)+|2-2.22|}{2}}^{D 3}+\overbrace{(2.5-1.75) * \frac{1}{1.75} * \frac{(3-2.22)+|3-2.22|}{2}}^{03} \\
& +\overbrace{(2.63-2) * \frac{1}{2} * \frac{(2-2.22)+|2-2.22|}{2}}^{05}=0.33
\end{aligned}
$$

The positive part of the Equation 1 is 0 for all the dimension except for $\mathrm{O}_{3}$ as the current maturity of the $\mathrm{F}_{4}(2.22)$ in equal or greater than the required maturity based on the type of the dependency (As mentioned earlier Strong perquisite, perquisite, Strong synergies, synergies require maturity levels $4,3,2$ and 1 respectively). In other words, an improvement in the maturity of $F_{4}$ only facilitates the improvement of the $\mathrm{O}_{3}$.

Figure 4-6 depicts the calculated scores of ISMETT's BI dimensions. As shown, BI budget, BI strategy, and process coverage are the first three areas that deserve more attention and/or investment. This is also consistent with the results presented in Figure 4-5 (the three dimensions are among the critical dimensions). 


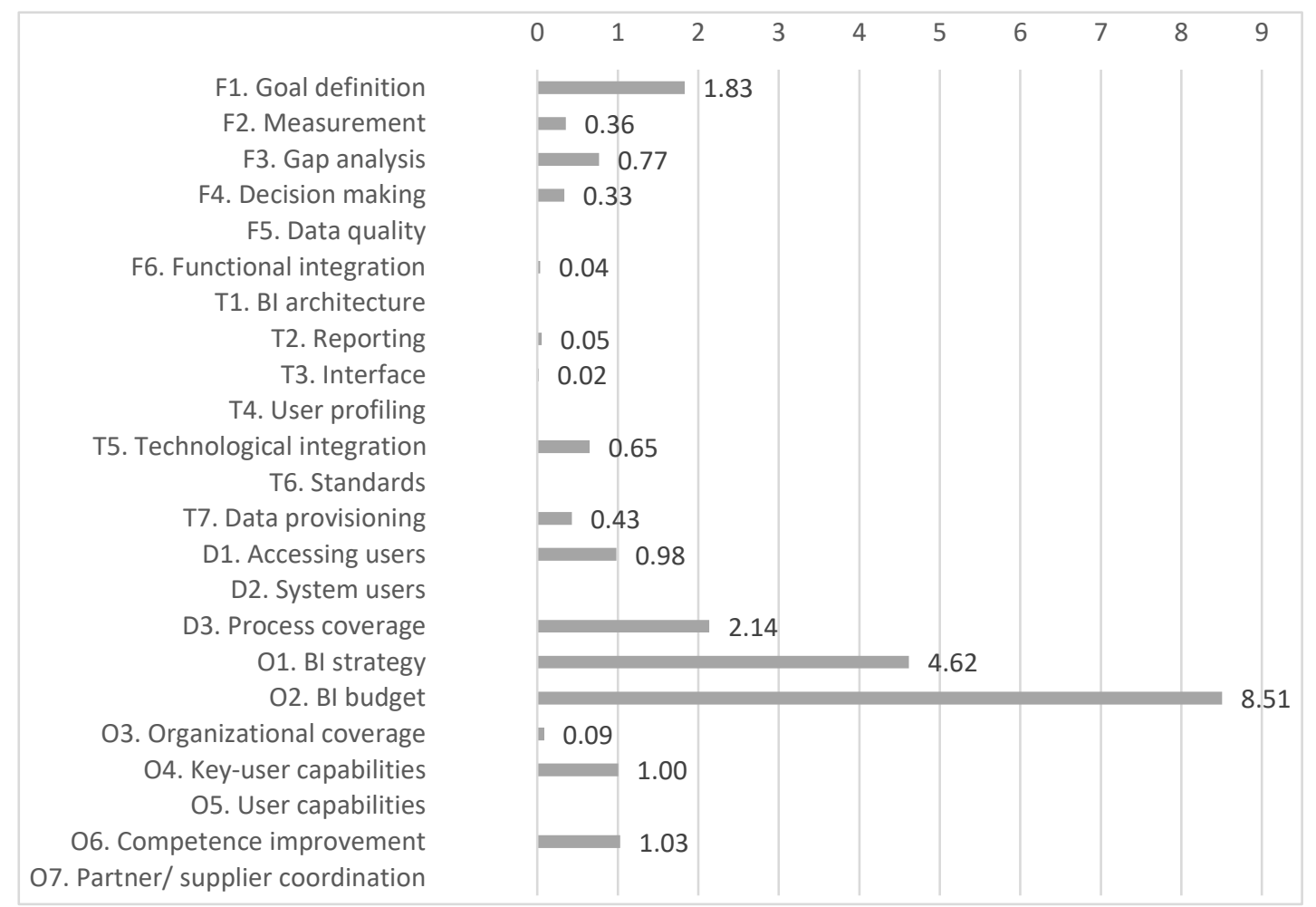

Figure 4-6: Priority scores of the dimensions for healthcare BI at ISMETT

\subsubsection{Discussion}

As mentioned in the first chapter, lack of available data and unobserved covariates are one of the main causes of poor risk adjustments and consequently less effective identification of unwarranted variations. Therefore, there are many instances of contradicting results found in the literature. Take for example, the different findings of our investigation (Section 4.1.3) in primary care of Spain compared to the results reported by Angulo-Pueyo et al. (2017). Therefore, improvements both in health data collection and analytical models for risk adjustments are necessary. Both these aspects are highly dependent on health information systems and supporting tools such as BI. For instance, the QOF pay-for-performance scheme has been successfully implemented thanks to the BI system 
that keeps the detailed registries of all patients in the national-level with interoperability standards. Moreover, it is able to combine the data and provide reports on numerous indicators, in a timely manner.

Beside the direct impact of the HIS in support and improvement of the operational tasks, they offer huge potentials in using the data in research as well as quality/outcome improvements (Weiner and Embi, 2009). Ancker et al, assert that issues with data quality and their root causes cannot be uncovered from the evaluation of the datasets and they are only evident from in-depth analyses of the workflow and process of data documentation (Ancker et al., 2011).

Through in-depth analysis as well as collaborative development and application of a healthcare specific maturity model in a real-case setting, we demonstrate that the development of a BI solution is an evolutionary process, and various discrete stages can be outlined in the roadmap towards a full exploitation of BI. Following this road map consequently improves the availability of the quality data needed for unwarranted variation reduction.

Accordingly, the inadequate level of exploitation could result in failure of the BI initiatives. Moreover, it is necessary to align the level of maturity with organizational structure, management decisions, and strategic short-term future changes for growth. Consequently, the clusters, priority scores, the maturity and its improvement strategy should be periodically re-evaluated. Generally, collecting quality health data is far more complex to be unfolded with pure technical solution and interventions that incentivize constant, comprehensive and accurate collection of the health data are needed (Weiner and Embi, 2009). Evaluation of the successful and failed implementation of health information systems indicates that when it comes to the success factors, socioorganizational issues are far more important than the technological ones (Kaplan and HarrisSalamone, 2009). 
The developed maturity model includes several dimensions as well as metrics. Some of the metrics such as interoperability are especially crucial to successful use of the health data for research purposes (Safran et al., 2007) such as reduction of unwarranted variations. Similarly, our results obtained by mapping the interdependency between the BI dimensions, suggest that BI budget is among the most important aspects to improve the maturity of the BI. As also asserted by Kaplan \& Harris-Salamone, appropriate fundings are crucial for success of health information system initiatives (Kaplan and Harris-Salamone, 2009). However, it should be noted that funding is only a necessary condition and there are many instances of failed health information systems with even adequate fundings (Adler-Milstein et al., 2008). By unveiling the relationships among the various dimensions, we also provided managers with a roadmap that prioritize the aspects of the BI solutions that need immediate improvements and attention.

\subsection{Phase 3: Advanced Analytics for Risk Adjustment}

In Chapter 3 (Section 3.3) we introduced the novel ARM algorithm called Length-Sort. In this section, the results of our experiments are presented for MaxLFI, LFIMiner (current state of the art algorithms for mining LFIs), as well as for the Length-Sort+MaxLFI and LengthSort+LFIMiner algorithms are presented in section 4.3.1. We also present the experiment results of INLA-MFP (state of the art algorithm for mining MFIs) and Length-Sort+INLA-MFP to demonstrate the efficiency improvements of the Length-Sort algorithm. Next, we demonstrate the rules discovered by Length-Sort from QOF dataset to highlight the application of the algorithm in efficient discovery of unwarranted variations. 


\subsubsection{Experimental result of Length-Sort Algorithm}

We compared the performance of both Length-Sort+LFIMiner and Length-Sort+MaxLFI algorithms with the original LFIMiner and MaxLFI algorithms, in terms of runtimes, number of transactions and items included when constructing the initial FP-tree. The LFIs found using the four algorithms were then compared to ensure that the same LFIs were discovered.

The runtime comparisons given in Figure 4-7 show that Length-Sort reduces the runtime in most of the tested datasets. LFIMiner and MaxLFI perform very similarly and, consequently, LengthSort+LFIMiner and Length-Sort+MaxLFI have very similar runtimes.
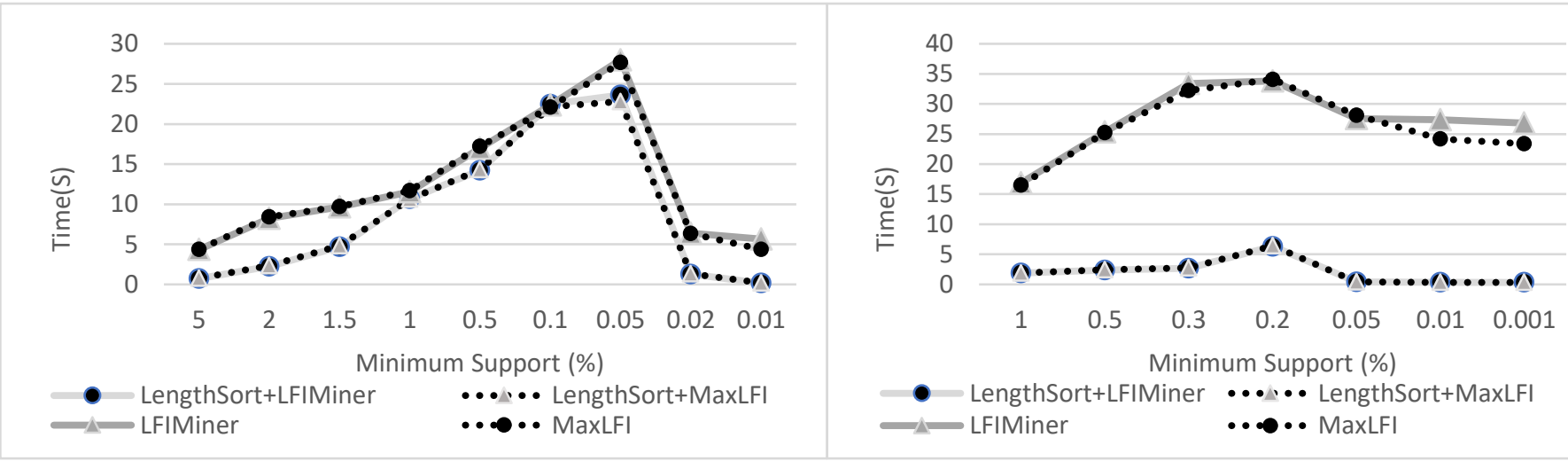

a) Groceries

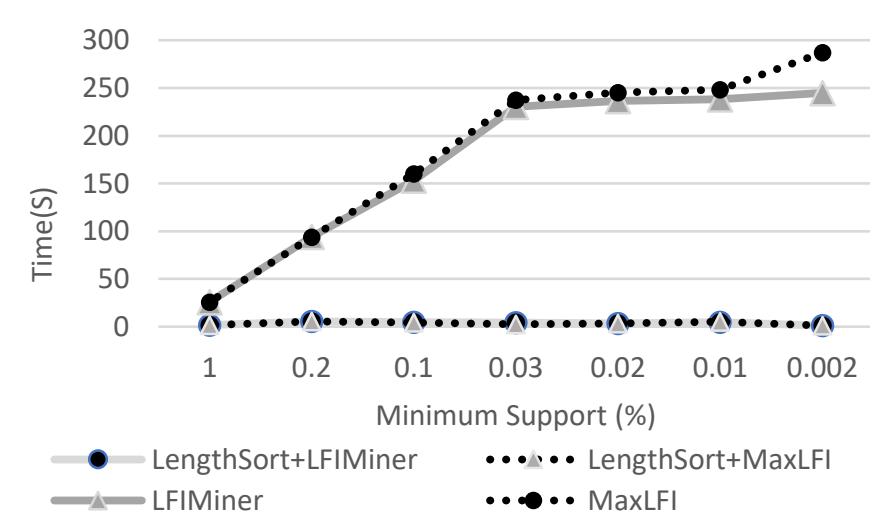

c)BMS-Web-View2

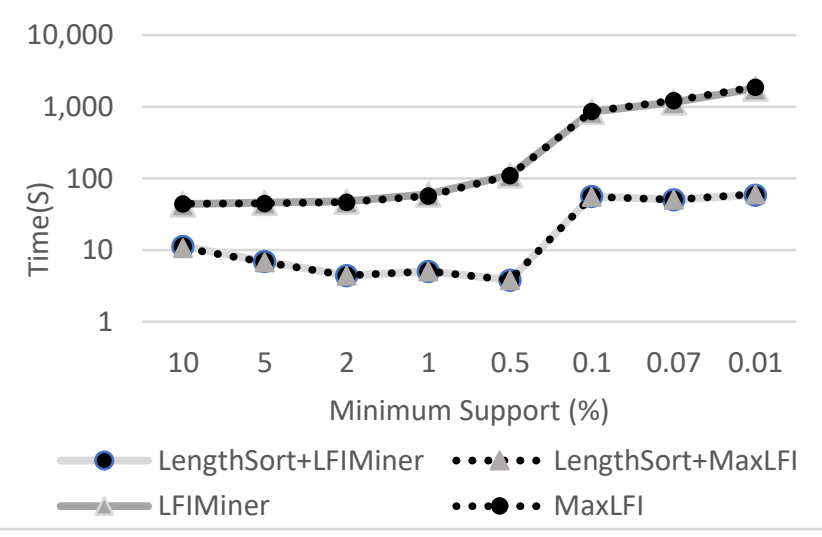

d) Retail 


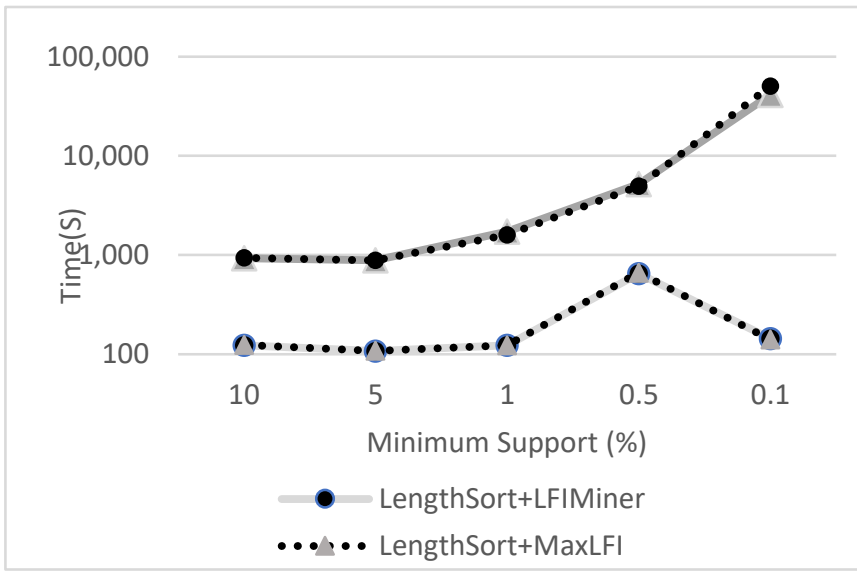

e) Kosarak

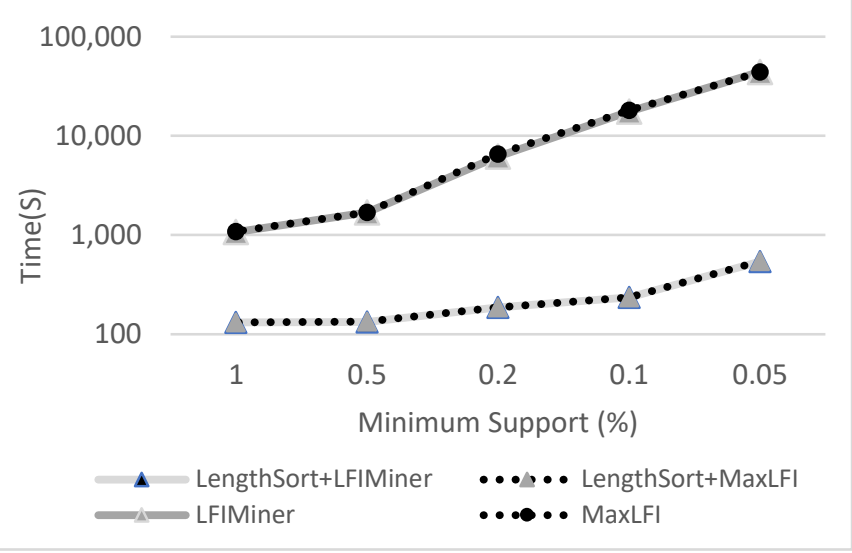

f) Chain Store

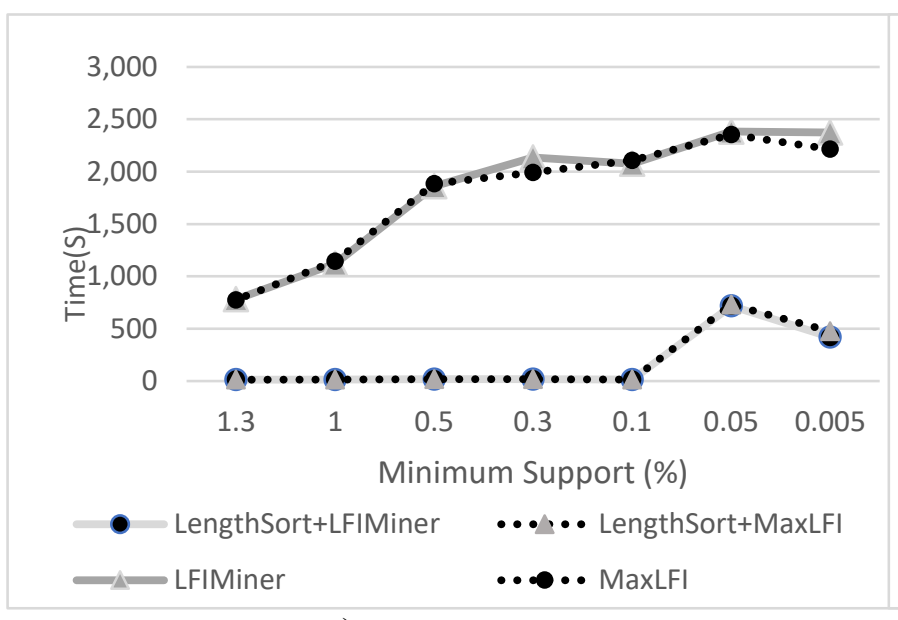

g) T10I4D100K

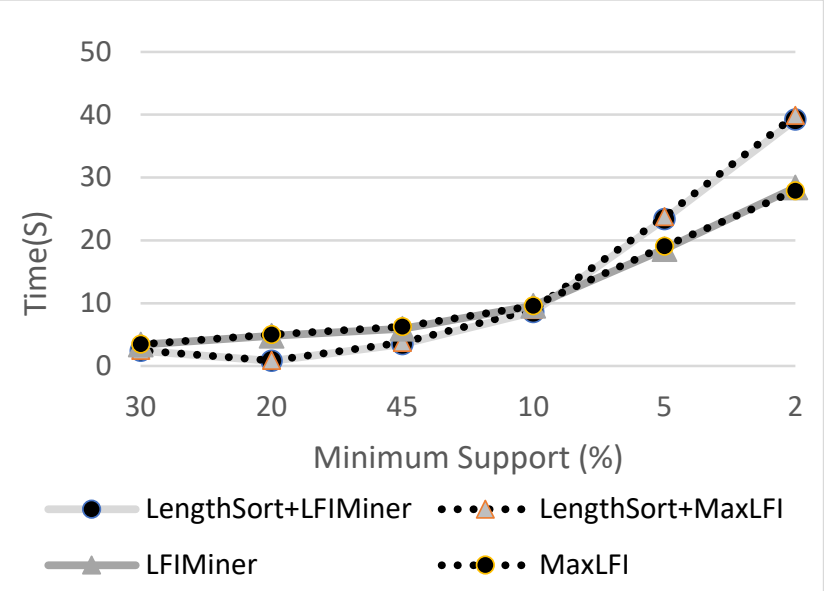

h) Mushrooms

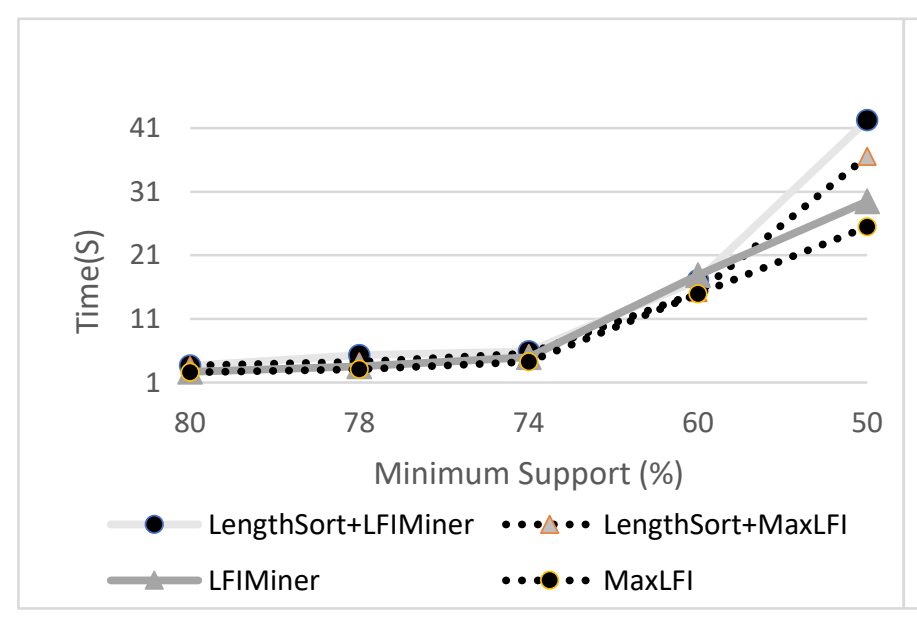

i) Chess

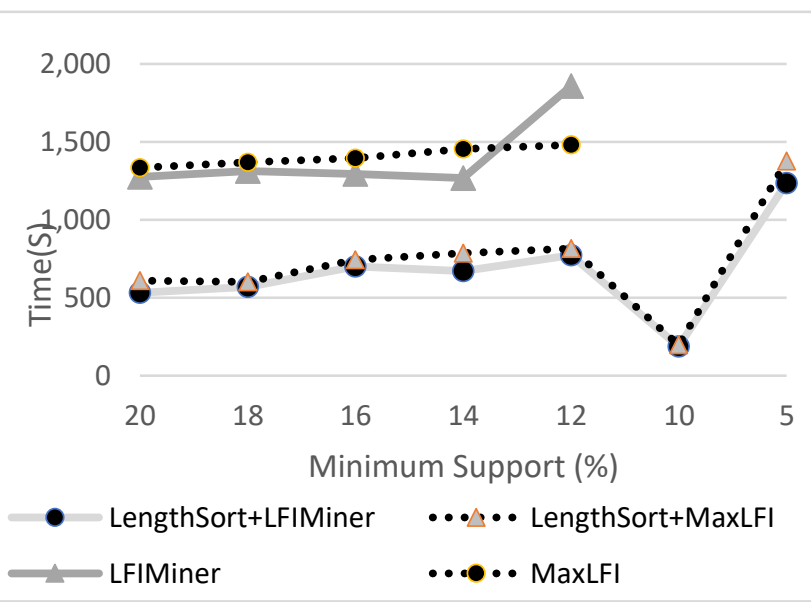

j) Susy

Figure 4-7:Runtime comparison for mining all the LFIs 
In addition, as reported in the experiments performed in (Hu et al., 2008), the runtime of the algorithms does not always increase monotonically as the support decreases. In the Groceries and BMS1 datasets, we can see that, at some point, the runtime decreases as the support decreases. This is because the maximum length increases as the support threshold decreases, resulting in a more effective pruning process (Hu et al., 2008). In the Kosarak and T10I4D100K datasets, this pattern occurs only for Length-Sort. So, in these two cases, the increase in maximum length leads to more effective pruning only for Length-Sort. LFIMiner and MaxLFI performed slightly better on Chess dataset. They are also faster in the lower support values on Mushrooms dataset. These two datasets are dense and have zero variation in the transactions lengths, in other words, all transactions have exactly same number of items. Given that Length-Sort pruning relies on the partitioning of the transactions, we think that the fixed transaction length is the main reason for inferior performance of the Length-Sort. Length-Sort however, performed better on Susy (LFIMiner and MaxLFI did not return the LFI after 20000 seconds for 5 and 10 percent supports) that has similar characteristics to Mushrooms and Chess. As we checked, there are more variations in the support of items Susy. Thus, after removing the infrequent items, the variation between the lengths of transactions also increases and consequently, Length-Sort can better prune further items and transaction. This is also supported by the better performance of Length-Sort in higher support values in Mushrooms dataset. 


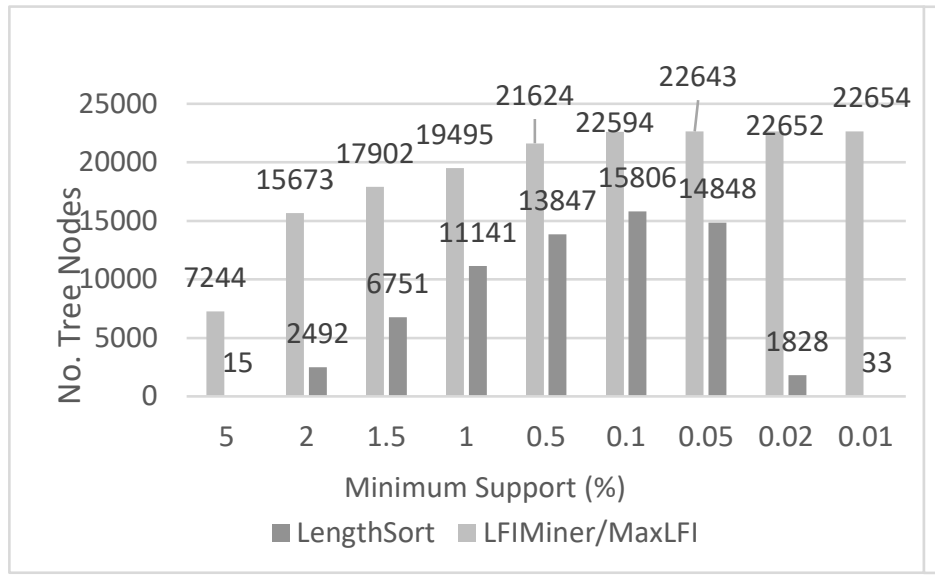

a) Groceries

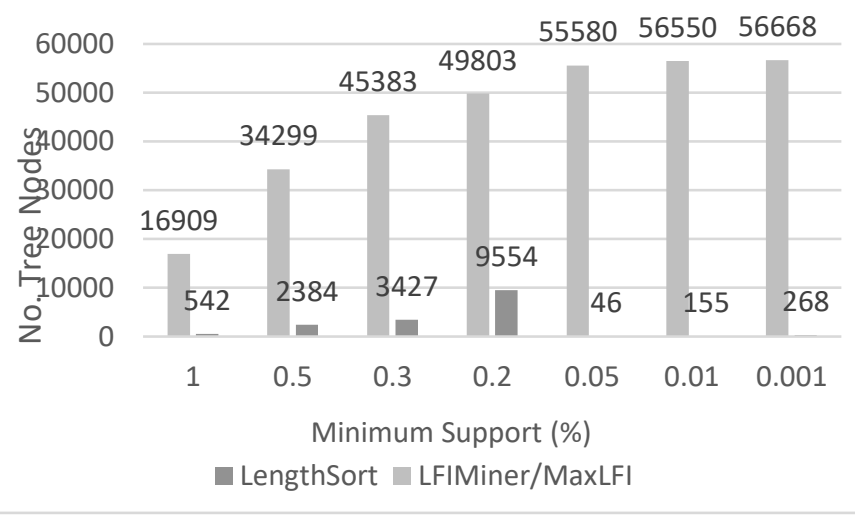

b) BMS-Web-View1

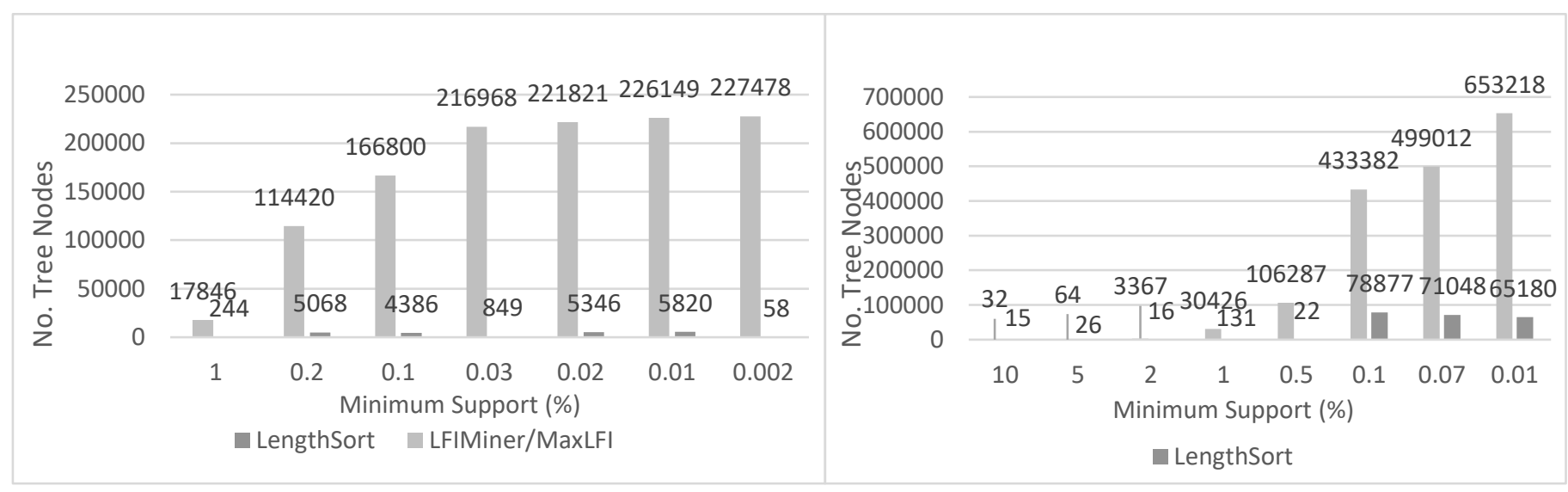

c) BMS-Web-View2

d) Retail

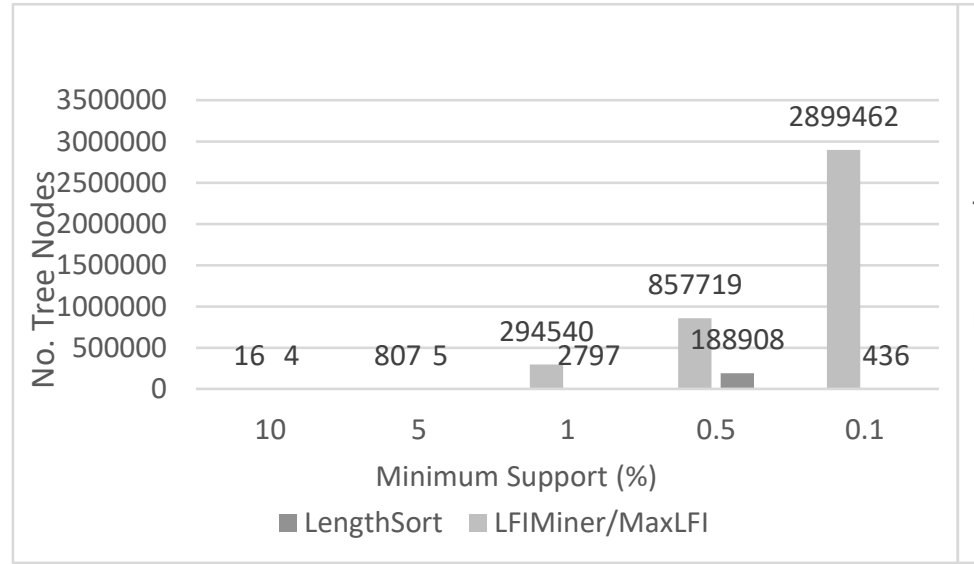

e) Kosarak

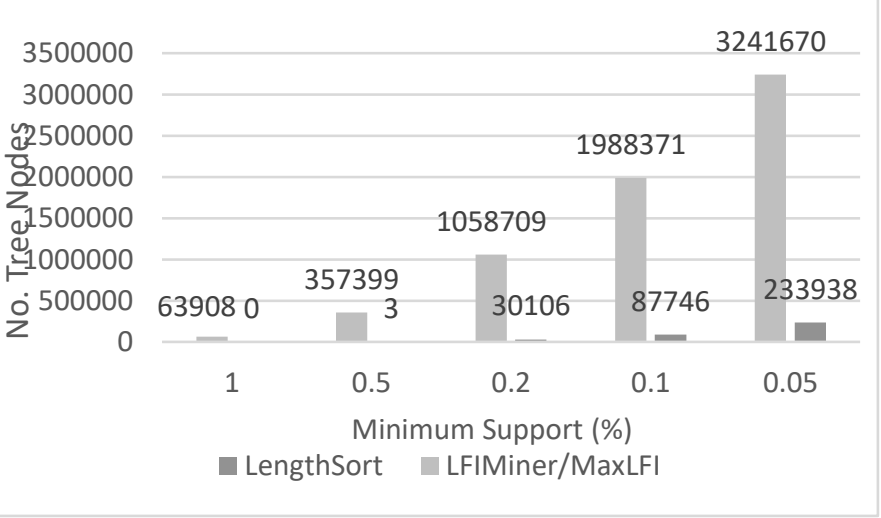

f) Chain Store 


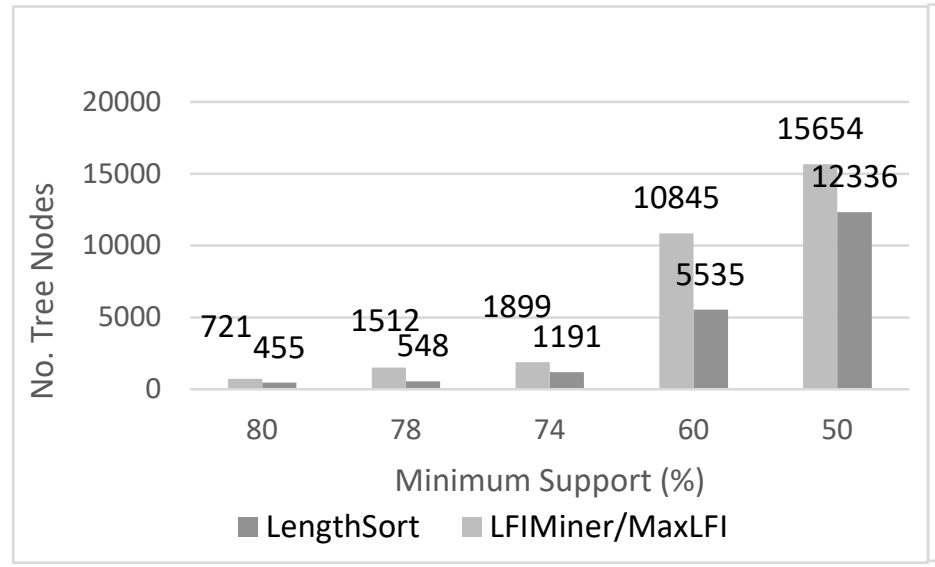

g) T10I4D100K

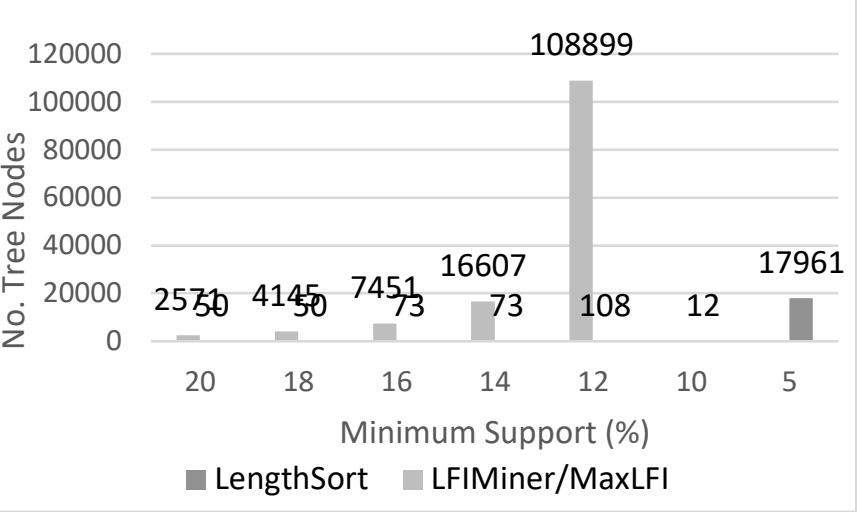

h) Mushrooms

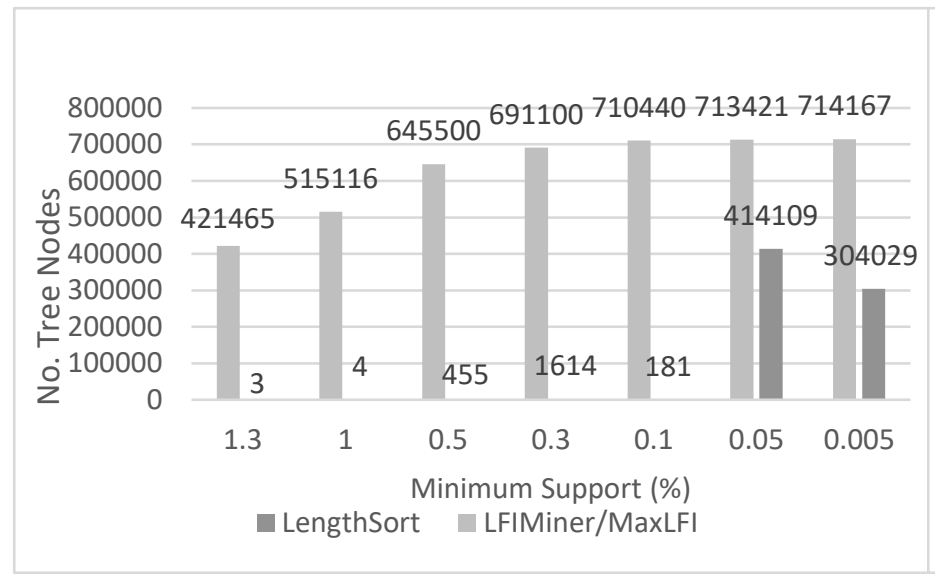

i) Chess

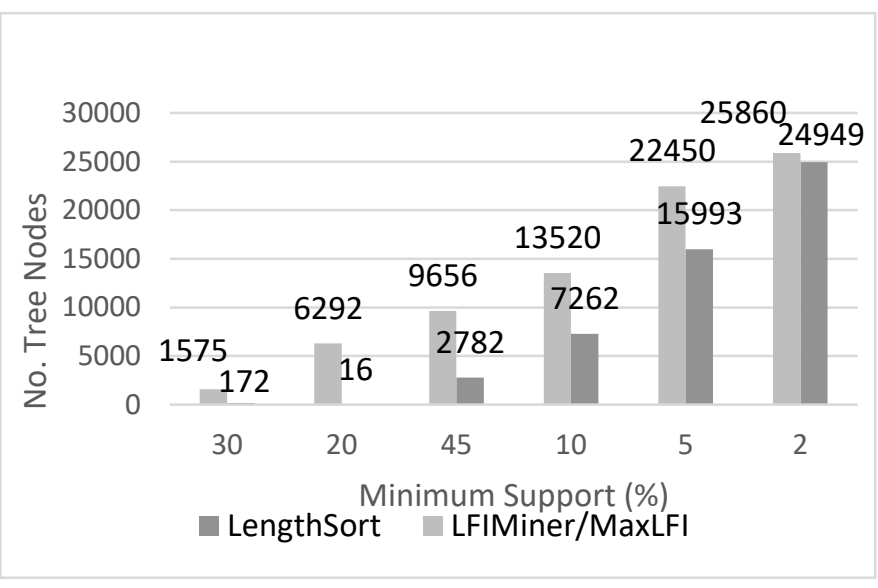

j) Susy

Figure 4-8: Number of initial tree nodes

Figure 4-8 shows the initial FP-tree size in terms of number of tree nodes. The sizes of the initial FP-trees are identical for MaxLFI and LFIMiner, as they use no pruning heuristics prior to the construction of the initial tree. Length-Sort+LFIMiner and Length-Sort+MaxLFI have also the same tree size, thus, only the two different tree sizes are reported in Figure 4-8. Length-Sort reduces FP-trees size significantly in all the experiments performed and, consequently, improves the performance. Chain Store data set at a 1 percent support threshold is a special case, where the size of the tree is 0 (Figure 4-8.f). This is because the upper bound found for the maximum length 
is one, and thus we only have single frequent itemsets and the construction of the tree is not necessary.

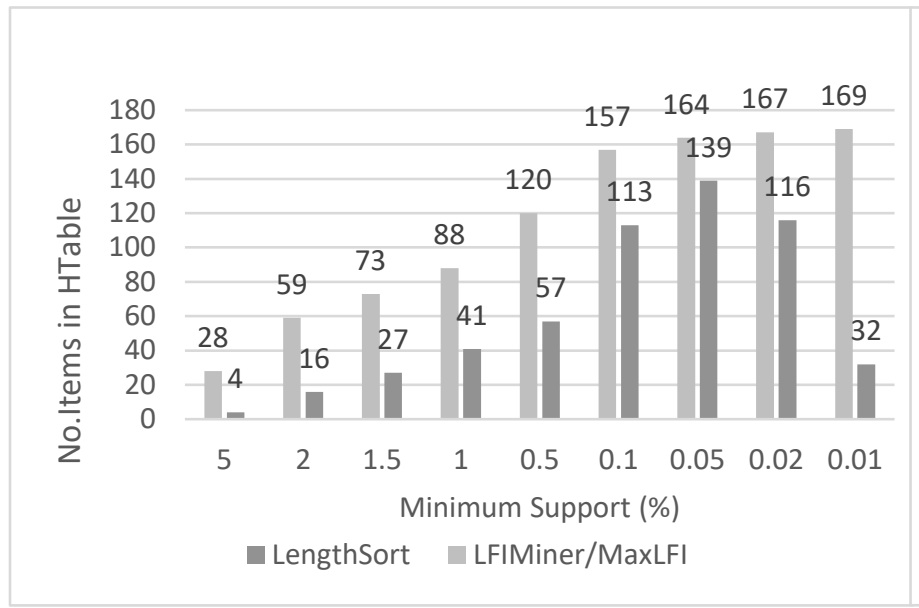

a) Groceries

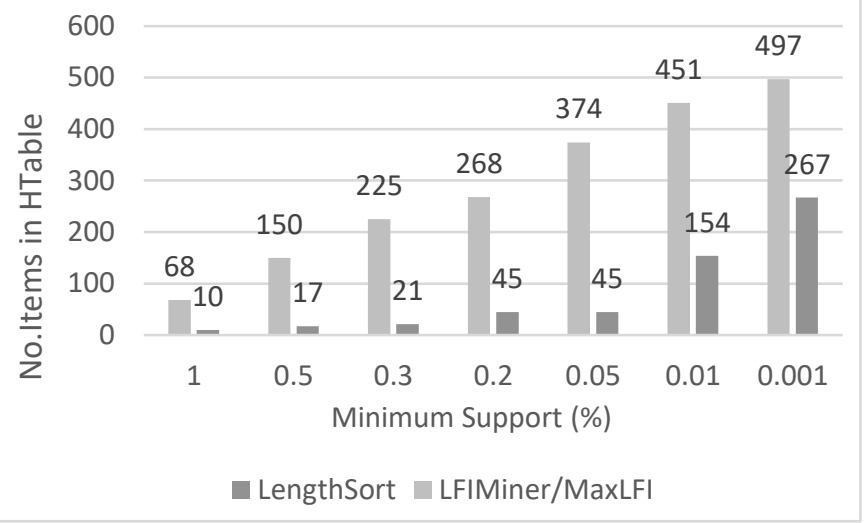

b) BMS-Web-View1

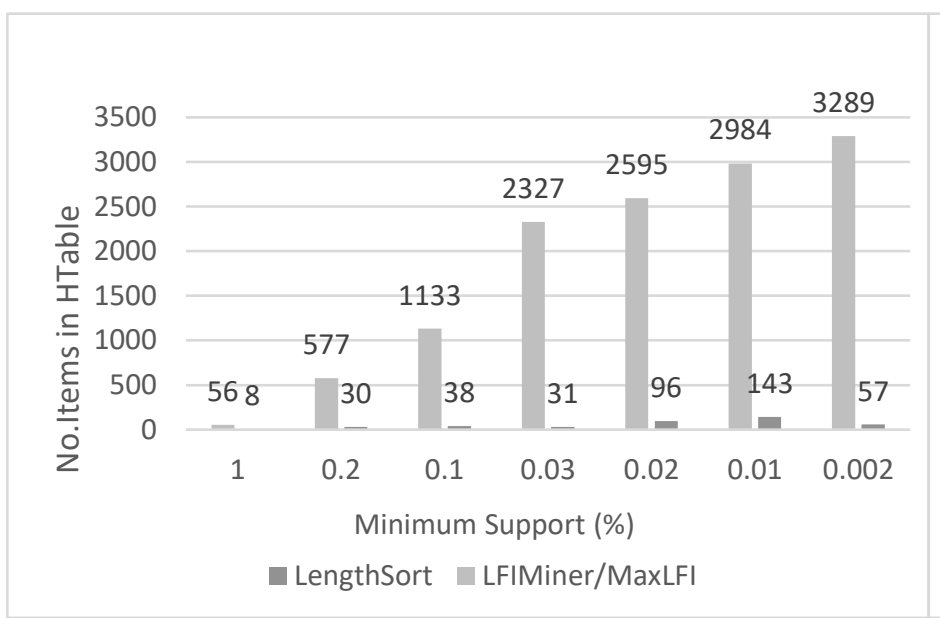

c) BMS-Web-View2

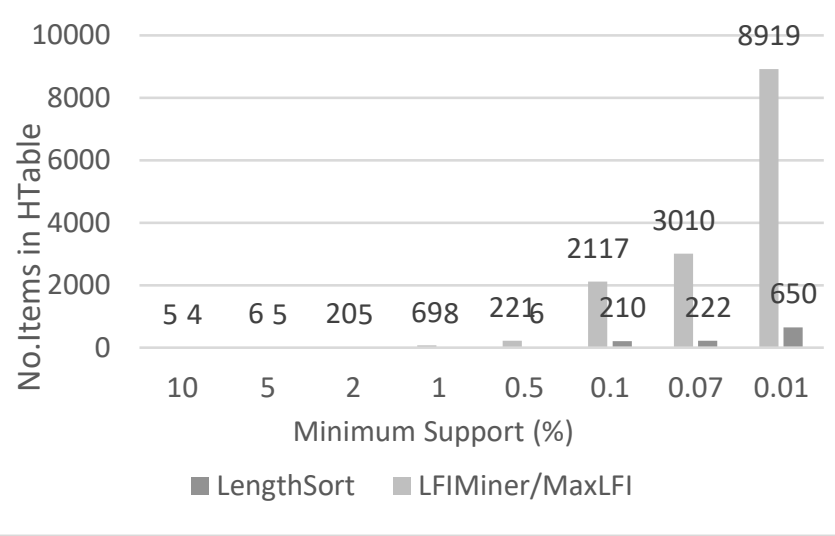

d) Retail 


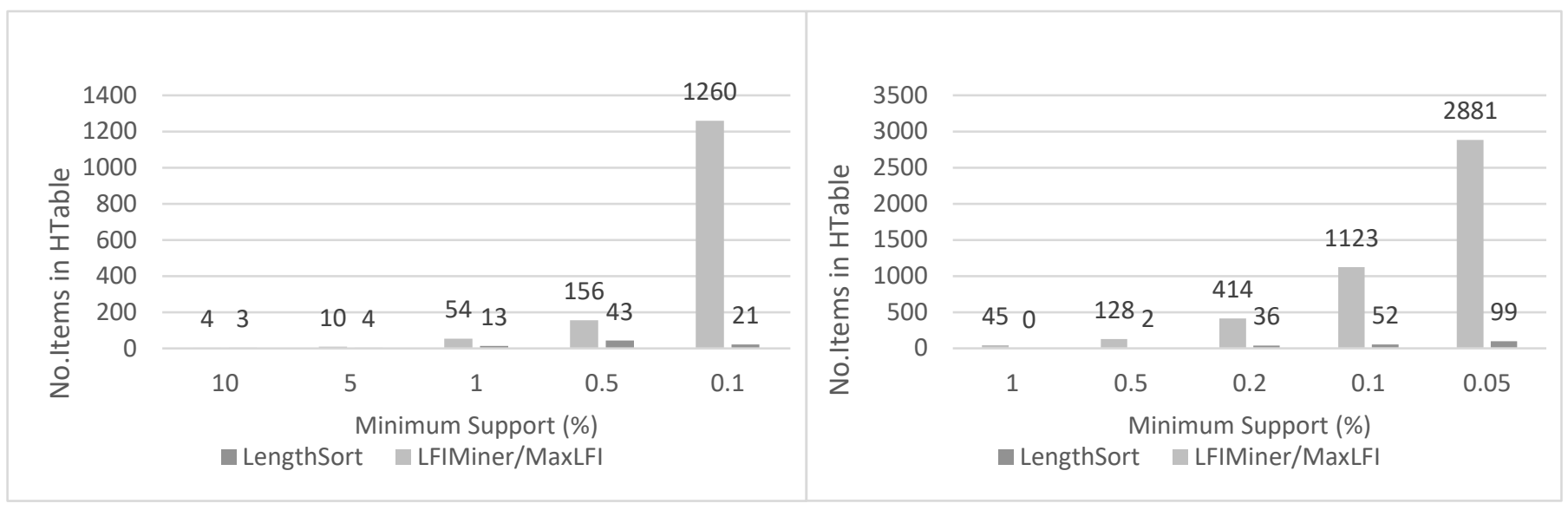

e) Kosarak

f) Chain Store

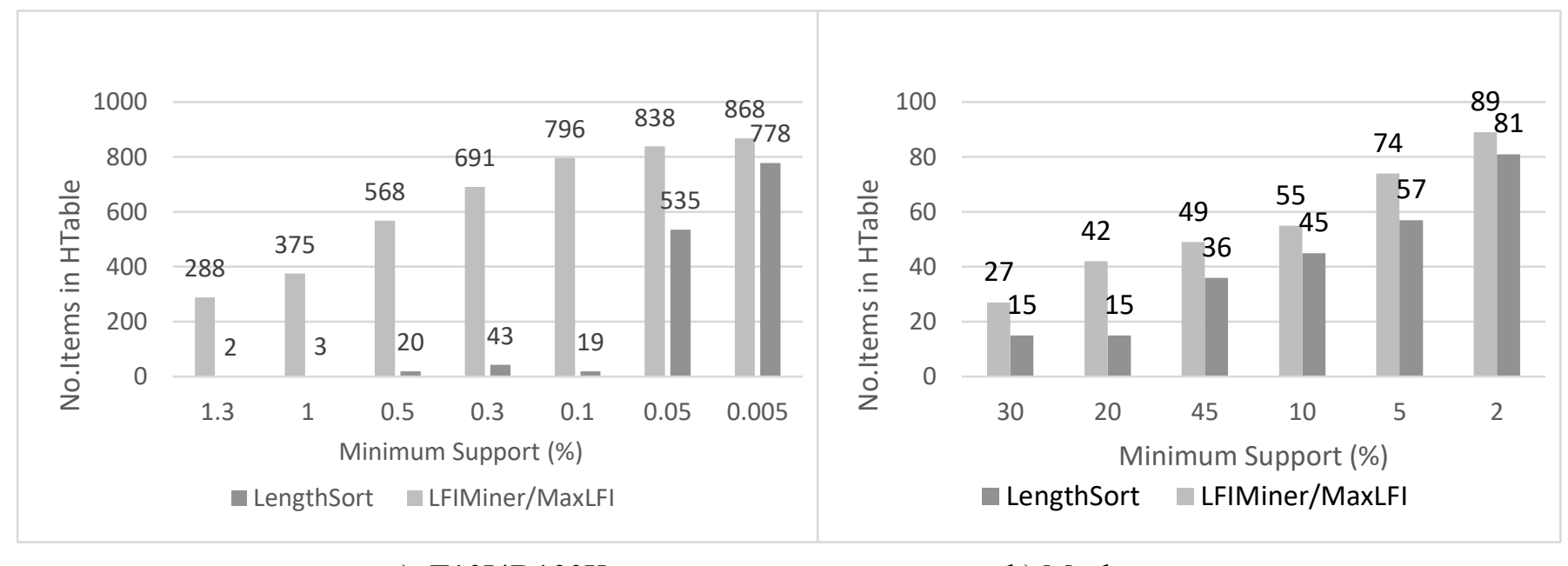
g) $\mathrm{T} 10 \mathrm{I} 4 \mathrm{D} 100 \mathrm{~K}$
h) Mushrooms

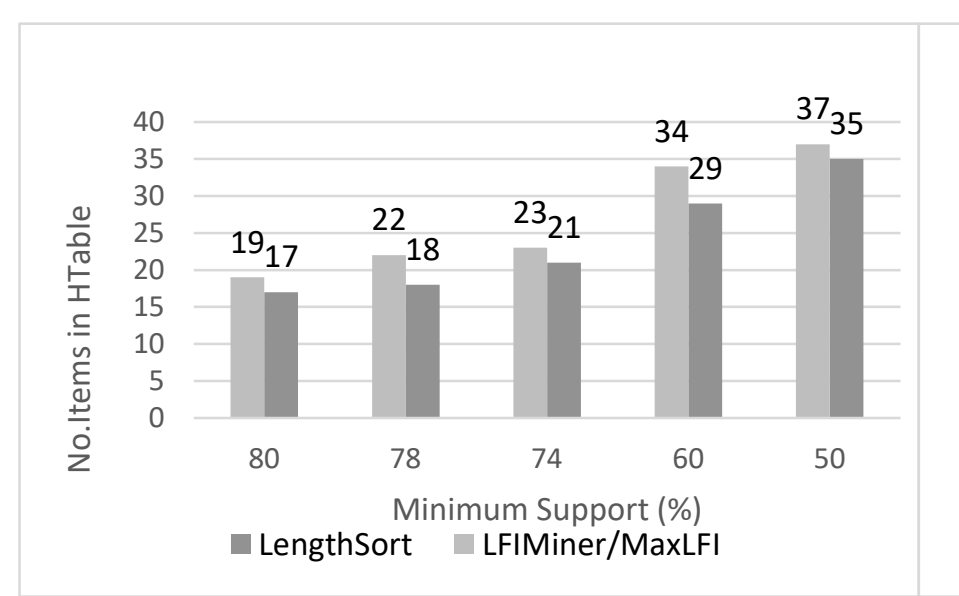

i) Chess

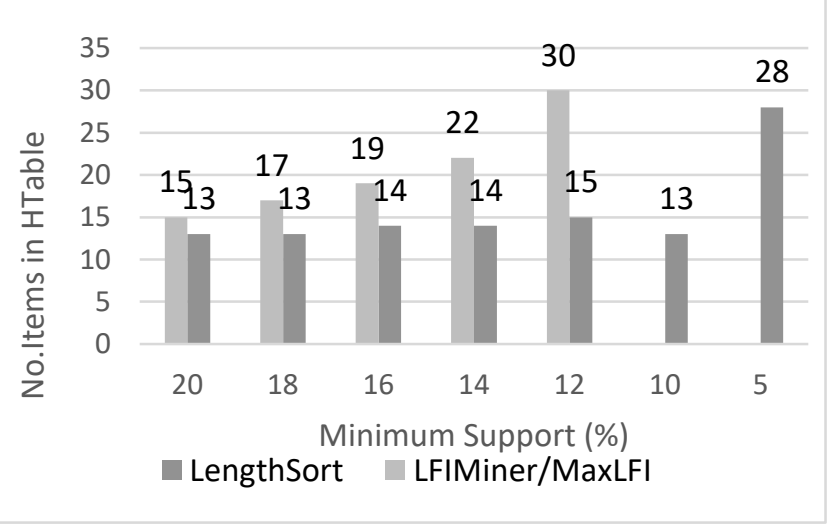

j) Susy

Figure 4-9: Number Items in the H-table 


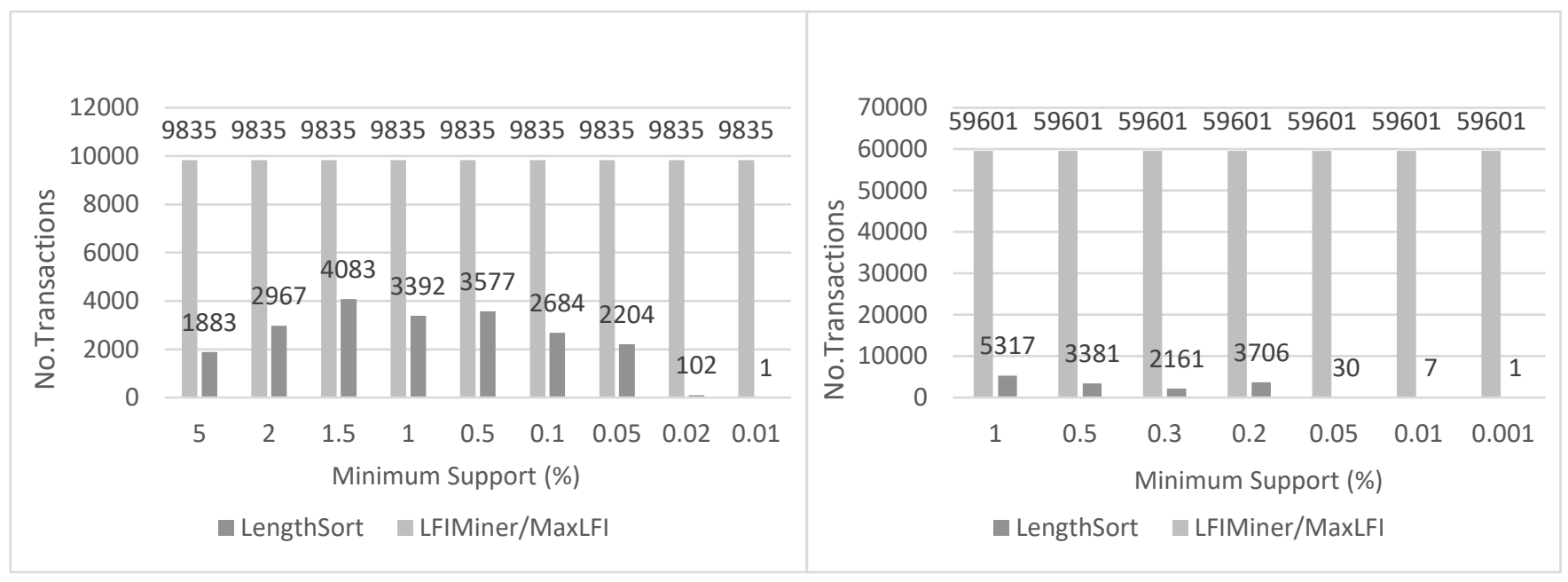

a) Groceries

b) BMS-Web-View1

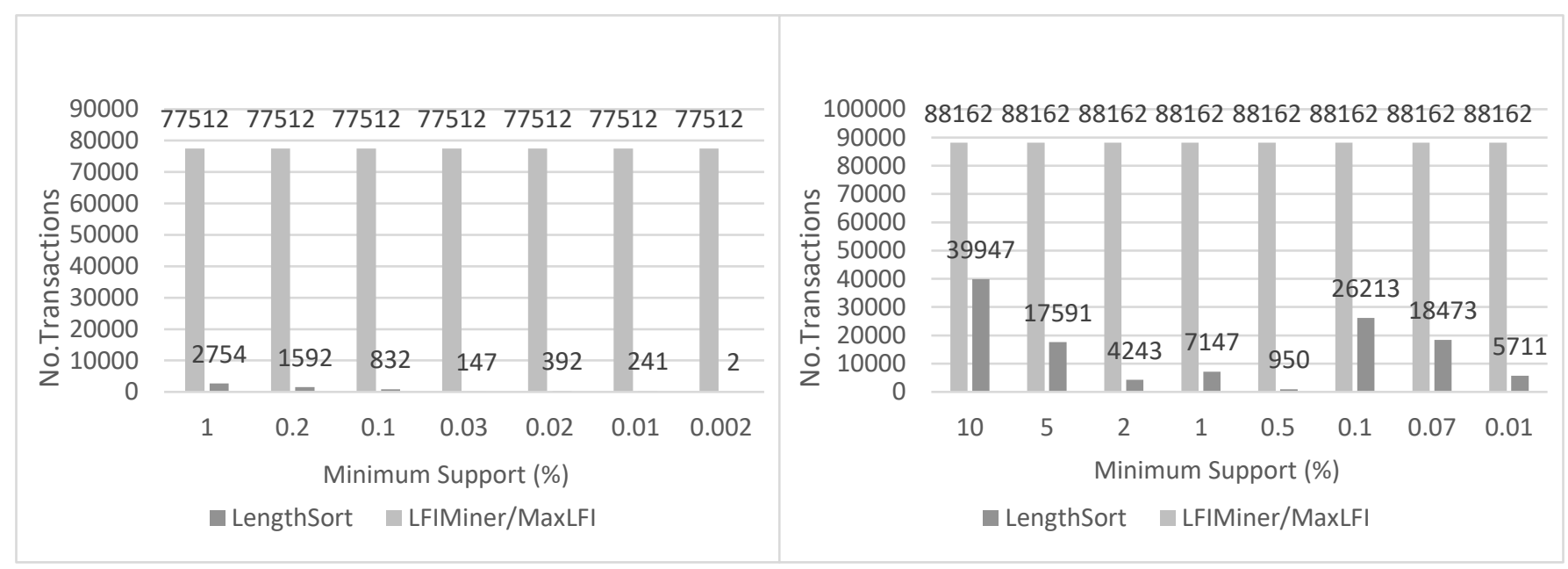

c) BMS-Web-View2

d) Retail

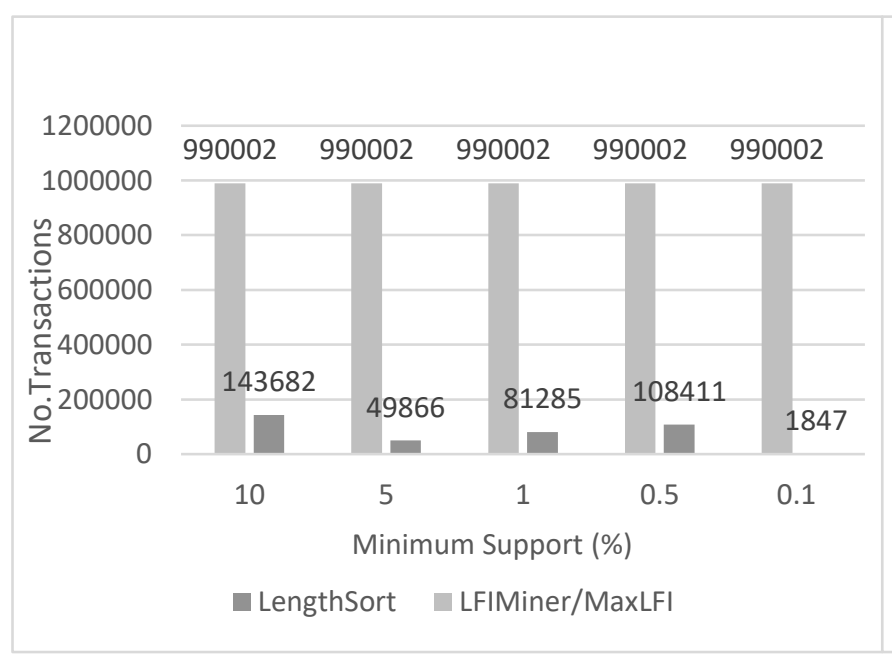

e) Kosarak

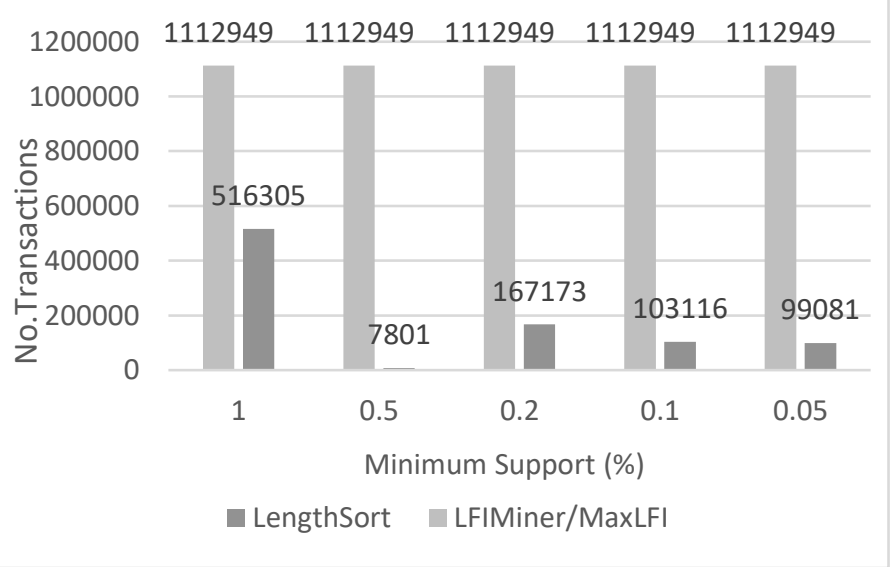

f) Chain Store 


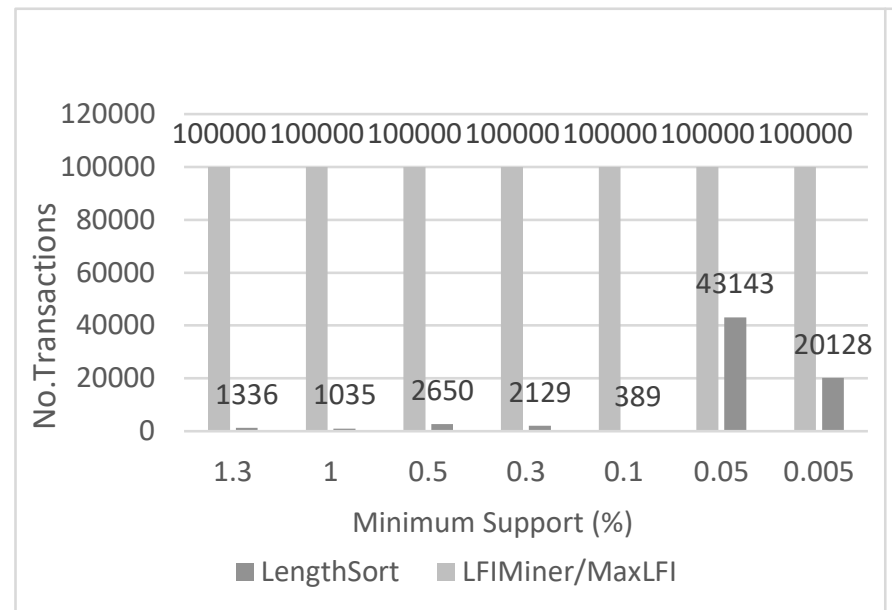

g) T10I4D100K

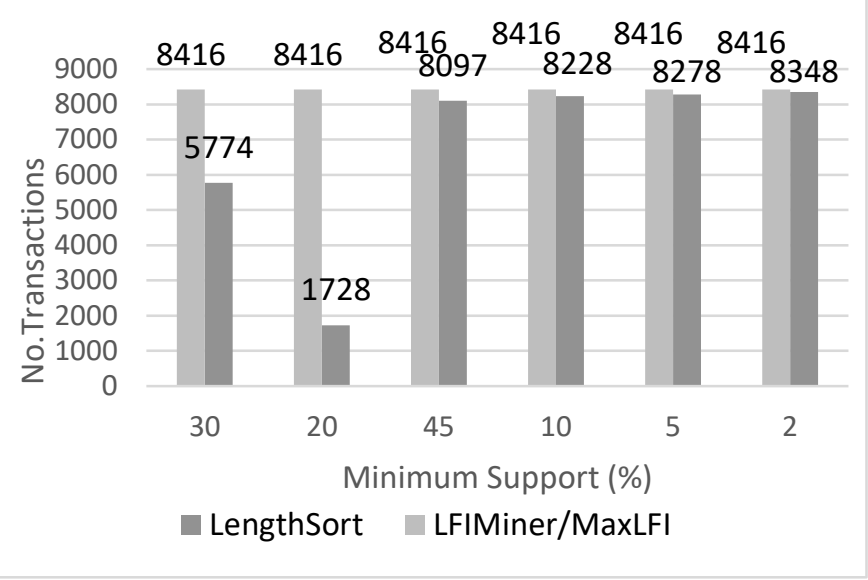

h) Mushrooms

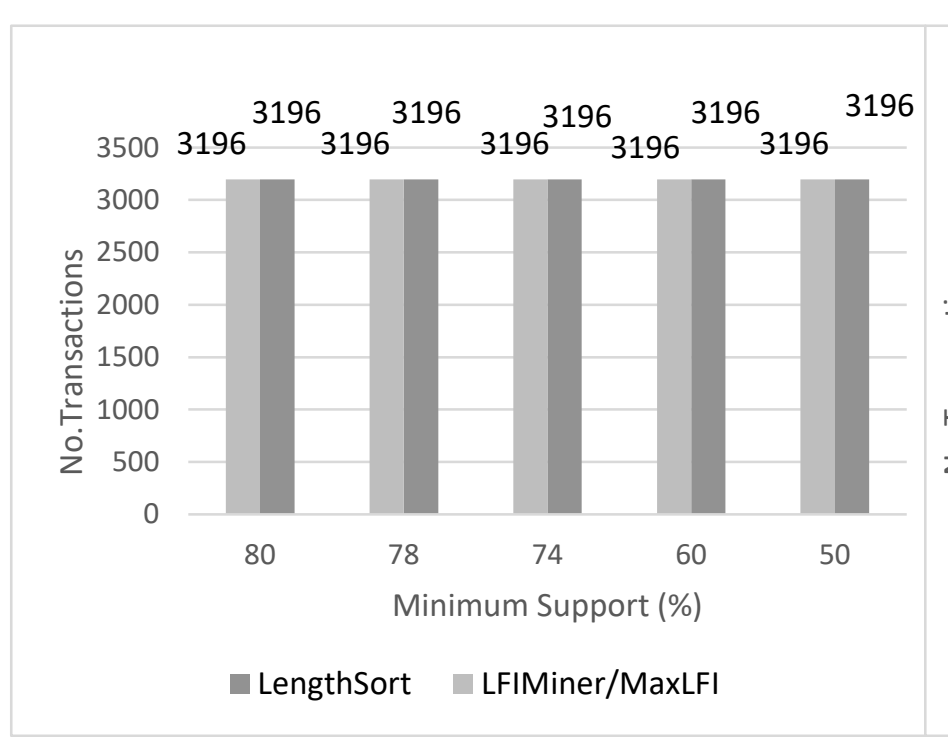

i) Chess

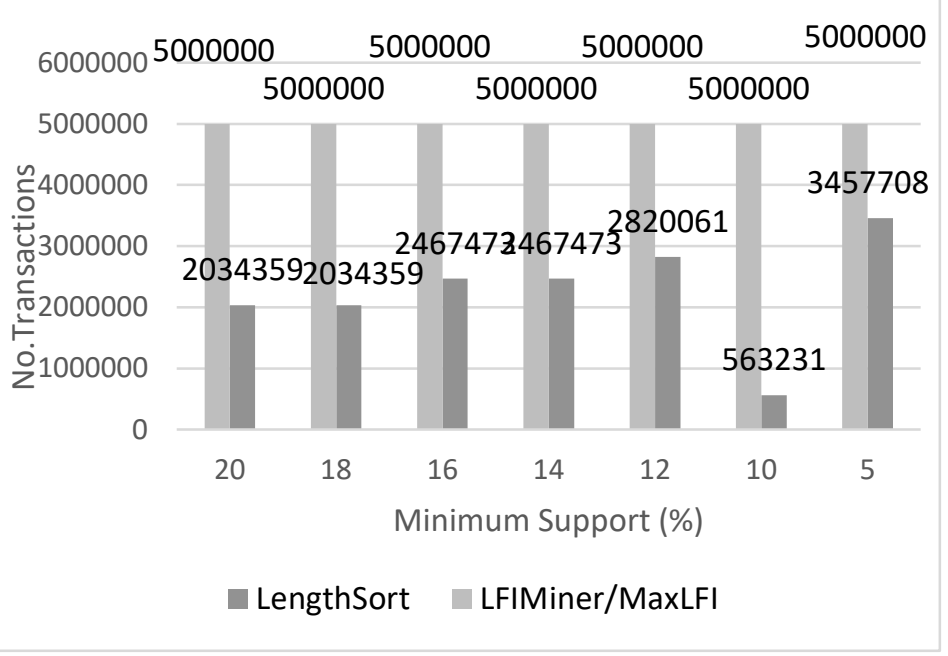

j) Susy

Figure 4-10: Number of transactions involved in constructing the initial FP-tree

Significant reduction to the size of the initial FP-tree is achieved by pruning both the transactions and the items. Figures 4-9 compares the number of items in the H-table and Figure 4-10 gives the number of transactions that are included in the initial FP-tree. The Figures show that, in most cases, only a small fraction of the transactions and/or items are used to construct the initial FP-tree. For LFIMiner and MaxLFI, the number of items in the H-table always increases as the minimum 
support threshold decreases. This is expected, as only the items whose support is less than the threshold are dropped. However, Length-Sort also prunes the items than cannot contribute to the itemsets that are long enough according to the estimated maximum length. For Length-Sort, if we compare the number of the included itemsets in the runs, in more than 14 percent of the instances ( 8 out of 56), the number of items decreased as the support threshold increased.

The number of transactions included in tree construction is constant in LFIMiner and MaxLFI, regardless of the threshold. Length-Sort, on the other hand, prunes the transactions and, as depicted in Figure 4-10, in some instances, the number of transactions is reduced as the support threshold decreases. As an example, consider the extremely low threshold support in the Groceries and BMS-Web-View 1 datasets (Figure 4-10.a and 4-10.b). We see that only one transaction has survived the pruning. The support count in these two examples is equal to one, so the only element in the LFI is the longest transaction in the dataset. As the longest transaction is unique in both datasets, only one transaction is included. This is the reason that in some datasets, the Length-Sort running time decreases as the support threshold decreases. Small support thresholds can increase the maximum length, and as the maximum length increases, more transactions and consequently more items are pruned. Figures 4-10.i and 4-10.h, show that the number of included transactions are very similar for Chess and lower support values of Mushrooms. This leads to the lower performance of Length-Sort on the two datasets.

Figure 4-11 gives the estimated maximum length (upper bound), the actual maximum length and the number of itemsets in the LFIs. 


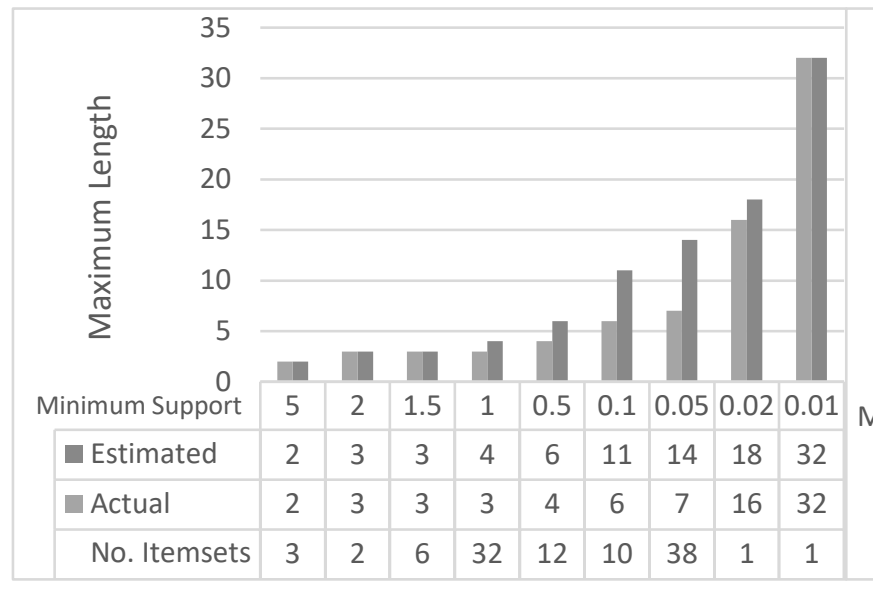

a) Groceries

c) BMS-Web-View2

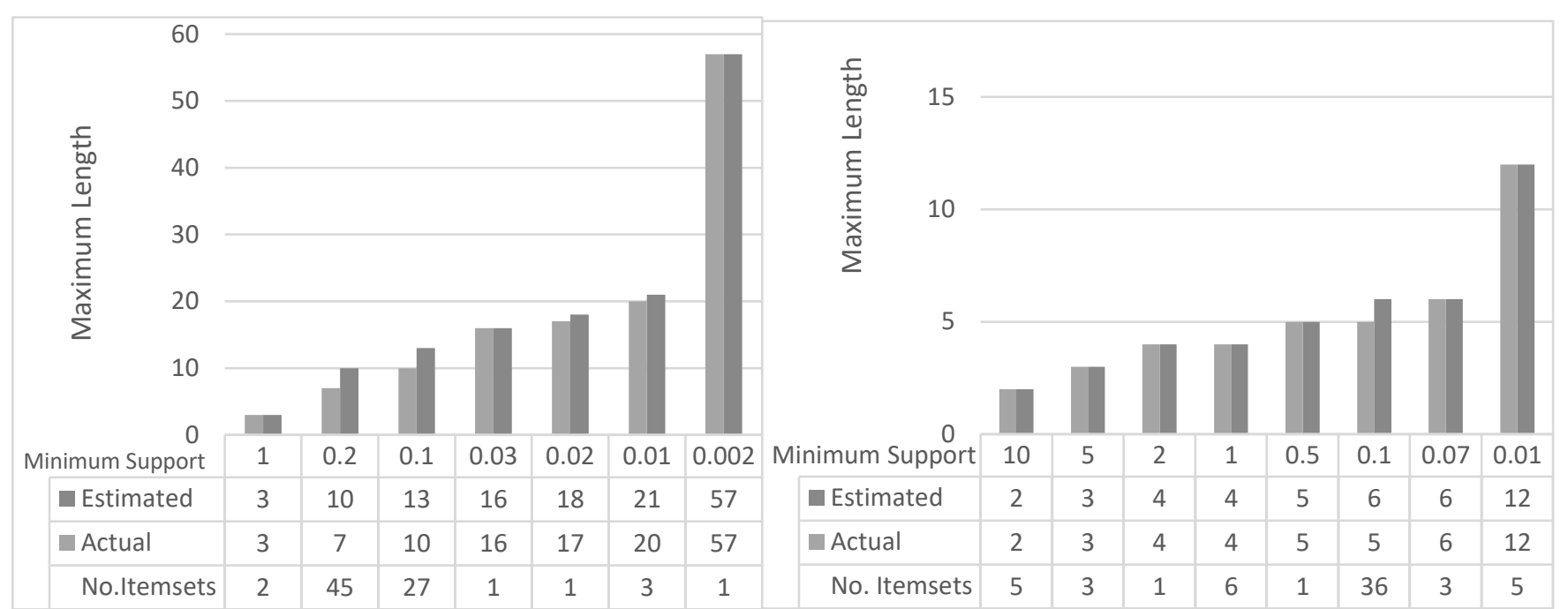

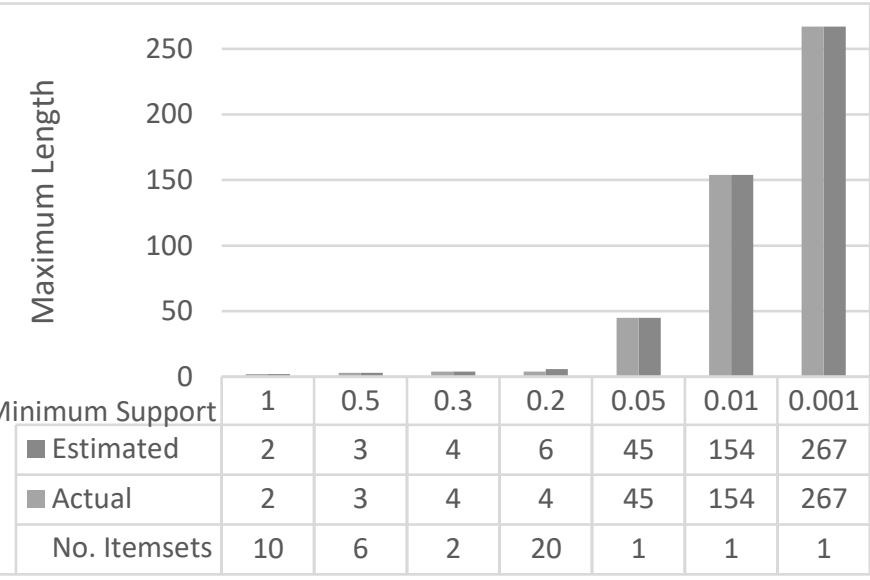

b) BMS-Web-View1

d) Retail

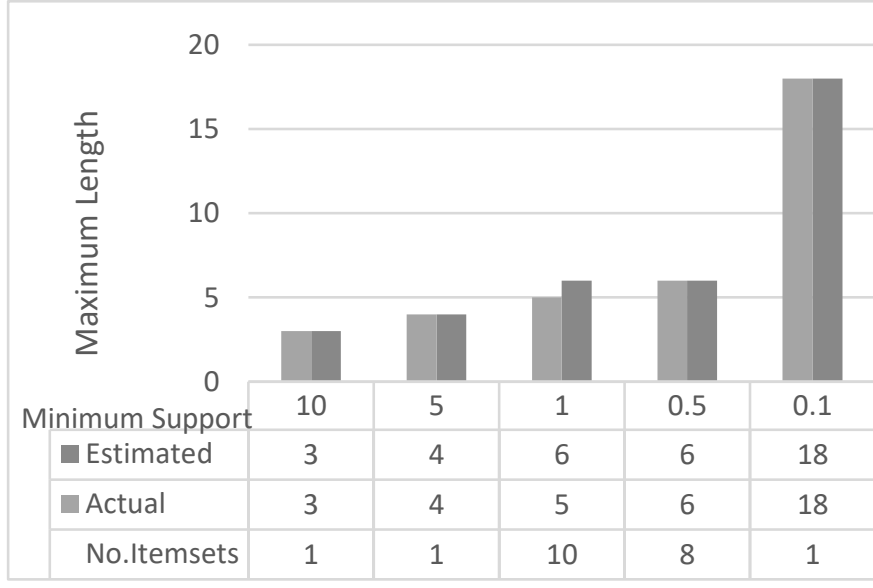

e) Kosarak

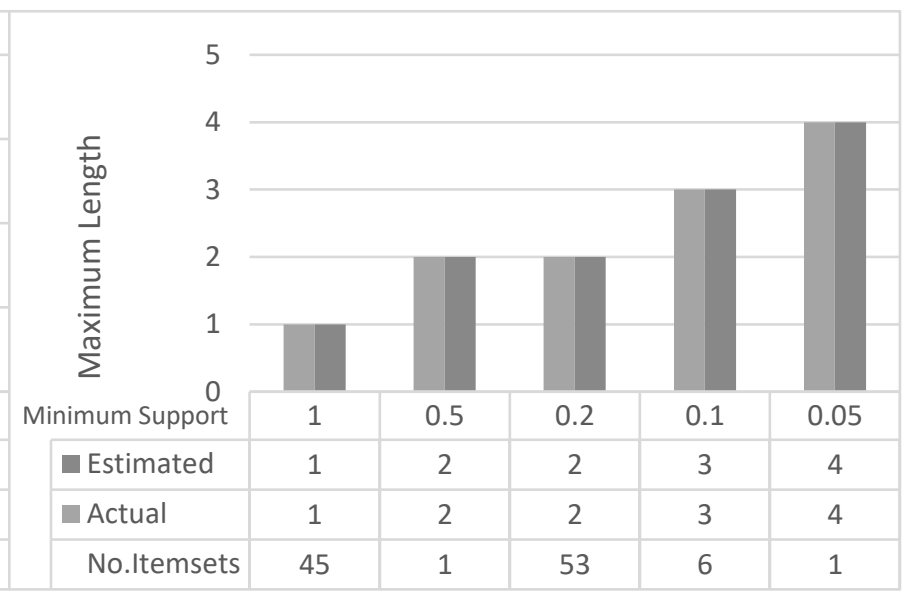

f) Chain Store 


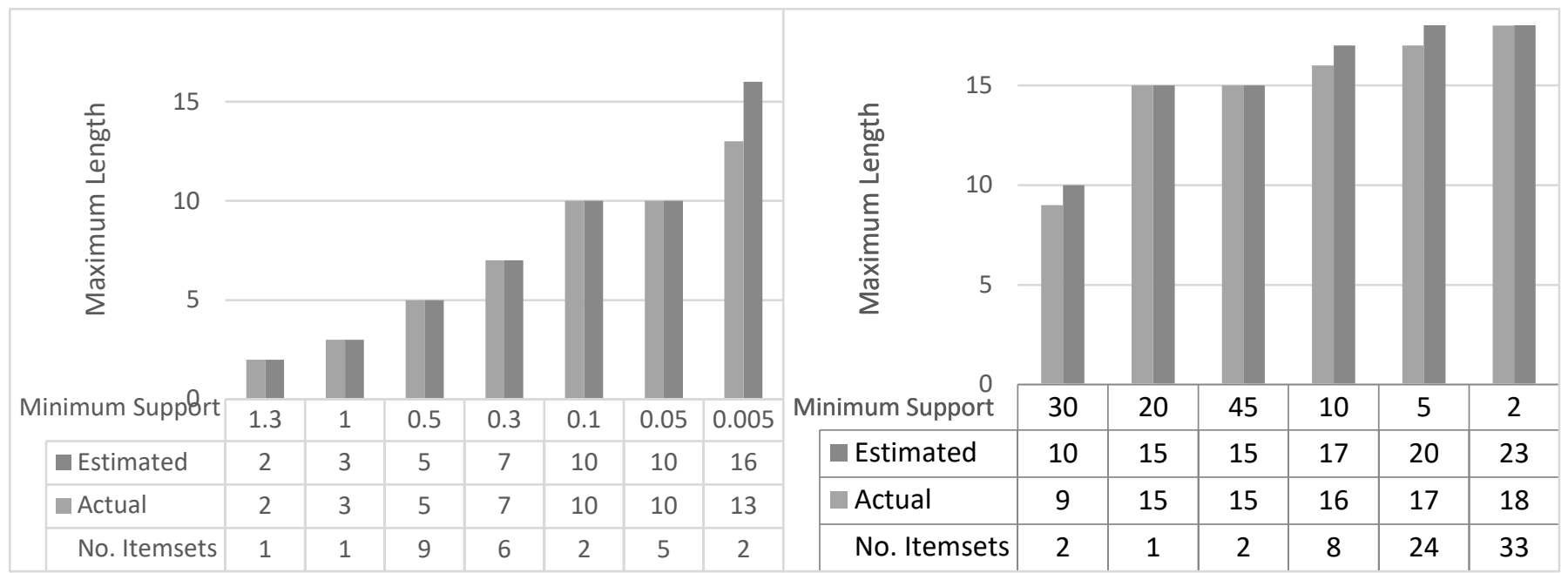

g) T10I4D100K

h) Mushrooms

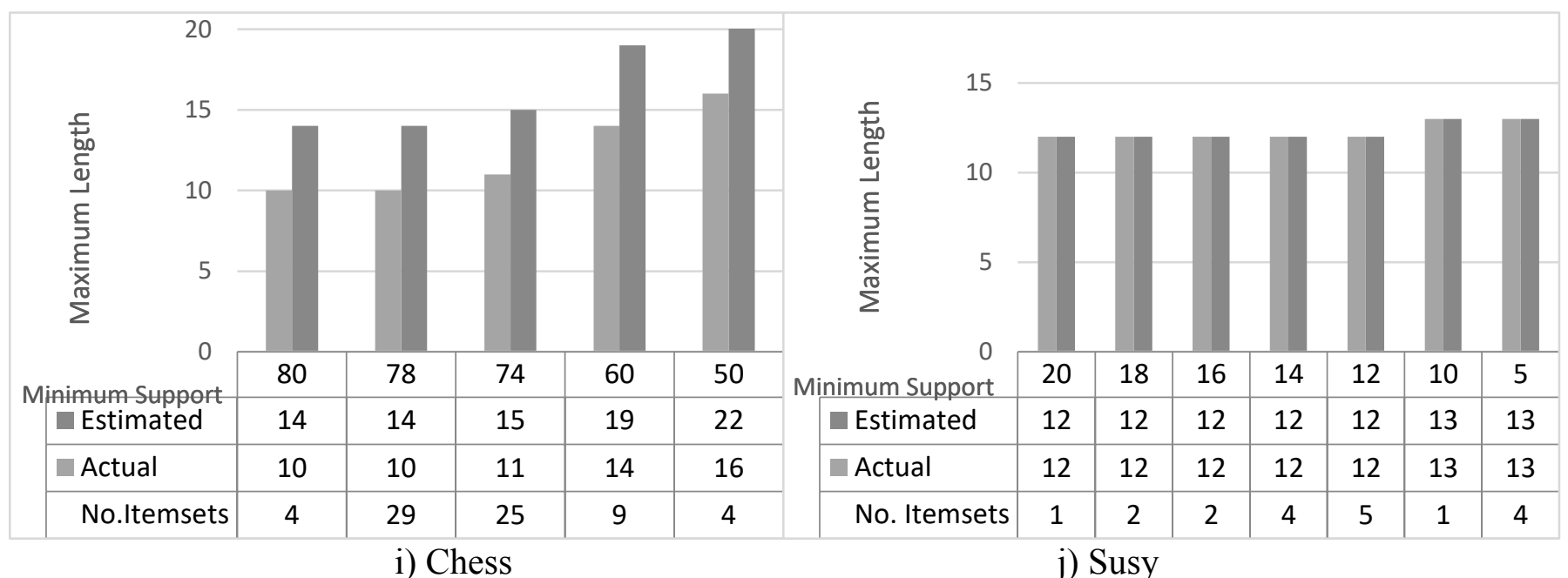

Figure 4-11: Estimated and actual maximum length of the frequent itemsets

As mentioned, the second run of the Length-Sort procedure and the updating to the FP-tree are both needed in the event that the estimated and actual maximum length are not equal. The second run of the Length-Sort was necessary in five of the nine experiments performed on the Groceries, four out of six for Mushrooms and all cases of the Chess dataset. The maximum difference between the actual and estimated maximum length also occurs in the Groceries dataset (14 vs 7 for a 0.05 percent threshold). When comparing with the other datasets, the ratios of the items that survived the pruning are higher in the Groceries, Mushrooms, Chess and Susy datasets (See Figure 4-9). So 
a less successful item pruning may contribute to the inaccurate estimate of the maximum length. It also worth mentioning that these datasets are denser than the other datasets. However, as we can see from Figure 4-7, Length-Sort results in improvements to the run time of the LFI mining process in the most cases when the estimated length was not accurate and an FP-tree update was necessary. As shown in Figure 4-11, the estimated maximum length is accurate in most of the experiments carried out on the other datasets. Length-Sort decreased the running time in all the instances that the estimated lengths were accurate.

On comparing the number of itemsets in the LFIs with the actual and estimated lengths, an inaccurate estimation of maximum lengths usually occurs when several itemsets are present in the LFI. So we argue that the accuracy of estimation does not depend on the length of the itemsets, but rather on the number of itemsets in the LFI. To summarize, the variation of the transactions' lengths, density of the dataset and the number of itemsets in LFI, are the main influencing factors on the accurate estimation of the length.

To test the scalability of the proposed algorithm, five synthetic datasets with different number of transactions were generated using IBM Quest dataset generators (available at ("IBM Quest Synthetic Data Generator," n.d.)). Figure 4-12 shows the parameters used to create the datasets and the runtime of the algorithms with respect to their dataset size. Except for the number of transactions, all the parameters were kept the same for generating the five datasets. As these parameters are the same, the five datasets are very similar and they differ only in the size. The minimum support threshold was fixed on 0.5 percent during the experiment. The results show that Length-Sort achieves good performance in terms of scalability. 


\begin{tabular}{|cc|}
\hline Parameters & \\
\hline No. transactions & $100 \mathrm{~K}-500 \mathrm{~K}$ \\
Average length of transactions & 10 \\
Number of items & 5000 \\
\hline
\end{tabular}

a) synthetic dataset parameters

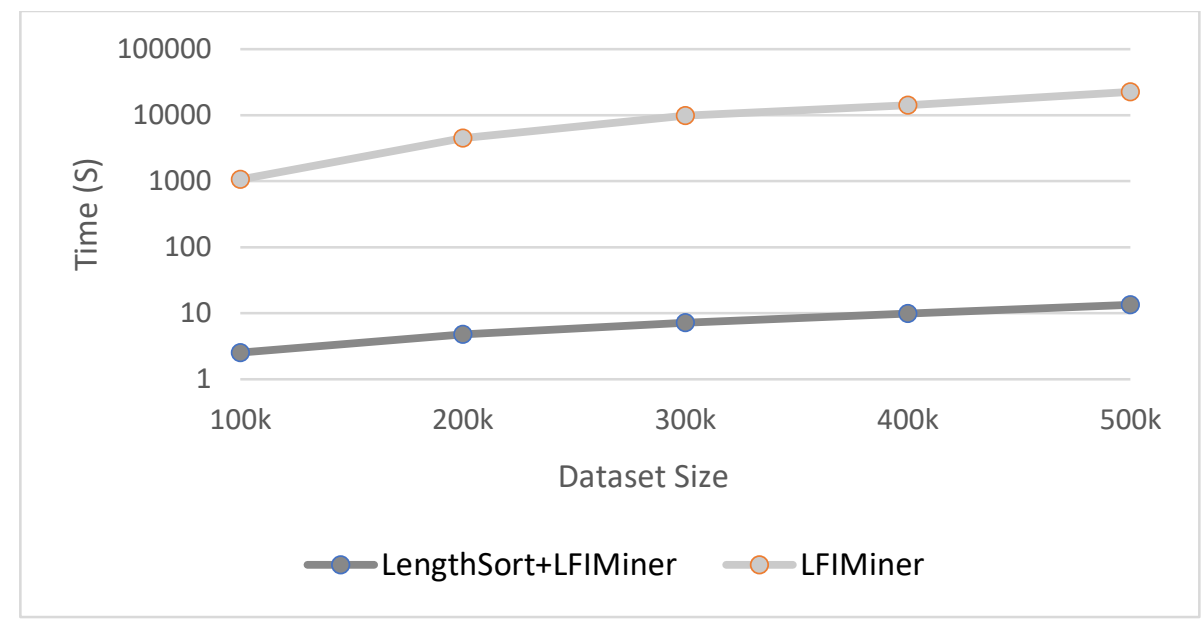

b) scalability test results

Figure 4-12: Scalability analysis of Length-Sort

As mentioned in Section 2.3.2, LFI can be mined by post-pruning the output of MFI algorithms.

To compare the performance gap, we performed the experiments on a subset of abovementioned datasets. Figure 4-13 shows the running times of INLA-MFP and Length-Sort+INLA-MFP. 


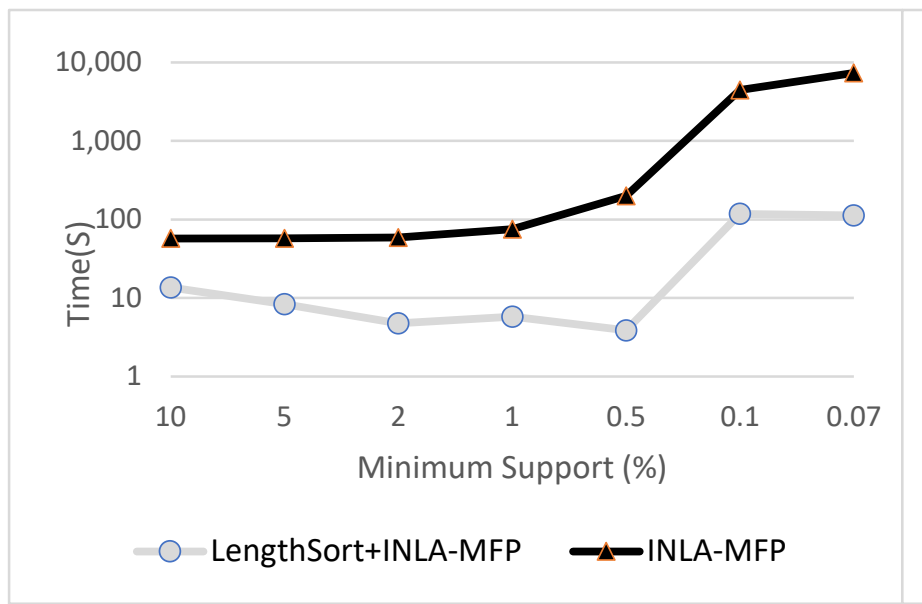

a) Retail

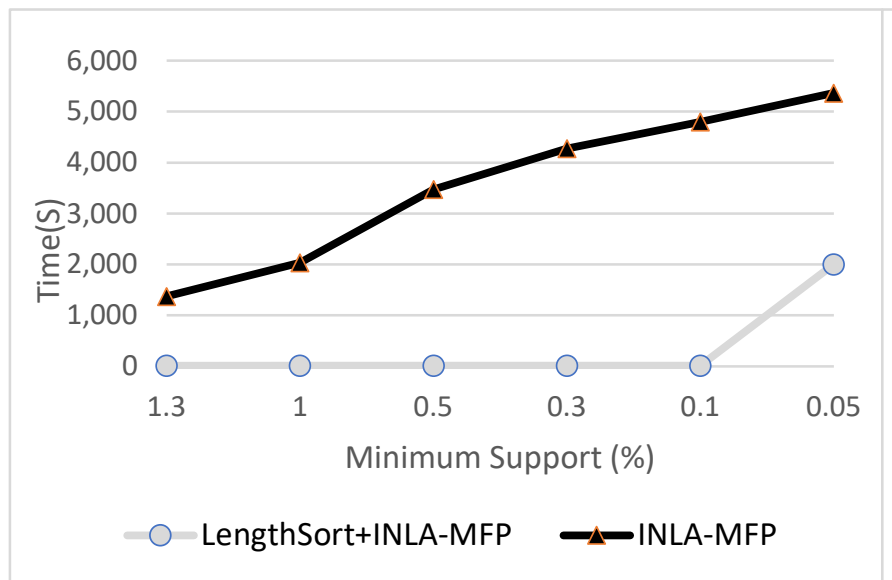

c) T10I4D100K

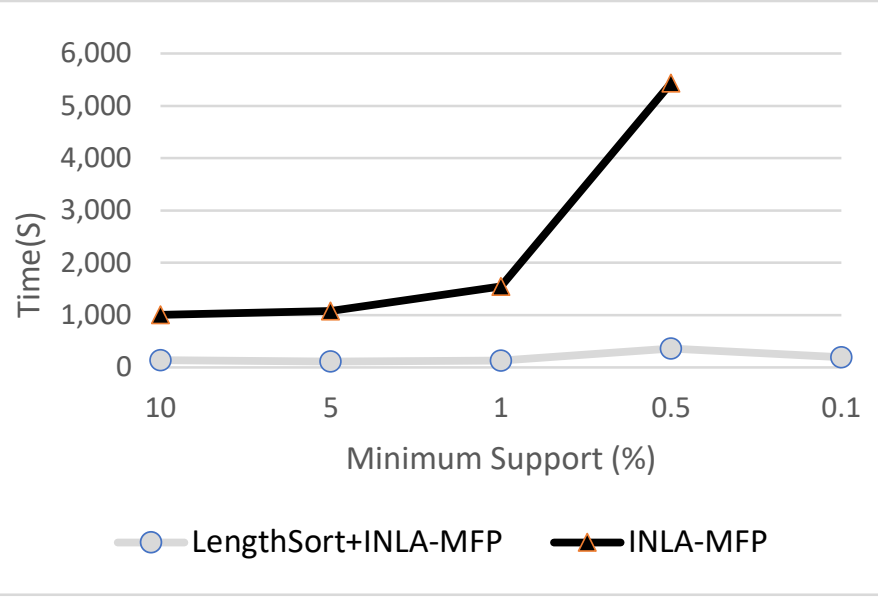

b) Kosarak

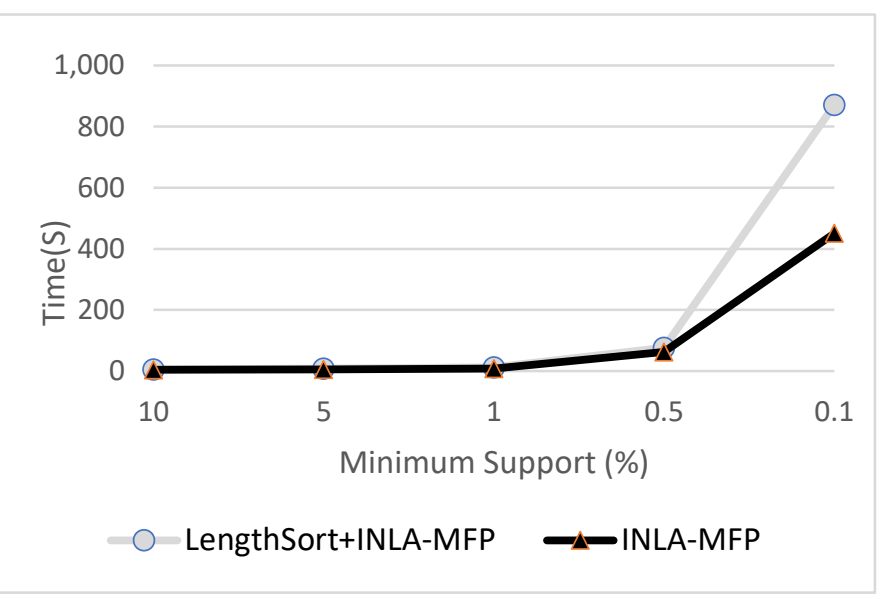

d) Chess

\section{Figure 4-13: Runtime comparisons for INLA-MFP and Length-Sort}

As can be seen from Figure 4-13, INLA-MFP runtimes are greater than the ones of LFIMiner and MaxLFI (see Figure 4-7) except for 1 percent support in Kosarak dataset. It should be noted that INLA-MFP returns the complete set of MFI while the other two algorithms return LFI which is smaller. Moreover, unlike LFIMiner and MaxLFI, INLA-MFP does not prune the itemsets that are not long enough to be part of LFI. This increases the runtime of the INLA-MFP.

The figure also demonstrates that Length-Sort can significantly improve the efficiency of the INLA-MFP except in Chess dataset, however Length-Sort+LFIMiner and Length-Sort+MaxLFI 
are still faster (except for 0.5 percent support in Kosarak) in mining LFI. FP-growth based mining algorithms (LFIMinwr and MaxLFI) are less efficient when it comes to sparse datasets (Deng et al., 2012). Length-Sort in fact makes the datasets denser by pruning the transactions and items. So Length-Sort prepares a denser input and is suitable to be coupled with FP-growth based algorithms. Length-Sort+ INLA-MFP is useful for mining MFI that are longer than a given threshold.

\subsubsection{Discovered Rules From QOF Dataset}

As the results discussed in the previous section demonstrated, Length-Sort improves the efficiency of ARM when it comes to discovery of long or maximal length association rules. Length-Sort also facilitates the discovery process as it only returns the rules longer than a specific threshold. In the following sections the sample rules discovered from QOF dataset by Length-Sort are presented. In section 4.3.2.1 we present and discuss some example of the rules discovered with Length-Sort and how they can be used to discover the unwarranted variations especially in more granular levels of analysis. In paragraph 4.3.2.2 we run a post-analysis to draw more detailed explorations.

\subsubsection{Sample of discovered rules}

As discussed in 3.3.2 we combined several data sources to create the input for Length-Sort. Namely we joined data from QOF achievements of the GP practices, their patient characteristics (percentages of sex and age groups), their work force data (Number of clinicians, nurses, etc.) as well as the weighted average of the deprivation index of the GPs patients. The final dataset after the discretization (categorizing and representing the continuous variables as binary ones), has 7066 
observations (GP practices) and 202 dummy variables. The total size of the dataset is 2.77 in megabytes.

Based on the discovered rules by Length-Sort, we demonstrate the application of the ARM in the study of unwarranted variations. In particular, the objective is to show that ARM can detect the variations while accounting for the relevant confounding and covariate variables. For this goal we present a sample of discovered rules in Tables 4-15 to 4-17. We discussed in section 2.3 that how ARM outputs a set of [If-Then] rules that satisfy a minimum support and confidence. The [If] part (also known as the antecedent or left-hand-side) should include all the relevant confounding variables (such as patient demographics, deprivation, etc.) to provide a reliable interpretation of the variations. Therefore, discovering the maximum length rules (and the focus of the Length-Sort algorithm) is very important. The [Then] part (also known as the consequent or right-hand-side) should include the indicators that are of interest (e.g. QOF indicators, or payments to GPs). Then by comparing the rules with same consequent we can measure the variations. This is explored further in the following paragraphs.

Table 4-15 depicts the rules that (See Table 3-7 in section 3.3.2 for detailed description of the variables in the rules):

- Include the indicators of the GP payment dataset (1.1-1.5);

- Contain a QOF indicator in the consequent (1.6-1.8);

- Involve regions in the antecedents (1.9-1.11). 


\begin{tabular}{|c|c|c|c|c|c|c|}
\hline $\begin{array}{c}\text { Rule } \\
\text { No }\end{array}$ & Antecedent & Consequent & Conf & Lift & Conv & Sup \\
\hline 1.1 & $\begin{array}{l}\{\% \text { Male } 14=\text { Low, } \% \text { Female } 65=\text { Low, } \\
\% \text { Female } 14=\text { Low, } \% \text { Tot } 14=\text { Low, } \\
\text { GP_degree_UK= High, } \\
\text { Dispensing = No, Rurality = Urban }\}\end{array}$ & $\begin{array}{l}\{\text { QOF_Payments }= \\
\text { Low }\}\end{array}$ & 0.83 & 4.5 & 4.8 & 0.021 \\
\hline 1.2 & $\begin{array}{l}\{\{\% \text { Male14=Low, } \% \text { Female14=Low, } \\
\% \text { Female65 = High, \%Male65= High, } \\
\% \text { Male14=Low, \%Tot65=High, GP_degree_UK } \\
=\text { High, Dispensing=Yes, Rurality=Rural }\}\end{array}$ & $\begin{array}{l}\{\text { NHS_Payments }= \\
\text { High }\}\end{array}$ & 0.90 & 4.9 & 8.1 & 0.027 \\
\hline 1.3 & $\begin{array}{l}\text { \{GP_Young=Low, GP_Elder=Low, } \\
\text { \%Male14=Low, \%Female14=Low, } \\
\text { \%Male14=Low, \%Male65=Low, \%Female } 65= \\
\text { Low, \%Tot65=Low }\}\end{array}$ & $\begin{array}{l}\{\text { Rot_Payment }= \\
\text { Low }\}\end{array}$ & 0.75 & 4.1 & 3.3 & 0.024 \\
\hline 1.4 & $\begin{array}{l}\text { \{Contract }=\text { GMS, } \% \text { Male } 14=\text { High, } \\
\% \text { Tot } 14=\text { High, Dispensing=Yes, National } \\
\text { Enhanced Services Payment }=\text { High }\}\end{array}$ & $\begin{array}{l}\{\text { Vaccin_Payment } \\
=\text { High }\}\end{array}$ & 0.79 & 3.9 & 3.7 & 0.021 \\
\hline 1.5 & $\begin{array}{l}\text { \{PtientsMale14= High, PtientsMale65= Low, } \\
\% \text { Male14= High, PtientsTot65 = Low, } \\
\text { Dispensing = No, Rurality=Urban, } \\
\text { NES_Payment =High }\}\end{array}$ & $\begin{array}{l}\{\text { Mening_Payment } \\
=\text { High }\}\end{array}$ & 0.80 & 3.9 & 4.0 & 0.024 \\
\hline 1.6 & $\begin{array}{l}\{\mathrm{DEM} 004=\text { Low }, \mathrm{DEP} 003=\text { Low, } \mathrm{MH} 007=\mathrm{Low} \\
\text { COPD003 }=\text { Low }\}\end{array}$ & $\{$ RA002 $=$ Low $\}$ & 0.86 & 4.2 & 5.7 & 0.024 \\
\hline 1.7 & $\begin{array}{l}\{\mathrm{STIA} 003=\text { Low, DM002= Low, DM012= } \\
\text { Low }\}\end{array}$ & $\{$ HYP006=Low $\}$ & 0.88 & 4.4 & 6.5 & 0.063 \\
\hline 1.8 & $\begin{array}{l}\{\text { PAD004=Low, STIA007=Low, Health } \\
\text { Depriv=Low }\}\end{array}$ & $\{\mathrm{CHD} 005=\mathrm{Low}\}$ & 0.81 & 4.0 & 4.1 & 0.025 \\
\hline 1.9 & $\begin{array}{l}\{\text { Region }=\mathrm{Q} 71, \mathrm{CHD} 007=\mathrm{Low}, \mathrm{STIA} 009=\mathrm{Low}, \\
\text { Dispensing=No, Rurality=Urban }\}\end{array}$ & $\{\mathrm{DM} 018=\mathrm{Low}\}$ & 0.90 & 4.5 & 8.3 & 0.035 \\
\hline 1.10 & $\begin{array}{l}\{\text { Region }=\text { Y } 54, \text { STIA009= Low, COPD007=Low, } \\
\text { Health Deprivation=Low, Dispensing=No, } \\
\text { Rurality=Urban }\}\end{array}$ & $\{\mathrm{CHD} 007=\mathrm{Low}\}$ & 0.89 & 4.4 & 7.0 & 0.022 \\
\hline \multirow[t]{2}{*}{1.11} & $\begin{array}{l}\{\text { Region }=\text { YDF } 28, \text { DM } 008=\text { Low, } \\
\text { Dispensing }=\text { No, Rurality }=\text { Urban }\}\end{array}$ & $\{\mathrm{DM} 009=\mathrm{Low}\}$ & 0.92 & 10.1 & 4.5 & 0.025 \\
\hline & Conf: Confidence; Conv: Conviction, Sup: Suppor & & & & & \\
\hline
\end{tabular}

Table 4-15: Sample of the discovered rules

As an example, the rule 1.1 asserts that $83 \%$ of the practices that: 
- are in urban areas;

- do not dispense drugs;

- have low percentage of female patients aged 65 or over and male/female/total patients aged 14 or less;

- have high percentage of GPs with degree obtained in UK;

receive total QOF payment per weighted patient that are in the lowest 20 percentile of all practices.

Appearance of age categories in the antecedent of the rule shows that the patients' age mix have important impact on the amount paid for QOF to GPs. It is expected that practices that have lower ratio of elderly (65 years old or more) receive less payments. This demonstrate that ARM effectively identified age mix categories as a confounding for the QOF payments.

The rule 1.2 predicts the practices that receive high average NHS payment per weighted patients with $90 \%$ confidence. Among other factors, the rule covers practices that dispense drugs and have high percentage of patients older than 65 (male and total). As dispensing practices receive the value of the dispensed drugs from NHS, higher average payments are expected. Again, two important confounding variables were detected.

This rule has lift of 4.9 , which means that the antecedent and consequent are observed together in the data set, almost 5 times more often as if they were independent (Brin et al., 1997). As mentioned, QOF and total NHS payments are already divided over the weighted patients, however the rules still show that patients age can be predictor of the total payments. This can imply that patients weighting formula does not adjust for the patients' age risk factor completely.

Rule 1.3 in the table implies that the age of GPs and patients are associated with low level of NHS payment for rotavirus and shingles immunization. According to the rules 1.4 and 1.5, high ratio of 
patients aged 14 or less and high total national enhanced services' payment, are associated with high payment for childhood vaccination and meningitis. As meningitis is also more common among children, it is rational that these categories of payments are higher among practices that have more patients aged 14 or less.

Rule 1.6 implies that practices which perform lower in terms of timely review of patients with dementia, depression and COPD and recoding of the alcohol consumption of patients with mental health problems, have also low performance in term of timely face to face reviews of rheumatoid arthritis patients.

Rule 1.7 asserts that practice performing lower in controlling the blood pressure of patients with stroke, TIA, and timely foot examination of diabetic patients, also have lower score on controlling the blood pressure of patients with hypertension.

According to rule 1.8, practices that are located in areas with low heath deprivation and have lower ratio of peripheral arterial, stroke or TIA patients who have a record of antiplatelet agent or an anti-coagulant, have also low corresponding ratio for the CHD patients.

Unlike the previous set of rules (1.1 -1.5), the patients' age and sex distribution does not appear in the antecedent of the rules in 1.6-1.8. This is due to the fact that the consequents are QOF indicators that are calculated as the ratios over patients with a given condition. Thus, the prevalence of the condition in different age categories of the patients on the practices' list would not influence the indicator (Otsubo et al., 2016).

Rule 1.9 indicates that $90 \%$ of the non-dispensing practices located in urban areas of region Q71 (London) and have low rates of influenza immunization for CHD and Stroke/TIA, also have low rates of influenza immunization of diabetic patients. Rule 1.10 in the table, implies similar 
associations between COPD, Stroke/TIA and diabetes mellitus influenza immunization of practices in Y54 (North of England).

The patterns discovered in the rules 1.6-1.9, suggests that GPs low performance on activities such as blood pressure control, influenza immunization and patients timely review on set of diseases are associated with similar activities in other conditions. The association across the deceases can be due to lack of additional staffing resources (Kontopantelis et al., 2014). However, if the practices contained in the rules had low staffing, variables such as patients per GP or patients per nurse ratios should appear in the antecedent. We argue that GPs' behavior toward the mentioned activities are the reason behind finding such associations. While the objective of financial incentives such as QOF is to change GPs' behavior (Downing et al., 2007), the discovered rules imply that this objective is not reached for the corresponding GPs contained in these rules. It is worth mentioning that rule 1.8 also includes low value for health deprivations in the antecedent. Patients in these areas are more prone to avoid timely visitations and can be reported as exceptions. Thus, the low performance of the GPs in rule 1.8 can be due to the fact that GPs did not report the exceptions properly. If we exclude the variable corresponding to health deprivation from rule 1.8 we get:

$$
\{\text { PAD004 }=\text { Low }, \quad \text { STIA007 }=\text { Low }\} \quad \rightarrow \quad\{\text { CHD005 }=\text { Low }\}
$$

which still satisfies the minimum threshold of the support, confidence, lift and conviction interest measures. However, interpreting this rule without the effect of the health deprivation index can be misleading or incomplete. This example shows that the length of the rules (number of the variables included in the rule) plays an important role in finding reliable rules. So using the long 
or maximum length rules provide more reliable detection of unwarranted variations. In particular, using Length-Sort instead of similar ARM algorithms also improves the efficiency of the unwarranted variations discovery. It can significantly reduce the running time needed for discovery of frequent itemsets. For the QOF dataset, Length-Sort discovered the frequent itemsets in about 9.5 hours while INLA-MFP did not conclude after running for more than 46 hours.

\subsubsection{Post-analysis of the discovered rules}

As we can see in the rules 1.9-1.11, association rules allow to mine rules that are in different levels

of geographic areas. However, not all the regions of the same level may end up in the rules. The reason behind is twofold; either the rule does not apply to other regions as they do not satisfy the minimum confidence, or the number of relevant observations in the region are not frequent enough to pass the minimum support threshold. For instance, among the regions corresponding to NHS England local offices, only Q71 is contained in the rules of Table 4-15. This is due to fact that this region contains more practices compared to other regions of the same level (more than 1,300 practices are located in Q71). Thus, the similar rules that contain other regions does not satisfy the minimum support threshold. However, it is straight forward to verify the same rules in other regions without re-running the whole analyses (Doddi et al., 2001). Table 4-16 depicts the rule 1.10 analyzed in other regions of the same level as well as in the country level. 


\begin{tabular}{|c|c|c|c|c|c|c|}
\hline $\begin{array}{l}\text { Rule } \\
\text { No }\end{array}$ & Antecedent & Consequent & Conf & Lift & $\begin{array}{l}\text { Con } \\
v\end{array}$ & Sup \\
\hline 2.1 & $\begin{array}{l}\{\text { Region=Y54,STIA009=Low,COPD007=Low, } \\
\text { Depriv=Low, Dispensing=No, Rurality=Urban }\}\end{array}$ & $\{$ CHD007=Low $\}$ & 0.89 & 4.46 & 7.0 & 0.022 \\
\hline 2.2 & $\begin{array}{l}\{\text { Region }=\text { Y } 55 \text {,STIA009=Low,COPD } 007=\text { Low, } \\
\text { Health Deprivation=Low, Dispensing=No, } \\
\text { Rurality=Urban }\}\end{array}$ & $\{\mathrm{CHD} 007=\mathrm{Low}\}$ & 0.87 & 4.3 & 6.1 & 0.009 \\
\hline 2.3 & $\begin{array}{l}\{\text { Region }=\text { Y } 56, \text { STIA009=Low,COPD } 007=\text { Low, } \\
\text { Depriv=Low, Dispensing=No, Rurality }=\text { Urban }\}\end{array}$ & $\{\mathrm{CHD} 007=\mathrm{Low}\}$ & 1 & 5.0 & $\infty$ & 0.003 \\
\hline 2.4 & $\begin{array}{l}\{\text { Region }=\text { Y } 57, \text { STIA009=Low,COPD } 007=\text { Low, } \\
\text { Depriv=Low, Dispensing=No, Rurality=Urban }\}\end{array}$ & $\{$ CHD007=Low $\}$ & 0.78 & 3.9 & 3.6 & 0.002 \\
\hline \multirow[t]{2}{*}{2.5} & $\begin{array}{l}\{\text { STIA009=Low,COPD007=Low, Health } \\
\text { Depriv=Low, Dispensing=No, Rurality=Urban }\}\end{array}$ & $\{$ CHD007=Low $\}$ & 0.88 & 4.4 & 6.8 & 0.035 \\
\hline & $\begin{array}{l}\text { Conf: Confidence; Conv: Conviction, Sup: } \\
\text { Support }\end{array}$ & & & & & \\
\hline
\end{tabular}

Table 4-16: Rules corresponding to geographical regions of the same level in rule 1.10 and the country level, which has not satisfied the minimum support threshold

As we can see in the table 4-16, the confidence of the rule varies from 0.78 to 1 in the four regions while the country level confidence is 0.88 (rule 2.5 ). The support of the rule is more than threshold (0.02) only in Y54 region so the rules were not discovered for the other regions. The difference between the confidences corresponding to the rules in different areas, can be used to measure the (unwarranted) variations in different geographical regions. It is worth noting that the age-sex categories are not in the antecedent of the rule. This is not an instance where ARM failed to recognize a relevant confounding effect. Both the STIA009 (Ratio of patients with transient ischemic attack or stroke who received influenza immunization) and COPD007 (Ratio of patients with COPD who received influenza immunization) indicators are measured based on the patients in the GP practices' registry that have the corresponding conditions and criteria, thus the patients demographics or prevalence of the condition has no effect on the indicators. 
We can also perform post analysis to investigate the individual effect of variables in the antecedent.

This can be done by removing a variable and recalculating the confidence of the corresponding rule. Table 4-17 depicts the results of the procedure applied to the rule 1.9.

\begin{tabular}{|c|c|c|c|c|c|c|}
\hline $\begin{array}{l}\text { Rule } \\
\text { No }\end{array}$ & Antecedent & Consequent & Conf & Lift & $\begin{array}{l}\text { Con } \\
v\end{array}$ & Sup \\
\hline 3.1 & $\begin{array}{l}\{\text { Region }=\mathrm{Q} 71, \mathrm{CHD} 007=\mathrm{Low}, \mathrm{STIA} 009=\mathrm{Low}, \\
\text { Dispensing }=\text { No, Rurality }=\text { Urban }\}\end{array}$ & $\{\mathrm{DM} 018=\mathrm{Low}\}$ & 0.90 & 4.5 & 8.3 & 0.035 \\
\hline 3.2 & $\begin{array}{l}\{\text { Region }=\mathrm{Q} 71, \mathrm{CHD} 007=\mathrm{Low}, \text { Dispensing }=\mathrm{No}, \\
\text { Rurality }=\text { Urban }\}\end{array}$ & $\{\mathrm{DM} 018=\mathrm{Low}\}$ & 0.86 & 4.3 & 5.5 & 0.040 \\
\hline 3.3 & $\begin{array}{l}\{\text { Region=Q71, STIA009=Low, Dispensing=No, } \\
\text { Rurality }=\text { Urban }\}\end{array}$ & $\{$ DM018=Low $\}$ & 0.83 & 4.1 & 4.5 & 0.040 \\
\hline \multirow[t]{2}{*}{3.4} & $\{$ Region $=$ Q71, Dispensing $=$ No, Rurality $=$ Urban $\}$ & $\{\mathrm{DM} 018=\mathrm{Low}\}$ & 0.32 & 1.6 & 1.2 & 0.058 \\
\hline & $\begin{array}{l}\text { Conf: Confidence; Conv: Conviction, Sup: } \\
\text { Support }\end{array}$ & & & & & \\
\hline
\end{tabular}

\section{Table 4-17: Comparing the relative importance of the variables in rule 1.9}

As we can see by removing one variable corresponding to the CHD and Stroke/TIA influenza, the confidence lift and convictions are still high. However, after removing both variables, the confidence drops to $0.32 \%$. This implies that the associations of these two variables to the consequent, are higher comparing to the other variables in the antecedents.

\subsubsection{Discussion}

As mentioned before, BI systems not only provide a platform for gathering, storing and managing the data, but they also provide decision makers with timely and relevant information using data mining (Bates et al., 2014; Shen et al., 2017). In other words, BI can incorporate advance analytics and predictive models to support decision making as well as to discover patterns such as the ones 
useful in unwarranted variation research. However, health research still needs more innovative analytical methods such as predictive models for hypotheses generation that can handle large health datasets (Auffray et al., 2016).

Length-Sort, our proposed ARM algorithm allows the mining to be performed on smaller initial and conditional FP-trees. This significantly improves the efficiency of the mining process and consequently ARM can be applied to larger datasets. Length-Sort in fact uses a pruning approach that estimates the upper bound of the maximum length, and reduces the search space horizontally and vertically (through pruning the unnecessary items and transactions). Moreover, with minimal modifications, our pruning approach can complement other algorithms to mine for instance maximal and closed itemsets that are longer than a user specified threshold. Length-Sort can be embedded in the hospitals' BI system to detect the variations in a more automated and timely manner.

Applying Length-Sort on QOF dataset demonstrated that ARM can discover rules considering the effects of various confounding variables. Moreover, we further analyzed the discovered rules to assess how their predictive accuracy would change within geographical regions. Using ARM also allowed to simultaneously detect the unwarranted variations in multiple geographical levels.

We also demonstrated how the relative importance of a variable can be detected based on the discovered rules. Several discovered rules in the study contained age, gender and health deprivations index variables in the antecedents. These are the variables that are used by the researchers to adjust the population level outcomes. This means that ARM can be used to detect confounding variables that affect the outcome of interest in unwarranted variation studies. On the other hand, ARM as a data mining tool has much more flexibility and exploratory power compared to the traditional statistical models that are used in unwarranted variations or in general in health 
policy and system research (Yoo et al., 2012). This means that many previously unknown risk factors can be discovered by this methodology. In this context, our results confirmed that the length of the rules plays an important rule. A larger number of variables in the antecedents usually means that the discovered rules might include larger number of confounding variables. Higher length also improves the specificity of the rules (Wright et al., 2010).

Studies in the unwarranted variation field need to rely on values such as case-mix weights, Elixhauser index (Elixhauser et al., 1998) and Charlson/Deyo measure (Charlson et al., 1987) to adjust for comorbidities and resources needed for care delivery. These indices are effective if the populations under study are large enough. As Bridges et al. (2005). assert, due to incomplete risk adjustments, several common quality indicators are in fact measuring the patients' severity instead of quality outcomes. Instead, the exploratory power of the ARM gives the ability to discover set of patients or practices that are very similar and then compare the outcomes of these similar populations. We argue that ARM can be more effective in detecting the performance patterns especially in the more granular levels of analyses. There are caveats in using ARM. The traditional standardization and risk adjustment methods are based on statistics discipline while ARM is based on data mining principles. The former is a hypothetico-deductive approach while the latter is inductive (Hand, 1999). Moreover, the discovered rules are in fact a small sample of many more potential rules that are analyzed. This increases the chances of discovering spurious rules (Wright et al., 2010) and type I error. Using multiple interest measures reduces the chance of including spurious rules. ARM should be considered more as a hypotheses generation practice (Doddi et al., 2001), complemented with hypotheses testing models (Zhang et al., 2016). Alternatively, one can use complementary algorithms to automatically test the discovered rules to further improve the reliability (Zhang et al., 2016). Applying ARM to large dataset may result in finding numerous 
rules with high confidence which may be time consuming to select the meaningful rules. Using Length-Sort to exclude the short rules and filtering the antecedents and consequents based on relevant variables helps in speeding up the process. However, for very large datasets, rule summarizations may also be necessary (Simon et al., 2015). 


\section{CONCLUSIONS \& FURTHER RESEARCH}

In this thesis, we investigated the unwarranted variations in healthcare. Reducing these variations is crucial to reach equitable and high-quality care delivery as well as trimming the raising economic burden of the healthcare sector.

Unwarranted variations are known to be complex with numerous influencing factors. Reducing the variations needs justified and evidence-based policy level interventions. To help the policy makers, researchers need to constantly investigate the performance patterns in various levels of analyses and detect the potential influencing factors. We shed light on these aspects by studying the performance patterns of the both secondary and primary care centers in Spanish healthcare system. In secondary care setting, our investigation reveals that for several outcome indicators, the level of performances of the regions are not dependent on the diagnostic categories. So if a region is performing better or worse than the average in a medical specialty, they also perform better or worse respectively in other diagnostic categories. Our analyses show that factors associated with these indicators are common across the medical conditions. According to these findings, we suggest that policy makers need to focus more on the interventions that simultaneously target various medical conditions. Moreover, our results confirm that reducing the utilization of resources such as bed-day stays in the hospitals does not reduce the quality of care in many Spanish regions. This can guide the disinvestments to be made in the eligible regions. So, this finding can help policy makers to reduce the unwarranted variations in regional levels specially in terms of the important performance indicators as well as the levels of resource utilization and spending. Regarding the preventable hospitalizations, our findings demonstrated that the better accessibility and utilization of primary care is a factor reducing such hospitalizations. However, accessibility of specialized care is also influencing the preventable admissions significantly. Similarly, these 
results can help policy makers to reduce the regional unwarranted variations in terms of preventable hospitalizations for instance by encouraging the GPs to refer the patients to specialist more frequently and allocating more GPs and/or specialist to the regions with higher rates of preventable hospital admissions.

There are limitations in the studies of the first study that should be considered when interpreting the findings. The study in the secondary care context is an observational cross-section study; thus no causal relations can be interpreted. We suggest that it would be useful to carry out further investigations using panel data to set out the relationship between the secondary care indicators. This would give better understanding of the interdependencies between the indicators. For instance, to clarify whether higher infection rates are the cause of longer stays in hospital or vice versa. Due to restrictions in accessing data, we were unable to make direct adjustments for comorbidities (e.g. Elixhauser index). However, we feel that this is unlikely to significantly change the results, as comorbidity was taken into consideration by the data owner when estimating the severity of an illness. We were also unable to separate the lengths of stay and infections in intensive care units from the total patient lengths of stay. The destination of discharged inpatients is also an important variable that can be used to improve the robustness of risk adjustment. Finally, our study looked at patients discharged from hospitals in Spain, so cross-country comparisons of the findings is another a fruitful path for the further investigations.

In the study performed in the preventable hospitalizations context, only three ACSCs have been considered, and the influencing factors may be different for other conditions. It must be pointed out, however, that the three conditions studied are among the most common ACSCs and we expect their influencing factors to be similar to those for other conditions. Some of the variables included in the model change slowly over time, meaning that their effect may be absorbed into the regional 
intercepts. This may result in false insignificant coefficients. We did, however, compare the results with random-effect models that can detect the effect of the time-invariant explanatory variables. The coefficients and their $\mathrm{p}$-values were very similar, and the only noticeable changes in $\mathrm{p}$-values were for proportion of people visiting specialists linked to CHF admissions and consultations with nurses in BP admissions. The number of regions (17) and the time period considered ( 9 years) may not be sufficient to detect some of the significant relationships. Finally, our study looked at patients admitted to public hospitals in Spain, so cross-country comparisons of this findings is a fruitful path for further investigations. More detailed study on the coordination between primary and specialized care as well as the continuity of care is another suggestion for further investigations. It would be beneficial to know whether fewer patients' consultations with specialists is due to lack of timely referrals from GPs or due to lower accessibility of specialists.

As argued before, reducing the unwarranted variations is highly dependent on two other aspects. First, timely access to quality data and second, reliable risk adjustments. These aspects are even more crucial when moving from larger to smaller levels of analyses. We believe that $\mathrm{BI}$ is a prominent remedy for both of these vital elements. BI as system that encompasses data collection, storage, analyses and reporting, has significant potentials in healthcare. Previous studies suggest that BI is not widespread in the health sector and many of the initiatives are failed in early stages of the implementations. The main contribution of the second phase is the development of a BI maturity model and the relative assessment questionnaire, which are specific for the healthcare industry and allow to effectively address the pressing issues associated with BI solutions within it. In addition, the designed maturity model was applied to the BI solution of ISMETT to directly show the applicability of the research results. 
Our result demonstrate that the development of a BI solution is essentially an evolutionary process, and that is possible to identify several discrete stages in the roadmap toward a full exploitation of $\mathrm{BI}$ in the realization of precision medicine. We proposed that an inadequate level of BI solution maturity could be a major reason behind the failure of many BI initiatives. We mapped the relationships among the dimensions of the BI solution (especially those among different development areas), depicting the different interactions in terms of prerequisite and synergies to be leveraged to successfully extend BI solutions to larger domains. The maturity model and the defined road map shed lights on how mangers can realize the disruptive potentials of BI in considering the idiosyncrasies of the hospitals. Consequently, through these actualized benefits, hospitals can both provide timely and high quality administrative data to discover the unwarranted variations as well as incorporate more advance analytics to facilitate the in depth variation analyses in the right time and right place.

We also showed how the level of maturity should always be consonant with organizational structure, management decisions, and strategic changes in terms of growth foreseen in the near future. Furthermore, the maturity should be periodically re-evaluated to adjust BI implementation and diffusion according to company and environmental changes. The clusters and priority scores of the dimensions are updated and maturity improvement strategy is adjusted after each period. This can be performed easily as the assessment questionnaire can be filled in matter of hours. However further research is needed to determine the optimal frequency for updating the maturity assessment and adjusting the improvement strategy. Moreover, by activating organization-wide processes of involvement, the BI maturity evaluation model described in the second phase allows healthcare practitioners to monitor and predict the quality of their BI solutions and the processes producing them. The artifacts are based on several dimensions and metrics, which not only enable 
any type of benchmarking regarding the strategies through which different healthcare organizations develop a BI solution, but are also useful tools for understanding which dimensions to focus in order to progressively make the BI solution of a healthcare organization more efficient and effective.

We envision three streams of research emerging out of our work in this phase Following the software process maturity paradigm, the first stream could focus on organizational attempts to characterize BI practices by empirically examining the consensual benefits attributed to a mature BI solution. For example, it is important to use the BI maturity model to systematically measure a hospital's ability, commitment, goals, and roadblocks in evaluating its performance on the different metrics, and to develop benchmarks to transition to higher levels of maturity. In this research stream, the basic premise is that consistent application of well-defined and measured BI processes, coupled with continual process improvement, will streamline BI project management, and substantially improve the productivity and data quality of BI solutions.

A second stream of research could focus on the metrics, the maturity levels and the interdependencies that have been developed. Based on their application at ISMETT, they appear to be comprehensive. But it is unclear whether all metrics and maturity levels are of equal value with respect to BI maturity assessment. And it is unclear how to effectively weigh and precisely measure the strength of both the synergies and the prerequisites that have been considered. It would be interesting to conduct field studies (in the form of surveys) that include a number of organizational (e.g., size, system architecture, structural attributes, resources, management attitude, and culture) and environmental (e.g., institutional and competitive forces, technology support structures) determinants of efforts that companies exert in pursuing initiatives to upgrade 
their BI maturity levels. Only in this way we can confirm that the synergies and perquisites developed for ISMETT are also generalizable to other hospitals.

Finally, an important future direction would be to employ our model/questionnaire to assess the BI maturity in different healthcare organizational settings and, based on those assessments, test a set of hypotheses relating to the consequences of BI maturity on their performance. Moreover, if the maturity model were applied to all (or the majority of) healthcare organizations in a regional healthcare system, the model could provide the regional healthcare directorate with useful knowledge to address the design of homogenizing policies and continual improvement strategies at a regional level.

In the third phase of the thesis, we developed a novel algorithm called Length-Sort, which can efficiently prune datasets to mine the maximum length frequent itemsets. This is especially important because, in many applications, frequent sets with a maximum length are more interesting and many of the frequent sets with lower length are redundant. The novelty of the Length-Sort algorithm lies in its feature of using information hidden within the lengths of the transactions. Using this implicit information helps users to determine the upper bound of the maximum length more efficiently and, furthermore, to prune the unnecessary items and reduce the searching space for the frequent itemsets. The fact that Length-Sort partitions the dataset according to its length will also result in reducing the search space by eliminating the unwanted transactions. Thus, by using Length-Sort, we can shrink the searching space horizontally by pruning the items, as well as vertically by discarding the unnecessary transactions. Our experimental results achieved on several datasets confirmed that Length-Sort pruning reduces the computational effort of mining maximum length frequent itemsets. 
Unlike similar algorithms, our proposed pruning methods are applied to dataset before constructing the FP-tree. This is especially beneficial as the mining will then be performed on smaller initial and conditional FP-trees. Length-Sort is also less sensitive to the support threshold.

Finally, Length-Sort can be applied to mine other type of frequent itemsets. With minimal modifications, Length-Sort can be used to mine itemsets longer than a user specified threshold more efficiently. In a similar vein, Length-Sort can complement other tree-based algorithms to mine, for instance, long maximal and long closed frequent itemsets in a more effective manner.

Employing the pruning techniques of LFIMiner and MaxLFI on N-List structure, would be a fruitful path for future studies. Also, it would be interesting to apply the Length-Sort approach to mining long/maximum length high utility itemsets.

As discussed, dealing with more granular levels of analysis, risk adjustment becomes more difficult as the "law of large numbers" may not hold. Traditional risk adjustment techniques usually transform the outcomes and/or risk factors to artificial values, to isolate the warranted variations due to differences between the populations. Afterwards, the different populations are comparable (for example consider direct and indirect standardizations or comorbidity indexes such as Elixhauser). We suggest an alternative approach that is especially useful for smaller levels of analyses. Using ARM, we first identify the populations (e.g. set of patients or set of practices) that are very similar and then we can directly compare the differences in the performances. The more similar the population, the more reliable the results. More similarity in the context of ARM is translated into the lengths of the discovered rules. That's why, we developed Length-Sort that mines such rules more efficiently. ARM also facilitates the explorations of the datasets. As it can handle larger datasets containing numerous risk factors as well as outcomes, it reveals previously 
unknown risk factors or interesting associations in terms of the performance patterns. ARM can also be incorporated in the BI systems to provide timely information in a more automatic manner. In terms of ARM application in unwarranted variations, we propose further research on the effect of various discretization methods on the discovered rules. This can provide a more systematic guide for discretization of various variables in the healthcare datasets. In the literature, there are various interest measures developed for ARM. Analyzing these measures and determining which measures are better suited in the unwarranted variation context is another fruitful path for further investigation.

The empirics of this $\mathrm{PhD}$ thesis is drawn from three different countries (Spain, Italy and England). Thus, considering their type of healthcare system is vital when interpreting our findings. Contextual factors such as insurance coverage, health service provision and access to the care are influenced by different actors in each type the health systems. NHS (UK and Spain health systems are categorized as this type) is one of the most common forms of health system, especially in Europe, and we believe that the empirical findings and policy implications of our study can be relevant for the decision-makers in many other European countries. In other words, the empirical findings are usually generalizable to the same health system type. In this regard, studies' implications (especially policy interventions of phase 1) are valid for the same health system type. However, we believe that our implications regarding the explorative variations' detection is not dependent on the healthcare system and is generalizable to other healthcare systems. Regarding the BI maturity model, while the model itself is not directly dependent on the system, some important dimensions such as BI budget and BI strategy are highly influenced by the actor responsible for regulations, financing and service provisions. 


\section{List of Abbreviations}

Abbreviation Page

$\begin{array}{ll}\text { ACSC : Ambulatory Care Sensitive Condition } & 17\end{array}$

ARM : Association Rules Mining 29

Atlas VPM : Atlas of Variations in Medical Practice of the Spanish National Health System 12

$\begin{array}{lc}\text { BI: Business Intelligence } & 6\end{array}$

$\begin{array}{ll}\text { BP : Bacterial Pneumonia } & 19\end{array}$

CHF : Congestive Heart Failure 19

CIO : Chief Information Officer $\quad 24$

CIR : Clinical Inquiry Research $\quad 28$

COPD : Chronic Obstructive Pulmonary Disease 19

$\begin{array}{ll}\text { CPP : Conditional Pattern-base Pruning } & 37\end{array}$

DRG : Diagnostic Related Group $\quad 44$

EHR : Electronic Health Records $\quad 6$

EQ5-95: External Quotient 48

EU-SILC : EU survey, Statistics on Income and Living Conditions 119

FCI : Frequent Closed Itemset

FIP : Frequent Item Pruning $\quad 37$

FP-growth : Frequent Pattern-growth $\quad 35$

FP-tree : Frequent-pattern tree $\quad 35$

GDP: Gross Domestic Product 1 
GP : General Practitioner

HIS : Healthcare Information System 22

H-table : Header-table $\quad 35$

ISCED: International Standard Classification of Education 53

ICT: Information and Communication Technologies 6

ISMETT : Mediterranean Institute for Transplantation and Advanced Specialized Therapies 28

ISR :Indirect Standardised Rate $\quad 89$

LFI : Maximum Length Frequent Itemset 33

MBDS : Minimum Basic Hospital Data Set $\quad 42$

MDC : Major Diagnostic Category $\quad 15$

MeSH : Medical Subject Heading $\quad 29$

MFI : Maximal Frequent Itemset 32

$\begin{array}{ll}\text { NHS : National Health Service } & 18\end{array}$

OECD : Organization for Economic Co-operation and Development 1

QOF : Quality and Outcome Framework $\quad 40$

RTF : Research Task Force $\quad 56$

SCV : Systematic Component of Variation $\quad 48$

WHO :World Health Organization $\quad 14$ 


\section{References}

Adler-Milstein, J., McAfee, A.P., Bates, D.W., Jha, A.K., 2008. The state of regional health information organizations: current activities and financingNo Title. Health Aff. 27, w60-69.

Agarwal, R., Gao, G.G., DesRoches, C., Jha, A.K., 2010. The digital transformation of healthcare: Current status and the road ahead. Inf. Syst. Res. 21, 796-809. https://doi.org/10.1287/isre.1100.0327

Agarwal, R., Aggarwal, C.C., Prasad, V.V. V., 2000. Depth first generation of long patterns, in: Proceedings of the Sixth ACM SIGKDD International Conference on Knowledge Discovery and Data Mining. pp. 108-118. https://doi.org/10.1145/347090.347114

Agrawal, R., Imieliński, T., Swami, A., 1993. Mining association rules between sets of items in large databases, in: ACM SIGMOD Record.

Agrawal, R., Mannila, H., Srikant, R., 1996. Fast Discovery of Association Rules. Adv. Knowl. Discov. data mining, 12, 307-328.

Alvarez Bartolomé, M., Gogorcena, A., 2014. "Spain: Geographic variations in health care," in: Geographic Variations in Health Care: What Do We Know and What Can Be Done to Improve Health System Performance? OECD Publishing, Paris.

Alyahya, M.S., Hijazi, H.H., Alshraideh, H.A., Al-Nasser, A.D., 2017. Using decision trees to explore the association between the length of stay and potentially avoidable readmissions: A retrospective cohort study. Informatics Heal. Soc. Care 1-17. https://doi.org/10.1080/17538157.2016.1269105

Ancker, J.S., Shih, S., Singh, M.P., Snyder, A., Edwards, A., Kaushal, R., Hitec Investigators, 2011. Root causes underlying challenges to secondary use of data, in: American Medical Informatics Association (AMIA )Annual Symposium Proceedings.

Angulo-Pueyo, E., Ridao-López, M., Martínez-Lizaga, N., García-Armesto, S., Peiró, S., Bernal-Delgado, E., 2017. Factors associated with hospitalisations in chronic conditions deemed avoidable: ecological study in the Spanish healthcare system. BMJ Open 7, e011844. https://doi.org/10.1136/bmjopen-2016-011844

Antonelli, D., Baralis, E., Bruno, G., Cagliero, L., Cerquitelli, T., Chiusano, S., Garza, P., Mahoto, N.., 2015. Meta: Characterization of medical treatments at different abstraction levels. ACM Trans. Intell. Syst. Technol. 6, 57.

Appleby, J., Raleigh, V., Frosini, F., Bevan, G., HaiYan, G., Lyscom, T., Gao, H., 2011. Variations in health care: the good, the bad and the inexplicable. King's Fund.

Auffray, C., Balling, R., Barroso, I., Bencze, L., Benson, M., Bergeron, J., Bernal-Delgado, E., Blomberg, N., Bock, C., Conesa, A., Del Signore, S., 2016. Making sense of big data in health research: towards an EU action plan. Genome Med. 8, 71.

Avison, D., Young, T., 2007. Time to rethink health care and ICT? Commun. ACM 50, 69-74. https://doi.org/10.1145/1247001.1247008

Ayal, M., Seidman, A., 2009. An Empirical Investigation of the Value of Integrating Enterprise Information Systems: The Case of Medical Imaging Informatics. J. Manag. Inf. Syst. 26, 43-68.

Basu, S., Andrews, J., Kishore, S., Panjabi, R., Stuckler, D., 2012. Comparative Performance of Private 
and Public Healthcare Systems in Low- and Middle-Income Countries: A Systematic Review. PLoS Med. 9, e1001244. https://doi.org/10.1371/journal.pmed.1001244

Bates, D., Saria, S., Ohno-Machado, L., Shah, A., 2014. Big data in health care: using analytics to identify and manage high-risk and high-cost patients. Health Aff. 33, 1123-1131.

Behkami, N.A., Daim, T.U., 2012. Research Forecasting for Health Information Technology ( HIT ), using technology intelligence. Technol. Forecast. Soc. Chang. 79, 498-508.

https://doi.org/10.1016/j.techfore.2011.08.015

Bernal-Delgado, E., Estupiñán-Romero, F., 2018. A data infrastructure for the assessment of health care performance: Lessons from the BRIDGE-health project. Arch. Public Heal. 76. https://doi.org/10.1186/s13690-017-0245-1

Bernal-Delgado, E., Garcia-Armesto, S., Peiro, S., 2014. Atlas of Variations in Medical Practice in Spain: The Spanish National Health Service under scrutiny. Health Policy (New. York). 114, 15-30. https://doi.org/10.1016/j.healthpol.2013.07.013

Berwick, D., Fox, D.M., 2016. "Evaluating the Quality of Medical Care”: Donabedian's Classic Article 50 Years Later. Milbank Q. 94, 237-241.

Billings, J., Anderson, G.M., Newman, L.S., 1996. Recent findings on preventable hospitalizations. Health Aff. 15, 239-249.

Böhm, K., Schmid, A., Götze, R., Landwehr, C., Rothgang, H., 2013. Five types of OECD healthcare systems: Empirical results of a deductive classification. Health Policy (New. York). 113, 258-269. https://doi.org/10.1016/j.healthpol.2013.09.003

Bohmer, R., Newell, J., Torchiana, D., 2002. The effect of decreasing length of stay on discharge destination and readmission after coronary bypass operation. Surgery 132, 10-15.

Borzekowski, R., 2009. Measuring the cost impact of hospital information systems: 1987-1994. J. Health Econ. 28, 938-49. https://doi.org/10.1016/j.jhealeco.2009.06.004

Bridges, J.F.P., Dor, A., Grossman, M., 2005. A Wolf Dressed in Sheep's Clothing. Appl. Health Econ. Health Policy 4, 55-64. https://doi.org/10.2165/00148365-200504010-00008

Brijs, T., Swinnen, G., Vanhoof, K., Wets, G., 1999. Using association rules for product assortment decisions: A case study, in: Proceedings of the Fifth International Conference on Knowledge Discovery and Data Mining. San Diego (USA), pp. 254-260.

Brin, S., Motwani, R., Ullman, J.D., Tsur, S., 1997. Dynamic itemset counting and implication rules for market basket data., in: ACM SIGMOD Int'l Conf. on Management of Data (ACM SIGMOD). pp. $265-276$.

British Medical Association (BMA), 2015. Focus on the global sum allocation formula (Carr-Hill Formula).

Brooks, J.M., Cook, E.A., Chapman, C.G., Kulchaitanaroaj, P., Chrischilles, E.A., Welch, S., Robinson, J., 2014. Geographic Variation in Statin Use for Complex Acute Myocardial Infarction Patients. Med. Care 52, S37-S44. https://doi.org/10.1097/MLR.0b013e3182a7fc3d

Bulger, E.M., Nathens, A.B., Rivara, F.P., Moore, M., MacKenzie, E.J., Jurkovich, G.J., 2002. Management of severe head injury: institutional variations in care and effect on outcome. Crit. Care Med. 30, 1870-1876.

Caldon, L.J.M., Walters, S.J., Reed, J.A., Murphy, A., Worley, A., Reed, M.W.R., 2005. Case-mix fails 
to explain variation in mastectomy rates: management of screen-detected breast cancer in a UK region 1997-2003. Br. J. Cancer 92, 55-9. https://doi.org/10.1038/sj.bjc.6602264

Carr-Hill, R., Sheldon, T., Smith, P., Martin, S., Peacock, S., Hardman, G., 1994. Allocating resources to health authorities: development of method for small area analysis of use of inpatient services. 1994;309(6961):1046-1049. BMJ 309, 1046-1049.

Carter, N., Day, P., Klein, R., 2002. How organisations measure success: The use of performance indicators in government. Routledge, London.

Chang, P., Lee, S., Hsieh, M., Huang, S., Tsui, K., 2002. Improvement of practice performance in urological surgery via clinical pathway implementation. World J. Urol. 20, 213-218.

Charlson, M., Pompei, P., Ales, K., MacKenzie, C., 1987. A new method of classifying prognostic comorbidity in longitudinal studies: development and validation. J. Chronic Dis. 40, 373-383.

Chaudhry, B., Wang, J., Wu, S., Maglione, M., Mojica, W., Roth, E., Morton, S.C., Shekelle, P.G., 2006. Systematic review: Impact of health information technology on quality, efficiency, and costs of medical care. Ann. Intern. Med. 144, 742-752. https://doi.org/0000605-200605160-00125 [pii]

Chaupain-Guillot, S., Guillot, O., 2015. Health system characteristics and unmet care needs in Europe: an analysis based on EU-SILC data. Eur. J. Heal. Econ. 16, 781-796. https://doi.org/10.1007/s10198014-0629-x

Chen, H., Chiang, R., Storey, V., 2012. Business Intelligence and Analytics: From Big Data to Big Impact. MIS Q. 36, 1165-1188.

Chen, T.J., Chou, L.F., Hwang, S.J., 2003. Application of a datamining technique to analyze coprescription patterns for antacids. Clin. Ther. 25, 2453-2463.

Cheng, P., Gilchrist, A., Robinson, K.M., Paul, L., 2009. The risk and consequences of clinical miscoding due to inadequate medical documentation: a case study of the impact on health services funding. Heal. Inf. Manag. J. 38, 35-46.

Cheung, W., Osmar R. Zaiane, 2003. Incremental mining of frequent patterns without candidate generation or support constraint. Proc. Seventh Int. Database Eng. Appl. Symp. IEEE 111-116.

Chiu, W., Yang, C., Lin, H., Chu, T., 2007. Development and implementation of a nationwide health care quality indicator system in Taiwan. Int. J. Qual. Heal. Care 19, 21-28.

Christensen, C.M., Grossman, J.., Hwang, J., 2009. The innovator's prescription, The Innovator's Prescription: A Disruptive Solution for Health Care. McGraw-Hill, New York (NY).

Chuah, M., Wong, K., 2011. A review of business intelligence and its maturity models. African J. Bus. Manag. 5, 3424-2428.

Coghlan, D., Brannick, T., 2005. Doing action research in your own organization. SAGE Publications, London (UK).

Corallo, A., Croxford, R., Goodman, D., Bryan, E., Srivastava, D., Stukel, T.A., 2014. A systematic review of medical practice variation in OECD countries. Health Policy (New. York). 114, 5-14.

Correia, T., Dussault, G., Pontes, C., 2015. The impact of the financial crisis on human resources for health policies in three southern-Europe countries. Health Policy (New. York). 119, 1600-1605.

Davenport, T., Harris, J., 2007. Competing on Analytics: The New Science of Winning, Harvard Business School Press. Boston (MA). 
Deng, Z.-H., 2016. DiffNodesets: An efficient structure for fast mining frequent itemsets. Appl. Soft Comput. 41, 214-223.

Deng, Z.-H., Lv, S., 2015. PrePost + : An efficient N-lists-based algorithm for mining frequent itemsets via Children - Parent Equivalence pruning. Expert Syst. Appl. 42, 5424-5432. https://doi.org/10.1016/j.eswa.2015.03.004

Deng, Z.-H., Wang, Z., Jiang, J., 2012. A new algorithm for fast mining frequent itemsets using N-lists. Sci. China Inf. Sci. 55, 2008-2030. https://doi.org/10.1007/s11432-012-4638-z

Dieleman, J.., Campbell, M., Chapin, A., Eldrenkamp, E., Fan, V.., Haakenstad, A., Kates, J., Li, Z., Matyasz, T., Micah, A., Reynolds, A., 2017. Future and potential spending on health 2015-40: development assistance for health, and government, prepaid private, and out-of-pocket health spending in 184 countries. Lancet 389, 2005-2030.

Dimitrovová, K., Perelman, J., 2018. Changes in access to primary care in Europe and its patterning, 2007-12: A repeated cross-sectional study. Eur. J. Public Health 28, 398-404. https://doi.org/10.1093/eurpub/cky019

Djenouri, Y., Comuzzi, M., 2017. GA-Apriori: Combining apriori heuristic and genetic algorithms for solving the frequent itemsets mining problem. Inf. Sci. (Ny). 420, 1-15.

Doddi, S., Marathe, A., Ravi, S.S., Torney, D.C., 2001. Discovery of association rules in medical data. Informatics Heal. Soc. Care 26, 25-33. https://doi.org/10.1080/14639230117529

Donabedian, A., 1966. Evaluating the quality of medical care. Milbank Q. 44, 166-203.

Downing, A., Rudge, G., Cheng, Y., Tu, Y.K., Keen, J., Gilthorpe, M.S., 2007. Do the UK government's new Quality and Outcomes Framework (QOF) scores adequately measure primary care performance? A cross-sectional survey of routine healthcare data. BMC Health Serv. Res. 7, 1-7. https://doi.org/10.1186/1472-6963-7-166

Eggli, Y., Desquins, B., Seker, E., Halfon, P., 2014. Comparing potentially avoidable hospitalization rates related to ambulatory care sensitive conditions in Switzerland: the need to refine the definition of health conditions and to adjust for population health status. BMC Health Serv. Res. 14, 25. https://doi.org/10.1186/1472-6963-14-25

El-Gayar, O., Timsina, P., 2014. Opportunities for Business Intelligence and Big Data Analytics in Evidence Based Medicine, in: 2014 47th Hawaii International Conference on System Sciences. IEEE, pp. 749-757. https://doi.org/10.1109/HICSS.2014.100

Elixhauser, A., Steiner, C., Harris, D., Coffey, R., 1998. Comorbidity measures for use with administrative data. Med. Care 36, 8-27.

Engelman, R., Rousou, J., Flack, J., 1994. Fast-track recovery of the coronary bypass patient. Ann. Thorac. 58, 1742-1746.

European Centre for Disease Prevention and Control, 2013. Point prevalence survey of healthcareassociated infections and antimicrobial use in European acute care hospitals. Stockholm: ECDC. https://doi.org/10.2900/86011

EuroStat, 2015. Healthcare expenditure statistics [WWW Document]. URL https://ec.europa.eu/eurostat/statisticsexplained/index.php/Healthcare_expenditure_statistics\#Health_care_expenditure (accessed 9.2.18).

Ferlie, E., Shortell, S., 2001. Improving the quality of health care in the United Kingdom and the United 
States: a framework for change. Milbank Q. 79, 281-315.

Fichman, R.G., Kohli, R., Krishnan, R., 2011. The role of information systems in healthcare: Current research and future trends. Inf. Syst. Res. 22, 419-428. https://doi.org/10.1287/isre.1110.0382

Fisher, E.., Wennberg, D.., Stukel, T.., Gottlieb, D.., Lucas, F.., Pinder, E.., 2003a. The Implications of Regional Variations in Medicare Spending. Part 2: Health Outcomes and Satisfaction with Care. Ann. Intern. Med. 138, 288-298. https://doi.org/10.7326/0003-4819-138-4-200302180-00007

Fisher, E.., Wennberg, D.., Stukel, T.., Gottlieb, D.., Lucas, F.., Pinder, E.., 2003b. The implications of regional variations in Medicare spending. Part 1: the content, quality, and accessibility of care. Ann. Intern. Med. 138, 273-287.

Fisher, E., Skinner, J., 2013. Making Sense Of Geographic Variations In Health Care: The New IOM Report [WWW Document]. Heal. Aff Blog. URL http://healthaffairs.org/blog/2013/07/24/makingsense-of-geographic-variations-in-health-care-the-new-iom-report/ (accessed 9.28.17).

Foshay, N., Kuziemsky, C., 2014. Towards an implementation framework for business intelligence in healthcare. Int. J. Inf. Manage. 34, 20-27. https://doi.org/10.1016/j.ijinfomgt.2013.09.003

Fournier-Viger, P., Lin, J.C.-W., Gomariz, A., Gueniche, T., Soltani, A., Deng, Z., Lam, H.T., 2016. The SPMF Open-Source Data Mining Library Version 2, in: 19th European Conference on Principles of Data Mining and Knowledge Discovery (PKDD). Springer, pp. 36-40. https://doi.org/10.1007/9783-319-46131-1_8

FP-Growth Association Rule Mining in MATLAB [WWW Document], n.d. URL http://yarpiz.com/98/ypml116-fp-growth (accessed 3.7.18).

Fraser, P., Moultrie, J., Gregory, M., 2002. The use of maturity models/grids as a tool in assessing product development capability, in: International Engineering Management Conference (IEMC), Cambridge, pp. 244-249.

Freeman, R.K., Dilts, J.R., Ascioti, A.J., Dake, M., Mahidhara, R.S., 2013. A comparison of length of stay, readmission rate, and facility reimbursement after lobectomy of the lung. Ann. Thorac. Surg. 96, 1740-1746. https://doi.org/10.1016/j.athoracsur.2013.06.053

Frequent Itemset Mining Dataset Repository [WWW Document], n.d. URL http://fimi.ua.ac.be/data/ (accessed 3.7.18).

Freund, T., Campbell, S.M., Geissler, S., Kunz, C.U., Mahler, C., Peters-Klimm, F., Szecsenyi, J., 2013. Strategies for Reducing Potentially Avoid- able Hospitalizations for Ambulatory Care- Sensitive Conditions. Ann. Fam. Med. 11, 363-370. https://doi.org/10.1370/afm.1498.INTRODUCTION

Friedman, J., Hastie, T., Tibshirani, R., 2001. The elements of statistical learning. Springer, Berlin: Springer series in statistics, New York.

Gandomi, A., Haider, M., 2015. Beyond the hype: Big data concepts, methods, and analytics. Int. J. Inf. Manage. 35, 137-144. https://doi.org/10.1016/j.ijinfomgt.2014.10.007

Garcia-Armesto, S., Angulo-Pueyo, E., 2015. Potential of geographical variation analysis for realigning providers to value-based care. ECHO case study on lower-value indications of C-section in five European. Eur. J. Public Health 25, 44-51.

Gellad, W.F., Good, C.B., Lowe, J.C., Donohue, J.M., 2010. Variation in prescription use and spending for lipid-lowering and diabetes medications in the VA Healthcare System. Am. J. Manag. Care 16, 741. 
Gibson, O., Segal, L., McDermott, R.A., 2013. systematic review of evidence on the association between hospitalisation for chronic disease related ambulatory care sensitive conditions and primary health .... BMC Health Serv. Res. 13, 336.

Gottlieb, D.J., Zhou, W., Song, Y., Andrews, K.G., Skinner, J.S., Sutherland, J.M., 2010. Prices don't drive regional Medicare spending variations. Health Aff. 29, 537-543.

Griffiths, P., Murrells, T., Dawoud, D., Jones, S., 2010. Hospital admissions for asthma, diabetes and COPD: is there an association with practice nurse staffing? A cross sectional study using routinely collected. BMC Health Serv. Res. 10, 276.

Hahsler, M., Hornik, K., Reutterer, T., 2006. Implications of probabilistic data modeling for mining association rules, in: Spiliopoulou, M., Kruse, R., Borgelt, C., Nurnberger, A., Gaul, W. (Eds.), From Data and Information Analysis to Knowledge Engineering. Springer, pp. 598-605.

Han, J., Pei, J., Yin, Y., 2000. Mining frequent patterns without candidate generation, in: ACM SIGMOD Record. pp. 1-12.

Hanauer, D.A., Rhodes, D.R., Chinnaiyan, A.M., 2009. Exploring Clinical Associations Using “ -Omics ' Based Enrichment Analyses 4, 1-7. https://doi.org/10.1371/journal.pone.0005203

Hand, D.J., 1999. Statistics and data mining: intersecting disciplines. ACM SIGKDD Explor. Newsl. 1, $16-19$.

Hand, D.J., Mannila, H., Smyth, P., 2001. Principles of data mining (adaptive computation and machine learning). MIT press, Cambridge, MA.

Hashem, T., Karim, R.M., Samiullah, M., Farhan, C., 2017. An efficient dynamic superset bit-vector approach for mining frequent closed itemsets and their lattice structure. Expert Syst. Appl. 67, 252271. https://doi.org/10.1016/j.eswa.2016.09.023

Health Barometer, Ministry of Health, Consumption and Social Welfare [WWW Document], n.d. URL https://pestadistico.inteligenciadegestion.mscbs.es/publicoSNS/Comun/ArbolNodos.aspx?idNodo=6 439 (accessed 5.17.19).

Hediger, V., Heinrich, A., Georgiev, P., Lazarevik, V., 2018. Health system financing: Tips for emerging markets.

Herrin, J., Andre, J.S., Kenward, K., 2015. Community factors and hospital readmission rates. Health Serv. Res. 50, 20-39.

Hu, T., Sung, S.Y., Xiong, H., Qian, F., 2008. Discovery of maximum length frequent itemsets. Inf. Sci. (Ny). 178, 69-87. https://doi.org/10.1016/J.INS.2007.08.006

IBM Quest Synthetic Data Generator [WWW Document], n.d. URL https://github.com/halfvim/quest (accessed 3.7.18).

ICMBD: Indicators and analysis axis model of the MBDS [WWW Document], n.d. URL https://icmbd.msssi.es/ICMBD/login-success.do (accessed 8.2.18).

Idri, A., Kadi, I., 2017. A Data Mining-Based Approach for Cardiovascular Dysautonomias Diagnosis and Treatment, in: IEEE International Conference on Computer and Information Technology (CIT) Helsinki. pp. 245-252.

Iezzoni, L.I., 2003. Risk adjustment for measuring health care outcomes, Vol. 3. ed. Health Administration Press, Chicago. 
Inouye, S.K., Bogardus Jr, S.T., Vitagliano, G., Desai, M.M., Williams, C.S., Grady, J.N., Scinto, J.D., 2003. Burden of illness score for elderly persons: risk adjustment incorporating the cumulative impact of diseases, physiologic abnormalities, and functional impairments. Med. Care 41, 70-83.

Institute of Medicine, 2003. The Future of the Public's Health in the 21st Century. The National Academies Press, Washington DC.

Israëls, A., 2013. Methods of Standardisation. Statistics Netherlands, The Hague.

Jaffer, A.K., Brotman, D.J., Bash, L.D., Mahmood, S.K., Lott, B., White, R.H., 2010. Variations in perioperative warfarin management: outcomes and practice patterns at nine hospitals. Am. J. Med. 123, 141-50. https://doi.org/10.1016/j.amjmed.2009.09.017

Janssen, M., Moors, E.H.M., 2015. Caring for healthcare entrepreneurs - Towards successful entrepreneurial strategies for sustainable innovations in Dutch healthcare. Technol. Forecast. Soc. Chang. 80, 1360-1374. https://doi.org/10.1016/j.techfore.2012.12.003

Javed, U., Deedwania, P.., Bhatt, D.., Cannon, C.., Dai, D., Hernandez, A.., Peterson, E.., Fonarow, G.., 2010. Use of intensive lipid-lowering therapy in patients hospitalized with acute coronary syndrome: an analysis of 65,396 hospitalizations from 344 hospitals participating in Get With The Guidelines (GWTG). Am. Heart J. 160, 1130-1136.

Johnson, M.L., 2003. Risk assessment and adjustment: Adjusting for sick patients or a sick system. Medical Care. Med. Care 41, 4-7.

Kaplan, B., Harris-Salamone, K.D., 2009. Health IT success and failure: recommendations from literature and an AMIA workshop. J. Am. Med. Informatics Assoc. 16, 291-299.

Karabatak, M., Ince, M.C., 2009. An expert system for detection of breast cancer based on association rules and neural network. Expert Syst. Appl. 36, 3465-3469.

Kelley, E., Hurst, J., 2006. Health Care Quality Indicators Project. Paris.

Keyhani, S., Falk, R., Howell, E.A., Bishop, T., Korenstein, D., 2013. Overuse and systems of care: a systematic review. Med. Care 51.

Kim, M., Ren, J., Tillis, W., Asche, C. V., Kim, I.K., Kirkness, C.S., 2016. Explaining the link between access-to-care factors and health care resource utilization among individuals with COPD. Int. J. COPD 11, 357-367. https://doi.org/10.2147/COPD.S95717

Koh, H., Tan, G., 2011. Data mining applications in healthcare. J. Healthc. Inf. 19, 65.

Kontopantelis, E., Springate, D., Reeves, D., Ashcroft, D.M., Valderas, J.M., Doran, T., 2014. Withdrawing performance indicators: Retrospective analysis of general practice performance under UK Quality and Outcomes Framework. BMJ 348, 1-17. https://doi.org/10.1136/bmj.g330

Kost, R., Littenberg, B., Chen, E., 2012. Exploring generalized association rule mining for disease cooccurrences., in: AMIA Annual Symposium Proceedings, American Medical Informatics Association. p. 1284.

Krumholz, H., Merrill, A., Schone, E., 2009. Patterns of hospital performance in acute myocardial infarction and heart failure 30-day mortality and readmission. Circ. Cardiovasc. Qual. Outcomes 2, 407-413.

Kuh, D., Ben-Shlomo, Y., 2004. A life course approach to chronic disease epidemiology, No.2. ed. Oxford University Press. 
Lahrmann, G., Marx, F., Winter, R., Wortmann, F., 2011. Business intelligence maturity: Development and evaluation of a theoretical model, in: Proceedings of the 44th Hawaii International Conference on System Sciences. pp. 1-10. https://doi.org/10.1109/HICSS.2011.90

Lazar, H., Fitzgerald, C., Ahmad, T., Bao, Y., 2001. Early discharge after coronary artery bypass graft surgery: are patients really going home earlier? J. Thorac. Cardiovasc. Surg. 121, 943-950.

Lerman, I., 2005. Adherence to treatment: the key for avoiding long-term complications of diabetes. Arch. Med. Res. 36, 300-306.

Lewis, R., Edwards, N., 2015. Improving length of stay: what can hospitals do? London.

Li, M., Mao, J., 2015. Hedonic or utilitarian? Exploring the impact of communication style alignment on user's perception of virtual health advisory services. Int. J. Inf. Manage. 35, 229-243. https://doi.org/10.1016/j.ijinfomgt.2014.12.004

Li, Y., Cai, X., Mukamel, D., Cram, P., 2013. Impact of length of stay after coronary bypass surgery on short-term readmission rate: an instrumental variable analysis. Med. Care 51, 45.

Lin, D., Kedem, Z.M., 1998. Pincer-Search : A New Algorithm for Discovering the Maximum Frequent Set 2 Association Rule Mining, in: International Conference on Extending Database Technology. Springer, Berlin, Heidelberg. pp. 103-119.

Lucas, F.L., Sirovich, B.E., Gallagher, P.M., Siewers, A.E., Wennberg, D.E., 2010. Variation in cardiologists' propensity to test and treat: is it associated with regional variation in utilization? Circ. Cardiovasc. Qual. Outcomes 3, 253-60. https://doi.org/10.1161/CIRCOUTCOMES.108.840009

Lupo, T., 2016. A fuzzy framework to evaluate service quality in the healthcare industry: An empirical case of public hospital service evaluation in Sicily. Appl. Soft Comput. 40, 468-478.

Magán, P., Alberquilla, Á., Otero, Á., Ribera, J.M., 2011. Hospitalizations for ambulatory care sensitive conditions and quality of primary care: their relation with socioeconomic and health care variables in the Madrid regional health service (Spain). Med. Care 17-23.

Mant, J., 2001. Process versus outcome indicators in the assessment of quality of health care. Int. J. Qual. Heal. Care 13, 475-480.

Martin, S., Smith, P., 1996. Explaining variations in inpatient length of stay in the National Health Service. J. Health Econ. 15, 279-304. https://doi.org/10.1016/0167-6296(96)00003-3

Marx, F., Wortmann, F., Mayer, J., 2012. A maturity model for management control systems. Bus. Inf. Syst. Eng. 4, 193-207.

Mays, N., 2011. Reducing unwarranted variations in healthcare in the English NHS. BMJ 342, d1849.

Mcandrew, R.M., Grabowski, D.C., Dangi, A., Young, G.J., 2016. Prevalence and patterns of potentially avoidable hospitalizations in the US long-term care setting. Int. J. Qual. Heal. Care 28, 104-109. https://doi.org/10.1093/intqhe/mzv110

McCormack, R., Michels, R., Ramos, N., 2013. Thirty-Day Readmission Rates as a Measure of Quality: Causes of Readmission After Orthopedic Surgeries and Accuracy of Administrative Data. J. Healthc. Manag. 58, 64-77.

McGraw, K., Harbison-Briggs, K., 1989. Knowledge acquisition: Principles and guidelines. PrenticeHall, New York (NY).

McPherson, K., Wennberg, J.E., Hovind, O.B., Clifford, P., 1982. Small-area variations in the use of 
common surgical procedures: an international comparison of New England, England, and Norway. N. Engl. J. Med. 307, 1310--1314.

Mercuri, M., Gafni, A., 2011. Medical practice variations: what the literature tells us (or does not) about what are warranted and unwarranted variations. J. Eval. Clin. Pract. 17, 671-7. https://doi.org/10.1111/j.1365-2753.2011.01689.x

Mercuri, M., Natarajan, M.K., Norman, G., Gafni, A., 2012. An even smaller area variation: differing practice patterns among interventional cardiologists within a single high volume tertiary cardiac centre. Health Policy 104, 179-85. https://doi.org/10.1016/j.healthpol.2010.11.006

Mettler, T., Rohner, P., 2009. Situational Maturity Models as Instrumental Artifacts for Organizational Design, in: 4th International Conference on Design Science Research in Information Systems and Technology. New York, p. 22.

Mettler, T., Vimarlund, V., 2009. Understanding business intelligence in the context of healthcare. Health Informatics J. 15, 254-264. https://doi.org/10.1177/1460458209337446

Mikaelsson, J., Shani, A., 2004. Rethinking and transforming product development, in: Adler N., Shani A.B., S.A. (Ed.), Collaborative Research in Organizations. Sage, Thousand Oaks, pp. 181-196.

Ministry of Housing Communities \& Local Government, n.d. English Indices of Deprivation 2015 LSOA Level [WWW Document]. URL http://opendatacommunities.org/data/societalwellbeing/imd/indices

Mobasher, B., Dai, H., Luo, T., Nakagawa, M., 2001. Effective personalization based on association rule discovery from web usage data, in: Proceedings of the 3rd International Workshop on Web Information and Data Management. pp. 9-15. https://doi.org/10.1145/502932.502935

Moens, S., Aksehirli, E., Goethals, B., 2013. Frequent Itemset Mining for Big Data, in: Proc. of the 2013 \{IEEE\} International Conference on Big Data. pp. 111-118.

Mohrman, A.M.J., Mohrman, S.A., 2004. Self-designing a performance management system, in: Alder, N., Shani, A.B., Styhre, A. (Eds.), Collaborative Research in Organizations: Foundations for Learning, Change, and Theoretical Development. Sage, Thousand Oaks.

Morgan, D.., Brownlee, S., Leppin, A.., Kressin, N., Dhruva, S.., Levin, L., Landon, B.., Zezza, M.., Schmidt, H., Saini, V., Elshaug, A.., 2015. Setting a research agenda for medical overuse. BMJ 351.

Muenchberger, H., Kendall, E., 2010. Predictors of preventable hospitalization in chronic disease: priorities for change. J. Public Health Policy 31, 150-163.

National Health System's Hospitalization Minimum Basic Data Set [WWW Document], n.d. URL http://icmbd.es/login-success.do

Nguyen, L.., Barshes, N.., 2010. Analysis of large databases in vascular surgery. J. Vasc. Surg. 52, 768774.

NHS England, n.d. Quality and Outcomes Framework [WWW Document]. URL https://digital.nhs.uk/catalogue/PUB30124

NHS England, n.d. NHS Payments to General Practices [WWW Document]. URL https://digital.nhs.uk/catalogue/PUB30089

NHS England, n.d. General and Personal Medical Services [WWW Document]. URL http://digital.nhs.uk/catalogue/PUB30149 
NHS England, n.d. Patients registered at a GP practice [WWW Document]. URL

https://digital.nhs.uk/GP-data-hub/Patients-registered-at-a-GP-practice

Nuti, S., Vainieri, M., Bonini, A., 2010. Disinvestment for re-allocation: A process to identify priorities in healthcare. Health Policy (New. York). 95, 137-143.

https://doi.org/10.1016/j.healthpol.2009.11.011

O’Malley, A.S., Reschovsky, J.D., Saiontz-Martinez, C., 2015. Interspecialty Communication Supported by Health Information Technology Associated with Lower Hospitalization Rates for Ambulatory Care-Sensitive Conditions. J. Am. Board Fam. Med. 28, 404-417. https://doi.org/10.3122/jabfm.2015.03.130325

Oderkirk, J., Ronchi, E., Klazinga, N., 2013. International comparisons of health system performance among OECD countries: opportunities and data privacy protection challenges. Health Policy (New. York). 112, 9-18.

OECD, 2018. Health spending [WWW Document]. URL https:/www.oecd-ilibrary.org/social-issuesmigration-health/health-spending/indicator/english_8643de7e-en.

OECD, 2017a. Avoidable Hospital Admissions, in: Health at a Glance 2017: OECD Indicators. OECD Publishing, Paris. https://doi.org/10.1787/health_glance-2013-43-en

OECD, 2017b. Consultations with doctors, in: Health at a Glance 2017: OECD Indicators. OECD Publishing, Paris. https://doi.org/http://dx.doi.org/10.1787/health_glance-2017-60-en

OECD, 2011. Health at a Glance 2011. Paris.

OECD, 2010. Improving Value in Health Care: Measuring Quality. OECD Healh Policy Studies.

Otsubo, T., Imanaka, Y., Morishima, T., Sasaki, N., Park, S., Lee, J., 2016. Variations in Healthcare Spending and Quality Among Institutions, in: Johnson, A., Stukel, T. (Eds.), Medical Practice Variations Health Services Research. Springer Boston, MA, pp. 383-406.

Ott, E., Saathoff, S., Graf, K., Schwab, F., Chaberny, I., 2013. The prevalence of nosocomial and community acquired infections in a university hospital. Dtsch Arztebl Int 110, 533-540.

Pai, F., Huang, K., 2011. Applying the Technology Acceptance Model to the introduction of healthcare information systems. Technol. Forecast. Soc. Chang. 78, 650-660. https://doi.org/10.1016/j.techfore.2010.11.007

Pei, J., Han, J., Mao, R., 2000. CLOSET:An efficient algorithm for mining frequent closed itemsets in dynamic transaction databases, in: ACM SIGMOD Workshop on Research Issues in Data Mining and Knowledge Discovery. pp. 21-30. https://doi.org/10.1504/IJISTA.2008.017275

Peiro, S., Maynard, A., 2015. Variations in health care delivery within the European Union. Eur. J. Public Health 25, 1-2. https://doi.org/10.1093/eurpub/cku223

Pine, M., Sonneborn, M., Schindler, J., Stanek, M., Maeda, J.L., Hanlon, C., 2012. Harnessing the power of enhanced data for healthcare quality improvement: lessons from a Minnesota Hospital Association Pilot Project. J. Healthc. Manag. 57, 406-18.

Popovič, A., Hackney, R., Coelho, P.S., Jaklič, J., 2012. Towards business intelligence systems success: Effects of maturity and culture on analytical decision making. Decis. Support Syst. 54, 729-739. https://doi.org/10.1016/j.dss.2012.08.017

Porebski, S., Straszecka, E., 2018. Extracting easily interpreted diagnostic rules. Inf. Sci. (Ny). 426, 1937. https://doi.org/10.1016/j.ins.2017.10.034 
Qaseem, A., Alguire, P., Dallas, P., Feinberg, L.E., Fitzgerald, F.T., Horwitch, C., Humphrey, L., Leblond, R., Moyer, D., Wiese, J.G., Weinberger, S., Alue, H.I.G.H., Are, C.O.S.T.O.C., 2012. Appropriate use of screening and diagnostic tests to foster high-value, cost-conscious care. Ann. Intern. Med. 156, 147-150.

Rizza, P., Bianco, A., Pavia, M., Angelillo, F., 2007. Preventable hospitalization and access to primary health care in an area of Southern Italy. BMC Health Serv. Res. 7, 134.

Roalfe, A.K., Holder, R.L., Wilson, S., 2008. Standardisation of rates using logistic regression: a comparison with the direct method. BMC Health Serv. Res. 8, 275. https://doi.org/10.1186/14726963-8-275

Romanow, D., Cho, S., Straub, D., 2012. Riding the Wave: Past Trends and Future Directions for Health IT Research. MIS Q. 36, 3-10.

Rosano, A., Loha, C.A., Falvo, R., Van Der Zee, J., Ricciardi, W., Guasticchi, G., De Belvis, A.G., 2013. The relationship between avoidable hospitalization and accessibility to primary care: A systematic review. Eur. J. Public Health 23, 356-360. https://doi.org/10.1093/eurpub/cks053

Ruiz, M.D., Martin-bautista, M.J., Sánchez, D., Vila, M.A., Delgado, M., 2014. Anomaly detection using fuzzy association rules. Int. J. Electron. Secur. Digit. Forensics 6, 25-37.

Saczynski, J., Lessard, D., Spencer, F., 2010. Declining length of stay for patients hospitalized with AMI: impact on mortality and readmissions. Am. J. Med. 123, 1007-1015.

Safran, C., Bloomrosen, M., Hammond, W.E., Labkoff, S., Markel-Fox, S., Tang, P.C., Detmer, D.E., 2007. Toward a national framework for the secondary use of health data: an American Medical Informatics Association White Paper. J. Am. Med. Informatics Assoc. 14, 1-9.

Saini, V., Garcia-Armesto, S., Klemperer, D., Paris, V., Elshaug, A.G., Brownlee, S., Ioannidis, J.P.A., Fisher, E.S., 2017. Drivers of poor medical care. Lancet 390, 178-190. https://doi.org/10.1016/S0140-6736(16)30947-3

Salam, A., Khayal, M.S.H., 2012. Mining top-k frequent patterns without minimum support threshold. Knowl. Inf. Syst. 30, 57-86.

Sanderson, C., Dixon, J., 2000. Conditions for which onset or hospital admission is potentially preventable by timely and effective ambulatory care. J. Heal. Serv. Res. policy 5, 222-230.

Schein, E.., 2008. Clinical inquiry/research, in: Reason, P., Bradbury, H. (Eds.), The SAGE Handbook of Action Research: Participative Inquiry and Practice. Sage, Thousand Oaks, pp. 266-279.

Schouten, J.A., Hulscher, M.E., Kullberg, B.J., Cox, A., Gyssens, I.C., van der Meer, J.W., Grol, R.P., 2005. Understanding variation in quality of antibiotic use for community-acquired pneumonia: effect of patient, professional and hospital factors. J. Antimicrob. Chemother. 56, 575-582.

Schwartz, A.L., Landon, B.E., Elshaug, A.G., Chernew, M.E., McWilliams, J.M., 2014. Measuring lowvalue care in Medicare. JAMA Intern. Med. 174, 1067-1076.

Sekimoto, M., Imanaka, Y., Shirai, T., Sasaki, H., Komeno, T., Lee, J., Yoshihara, K., Ashihara, E., Maekawa, T., 2010. Risk-adjusted assessment of incidence and quantity of blood use in acute-care hospitals in Japan: an analysis using administrative data. Vox Sang. 98, 538-546.

Sen, A., Ramamurthy, K., Sinha, A., 2012. A model of data warehousing process maturity. IEEE Trans. Softw. Eng. 38, 336-353.

Shen, C.C., Chang, R.E., Hsu, C.J., Chang, I.C., 2017. How business intelligence maturity enabling 
hospital agility. Telemat. Informatics 34, 450-456. https://doi.org/10.1016/j.tele.2016.06.009

Shortell, S.M., 2004. Increasing value: a research agenda for addressing the managerial and organizational challenges facing health care delivery in the United States. Med. Care Res. Rev. 61, 12S-30S. https://doi.org/10.1177/1077558704266768

Simon, G.J., Caraballo, P.J., Therneau, T.M., Cha, S.S., Castro, M.R., Li, P.W., 2015. Extending Association Rule Summarization Techniques to Assess Risk of Diabetes Mellitus. IEEE Trans. Knowl. Data Eng. 27, 130-141. https://doi.org/10.1109/TKDE.2013.76

Singh, J., Ram, H., 2013. Improving efficiency of Apriori algorithm using transaction reduction. Int. J. Sci. Res. Publ. 3, 1-4.

Singh, S., Lin, Y., Kuo, Y., Nattinger, A., 2014. Variation in the risk of readmission among hospitals: the relative contribution of patient, hospital and inpatient provider characteristics. J. Gen. Intern. Med. $29,572-578$.

Soni, J., Ansari, U., Sharma, D., Soni, S., 2011. Predictive data mining for medical diagnosis: An overview of heart disease prediction. Int. J. Comput. Appl. 17, 43-48.

Spain Institute of Statistics [WWW Document], n.d. URL http://www.ine.es

SPMF:An Open-Source Data Mining Library [WWW Document], n.d. URL http://www.philippefournier-viger.com/spmf/index.php?link=datasets.php (accessed 3.7.18).

Stebbins, M., Shani, A., 2009. Clinical inquiry and reflective design in a secrecy-based organization. J. Appl. Behav. Sci. 45, 59-89.

Stilou, S., Bamidis, P.D., Maglaveras, N., Pappas, C., 2001. Mining association rules from clinical databases: an intelligent diagnostic process in healthcare. Stud. Health Technol. Inform. 2, 13991403.

Tai, T.A., Phong, N.T., Anh, N.K., 2011. An efficient algorithm for discovering maximum length frequent itemsets, in: Third International Conference on Knowledge and Systems Engineering (KSE) IEEE. pp. 62-69.

Tai, Y.-M., Chiu, H.-W., 2009. Comorbidity study of ADHD: applying association rule mining (ARM) to National Health Insurance Database of Taiwan. Int. J. Med. Inform. 78, e75-83.

Tan, P.-N., Steinbach, M., Kumar, V., 2006. Introduction to Data Mining. Addison-Wesley Longman, Boston, MA.

Tanbeer, S.K., Ahmed, C.F., Jeong, B.-S., Lee, Y.-K., 2009. Efficient single-pass frequent pattern mining using a prefix-tree. Inf. Sci. (Ny). 179, 559-583.

The Primary Health Care Information System (SIAP) [WWW Document], n.d. URL https://pestadistico.inteligenciadegestion.mscbs.es/publicoSNS/Comun/ArbolNodos.aspx?idNodo=6 397 (accessed 5.17.19).

The Specialized Care Information System (SIAE) [WWW Document], n.d. URL https://pestadistico.inteligenciadegestion.mscbs.es/publicoSNS/Comun/ArbolNodos.aspx?idNodo=2 0675 (accessed 5.17.19).

Thomson, S., Figueras, J., Evetovits, T., Jowett, M., Mladovsky, P., Maresso, A., Cylus, J., Karanikolos, M., Kluge, H., 2014. Economic crisis, health systems and health in Europe: impact and implications for policy. Open University Press, Maidenhead. 
Thygesen, Lau C., Christiansen, Terkel, Garcia-Armesto, S., Angulo-Pueyo, Ester, Martínez-Lizaga, N., Bernal-Delgado, Enrique, Bernal-Delgado, E., García-Armesto, S., Martínez, N., Seral, M., Estupiñán, F., Comendeiro, M., Angulo-Pueyo, E., Ridao, M., Baixaulí, C., Librero, J., Christiansen, T., Thygesen, L. C., Bloor, K., Cookson, R., Gutacker, N., Mateus, C., Nunes, C., Joaquim, I., Yazbeck, A.M., Galsworthy, M., Albreht, T., Munck, J., Güntert, B., Bremner, J., Giepmans, P., Dix, O., 2015. Potentially avoidable hospitalizations in five European countries in 2009 and time trends from 2002 to 2009 based on administrative data. Eur. J. Public Health 25, 35-43. https://doi.org/10.1093/eurpub/cku227

Tremblay, M.C., Hevner, A.R., Berndt, D.J., 2012. Design of an information volatility measure for health care decision making. Decis. Support Syst. 52, 331-341. https://doi.org/10.1016/j.dss.2011.08.009

Tsai, T.C., Joynt, K.E., Orav, E.J., Gawande, A. a, Jha, A.K., 2013. Variation in surgical-readmission rates and quality of hospital care. Supplementary Appendix. N. Engl. J. Med. 369, 1134-42. https://doi.org/10.1056/NEJMsa1303118

UK Prospective Diabetes Study Group, 1998. Tight blood pressure control and risk of macrovascular and microvascular complications in type 2 diabetes: UKPDS 38. BMJ Br. Med. J. 317, 703-713.

van Mourik, M.S.M., van Duijn, P.J., Moons, K.G.M., Bonten, M.J.M., Lee, G.M., 2015. Accuracy of administrative data for surveillance of healthcare-associated infections: a systematic review. BMJ Open 5. https://doi.org/10.1136/bmjopen-2015-008424

Van Steenbergen, L.N., Rutten, H.J.T., Creemers, G.J., Pruijt, J.F.M., Coebergh, J.W.W., Lemmens, V.E.P.P., 2009. Large age and hospital-dependent variation in administration of adjuvant chemotherapy for stage III colon cancer in southern Netherlands. Ann. Oncol. 21, 1273-1278.

Vo, B., Pham, S., Le, T., Deng, Z.., 2017. A novel approach for mining maximal frequent patterns. Expert Syst. Appl. 73, 178-186.

Wang, H.H.S., Lloyd, J.C., Wiener, J.S., Routh, J.C., 2016. Nationwide trends and variations in urological surgical interventions and renal outcome in patients with spina bifida. J. Urol. 195, 11891195.

Wang, Y., Hou, W., Wang, F., 2018. Mining co-occurrence and sequence patterns from cancer diagnoses in New York State. PLoS One 13, 1-16. https://doi.org/10.1371/journal.pone.0194407

Weiner, M.G., Embi, P.J., 2009. Toward Reuse of Clinical Data for Research and Quality Improvement: The End of the Beginning? Ann. Intern. Med. 151, 359-360. https://doi.org/10.7326/0003-4819151-5-200909010-00141

Welch, H.G., Sharp, S.M., Gottlieb, D.J., Skinner, J.S., Wennberg, J.E., 2011. Geographic variation in diagnosis frequency and risk of death among Medicare beneficiaries. Jama 305, 1113-1118.

Wennberg, J.E., 2014. Forty years of unwarranted variation-And still counting. Health Policy (New. York). 114, 1-2. https://doi.org/10.1016/j.healthpol.2013.11.010

Wennberg, J.E., 2010. Tracking medicine: a researcher's quest to understandhealth care. Oxford University Press, New York, NY.

Wennberg, J.E., 2002. Unwarranted variations in healthcare delivery: implications for academic medical centres. BMJ Br. Med. J. 325, 961-964.

Wennberg, J.E., 1987. Population illness rates do not explain population hospitalization rates: a comment on Mark Blumberg's thesis that morbidity adjusters are needed to interpret small. Med. Care 354359. 
Wennberg, J.E., Gittelsohn, A., 1973. Small area variations in health care delivery:a population-based health information system can guide planning andregulatory decision-making. Science (80-. ). 182, $1102-1108$.

Womack, J.P., Jones, D.T., 2003. LEAN THINKING. Simon and Schuster, New York (NY).

Wooldridge, J., 2010. Econometric analysis of cross section and panel data. MIT press.

Worcester, M.U.C., Stojcevski, Z., Murphy, B., Goble, A.J., 2003. Long-term behavioral outcomes after attendance at a secondary prevention clinic for cardiac patients. J. Cardiopulm. Rehabil. Prev. 23, 415-422.

World Health Organization, 2008. Framework and standards for country health information systems. Geneva, Switzerland.

Wright, A., Chen, E.S., Maloney, F.L., 2010. An automated technique for identifying associations between medications, laboratory results and problems. J. Biomed. Inform. 43, 891-901. https://doi.org/10.1016/j.jbi.2010.09.009

Wu, J.M.-T., Zhan, J., Lin, J.C.-W., 2017. An ACO-based approach to mine high-utility itemsets. Knowledge-Based Syst. 116, 102-113.

Yoo, I., Alafaireet, P., Marinov, M., Pena-Hernandez, K., Gopidi, R., Chang, J.F., Hua, L., 2012. Data mining in healthcare and biomedicine: A survey of the literature. J. Med. Syst. 36, 2431-2448. https://doi.org/10.1007/s10916-011-9710-5

Zhang, A., Shi, W., Webb, G.I., 2016. Mining significant association rules from uncertain data. Data Min. Knowl. Discov. 30, 928-963. https://doi.org/10.1007/s10618-015-0446-6

Zimlichman, E., Henderson, D., Tamir, O., Franz, C., Song, P., Yamin, C.K., Keohane, C., Denham, C.R., Bates, D.W., 2013. Health Care-Associated Infections. JAMA Intern. Med. 173, 2039. https://doi.org/10.1001/jamainternmed.2013.9763 


\section{Annex A}

ICD9 codes for inclusion and exclusion criteria used by Spanish ministry of Health, Social

Services and Equality of for the four potentially avoidable condition

Chronic Obstructive Pulmonary Disease Admission Rate Inclusion:

Patients 40 years and older with the following principal diagnoses:

491.0 SIMPLE CHR BRONCHITIS

491.1 MUCOPURUL CHR BRONCHITIS

491.20 OBS CHR BRNC W/O ACT EXA

491.21 OBS CHR BRNC W ACT EXA

491.22 OBS CHR BRONC W AC BRONC

491.8 CHRONIC BRONCHITIS NEC

491.9 CHRONIC BRONCHITIS NOS

492.0 EMPHYSEMATOUS BLEB

492.8 EMPHYSEMA NEC

494 BRONCHIECTASIS

494.0 BRONCHIECTAS W/O AC EXAC

494.1 BRONCHIECTASIS W AC EXAC

496 CHR AIRWAY OBSTRUCT NEC

466.0 ACUTE BRONCHITIS

490 BRONCHITIS NOS

\section{Exclusion:}

Cases with any listed diagnosis codes for cystic fibrosis and anomalies of the respiratory system Obstetric admissions 


\section{Congestive Heart Failure Admission Rate \\ Inclusion}

Patients 15 years and older the following principal diagnoses:

398.91 RHEUMATIC HEART FAILURE

402.01 MAL HYPERT HRT DIS W CHF

402.11 BENIGN HYP HRT DIS W CHF

402.91 HYPERTEN HEART DIS W CHF

404.01 MAL HYPER HRT/REN W CHF

404.03 MAL HYP HRT/REN W CHF/RF

404.11 BEN HYPER HRT/REN W CHF

404.13 BEN HYP HRT/REN W CHF/RF

404.91 HYPER HRT/REN NOS W CHF

404.93 HYP HT/REN NOS W CHF/RF

428.0 CONGESTIVE HEART FAILURE

428.1 LEFT HEART FAILURE

428.20 SYSTOLIC HRT FAILURE NOS

428.21 AC SYSTOLIC HRT FAILURE

428.22 CHR SYSTOLIC HRT FAILURE

428.23 AC ON CHR SYST HRT FAIL

428.30 DIASTOLC HRT FAILURE NOS

428.31 AC DIASTOLIC HRT FAILURE

428.32 CHR DIASTOLIC HRT FAIL

428.33 AC ON CHR DIAST HRT FAIL

428.40 SYST/DIAST HRT FAIL NOS

428.41 AC SYST/DIASTOL HRT FAIL

428.42 CHR SYST/DIASTL HRT FAIL

428.43 AC/CHR SYST/DIA HRT FAIL

428.9 HEART FAILURE NOS

\section{Exclusion:}

Cases with any listed procedure codes for cardiac procedure

Obstetric admissions 


\section{Bacterial Pneumonia Admission Rate}

\section{Inclusion:}

Patients 15 years and older the following principal diagnoses:

481 PNEUMOCOCCAL PNEUMONIA

482.2 H.INFLUENZAE PNEUMONIA

482.30 STREP PNEUMONIA UNSPEC

482.31 GRP A STREP PNEUMONIA

482.32 GRP B STREP PNEUMONIA

482.39 OTH STREP PNEUMONIA

482.41 METH SUS PNEUM D/T STAPH

482.42 METH RES PNEU D/T STAPH

482.9 BACTERIAL PNEUMONIA NOS

483.0 MYCOPLASMA PNEUMONIA

483.1 CHLAMYDIA PNEUMONIA

483.8 OTH SPEC ORG PNEUMONIA

485 BRONCOPNEUMONIA ORG NOS

486 PNEUMONIA, ORGANISM NOS

Exclusion:

Cases with codes for immunocompromised state

Cases with codes for sickle cell anemia or HB-S disease

Obstetric admissions 


\begin{tabular}{|c|c|c|c|c|c|c|}
\hline \multirow[b]{2}{*}{ Dimension } & \multirow[b]{2}{*}{ Metric } & \multirow[b]{2}{*}{ Sub-metric ${ }^{*}$} & \multicolumn{4}{|c|}{ Maturity levels } \\
\hline & & & $\begin{array}{l}\text { Level 1: } \\
\text { Initial }\end{array}$ & $\begin{array}{l}\text { Level 2: } \\
\text { Managed }\end{array}$ & $\begin{array}{l}\text { Level 3: } \\
\text { Systematic }\end{array}$ & $\begin{array}{l}\text { Level 4: } \\
\text { Disrupted }\end{array}$ \\
\hline \multirow{3}{*}{$\begin{array}{l}F_{1} . \text { Goal } \\
\text { definition }\end{array}$} & $\begin{array}{l}\text { Level of data } \\
\text { granularity }^{* *}\end{array}$ & $\begin{array}{l}\text { Economic } \\
\text { Production } \\
\text { Qualitative }\end{array}$ & $\begin{array}{l}\text { None or } \\
\text { organization }\end{array}$ & Unit or ward & $\begin{array}{l}\text { Event or } \\
\text { cure episode }\end{array}$ & $\begin{array}{l}\text { Treatment } \\
\text { procedure }\end{array}$ \\
\hline & $\begin{array}{l}\text { Functional } \\
\text { support }\end{array}$ & $\begin{array}{l}\text { Economic } \\
\text { Production } \\
\text { Qualitative } \\
\end{array}$ & No support & $\begin{array}{l}\text { Input of } \\
\text { consolidated } \\
\text { targets }\end{array}$ & $\begin{array}{l}\text { Budget } \\
\text { development }\end{array}$ & $\begin{array}{l}\text { Budget } \\
\text { dynamic } \\
\text { management }\end{array}$ \\
\hline & Frequency $^{* *}$ & $\begin{array}{l}\text { Economic } \\
\text { Production } \\
\text { Qualitative }\end{array}$ & Annually & Quarterly & Monthly & $\begin{array}{l}\text { Weekly } \\
\text { or daily }\end{array}$ \\
\hline \multirow{3}{*}{$F_{2}$. Measurement } & $\begin{array}{l}\text { Level of data } \\
\text { granularity }\end{array}$ & $\begin{array}{l}\text { Economic } \\
\text { Production } \\
\text { Qualitative }\end{array}$ & $\begin{array}{l}\text { None or } \\
\text { organization }\end{array}$ & Unit or ward & $\begin{array}{l}\text { Event or } \\
\text { cure episode }\end{array}$ & $\begin{array}{l}\text { Treatment } \\
\text { procedure }\end{array}$ \\
\hline & $\begin{array}{l}\text { Functional } \\
\text { support }\end{array}$ & $\begin{array}{l}\text { Economic } \\
\text { Production } \\
\text { Qualitative } \\
\end{array}$ & No support & $\begin{array}{l}\text { Only some } \\
\text { operative units, } \\
\text { manually }\end{array}$ & $\begin{array}{l}\text { All operating } \\
\text { units, manually }\end{array}$ & $\begin{array}{l}\text { All operating } \\
\text { units and } \\
\text { automatically** }\end{array}$ \\
\hline & Frequency $^{* *}$ & $\begin{array}{l}\text { Economic } \\
\text { Production } \\
\text { Qualitative } \\
\end{array}$ & Quarterly & Monthly & $\begin{array}{l}\text { Weekly } \\
\text { or daily }\end{array}$ & Real time \\
\hline \multirow{3}{*}{$F_{3}$. Gap analysis } & $\begin{array}{l}\text { Level of data } \\
\text { granularity }^{*}\end{array}$ & $\begin{array}{l}\text { Economic } \\
\text { Production } \\
\text { Qualitative }\end{array}$ & $\begin{array}{l}\text { None or } \\
\text { organization }\end{array}$ & Unit or ward & $\begin{array}{l}\text { Event or } \\
\text { cure episode }\end{array}$ & $\begin{array}{l}\text { Treatment } \\
\text { procedure }\end{array}$ \\
\hline & $\begin{array}{l}\text { Functional } \\
\text { support }\end{array}$ & $\begin{array}{l}\text { Economic } \\
\text { Production } \\
\text { Qualitative } \\
\end{array}$ & No support & $\begin{array}{l}\text { Only data } \\
\text { collection }\end{array}$ & $\begin{array}{l}\text { Data collection } \\
\text { and gap } \\
\text { visualisation }\end{array}$ & $\begin{array}{l}\text { Data collection } \\
\text { and automatic } \\
\text { gap analysis }\end{array}$ \\
\hline & Frequency $^{* *}$ & $\begin{array}{l}\text { Economic } \\
\text { Production } \\
\text { Qualitative }\end{array}$ & Quarterly & Monthly & $\begin{array}{l}\text { Weekly } \\
\text { or daily }\end{array}$ & Real time \\
\hline \multirow{3}{*}{$\begin{array}{l}F_{4} . \text { Decision } \\
\text { making }\end{array}$} & $\begin{array}{l}\text { Level of data } \\
\text { granularity }\end{array}$ & $\begin{array}{l}\text { Economic } \\
\text { Production } \\
\text { Qualitative }\end{array}$ & $\begin{array}{l}\text { None or } \\
\text { organization }\end{array}$ & Unit or ward & $\begin{array}{l}\text { Event or } \\
\text { cure episode }\end{array}$ & $\begin{array}{l}\text { Treatment } \\
\text { procedure }\end{array}$ \\
\hline & $\begin{array}{l}\text { Functional } \\
\text { support }\end{array}$ & $\begin{array}{l}\text { Economic } \\
\text { Production } \\
\text { Qualitative }\end{array}$ & No support & $\begin{array}{l}\text { Ex post } \\
\text { analysis }\end{array}$ & OLAP & $\begin{array}{l}\text { Active support } \\
\text { to decision } \\
\text { making }\end{array}$ \\
\hline & Frequency $^{* *}$ & $\begin{array}{l}\text { Economic } \\
\text { Production } \\
\text { Qualitative } \\
\end{array}$ & Quarterly & Monthly & $\begin{array}{l}\text { Weekly } \\
\text { or daily }\end{array}$ & Real time \\
\hline \multirow{2}{*}{$F_{5}$. Data quality } & $\begin{array}{l}\text { Controls on } \\
\text { inbound data }\end{array}$ & $\begin{array}{l}\text { Economic } \\
\text { Production } \\
\text { Qualitative } \\
\end{array}$ & $\begin{array}{l}\text { No automatic } \\
\text { controls }\end{array}$ & $\begin{array}{l}\text { Controls on } \\
\text { less than } \\
40 \% \text { of data }\end{array}$ & $\begin{array}{l}\text { Controls on } \\
\text { less than } \\
80 \% \text { of data }\end{array}$ & $\begin{array}{l}\text { Systematic } \\
\text { controls on all } \\
\text { managed data }\end{array}$ \\
\hline & $\begin{array}{l}\text { Controls on } \\
\text { outbound } \\
\text { data }\end{array}$ & $\begin{array}{l}\text { Economic } \\
\text { Production } \\
\text { Qualitative }\end{array}$ & $\begin{array}{l}\text { No automatic } \\
\text { controls }\end{array}$ & $\begin{array}{l}\text { Controls on } \\
\text { less than } \\
40 \% \text { of data }\end{array}$ & $\begin{array}{l}\text { Controls on } \\
\text { less than } \\
80 \% \text { of data }\end{array}$ & $\begin{array}{l}\text { Systematic } \\
\text { controls on all } \\
\text { managed data }\end{array}$ \\
\hline \multirow{3}{*}{$\begin{array}{l}F_{6} . \text { Functional } \\
\text { integration }\end{array}$} & $\begin{array}{l}\text { Internal data } \\
\text { integration }^{* * *}\end{array}$ & $\begin{array}{l}\text { Economic } \\
\text { Production } \\
\text { Qualitative }\end{array}$ & None & $\begin{array}{l}\text { Integration } \\
\text { of less than } \\
30 \% \text { of data }\end{array}$ & $\begin{array}{l}\text { Integration } \\
\text { of less than } \\
70 \% \text { of data }\end{array}$ & $\begin{array}{l}\text { Integration } \\
\text { of more than } \\
70 \% \text { of data }\end{array}$ \\
\hline & External data & integration $^{* * * *}$ & None & Two & $\begin{array}{l}\text { Three, on } \\
\text { less than } 50 \% \\
\text { of processes }\end{array}$ & $\begin{array}{l}\text { Three, on } \\
\text { more than } 50 \% \\
\text { of processes }\end{array}$ \\
\hline & $\begin{array}{l}\text { Integration an } \\
\text { functional are }\end{array}$ & nong & None & Two & Three & All \\
\hline \multicolumn{7}{|c|}{ 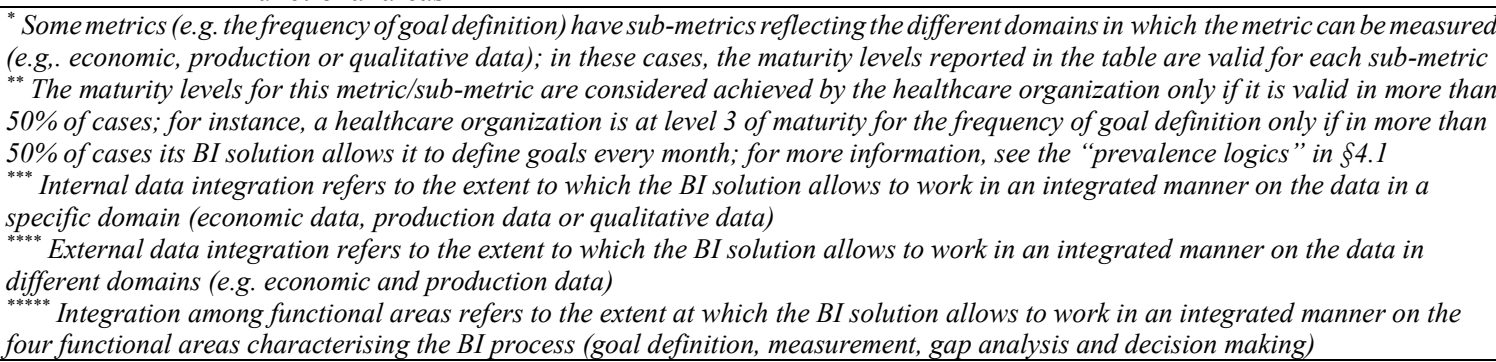 } \\
\hline
\end{tabular}

Table B.1. Dimensions, metrics, and maturity levels in the functional area 


\begin{tabular}{|c|c|c|c|c|c|c|}
\hline Dimension & Metric & Sub-metric* & $\begin{array}{l}\text { Level 1: } \\
\text { Initial }\end{array}$ & $\begin{array}{l}\text { Level 2: } \\
\text { Managed }\end{array}$ & $\begin{array}{l}\text { Level 3: } \\
\text { Systematic }\end{array}$ & $\begin{array}{l}\text { Level 4: } \\
\text { Disrupted }\end{array}$ \\
\hline $\begin{array}{l}T_{1 .} \mathrm{BI} \\
\text { architecture }\end{array}$ & \multicolumn{2}{|c|}{ Structure of the architecture } & No architecture & No decoupling & $\begin{array}{l}\text { Transactional } \\
\text { and analytics } \\
\text { decoupling }\end{array}$ & $\begin{array}{l}\text { Multi-level } \\
\text { architecture } \\
\text { for analytics }\end{array}$ \\
\hline \multirow{2}{*}{$T_{2}$. Reporting } & Quality** $^{* *}$ & $\begin{array}{l}\text { Economic } \\
\text { Production } \\
\text { Qualitative }\end{array}$ & Static & $\begin{array}{l}\text { Static with } \\
\text { graphic data } \\
\text { visualisation }\end{array}$ & $\begin{array}{l}\text { Dynamic data } \\
\text { navigation }\end{array}$ & $\begin{array}{l}\text { Dynamic } \\
\text { statistical } \\
\text { simulation }\end{array}$ \\
\hline & Distribution $^{* *}$ & $\begin{array}{l}\text { Economic } \\
\text { Production } \\
\text { Qualitative }\end{array}$ & Paper-based & $\begin{array}{l}\text { Digital but } \\
\text { manual }\end{array}$ & $\begin{array}{l}\text { Digital and } \\
\text { automatic }\end{array}$ & $\begin{array}{l}\text { Always } \\
\text { and directly } \\
\text { accessible }\end{array}$ \\
\hline \multirow[b]{2}{*}{$T_{3}$. Interface } & \multicolumn{3}{|c|}{ Interface characteristics } & Client-server & Web-based & $\overline{\text { Advanced (RIA) }}$ \\
\hline & \multicolumn{2}{|c|}{$\begin{array}{l}\text { Device through which it is } \\
\text { possible to access the system }\end{array}$} & $\begin{array}{l}\text { There is no } \\
\text { BI solution }\end{array}$ & $\begin{array}{l}\text { Only through } \\
\text { specific devices }\end{array}$ & $\begin{array}{l}\text { All desktop } \\
\text { devices }\end{array}$ & $\begin{array}{l}\text { All mobile } \\
\text { devices }\end{array}$ \\
\hline $\begin{array}{l}T_{4} \text {. User } \\
\text { profiling }\end{array}$ & \multicolumn{2}{|c|}{ Profiling level of BI users } & No profiling & $\begin{array}{l}\text { Macro-area } \\
\text { profiling }\end{array}$ & $\begin{array}{l}\text { Single user } \\
\text { profiling }\end{array}$ & $\begin{array}{l}\text { Context-based } \\
\text { profiling }\end{array}$ \\
\hline \multirow{2}{*}{$\begin{array}{l}\text { T5. Technological } \\
\text { integration }\end{array}$} & \multicolumn{2}{|c|}{$\begin{array}{l}\text { Integration with internal } \\
\text { systems (automatic data } \\
1 \text { alimentation) }\end{array}$} & None & $\begin{array}{l}\text { Integration } \\
\text { with less than }\end{array}$ & $\begin{array}{l}\text { Integration } \\
\text { with less than }\end{array}$ & $\begin{array}{l}\text { Integration } \\
\text { with more than }\end{array}$ \\
\hline & \multicolumn{2}{|c|}{$\begin{array}{l}\text { Integration with } \\
\text { external systems }\end{array}$} & Manual & $\begin{array}{l}\text { Mono- } \\
\text { directional }\end{array}$ & $\begin{array}{l}\text { Manual } \\
\text { bi-directional }\end{array}$ & $\begin{array}{l}\text { Automatic } \\
\text { bi-directional }\end{array}$ \\
\hline \multirow[t]{2}{*}{$T_{6 .}$ Standards } & \multicolumn{2}{|c|}{$\begin{array}{l}\text { Usage of interoperability } \\
\text { standards by the BI solution }\end{array}$} & $\begin{array}{l}\text { No standards } \\
\text { used by the } \\
\text { BI applications }\end{array}$ & $\begin{array}{l}\text { Standards for } \\
\text { less than } 50 \% \text { of } \\
\text { BI applications }\end{array}$ & $\begin{array}{l}\text { Standards for } \\
\text { less than } 85 \% \text { of } \\
\text { BI applications }\end{array}$ & $\begin{array}{l}\text { Standards for } \\
\text { more than } 85 \% \text { of } \\
\text { BI applications }\end{array}$ \\
\hline & \multicolumn{2}{|c|}{$\begin{array}{l}\text { Number of interoperability } \\
\text { standards supported }\end{array}$} & No standards & $\begin{array}{l}\text { Only one } \\
\text { standard }\end{array}$ & Few standards & $\begin{array}{l}\text { The majority } \\
\text { of standards }\end{array}$ \\
\hline \multirow{3}{*}{$\begin{array}{l}T 7 . \text { Data } \\
\text { provisioning }\end{array}$} & $\begin{array}{l}\text { Level of data } \\
\text { granularity of } \\
\text { inbound data }\end{array}$ & $\begin{array}{l}\text { Economic } \\
\text { Production } \\
\text { Qualitative }\end{array}$ & $\begin{array}{l}\text { None or } \\
\text { organization }\end{array}$ & Unit or ward & $\begin{array}{l}\text { Event or } \\
\text { cure episode }\end{array}$ & $\begin{array}{l}\text { Treatment } \\
\text { procedure }\end{array}$ \\
\hline & \multirow[b]{2}{*}{ Frequency $^{* *}$} & Economic & & & & \\
\hline & & $\begin{array}{l}\text { Production } \\
\text { Qualitative }\end{array}$ & Quarterly & Monthly & $\begin{array}{l}\text { Weekly } \\
\text { or daily }\end{array}$ & Real time \\
\hline
\end{tabular}

\footnotetext{
${ }^{*}$ Some metrics (e.g., the quality of reporting) have sub-metrics reflecting the different domains in which the metric can be measured (e.g., economic, production or qualitative data); in these cases, the maturity levels reported in the table are valid for each sub-metric

** The maturity levels for this metric/sub-metric are considered achieved by the healthcare organization only if it is valid in more than $50 \%$ of cases; for example, a healthcare organization is at level 2 of maturity for the quality of reporting only if in more than $50 \%$ of cases its BI solution has static reporting with tools for graphic data visualisation; if the BI solution provides these tools only in $30 \%$ of cases the healthcare organization achieves a maturitylevel of 1 (static reporting); formore info., see the "prevalence logics" in $\$ 4.1$
}

Table B.2. Dimensions, metrics, and maturity levels in the technological area 


\begin{tabular}{|c|c|c|c|c|c|c|}
\hline \multirow[b]{2}{*}{ Dimension } & \multirow[b]{2}{*}{ Metric } & \multirow[b]{2}{*}{ Sub-metric* } & \multicolumn{4}{|c|}{$\longrightarrow$ Maturity levels $\longrightarrow$} \\
\hline & & & $\begin{array}{l}\text { Level 1: } \\
\text { Initial }\end{array}$ & $\begin{array}{l}\text { Level 2: } \\
\text { Managed }\end{array}$ & $\begin{array}{l}\text { Level 3: } \\
\text { Systematic }\end{array}$ & $\begin{array}{l}\text { Level 4: } \\
\text { Disrupted }\end{array}$ \\
\hline \multirow{4}{*}{$\begin{array}{l}D_{l .} \text { Accessing } \\
\text { users }\end{array}$} & \multirow{2}{*}{$\begin{array}{l}\text { Administrative } \\
\text { realm }\end{array}$} & Directors & $\begin{array}{l}\text { Less than } 50 \% \\
\text { of directors }\end{array}$ & $\begin{array}{l}\text { Between } \\
50 \% \text { and } 70 \% \\
\text { of directors }\end{array}$ & $\begin{array}{l}\text { Between } \\
70 \% \text { and } 90 \% \\
\text { of directors }\end{array}$ & $\begin{array}{l}\text { More than } 90 \% \\
\text { of directors }\end{array}$ \\
\hline & & Other users & $\begin{array}{l}\text { Less than } 25 \% \\
\text { of users }\end{array}$ & $\begin{array}{l}\text { Between } \\
25 \% \text { and } 50 \% \\
\text { of users }\end{array}$ & $\begin{array}{l}\text { Between } \\
50 \% \text { and } 75 \% \\
\text { of users }\end{array}$ & $\begin{array}{l}\text { More than } 75 \% \\
\text { of directors }\end{array}$ \\
\hline & \multirow{2}{*}{$\begin{array}{l}\text { Clinical } \\
\text { realm }\end{array}$} & Directors & $\begin{array}{l}\text { Less than } 50 \% \\
\text { of directors }\end{array}$ & $\begin{array}{l}\text { Between } \\
50 \% \text { and } 70 \% \\
\text { of directors }\end{array}$ & $\begin{array}{l}\text { Between } \\
70 \% \text { and } 90 \% \\
\text { of directors }\end{array}$ & $\begin{array}{l}\text { More than } 90 \% \\
\text { of directors }\end{array}$ \\
\hline & & $\begin{array}{l}\text { Physicians } \\
\text { Nurses } \\
\text { Other users }\end{array}$ & $\begin{array}{l}\text { Less than } 25 \% \\
\text { of users }\end{array}$ & $\begin{array}{l}\text { Between } \\
25 \% \text { and } 50 \% \\
\text { of users }\end{array}$ & $\begin{array}{l}\text { Between } \\
50 \% \text { and } 75 \% \\
\text { of users }\end{array}$ & $\begin{array}{l}\text { More than } 75 \% \\
\text { of directors }\end{array}$ \\
\hline \multirow{4}{*}{$D_{2}$. System users } & \multirow{2}{*}{$\begin{array}{l}\text { Administrative } \\
\text { realm }\end{array}$} & Directors & $\begin{array}{l}\text { The system } \\
\text { does not trace } \\
\text { its use }\end{array}$ & $\begin{array}{l}\text { Less than } 50 \% \\
\text { of users }\end{array}$ & $\begin{array}{l}\text { Between } \\
50 \% \text { and } 75 \% \\
\text { of users }\end{array}$ & $\begin{array}{l}\text { More than } 75 \% \\
\text { of directors }\end{array}$ \\
\hline & & Other users & $\begin{array}{l}\text { The system } \\
\text { does not trace } \\
\text { its use }\end{array}$ & $\begin{array}{l}\text { Less than } 25 \% \\
\text { of users }\end{array}$ & $\begin{array}{l}\text { Between } \\
25 \% \text { and } 50 \% \\
\text { of users }\end{array}$ & $\begin{array}{l}\text { More than } 50 \% \\
\text { of directors }\end{array}$ \\
\hline & \multirow{2}{*}{$\begin{array}{l}\text { Clinical } \\
\text { realm }\end{array}$} & Directors & $\begin{array}{l}\text { The system } \\
\text { does not trace } \\
\text { its use }\end{array}$ & $\begin{array}{l}\text { Less than } 50 \% \\
\text { of users }\end{array}$ & $\begin{array}{l}\text { Between } \\
50 \% \text { and } 75 \% \\
\text { of users }\end{array}$ & $\begin{array}{l}\text { More than } 75 \% \\
\text { of directors }\end{array}$ \\
\hline & & $\begin{array}{l}\text { Physicians } \\
\text { Nurses } \\
\text { Other users }\end{array}$ & $\begin{array}{l}\text { The system } \\
\text { does not trace } \\
\text { its use }\end{array}$ & $\begin{array}{l}\text { Less than } 25 \% \\
\text { of users }\end{array}$ & $\begin{array}{l}\text { Between } \\
25 \% \text { and } 50 \% \\
\text { of users }\end{array}$ & $\begin{array}{l}\text { More than } 50 \% \\
\text { of directors }\end{array}$ \\
\hline \multirow{15}{*}{$\begin{array}{l}D_{3} \text {. Process } \\
\text { coverage }\end{array}$} & \multirow{7}{*}{$\begin{array}{l}\text { Administrative } \\
\text { realm }\end{array}$} & $\begin{array}{l}\text { General } \\
\text { accounting }\end{array}$ & None & One or two & Three & All \\
\hline & & $\begin{array}{l}\text { Management } \\
\text { accounting }{ }^{* *}\end{array}$ & None & One or two & Three & All \\
\hline & & Purchasing ${ }^{* *}$ & None & One or two & Three & All \\
\hline & & $\begin{array}{l}\text { Logistics and } \\
\text { warehouse }^{* *}\end{array}$ & None & One or two & Three & All \\
\hline & & $\begin{array}{l}\text { Human } \\
\text { resources }\end{array}$ & None & One or two & Three & All \\
\hline & & $\begin{array}{l}\text { Information } \\
\text { systems }\end{array}$ & None & One or two & Three & All \\
\hline & & $\begin{array}{l}\text { Other } \\
\text { processes }\end{array}$ & None & One or two & Three & All \\
\hline & \multirow{8}{*}{$\begin{array}{l}\text { Clinical } \\
\text { realm }\end{array}$} & $\begin{array}{l}\text { Emergency } \\
\text { room }^{* *}\end{array}$ & None & One or two & Three & All \\
\hline & & $\begin{array}{l}\text { Admission, } \\
\text { discharge, } \\
\text { transfers }\end{array}$ & None & One or two & Three & All \\
\hline & & $\begin{array}{l}\text { Outpatient, } \\
\text { inpatient** }^{* *}\end{array}$ & None & One or two & Three & All \\
\hline & & $\begin{array}{l}\text { Operating } \\
\text { rooms }\end{array}$ & None & One or two & Three & All \\
\hline & & Laboratory $^{* *}$ & None & One or two & Three & All \\
\hline & & Imaging $^{* *}$ & None & One or two & Three & All \\
\hline & & $\begin{array}{l}\text { Community } \\
\text { care }^{* *}\end{array}$ & None & One or two & Three & All \\
\hline & & $\begin{array}{l}\text { Other } \\
\text { processes }^{* *}\end{array}$ & None & One or two & Three & All \\
\hline \multicolumn{7}{|c|}{$\begin{array}{l}{ }^{*} \text { Some metrics (e.g., the accessing users in the admin. realm) have sub-metrics reflecting the different domains in } \\
\text { which the metric can be measured (e.g., economic, production or qualitative); in these cases, the maturity levels } \\
\text { reported in the table are valid for each sub-metric } \\
{ }^{* *} \text { Process coverage reflects how many of the four functional areas characterising the BI process (goal definition, } \\
\text { measurement, gap analysis and decision making) are covered by the BI solution }\end{array}$} \\
\hline
\end{tabular}

Table B.3. Dimensions, metrics, and maturity levels in the diffusional area 


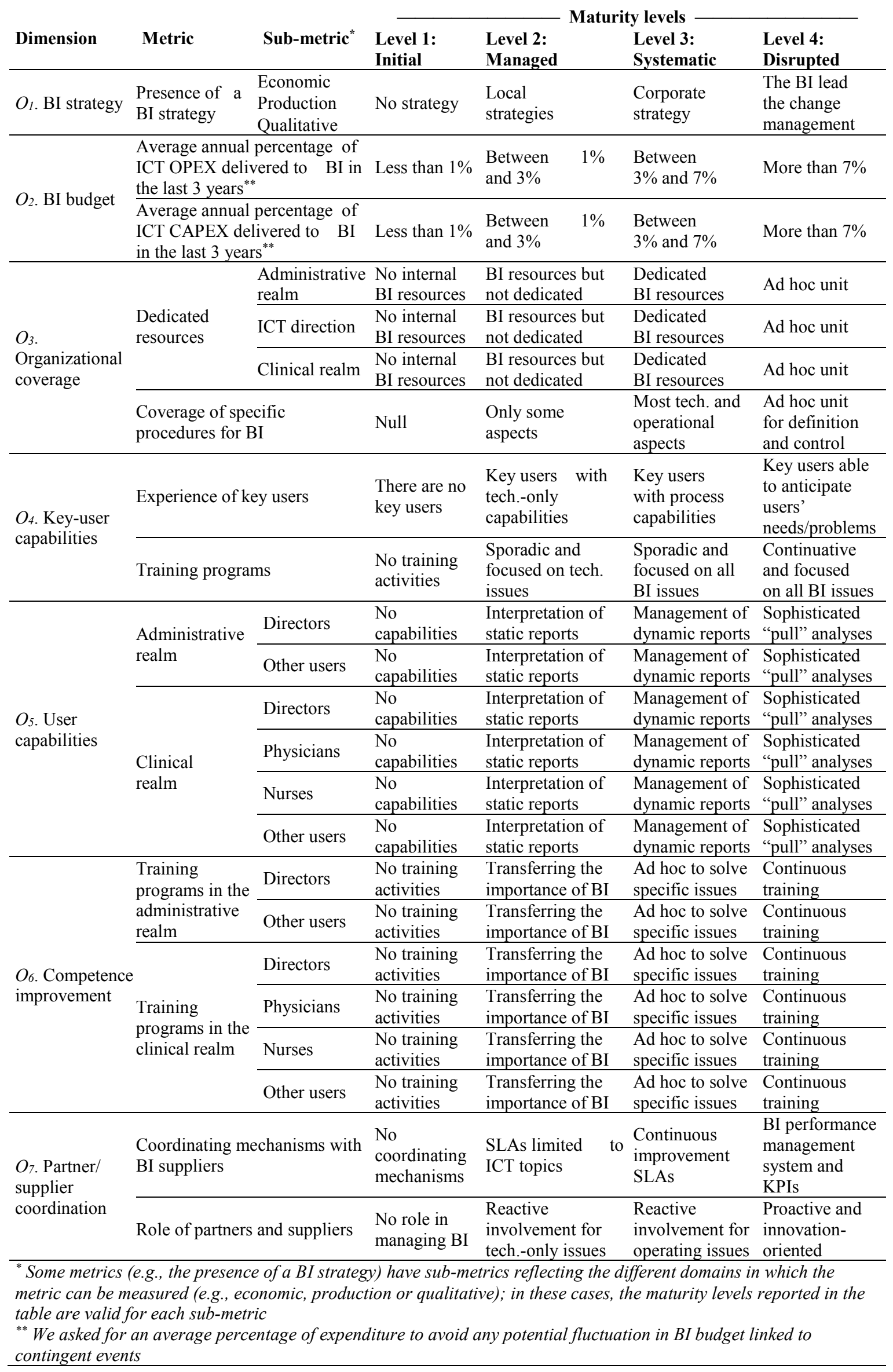

Table B.4. Dimensions, metrics, and maturity levels in the organizational area 


\begin{tabular}{|c|c|c|c|c|c|}
\hline & & Area & Dimension & Metric & Sub-metric \\
\hline & & Functional & $F_{1}$. Goal definition & Level of data granularity & Economic \\
\hline \multirow[t]{6}{*}{ Current } & Future & \multicolumn{4}{|c|}{$\begin{array}{l}\text { Question: What is the level of granularity of the data on which the BI solutions can work in order } \\
\text { to support the definition of a goal in the economic domain (cost and revenues)? }\end{array}$} \\
\hline & & \multicolumn{4}{|c|}{$\begin{array}{l}\text { In more than } 50 \% \text { of cases the BI solution does not support the definition of a goal in the economic } \\
\text { domain; when the BI solution supports this functionality, the relative data can be considered only at } \\
\text { a corporate level (e.g., when it is necessary to define the goals to be achieved, the BI solution } \\
\text { presents and allows working on drug costs for the entire healthcare organization) }\end{array}$} \\
\hline & & \multicolumn{4}{|c|}{$\begin{array}{l}\text { In more than } 50 \% \text { of cases the BI solution supports the definition of a goal in the economic domain } \\
\text { with data at the level of unit and/or ward (e.g., when it is necessary to define the goals to be } \\
\text { achieved, the BI solution presents and allows working on the costs of diagnostic procedures of each } \\
\text { department constituting the healthcare organization) }\end{array}$} \\
\hline & & \multicolumn{4}{|c|}{$\begin{array}{l}\text { In more than } 50 \% \text { of cases the BI solution supports the definition of a goal in the economic domain } \\
\text { with data at the level of the single event or cure episode (e.g., when it is necessary to define the } \\
\text { goals to be achieved, the BI solution presents and allows working on the cost of a DRG) }\end{array}$} \\
\hline & & \multicolumn{4}{|c|}{$\begin{array}{l}\text { In more than } 50 \% \text { of cases the BI solution supports the definition of a goal in the economic domain } \\
\text { with atomic data at the level of the single treatment procedure (e.g., when it is necessary to define } \\
\text { the goals to be achieved, the BI solution presents and allows working on the costs of the HRs for } \\
\text { each treatment) }\end{array}$} \\
\hline & & Organizational & 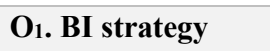 & Presence of BI strategy & Economic \\
\hline Current & Future & \multicolumn{4}{|c|}{ Question: Is there a BI strategy in the hospital on the economic aspects (costs, revenues)? } \\
\hline & & \multicolumn{4}{|c|}{ There is no BI business strategy for the economic aspect } \\
\hline & & \multicolumn{4}{|c|}{$\begin{array}{c}\text { There is a BI strategy on this aspect, but it is defined locally by units or departments. The local strategies } \\
\text { are partially aligned with the company's strategy }\end{array}$} \\
\hline & & \multicolumn{4}{|c|}{$\begin{array}{c}\text { There is a BI strategy on this aspect, aligned with the business strategy and with a strong commitment } \\
\text { from the corporate level management }\end{array}$} \\
\hline & & \multicolumn{4}{|c|}{$\begin{array}{c}\text { The BI Lead the change management on this aspect and BI indicators directly affect the business strategy } \\
\text { and strategic decisions }\end{array}$} \\
\hline
\end{tabular}

Table B.5: Sample questionnaire 


\begin{tabular}{|l|l|l|l|}
\hline Area & Dimension & Metric & Sub-metric \\
\hline Technological & $\mathbf{T}_{3}$. Interface & Interface characteristics & - \\
\hline
\end{tabular}

\begin{tabular}{|l|l|l|}
\hline current & Quture & Question: Which are the most advanced characteristics of the interface of the BI solution? \\
\hline & & There is no real BI solution available or it has a command line interface \\
\hline
\end{tabular}

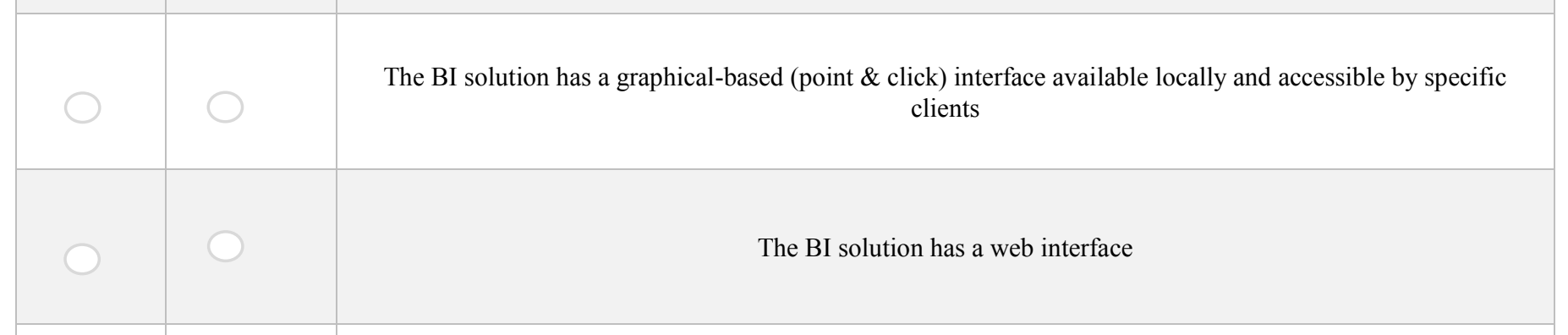

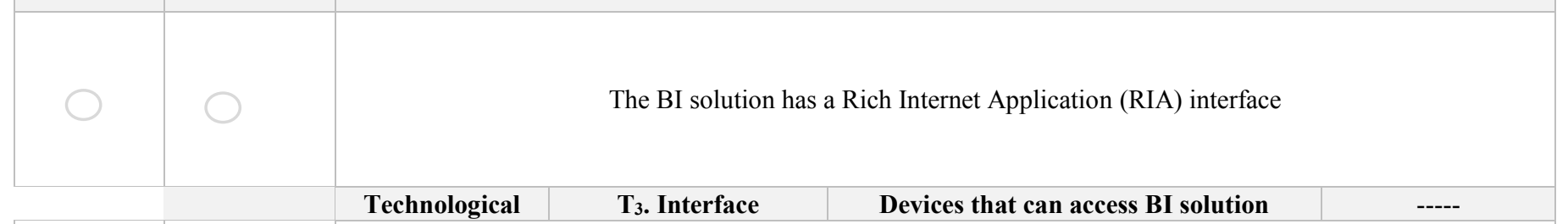

\begin{tabular}{|l|l|c|c|}
\hline Current & Technological & T3. Interface & Devices that can access BI solution \\
\hline & Question: Which are the devices that can be used to access the BI solution? \\
\hline & No real BI solution has been implemented in the organization \\
\hline & Users can access the BI solution only through specific workstations \\
\hline & Users can access the BI solution through any desktop devices (PC, notebook, etc.) connected to the network \\
\hline & \\
\hline & \\
\hline
\end{tabular}

Table B.5: Questionnaire sample (continued) 
